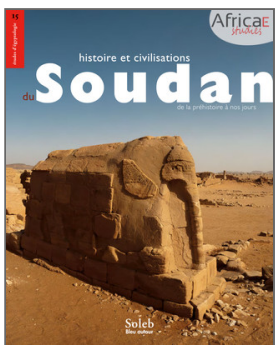

Olivier Cabon (dir.)

Histoire et civilisation du Soudan

De la préhistoire à nos jours

\title{
7. Des temples dans la savane
}

Le royaume de Méroé. 290 av. J.-C.-350 apr. J.-C.

\section{Claude Rilly}

DOI : 10.4000/books.africae. 2817

Éditeur: Africae, Soleb, Bleu autour

Lieu d'édition : Paris, Khartoum

Année d'édition : 2017

Date de mise en ligne : 17 janvier 2022

Collection : Africae Studies

EAN électronique : 9782493207074

\section{OpenEdition}

\section{Books}

http://books.openedition.org

\section{Référence électronique}

RILLY, Claude. 7. Des temples dans la savane : Le royaume de Méroé. 290 av. J.-C.-350 apr. J.-C In : Histoire et civilisation du Soudan : De la préhistoire à nos jours [en ligne]. Paris, Khartoum : Africae, 2017 (généré le 28 janvier 2022). Disponible sur Internet : <http://books.openedition.org/africae/2817>. ISBN 9782493207074. DOI : https://doi.org/10.4000/books.africae.2817. 


\section{des temples dans la savane}

le royaume de Méroé

290 av. J.-C. -350 apr. J.-C. 
Avec l'installation sur le trône d'Égypted'une dynastie macédonienne, les Lagides (305-31 av. J.-C.), les Grecs entrèrent en contact direct avec le royaume de Koush, cette terre qu'ils nommaient «l'Éthiopie». Ils étaient a priori bien disposés envers leurs nouveaux voisins, qu'Homère et Hérodote avaient décrits en des termes élogieux, les parant de toutes les vertus du corps et de l'esprit, ainsi que nous l'avons évoqué dans le chapitre précédent. Si les Grecs connaissaient une certaine forme de xénophobie, opposant leur culture à toutes les autres qualifiées de "barbares», ils étaient exempts de racisme, qui n’apparaitra que tard dans la culture occidentale. Les Noirs étaient pour eux une humanité simplement différente sur le plan physique. Les quelques exemples de vases grecs du ve siècle, canthares ou œnochoés, opposant sur leurs panses deux visages en relief, l'un européen, l'autre africain, montrent que cette diversité physique était reconnue, voire magnifiée, mais n'était pas matière à hiérarchisation.

\section{Koush et la dynastie ptolémaïque}

Or, maintenant que les deux royaumes, hellénistique et koushite, étaient face à face, les réalités de la géopolitique allaient s'imposer. Comme précédemment, l'enjeu principal en était la Basse-Nubie et ses mines d'or. Il semble que, dès le changement de pouvoir en Égypte, le royaume koushite (sans doute durant les derniers règnes napatéens) ait réagi en fortifiant sa présence militaire en Basse-Nubie et en testant les défenses du nouvel occupant. Peutêtre dès le règne de Ptolémée Ir Sôter (305-283) et de manière sûre au début du règne de son successeur Ptolémée II Philadelphe (283-246), des escarmouches sont lancées par les Koushites sur les cités frontalières d'Assouan et Éléphantine. Vers 274, Ptolémée Philadelphe envoie une expédition qui s'empare de la Basse-Nubie jusqu’à Bouhen, aux abords de la deuxième cataracte. La région est alors divisée en deux provinces: le Dodécaschène (terre des 12 schènes, soit $128 \mathrm{~km}$ ), entre Assouan et Hiéra Sycaminos (moderne Maharraqa), et le Triacontaschène (terre des 30 schènes, soit $320 \mathrm{~km}$ ), au sud jusquà la deuxième cataracte. Les revenus du Dodécaschène sont attribués au temple d'Isis de Philae, dont les Ptolémées vont faire un complexe religieux d'importance nationale.

Parallèlement aux opérations militaires, une nouvelle diplomatie fut mise en place pour assurer la continuité des échanges avec le royaume koushite. La politique de prestige des Lagides et le rayonnement de la nouvelle capitale, Alexandrie, construite par Ptolémée I ${ }^{\mathrm{er}}$, rendaient nécessaire l'acquisition de matériaux luxueux comme l'ivoire et l'ébène, les peaux de fauves et les plumes d'autruche, mais aussi d'esclaves exotiques, très appréciés dans le monde hellénistique, et, nouveauté dans l'arsenal militaire, 
introduite depuis les campagnes d'Alexandre en Inde, d'éléphants de combat. À ces besoins commerciaux s'ajoutaient la soif de connaissances et la curiosité scientifique qui caractérisaient la culture grecque et qui s'incarnaient depuis peu dans la grande bibliothèque d'Alexandrie édifiée sous Ptolémée Sôter. Aussi vit-on fleurir à partir du début du III ${ }^{\mathrm{e}}$ siècle des traités littéraires ou géographiques dont l'Éthiopie était, en partie ou en totalité, la matière. Certains de ces polygraphes sont supposés avoir voyagé jusqu’à Méroé, comme Dalion et Bion de Soles, tous deux auteurs d'ouvrages appelés Aithiopika (les Éthiopiques), ou Aristocréon, un géographe. D'autres, comme Ératosthène, directeur de la bibliothèque d'Alexandrie et célèbre pour avoir le premier calculé la circonférence de la Terre, ou comme Agatharchide de Cnide, secrétaire à la cour de Ptolémée VI Philopator, se sont reposés sur les récits des voyageurs et les archives alexandrines. Aucun de ces ouvrages ne nous est parvenu entier et seules nous sont connues des citations plus ou moins fidèles dans les œuvres de Diodore de Sicile (90-30 av. J.-C.), Strabon (64 av. J.-C.-21/25 apr. J.-C.), Pline l'Ancien (23-79 apr. J.-C.) et Athénée de Naucratis (170-230 [?] apr. J.-C.).

le Soudan

192

\section{Ergaménès et le mythe grec} de la fondation du royaume de Méroé

L'un de ces fragments a revêtu une grande importance dans l'histoire de la nubiologie, car il est à l'origine de la division traditionnelle, actuellement

des origines

à la chute

du sultanat

Fung contestée mais toujours en usage, entre royaume de Napata et royaume de Méroé. Ce passage emprunté à Agatharchide de Cnide est cité par Diodore de Sicile dans sa Bibliothèque historique:

《 De tous les faits, le plus étrange concerne la mort des rois. À Méroé, en effet, les prêtres qui honorent les dieux et leur rendent le culte occupent le rang le plus élevé et le plus puissant si bien que, lorsqu'ils le décident, ils envoient au roi un messager lui ordonnant de mourir, (ajoutant) que c'est un décret divin rendu par l'oracle et qu'en aucun cas un simple mortel ne peut négliger les ordres des immortels. [...] Précédemment, les rois obéissaient aux prêtres, non qu'ils y fussent contraints par la force ou les armes, mais parce que leur esprit était soumis à cette superstition. Or, au temps de Ptolémée II, le roi des Éthiopiens, Ergaménès, qui avait reçu une éducation grecque et agissait en philosophe, fut le premier à dédaigner cet ordre. Il prit une décision digne d'un roi et, entouré de soldats, entra dans le saint des saints, où se trouvait le naos d'or des Éthiopiens. Il égorgea tous les prêtres et, ayant aboli cet usage, engagea des réformes selon ses propres principes. 
Lorsque Reisner fouilla les cimetières royaux de Méroé, Begrawwiya Sud et Nord, deux rois furent identifiés portant des noms très semblables à l'Ergaménès cité par Agatharchide. Le premier était lu Arakakamani à l'époque (tombe Beg. S.6) et le second Arqamani ou Arkamani (Beg. N.7). C'est ce dernier, postérieur de plusieurs décennies, qui fut assimilé au souverain de la légende, car Reisner pensait que, jusqu’à son règne, l'État koushite avait été divisé en deux royaumes, l'un autour de Napata (les Néo-Ramessides), l'autre autour de Méroé. Une fois abandonnée cette théorie, dans les années 1960, Arakakamani, lu désormais Arkamaniqo, fut assimilé à Ergaménès. Son tombeau de Begrawwiya Sud est en effet la première tombe royale de Méroé. Une interprétation historique nouvelle, fidèle à la narration d'Agatharchide, se mit en place: le royaume napatéen sur le déclin aurait été une théocratie où les prêtres d'Amon de Napata exerçaient la réalité du pouvoir. Ergaménès aurait mis fin à cet empiètement des religieux sur les prérogatives royales par un violent coup d'État, aurait transféré la capitale de Napata à Méroé et y aurait inauguré une nouvelle nécropole royale. Cette rupture politique et religieuse permettait de distinguer deux phases successives dans l'histoire koushite: le royaume de Napata et le royaume de Méroé.

Certains détails du récit d'Agatharchide sont en effet convaincants: si le temple d'Amon de Napata n'y est pas cité, la mention de l'oracle, qui présidait, on s'en souvient, au choix des souverains, et celle de la chapelle dorée construite par Amannote-erike et utilisée pour l'intronisation de Nastasen sont conformes à la réalité. Le nom du roi, Ergaménès, même s'il est quelque peu hellénisé, est reconnaissable. En fait, l'élément -qo final n'est qu’une formule de présentation ("c'est lui $\mathrm{X} »)$. On le trouve fréquemment ajouté ad libitum à l'époque méroïtique, alors qu'il est constitutif $\mathrm{du}$ nom sous la $X X V^{e}$ dynastie (comme dans Shabaqo ou Taharqo). Par conséquent, le nom du roi de Beg. S. 6 est bien Arkamani, premier du nom, alors que le souverain de Beg. N. 7 est Arkamani II, offrant un des exemples rarissimes de réutilisation d'un nom royal dans l'histoire méroïtique. La date de son règne, malgré l'imprécision qui règne sur la chronologie de ces époques, s'accorde également avec le début de celui de Ptolémée II. Il est bien de surcroît le premier souverain à n'être plus inhumé dans la région napatéenne.

Mais ce scénario ne tenait pas compte de plusieurs éléments. La capitale politique était déjà Méroé depuis longtemps. Hérodote, par exemple, au v viècle avant notre ère, n'en connait pas d'autre et ne cite pas le nom de Napata. D'autre part, ni le culte d'Amon, ni le rayonnement de Napata ne semblent connaître d'éclipse durant toute la période méroïtique. Les noms des trois premiers rois de Méroé, Arkamani I ${ }^{\text {er }}$, Amanislo et Amanitékha, comportent d'ailleurs toujours le nom d'Amon, «Amani» en méroïtique. Aussi l'historien hongrois László Török, dont les ouvrages 
font aujourd'hui référence, proposa-t-il dans les années 1990 une nouvelle interprétation qui minorait la rupture entre les deux royaumes. Le récit d'Agatharchide contient en effet des éléments recyclés de mythes anciens, que l'on trouve par exemple chez Hérodote. On ajoutera que le massacre des prêtres rappelle étrangement le mythe du roi Busiris, une légende grecque selon laquelle Héraclès, sur le point d'être sacrifié sur l'ordre de ce roi légendaire d'Égypte, brisa ses chaînes et tua les prêtres qui devaient procéder à son immolation. De manière générale, le récit emprunté par Agatharchide est pour Diodore un prétexte pour opposer la superstition à l'esprit rationnel éclairé par la philosophie grecque. Ergaménès est en quelque sorte un Socrate armé qui se serait révolté contre le verdict de ses juges.

\section{Les débuts du royaume de Méroé : rupture et continuité}

le Soudan

\section{4}

des origines

à la chute

du sultanat

Fung

On ne peut toutefois rejeter au rang de mythe ou de parabole l'ensemble du récit: il est certain qu'Ergaménès/Arkamani est le premier roi inhumé à Méroé. Pour Török, cette rupture correspond à un changement de dynastie qui s'est peut-être effectué dans la violence. Il rappelle que le nom de couronnement égyptien adopté par Arkamani Ir était Khenem-ib-Rê, «le cœur de Rê se réjouit». Or, c'était originellement celui du pharaon Amasis de la XXVI e dynastie, un ancien général (il avait participé à l'expédition de Psammétique II contre Koush) qui avait déposé son prédécesseur. Pour Török, Arkamani I ${ }^{e r}$ assumait ainsi une légitimité obtenue par la force et non héritée par les liens du sang. Selon cette nouvelle interprétation, l'arrivée au pouvoir d'Arkamani Ir constitue une rupture politique et dynastique, mais non une révolution idéologique et religieuse. Il est d'ailleurs assez probable que la lignée des rois napatéens avait déjà connu plusieurs fois des changements dynastiques, et les stèles d'intronisation d'Aspelta et de Harsiotef contiennent des éléments en ce sens. Il n'y aurait donc pas entre le royaume de Napata et celui de Méroé de solution de continuité brutale, la différence principale résidant dans le choix du lieu d'inhumation royale.

Au fil du temps, le royaume de Méroé va toutefois développer des caractéristiques qui diffèrent des usages napatéens. Certaines d'entre elles sont en place dès le début et sont vraisemblablement liées aux particularités de l'île de Méroé, la province méridionale à laquelle se rattachait la nouvelle dynastie. La première concerne le costume royal. Dans les représentations napatéennes, le monarque est généralement vêtu d'un pagne court à devanteau, comme aux époques pharaoniques anciennes. En revanche, les souverains méroïtiques arborent un costume complexe, dit "tripartite», composé d'un manteau ajusté de lin blanc, d'une longue cordelière à glands descendant le long du torse jusqu'aux chevilles et d'une large écharpe à franges 
teinte en rouge, passée sur une épaule et tombant jusqu'à la taille de l'autre côté. En revanche, les couronnes restent les mêmes, avec une prééminence de la calotte koushite et de l'imposante couronne composite hemhem, formée d'un échafaudage de faisceaux de papyrus, de disques solaires et de cobras sur deux cornes torsadées. Restent également en usage le collier ouvert à pendentifs terminés par des têtes de béliers (déjà présent dès les débuts de la $\mathrm{XXV}^{\mathrm{e}}$ dynastie) et les sandales, souvent très ornementées. De façon générale, la tenue royale méroïtique, volontiers surchargée de bijoux en tout genre, contraste avec la sobriété du costume napatéen.

Une autre nouveauté apparue dès les premiers règnes méroïtiques est le rôle politique accru des femmes de la famille royale. Certes, la reinemère notamment tient le second rang protocolaire dans les stèles napatéennes, où elle est souvent appelée «maîtresse de Koush". Mais, à Nouri, la principale nécropole napatéenne, tous les souverains identifiés sont des rois, occupant de leurs imposants monuments le cœur de l'espace funéraire, tandis que les reines, mères ou épouses, sont inhumées dans une annexe, située au nordouest, sous des pyramides de dimensions réduites. Dans la partie méroïtique de la nécropole de Begrawwiya Sud à Méroé, rois et reines partagent en revanche un espace commun, un usage qui avait toutefois commencé dès la fin de l'ère napatéenne, dans le cimetière de Barkal. Mais, surtout, les deux reines présentes, Bartaré (Beg. S. 10) et Kanarta (Beg. S. 4), sont figurées en costume tripartite de souverain méroïtique et sont coiffées de la calotte royale koushite. Au-dessus du nom de Bartaré est gravée la mention «fils (sic) de Rê» et «roi de Haute et Basse-Égypte». On a suggéré que Bartaré ait été la mère de Sabrakamani, le dernier (?) des rois de Napata, mais, en ce cas, on attendrait qu'elle ait été inhumée à Barkal Sud, comme les autres reines néo-ramessides. Il serait plus judicieux de faire d'elle la mère d'un des deux premiers rois méroïtiques, Arkamani Ir ${ }^{\text {er }}$ Amanislo, et de Kanarta, la mère ou la grande épouse d'Amanislo. L'une comme l'autre ont apparemment exercé le pouvoir suprême, en tant que régentes, lors de la minorité de leurs fils, plutôt qu'en tant que souveraines à part entière, comme on en verra des exemples aux siècles suivants. Malgré leurs atours et leurs titres royaux, elles ne disposent en effet que de monuments de petite taille, éclipsés par la masse des deux pyramides d'Arkamani Ire et d'Amanislo.

\section{Amanislo, des lions de Prudhoe à l'opéra de Verdi}

Sur le règne d'Arkamani ${ }^{\text {er }}$, on ne dispose pas d'éléments plus précis que le récit légendaire d'Agatharchide, ses deux noms et la localisation de sa sépulture en un nouveau lieu. Son successeur, Amanislo, est à peine mieux connu. Sa pyramide et celle de sa mère ou épouse Kanarta, 


\section{6}

des origines

à la chute

du sultanat

Fung

ainsi que quelques autres petits monuments pour des membres de sa famille, occupent les dernières places disponibles sur l'affleurement gréseux où fut bâtie la nécropole de Begrawwiya Sud. On possède une trace de son activité par ses cartouches gravés sur les deux statues de lion en granite rouge transportées en Angleterre par Lord Prudhoe et données en 1835 au British Museum.

Originellement érigées par Amenhotep III devant le temple de Soleb, elles furent très vraisemblablement transférées au Gébel Barkal sur l'ordre de Piankhy lors de l'aménagement du grand temple d'Amon, en même temps que les mieux conservés des béliers de Soleb. Cette hypothèse est plus plausible que celle, plus souvent évoquée, d'un transport depuis Soleb sous Amanislo lui-même, d'une part parce qu'elle économise les déplacements et d'autre part parce qu'il est peu vraisemblable que ces deux statues magnifiques, bien plus remarquables que les béliers, aient été laissées en place par Piankhy. Amanislo les fit transférer d'un lieu inconnu, sans doute le grand sanctuaire d'Amon, pour orner la voie processionnelle qui reliait le palais cérémoniel B 1200 aux temples, celle qu'empruntaient les rois pour leur couronnement.

Alors que Piankhy et ses successeurs s'étaient abstenus d'y inscrire leur nom, Amanislo y fit graver ses deux cartouches. Son nom de couronnement, Ankh-Nefer-ib-Rê, "que vive Néféribrê», renvoie curieusement non au dieu Rê directement, mais à un lointain prédécesseur, Amannote-erike, qui avait choisi Néféribrê comme nom de couronnement. Mais il contient également la mention du "cœur de Rê» (ib-Rê) présente également dans le nom de couronnement de son prédécesseur Arkamani I ${ }^{\text {er }}$. Son nom de naissance est transcrit en égyptien Jmn-jsr, où l'hiéroglyphe de la bouche peut représenter aussi bien un « $\mathrm{r}$ » qu'un «1" méroïtique, voire un « $\mathrm{d}$ » intervocalique (rétroflexe). Comme, de plus, il n'est pas exclu que le nom d'Amon, Jmn en égyptien, Amani en méroïtique, soit placé en antéposition honorifique, de nombreuses lectures sont possibles, d'autant que l'élément noté jsr en égyptien n'est pas identifié en méroïtique: Asalo-Amani, Asaro-Amani, Amani-asalo, Amaniasedewa, etc. La lecture Amanislo, suggérée par Dunham dans la publication des fouilles de Reisner, repose sur une interprétation Amani-se-l-o, "c'est celui d'Amon", très discutable, entre autres parce qu'elle ne tient pas compte de l'initiale vocalique de $j s r$.

Le nom, connu dès 1835 par les lions de Lord Prudhoe, avait été transcrit Amonasro par Auguste Mariette, le grand égyptologue français, nommé directeur des Antiquités au Caire par le khédive d'Égypte. Or, le successeur de ce dernier, Ismail Pacha, se mit en tête de faire représenter un grand opéra comme point d'orgue des festivités de l'inauguration 
du Canal de Suez. Mariette fut chargé d'imaginer l'intrigue et de superviser les costumes et les décors. La musique fut commandée à Verdi et le livret à Ghislanzoni. En décembre 1871, la première d'Aïda eut lieu à l'Opéra khédival du Caire, construit pour l'occasion. Le scénario imaginé par Mariette mettait en scène une guerre entre Égyptiens et «Éthiopiens» et, parmi les rares noms de rois koushites connus alors, il choisit le nom d'Amonasro pour le re d'Etiopia, père d'Aïda. Bien entendu, l'histoire est entièrement fictive car on n'a aucune trace de conflit entre Égyptiens et Koushites au début de la période méroïtique. Mais il est assez amusant de voir par quels concours de circonstances, depuis le transport des lions de Soleb à Napata, puis de Napata à Londres, Amonasro/Amanislo est devenu, du moins pour les mélomanes, le plus connu des rois méroïtiques, alors même qu'on ignore presque tout de son règne. Le fait qu'il ait rénové le palais cérémoniel du Gébel Barkal montre en tout cas la continuité de la dévotion royale envers Amon de Napata à l'époque méroïtique, en contradiction avec le mythe grec d'Ergaménès. Amanislo a peut-être fait exécuter des travaux également à Semna, en Basse-Nubie, où apparaît un cartouche qui pourrait renfermer son nom.

Après l'inhumation d'Amanislo, il ne restait plus de place dans le cimetière sud de Begrawwiya. Un nouvel emplacement également en hauteur, de l'autre côté d'une petite vallée, fut donc choisi à proximité: Begrawwiya Nord (en abrégé Beg. N). Depuis près d'un siècle, le sable a envahi en partie le lieu, ajoutant à la beauté du paysage par l'opposition de couleur entre les dunes blondes et les monuments de grès noir, mais contribuant aussi à la dégradation des gravures dans les chapelles funéraires laissées à ciel ouvert. C'est là, jusqu'à la fin du royaume de Méroé, que furent enterrés les souverains, rois et reines régnantes, au nombre d'une quarantaine, plus deux princes. Le premier, Amanitékha, n'est connu que par son double cartouche rescapé de sa chapelle funéraire détruite (Beg. N. 4). Son nom de couronnement, Men-ib-Rê, «stable est le cœur de Rê», le situe clairement dans la lignée d'Arkamani Irer (Khenemib-Rê) et Amanislo (Ankh-Nefer-ib-Rê). D'un possible successeur, on ne possède qu'une titulature incomplète retrouvée sur des blocs issus d'un monument détruit à Begrawwiya Nord. Elle est composée de trois des cinq noms traditionnellement dévolus aux pharaons. Le premier, le nom d'Horus, commence par "Taureau puissant», comme la plupart des rois de Napata, et n'apporte donc aucune information spécifique. En revanche, le nom d'" Horus d'or " du second est plus significatif, puisqu'il contient le segment jry jh.t, "celui qui fait le bien", attesté dans la titulature de Ptolémée III Évergète I ${ }^{\text {er }}$ (246-222 av. J.-C.). Elle permet de placer le règne de ce souverain vers le milieu du III $^{\mathrm{e}}$ siècle. 


\section{nécropole de Begrawwiya Sud (Méroé)}

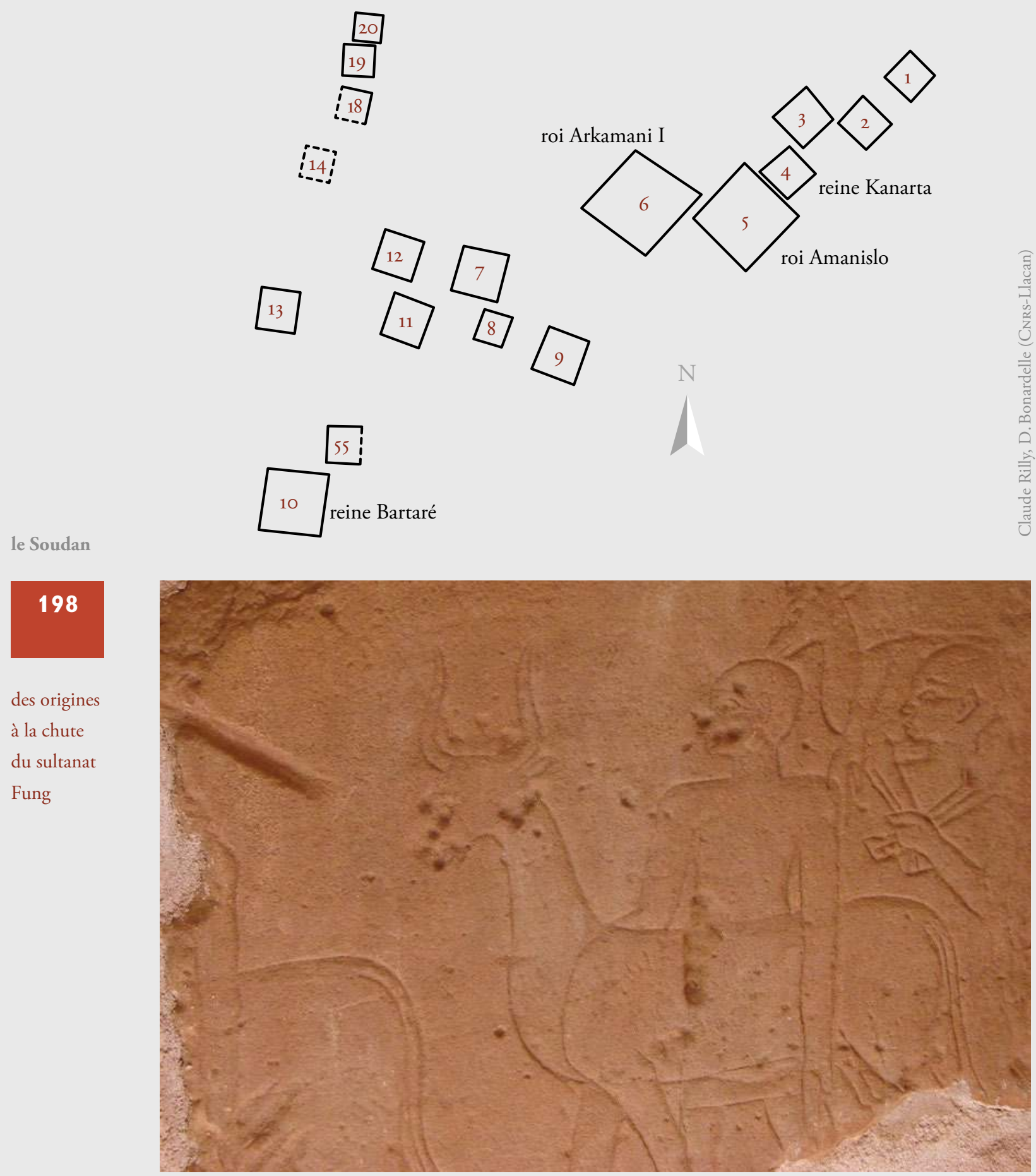

Méroé, Beg. S.7, relief de la chapelle d’un chef d'armée. 


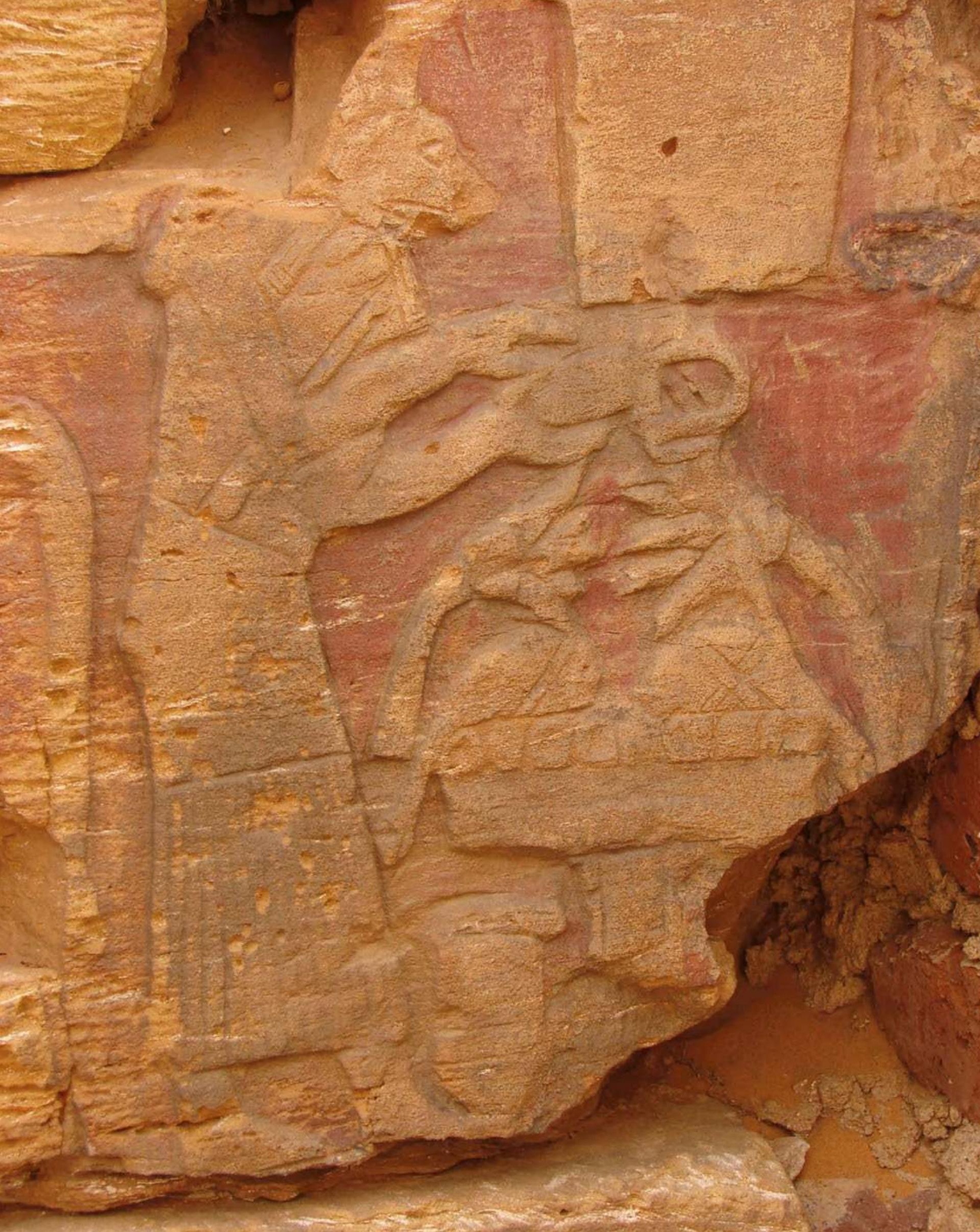


nécropole de Begrawwiya Nord (Méroé)

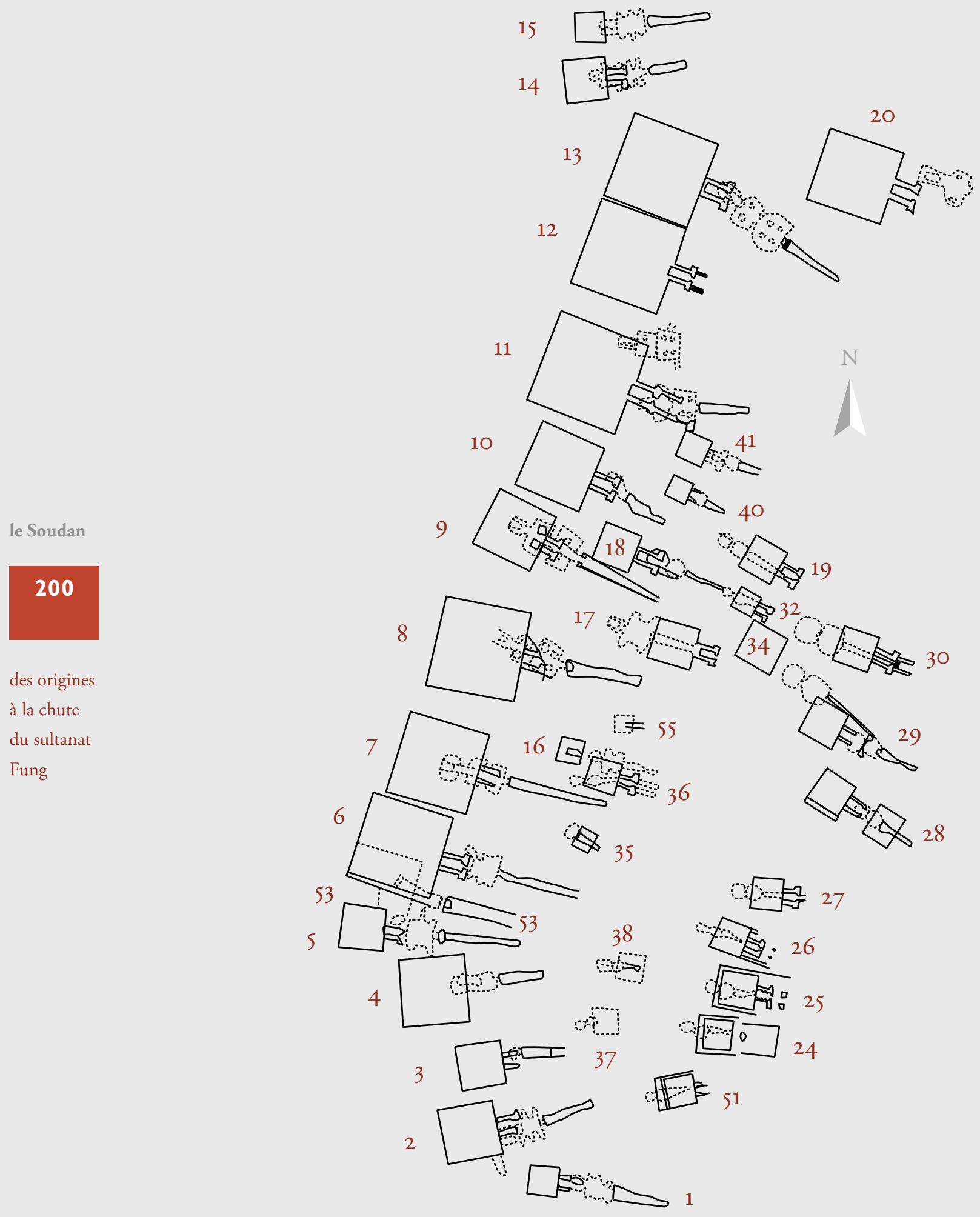




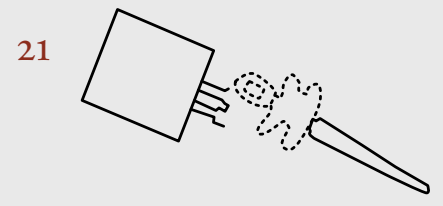

22

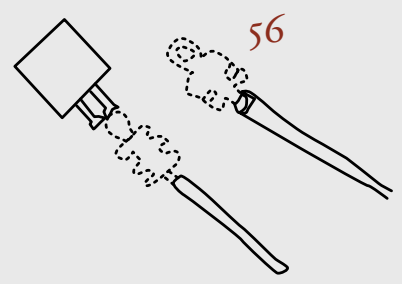

\section{1}

$\begin{array}{cl}\text { Beg.N. } 1 & \text { Amanitoré (reine) } \\ 2 & \text { Amanakhabalé (roi) } \\ 4 & \text { Amanitékha (roi) } \\ 5 & \text { Arikankharor (prince) } \\ 6 & \text { Amanishakhéto (reine) } \\ 7 & \text { Arkamani II (roi) } \\ 8 & \text { Adikhalamani (roi) } \\ 9 & \text { Tabirqo (roi) } \\ 10 & \text { Prince? } \\ 11 & \text { Nahirqo (reine) } \\ 12 & \text { Tanéyidamani (roi) } \\ 13 & \text { Naqyrinsan (roi) } \\ 14 & \text { Princes Arikankharor } \\ 15 & \text { et Shorkaror } \\ 16 & \text { Amanakharéqérem (roi)? } \\ 17 & \text { Amanitenmomidé (roi) }\end{array}$

18 Amanakhatashan (reine)

des temples

dans

la savane

19 Tarékéniwal (roi)

20 Horus Ka-Nakht [...]

21 Téritéqas (roi)?

22 Natakamani (roi)

28 Téqoride-Amani (roi)

29 Takide-Amani (roi)

30 Roi non identifié

32 Amanakhalika (reine)?

34 Ariténé-yesbokhé (roi)?

36 Amanitaraqidé (roi)

37 Amanakhadoké (reine)?

38 Pisakara (roi)?

40 Roi?

41 Roi?

53 Arnékhamani (roi)? 


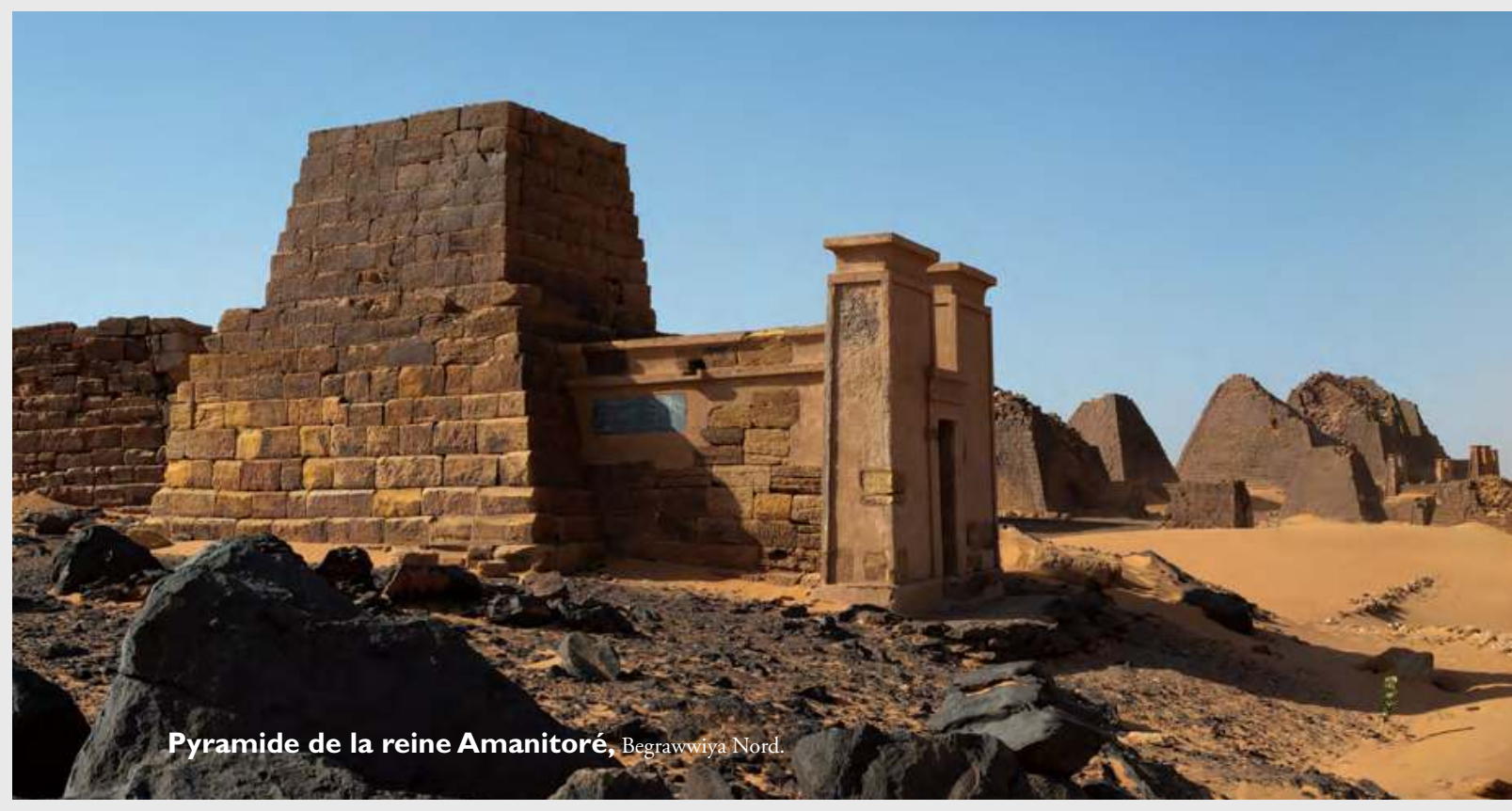

le Soudan

202

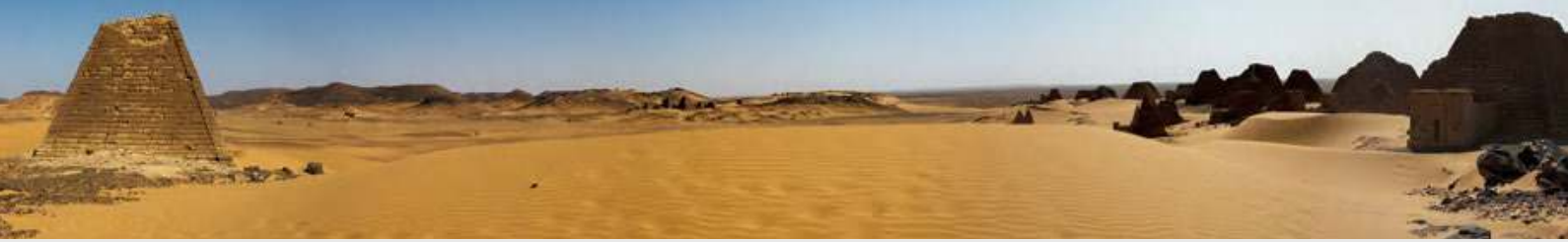

des origines

à la chute

du sultanat

Fung

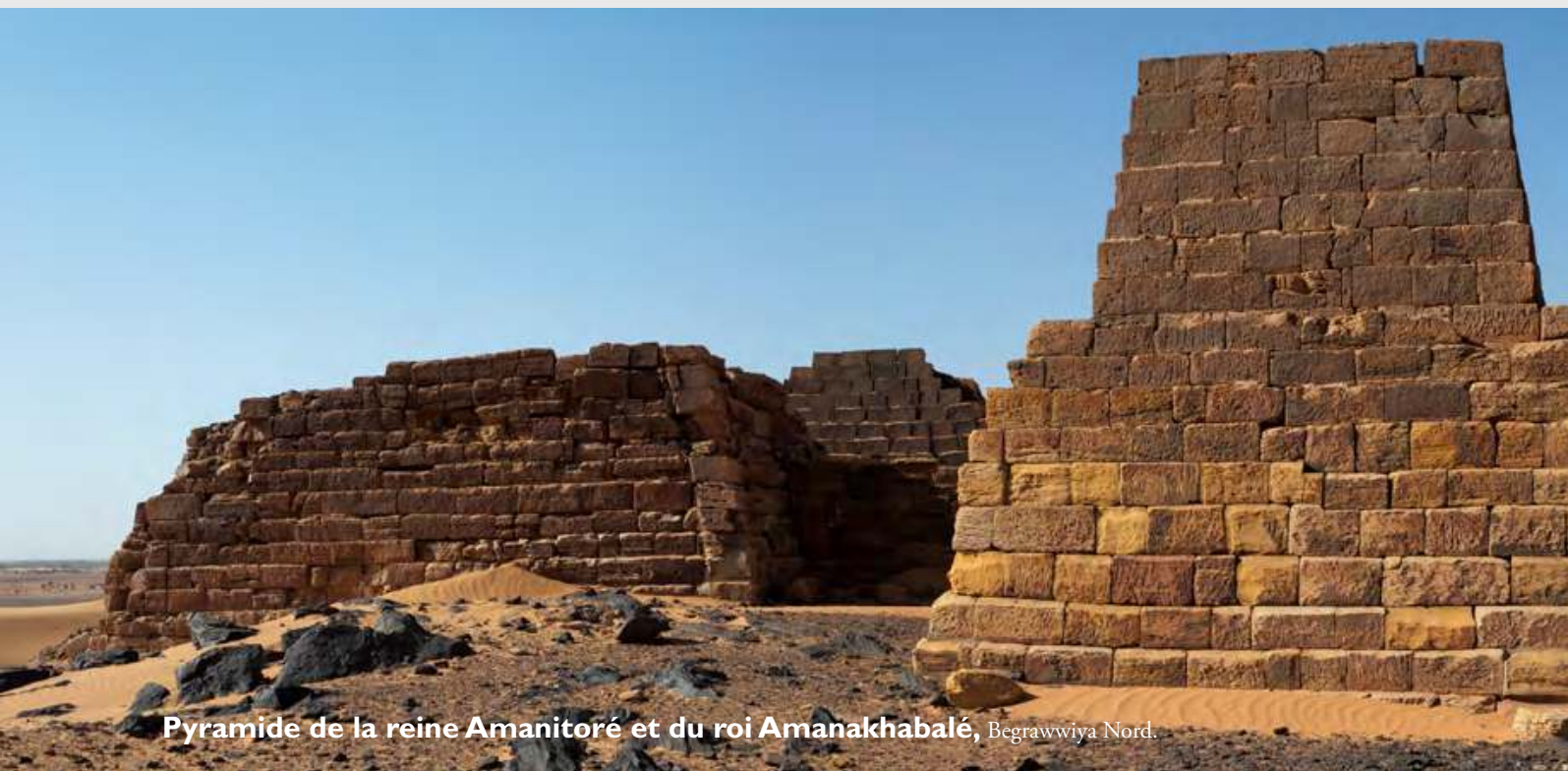



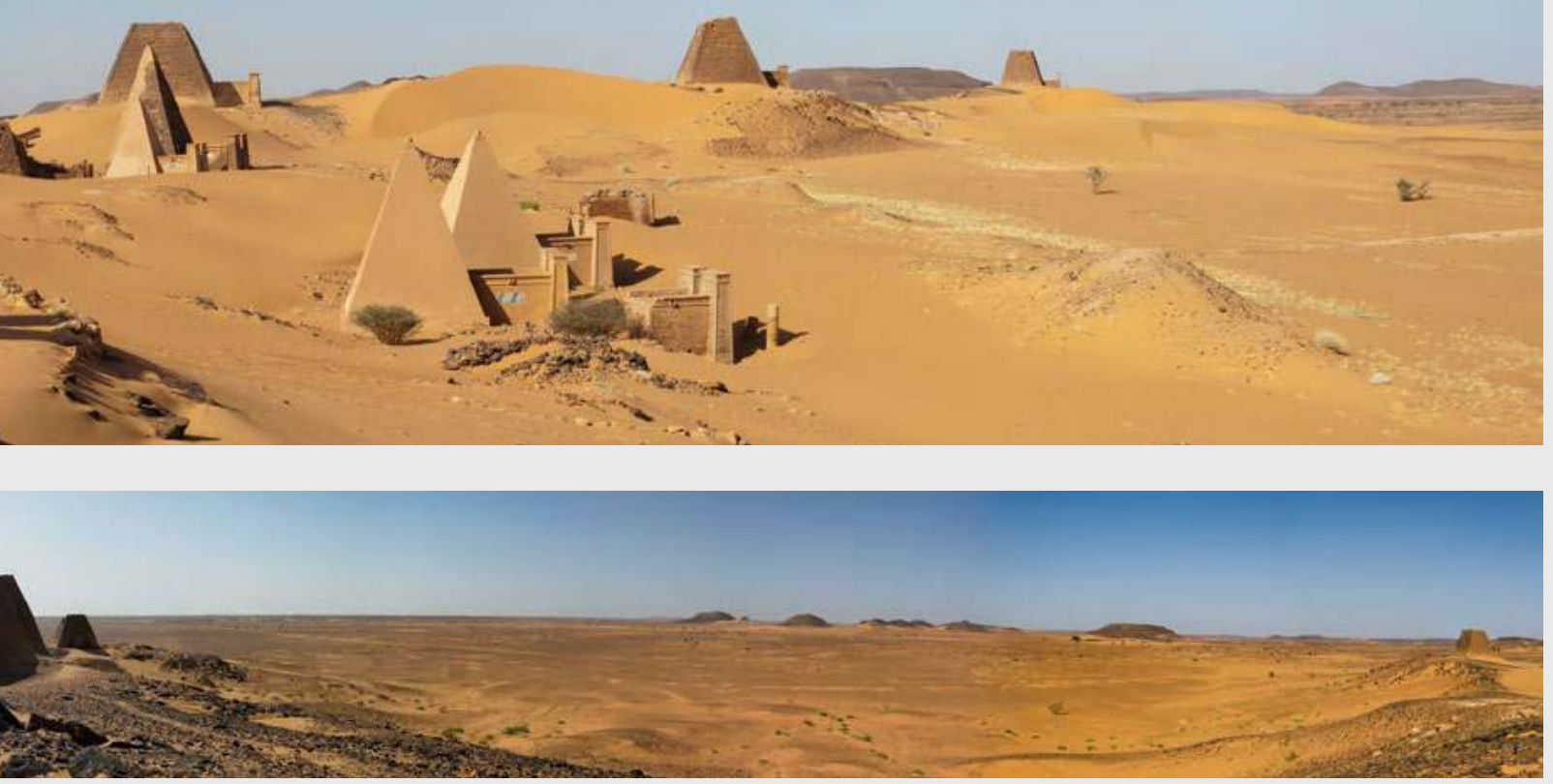

\section{3}

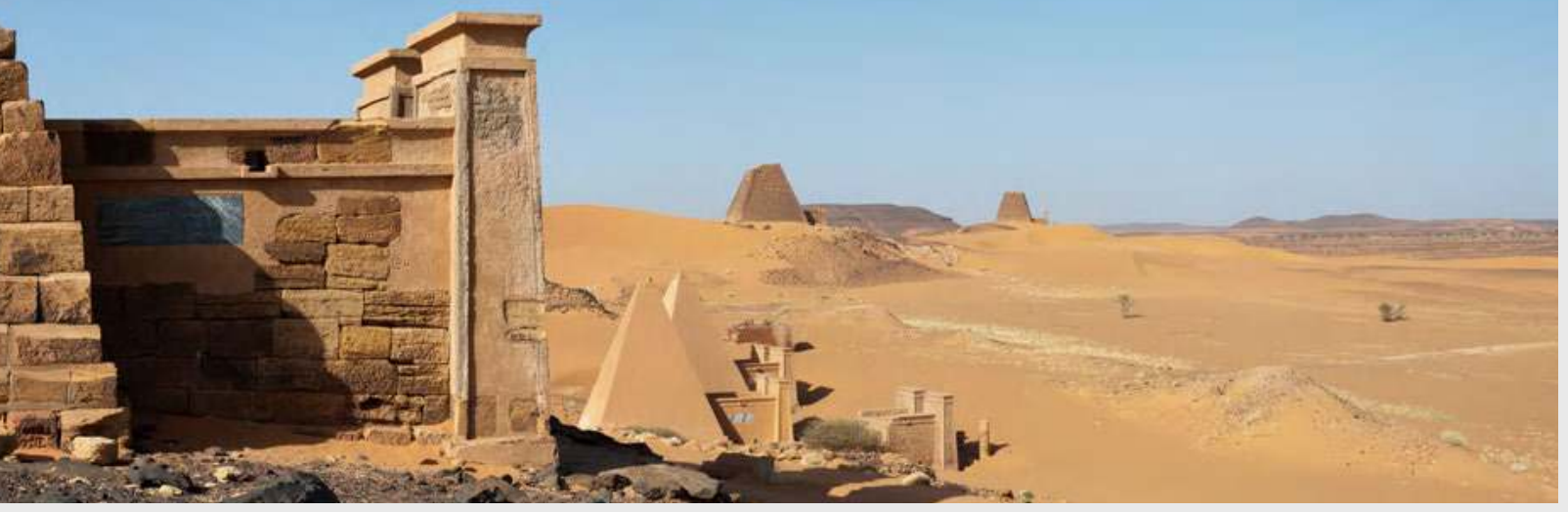

des temples 


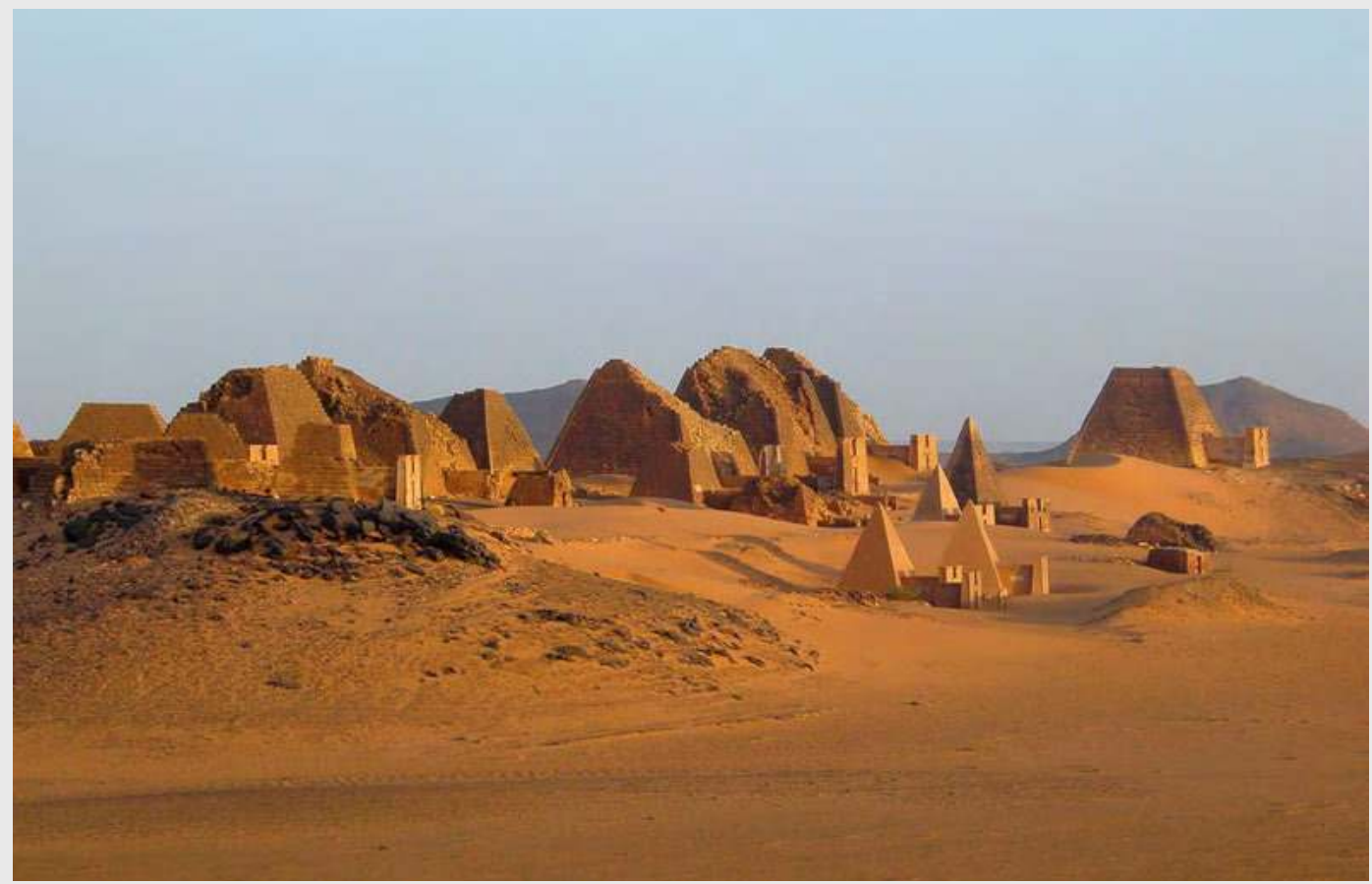

Méroé, vue de Beg. N. depuis Beg. S.

le Soudan

\section{4}

des origines à la chute du sultanat Fung

\section{AETIIOPEN}

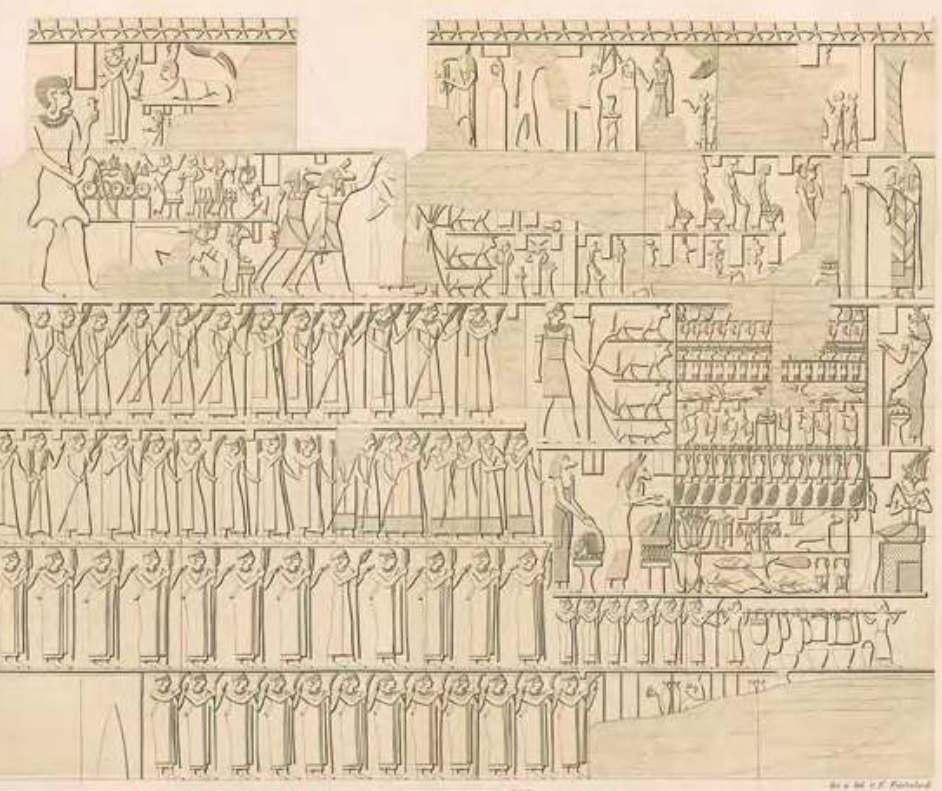

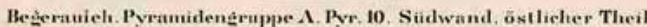

Procession funéraire de la reine Nahirqo, chapelle de la pyramide de Méroé Beg. N.11, d'après Carl Richard Lepsius, Denkmäler aus Aegypten und Aethiopien, vol. V, pl. 33. 


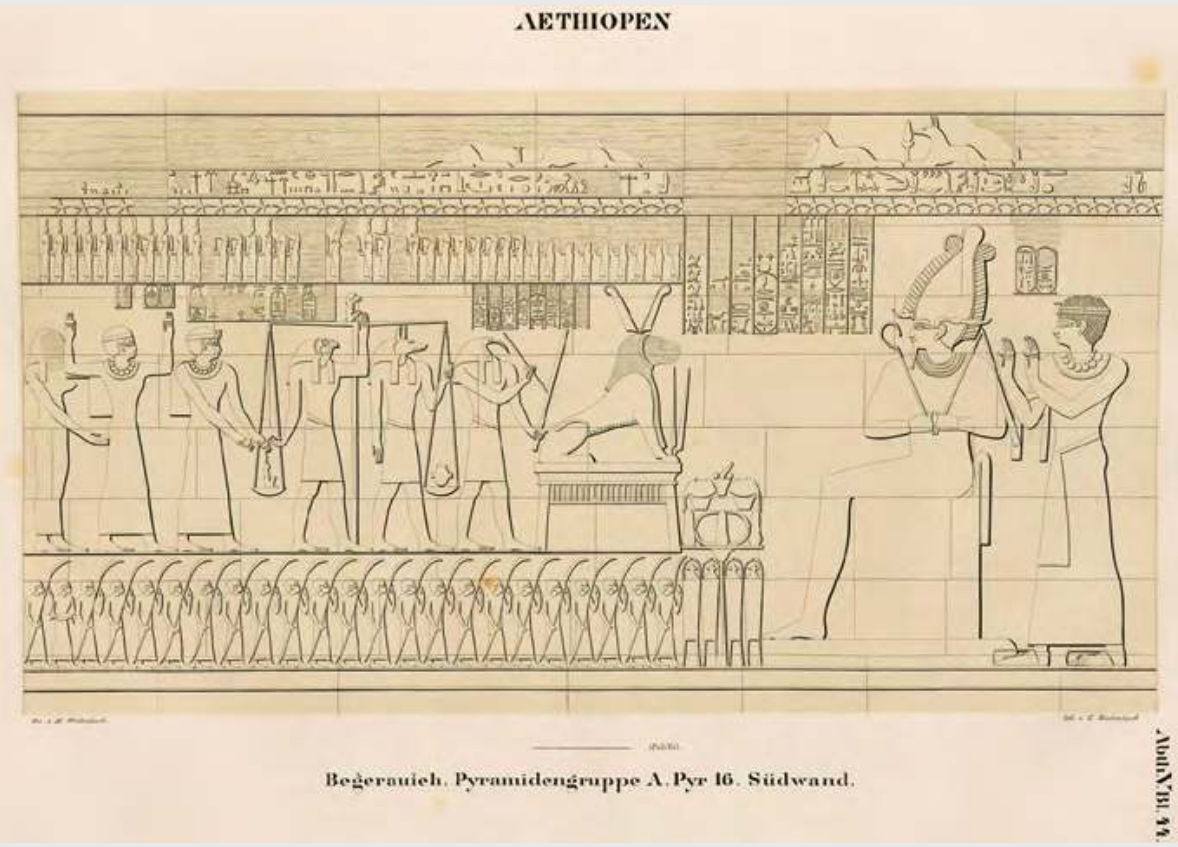

La pesée du cœur du prince Arikankharor, chapelle de la pyramide de Méroé Beg. N. 5, d'après Carl Richard Lepsius, Denkmäler aus Aegypten und Aethiopien, vol. V, pl. 44.

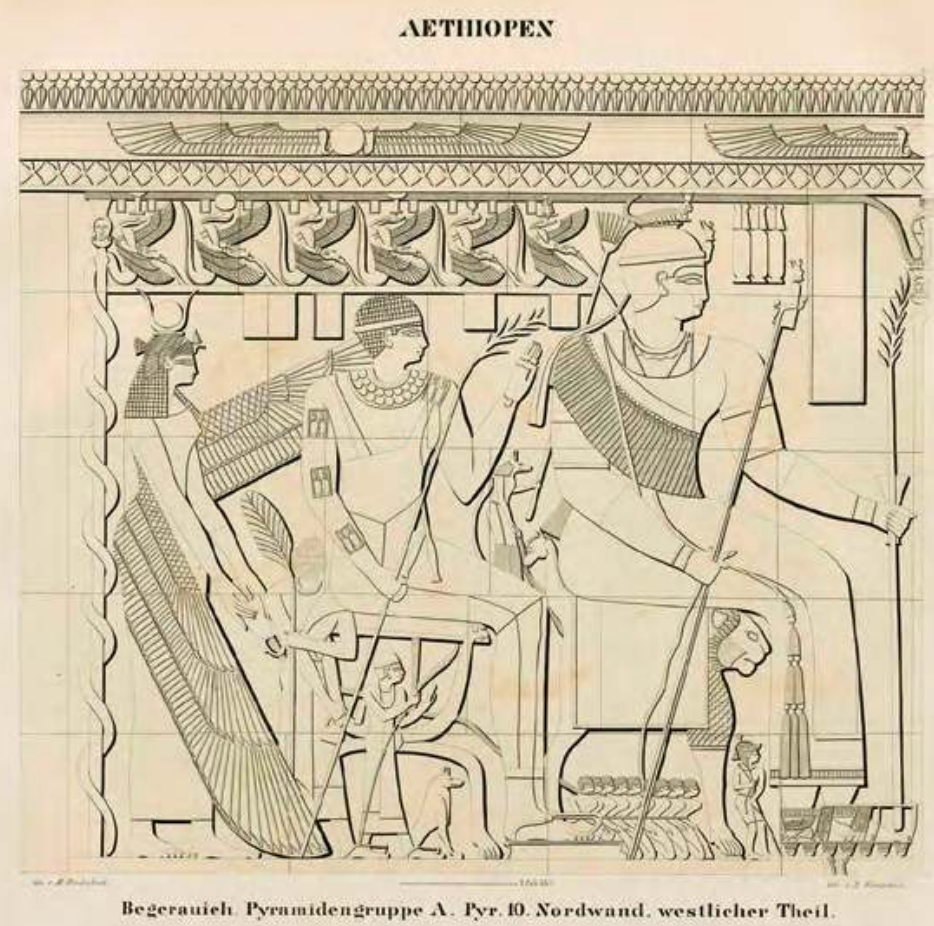

\section{5}

des temples dans

la savane

La reine Nahirqo sur le trône au lion, chapelle de la pyramide de Méroé Beg. N.11, d'après Carl Richard Lepsius, Denkmäler aus Aegypten und Aethiopien, vol. V, pl. 30. 


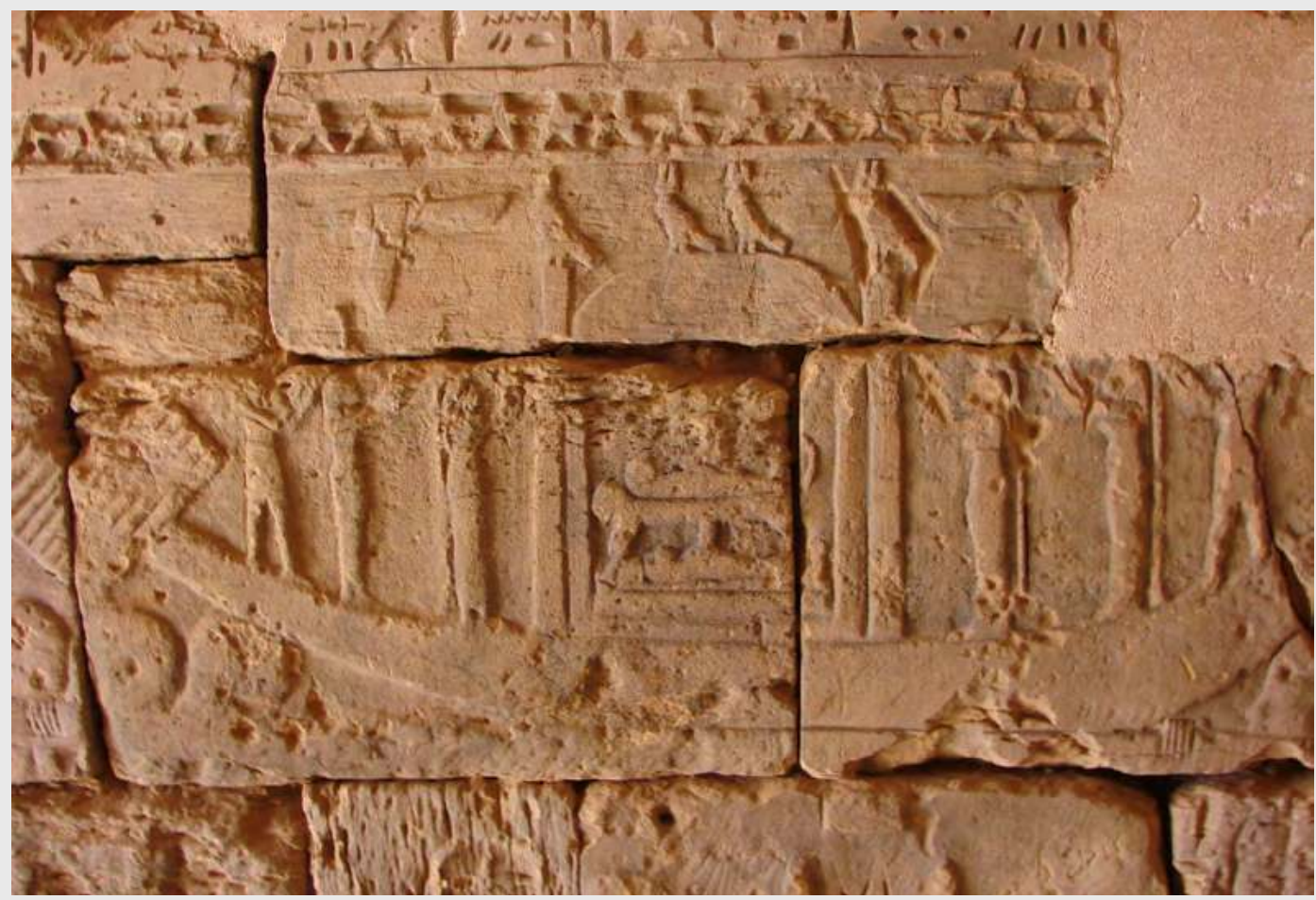

le Soudan

Le catafalque d’Amanitoré, Méroé, Beg N.1.

\section{6}

des origines

à la chute

du sultanat

Fung

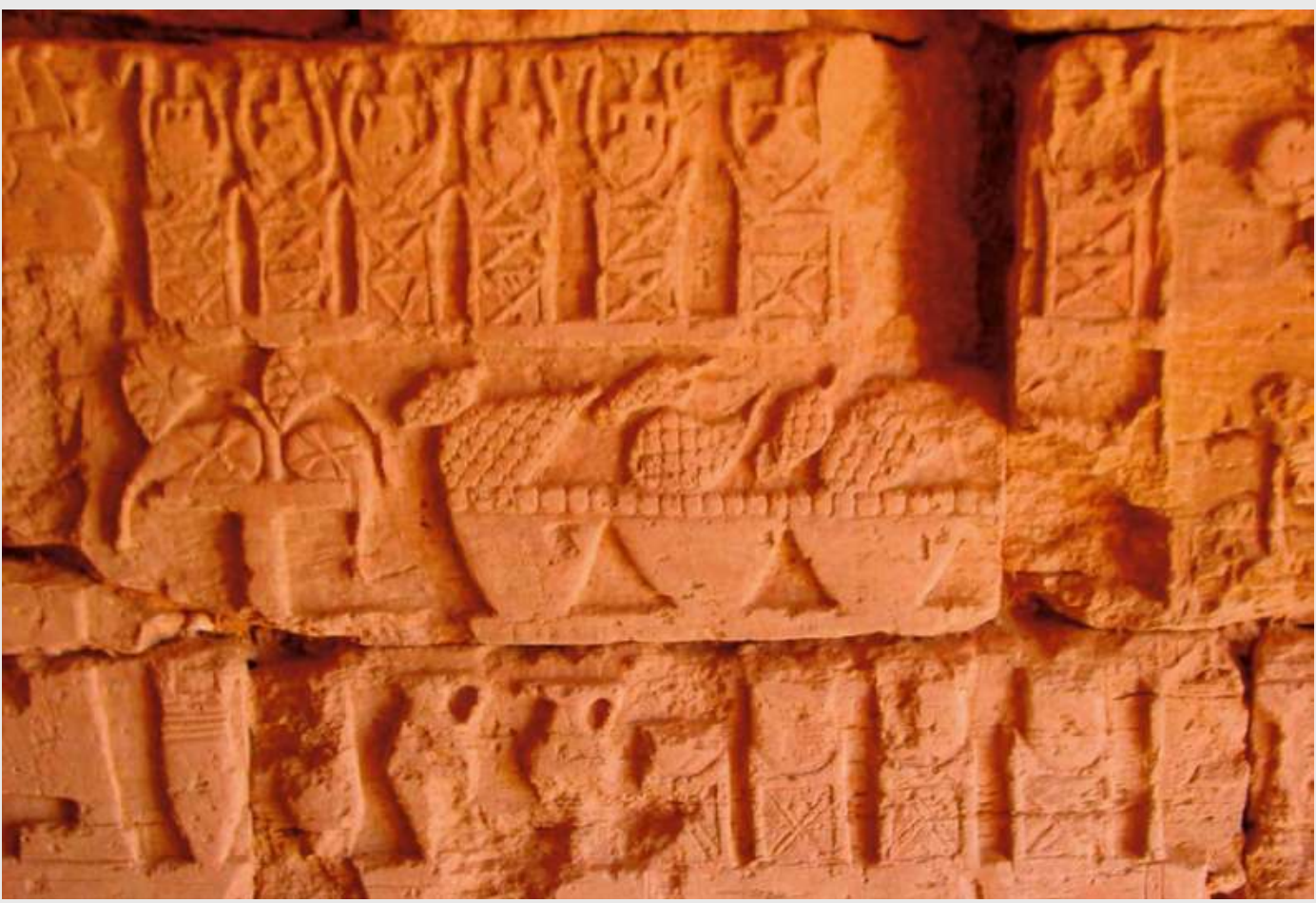

Reliefs de la chapelle du roi Tanéyidamani (Méroé, Beg. N. 12)... 


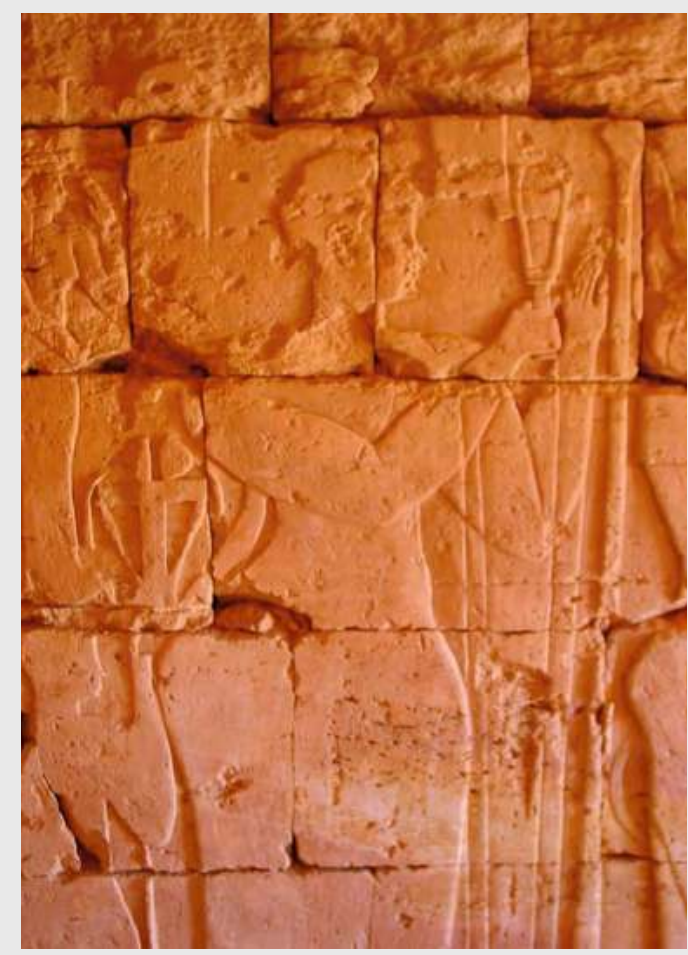

La reine joue du sistre...

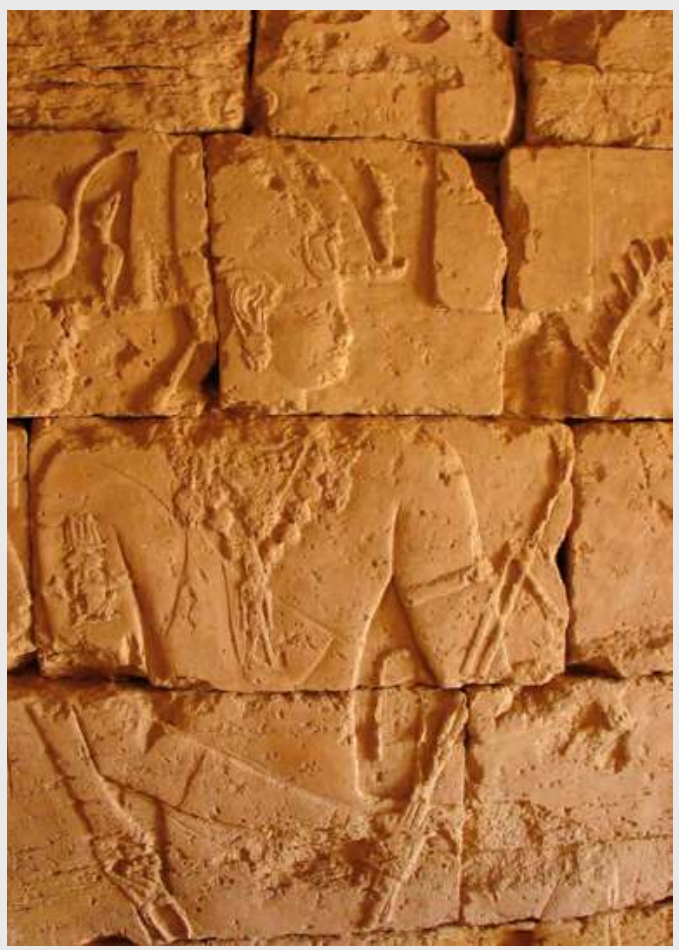

Le roi Tanéyidamani trônant en majesté.

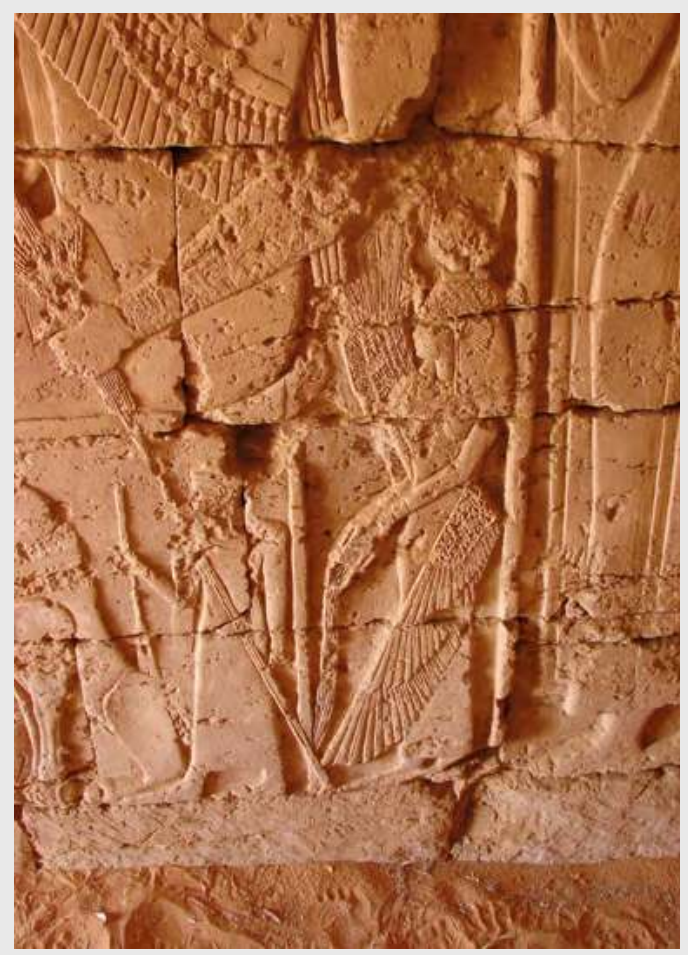

Isis protégeant de ses ailes le roi Tanéyidamani...

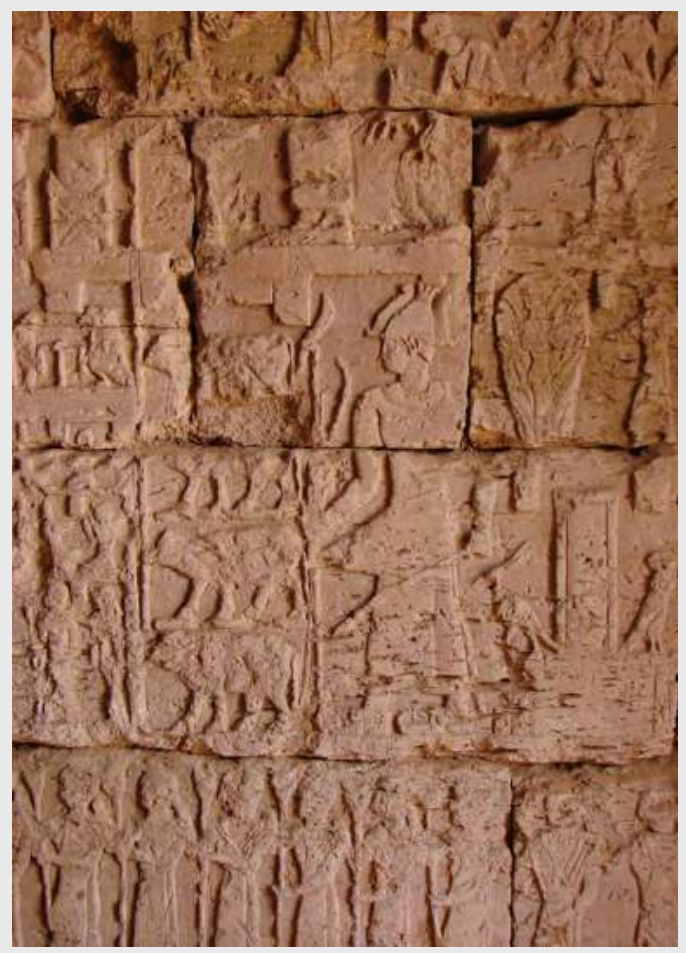

des temples dans

la savane 


\section{Arnékhamani et les temples de Musawwarat}

le Soudan

\section{8}

des origines

à la chute

du sultanat

Fung

Le roi suivant, Arnékhamani, est mieux connu. Bien que l'on ignore où il fut inhumé (peut-être en Beg. N. 53, une sépulture dont la pyramide a été entièrement détruite), on possède en revanche d'assez nombreuses traces de son activité architecturale et cultuelle. Il prit comme nom de trône Kheperka-Rê, "l'âme de Rê est en devenir", emprunté à Sésostris I Ir, renouant ainsi avec la tradition des noms anciens, attestés de préférence en Nubie, puisque ce pharaon avait lancé la construction des forteresses de la deuxième cataracte au Moyen Empire. Le nom de naissance d'Arnékhamani est toujours accompagné d'une épithète: "qu'il vive éternellement, aimé d'Amon » au début de son règne, «aimé d'Isis» à la fin. Cette évolution possède un parallèle dans celle des épithètes des rois lagides en Égypte. Dans les cartouches de Ptolémée Ier et de Ptolémée II Philadelphe, on trouve "qu'il vive éternellement, aimé d'Amon». Chez Ptolémée III Évergète I ${ }^{\mathrm{er}}$, le dieu Ptah remplace Amon, tandis que Ptolémée IV Philopatôr est dit "aimé d'Isis». Si la formule incluant Ptah, divinité peu présente en Nubie, n'a guère eu d'influence à Méroé, on peut relier avec assurance l'apparition d'Isis dans le cartouche d'Arnékhamani à l'arrivée sur le trône de Ptolémée IV Philopatôr (222-204). Son règne devrait donc être placé à peu près entre 240 et $215 \mathrm{av}$. J.-C.

Le nom d'Arnékhamani est une transcription de l'égyptien JrnhJmn et présente donc des incertitudes dans la reconstruction de l'original méroïtique, le signe $r$ pouvant être un « $\mathrm{r}$ ", un «1» ou un " $\mathrm{d}$ » intervocalique et les deux premières voyelles "a $\mathbf{a}$ " et "é" étant purement arbitraires. Or, un sistre de bronze argenté, de provenance inconnue et apparu sur le marché de l'art européen en 2015, non seulement comporte sur l'arceau les deux cartouches du roi en écriture égyptienne (où il est "aimé d'Isis»), mais livre de surcroît la plus ancienne inscription datée en cursive méroïtique, gravée sur le manche. Le souverain y est cette fois nommé Elxmni, une séquence à lire «Élankhamani», puisque le «n» n'est jamais écrit en méroïtique s'il est directement suivi d'une consonne mais que sa présence se déduit de la transcription égyptienne. C'est la véritable prononciation du nom royal, dont "Arnékhamani» n'est qu'une approximation mais que nous conserverons ici pour ne pas égarer le lecteur. Ce composé signifie très probablement «il l'a donné, Amon» et correspond à l'égyptien Padiamon, un anthroponyme courant à l'époque tardive. Bien que l'inscription comporte de nombreux points obscurs, elle précise que l'objet a été offert pour le culte d'Isis. On connait également une égide de bronze surmontée de la tête de cette déesse et gravée aux noms du souverain, cette fois "aimé d'Amon", qui provient de Kawa et se trouve aujourd'hui au British Museum. 
Mais le témoignage le plus éclatant du règne d'Arnékhamani se trouve au sud de Méroé, au cœur de la savane sèche du Boutana, à Musawwarat es-Sufra. Là, à quelque $35 \mathrm{~km}$ du Nil, fut bâti un gigantesque complexe cultuel, l'un des mieux conservés du Soudan. Fouillé depuis 1960 par les archéologues de l'université Humboldt de Berlin (ancienne RDA) sous les directions successives de Fritz Hintze, de Steffen Wenig, de Pawel Wolf et de Claudia Näser, le site s'étend sur un vaste cirque de quatre à cinq kilomètres de diamètre entouré de collines et traversé par le Wadi es-Sufra, un oued saisonnier. Il comprend deux réservoirs qui permettaient de conserver pendant plusieurs mois l'eau des pluies d'été (nommés hafir en arabe local), un vaste ensemble de bâtiments cultuels appelé la «Grande Enceinte», un second complexe peut-être à vocation résidentielle, la «Petite Enceinte», et un temple rectangulaire dit «temple du Lion», rebâti en 1969-1970 par l'équipe de Hintze, ainsi que plusieurs autres édifices de moindre importance.

La Grande Enceinte de Musawwarat est le plus remarquable des monuments du site. Elle s'organise sur 40 hectares en un vaste ensemble de cours et de couloirs labyrinthiques reliant trois temples alignés du nord au sud, plus un quatrième sur la bordure est. Les analyses architecturales ont montré qu'elle a connu huit périodes de construction, s'étageant sans doute entre la fin de l'époque napatéenne et le milieu de la période méroïtique. Les deux phases les plus actives correspondent au règne d'Arnékhamani et, au milieu du $\mathrm{I}^{\text {er }}$ siècle de notre ère, au règne conjoint du roi Natakamani et de la Candace Amanitoré. Les murs de grès fin sont couverts de centaines de graffiti: dessins d'animaux, de divinités, portraits humains, mais aussi courtes inscriptions qui vont de l'époque méroïtique archaïque jusqu'aux temps modernes.

Sur le mur nord du complexe 200, le sanctuaire central, deux graffiti du XIX ${ }^{e}$ siècle se répondent en français (voir p. 217). Ils témoignent de la redécouverte des antiquités soudanaises par les voyageurs occidentaux. Ils furent inscrits à un mois d'intervalle par deux explorateurs français qui avaient accompagné la conquête du Soudan par les Turcs. Le premier, le Lorientais Louis Linant de Bellefonds, avait pris part en tant que dessinateur à une petite expédition envoyée d'Égypte par le collectionneur britannique William J. Bankes. Il y écrit: «L'an de Jésus 1822, Louis Linant a visité ces ruines renommées. Il y est venu mandé par l'Angleterre et il a pénétré jusqu'au royaume de Sennar, grâce aux conquêtes d'Ismaïle [sic] Pacha, général des armées de son père Mohamed Ali, vice-roi d'Égypte.» La mention des «ruines renommées» est due à une confusion. Linant de Bellefonds était passé le long du Nil au niveau de Méroé sans s'arrêter. C'est en revenant de son voyage à Sennar, sur le Nil Bleu, qu'il découvrit 
Musawwarat (et Naga), et il crut que ces ruines étaient celles de la capitale mythique du royaume koushite. Il rencontra peu après à Shendi, la ville moderne la plus proche, Frédéric Cailliaud, un minéralogiste nantais engagé par Méhémet Ali, qui venait de visiter Méroé et avait été le premier à l'identifier. Alors que Linant de Bellefonds, convaincu de son erreur, revenait sur ses pas vers la véritable Méroé, Cailliaud, de son côté, se mit en route pour Musawwarat et Naga. Son graffito est ironiquement démarqué de celui de Linant de Bellefonds: "L'an de Jésus 1822, Frédéric Cailliaud a visité ces ruines renommées. Il y est venu mandé de la France, favorisé par le prince Ismaël Pacha. Il a pénétré au-delà du Fazole (Fazugli sur le Nil Bleu) par $10^{\circ}$ de latitude, où il a visité des peuples païens. "À son retour en France, Cailliaud publia en 1826 la première description moderne détaillée des sites archéologiques du Soudan dans son ouvrage Voyage à Méroé.

\section{Le dieu Apédémak, au centre d'une nouvelle théologie}

le Soudan

210

des origines

à la chute

du sultanat

Fung

Les textes méroïtiques y sont assez divers, mais une grande partie sont des graffiti de dévotion au dieu principal de Musawwarat, une divinité à tête de lion nommée Apédémak. Or, si le panthéon égyptien comporte quelques dieux léontocéphales de rang secondaire (Mahès, Chesmou, parfois Néfertoum), il ne s'agit pas ici d'une importation égyptienne mais d'une divinité locale. Son nom est méroïtique et se compose de $m k$, «dieu», (prononcé /maka/), et d'un premier élément Apede- (prononcé /abede/ avec un « $\mathrm{d}$ » rétroflexe proche de $/ \mathrm{r} /$ ) que l'on retrouve dans les langues modernes apparentées pour désigner le «Créateur». La langue nara, en Érythrée, et le nyimang, dans les Monts Nouba, possèdent même des termes proches, respectivement Ėbbéré et Ábŕdì, qui servent aujourd'hui à nommer Allah chez ces peuples récemment convertis à l'islam. Une influence méroïtique chez ces tribus très éloignées du Nil est exclue; la proximité des noms s'explique par une origine commune remontant au troisième millénaire. Le terme semble formé sur une racine verbale conservée en nubien du Kordofan et qui signifie «modeler», "créer». Il est donc très vraisemblable que, loin d'être un nouveau venu, le dieu Apédémak soit un ancien dieu-créateur, honoré de toute antiquité par la population koushite mais jusqu'alors jamais représenté dans un temple officiel.

Quelle était la raison d'une telle exclusion? Plusieurs hypothèses sont envisageables. D'une part, il a pu exister un tabou sur sa représentation. On connaît en effet une autre divinité méroïtique, Mash, dieu du Soleil, qui n'est attesté que par l'existence d'un clergé spécifique mentionné dans les textes, mais dont aucune représentation certaine n’a pour l'heure été retrouvée. D'autre part, les dieux napatéens figurés 
dans les lieux de culte sont tous d'origine égyptienne, quand bien même, comme Amon de Napata à tête de bélier, ils sont le fruit d'un synchrétisme ancien avec les dieux locaux. Il est certain que ce fait doit être mis en relation avec la légitimité de la monarchie koushite, fondée sur l'héritage le plus strict possible de la royauté pharaonique. L'incorporation d'Apédémak et d'autres dieux locaux dans le culte officiel est une innovation. Elle témoigne de l'influence de la culture du sud sur la nouvelle dynastie qui en est issue et constitue l'aboutissement d'un phénomène que nous avons déjà vu à l'œuvre durant les derniers siècles du royaume de Napata: la civilisation koushite est désormais ancienne et prestigieuse et elle peut donc concurrencer la culture égyptienne comme référence de l'idéologie royale. C'était déjà vrai pour le choix des noms de couronnement, souvent empruntés à des prédécesseurs plus ou moins lointains et non aux pharaons égyptiens. Ce le sera maintenant pour le culte royal, où vont se juxtaposer le panthéon égyptien présidé par Amon et le panthéon méroïtique présidé par Apédémak.

Musawwarat est en quelque sorte le laboratoire de cette nouvelle théologie mixte. La Grande Enceinte comporte ainsi des linteaux ornés de sculptures où voisinent des protomés du bélier d'Amon, du lion d'Apédémak et le buste de Shébo, un autre dieu dont la tête est coiffée du pschent, la double couronne pharaonique. Ce dernier, malgré sa ressemblance avec le dieu égyptien Atoum, est purement méroïtique. Son nom, connu jusqu'à récemment par sa transcription égyptienne Sbjwmkr dans l'hymne qui lui est dédié dans le temple du Lion de Musawwarat, et donc écrit Sébiouméker, est depuis peu attesté sous sa forme méroïtique Sebo "Shébo" dans le temple 200 de Naga. La forme égyptienne Sbjwmkr est très certainement transcrite du composé méroïtique Sebo-mk-l, "le dieu Shébo ". Les inscriptions d'origine sont trop rares ou mal conservées pour que l'on puisse attribuer avec certitude à telle ou telle divinité chacun des trois sanctuaires compris à l'intérieur de la Grande Enceinte, mais on suppose que le temple central était consacré à Apédémak, tandis que le quatrième, sur la bordure orientale, où des statues colossales de ces deux dieux ont été retrouvées, était dédié à Shébo et Arensnouphis, un dieu tardif au nom égyptien, adoré aussi à Philae.

La Grande Enceinte, comme le démontrent les graffiti innombrables de ses murs, était le lieu central de fêtes religieuses annuelles en l'honneur d'Apédémak et d'Amon. Y convergeaient la population établie le long du Nil, des pèlerins venus parfois de loin et la famille royale. Outre la Petite Enceinte, où se trouvait une résidence sans doute prévue pour le clergé, il n'y avait pas d'habitat en dur ni de cimetière à Musawwarat. Des jardins, alimentés en eau par un réseau complexe relié aux réservoirs, 
étaient d'année en année réaménagés pour l'occasion, comme l'ont montré les fouilles récentes. Il est en effet probable que, dès le milieu de la saison sèche, vers février, les réservoirs étaient à sec, et la trop grande profondeur de la nappe phréatique à cet endroit excluait la construction de puits.

\section{Le temple du Lion à Musawwarat}

le Soudan

212

des origines

à la chute

du sultanat

Fung

L'autre lieu emblématique de Musawwarat est le temple du Lion, situé à l'est, de l'autre côté du Wadi es-Sufra. Magnifiquement restauré par l'équipe archéologique allemande, il offre le seul exemple d'un temple méroïtique du III $^{\mathrm{e}}$ siècle presque intact. Il est constitué d'un simple édifice rectangulaire à salle unique (une structure connue uniquement pour les dieux locaux), le plafond étant soutenu par six colonnes. La façade revêt la forme d'un pylône et a dû être refaite après un effondrement survenu peu après la construction. Contrairement à la Grande Enceinte, il date entièrement du règne d'Arnékhamani et présente une riche décoration gravée. À l'extérieur, sur le côté sud, le roi apparait debout en majesté, vêtu du costume tripartite, coiffé de la calotte koushite surmontée de la lourde couronne hemhem. Il élève la paume droite vers Apédémak qui lui tend son sceptre à tête de lion. Sous la main divine, le petit prince Arka, précédant son père, honore le dieu de deux brasiers d'encens. Apédémak est ici armé d'un arc et assume la fonction de dieu guerrier, terrible protecteur de la dynastie. Il est suivi d'un défilé divin où l'on distingue Amon de Thèbes à tête humaine, Shébo, Arensnouphis, Horus et Thot. Les proportions massives des dieux, leurs épaules larges, leurs muscles apparents offrent avec la finesse des visages et la luxuriance des bijoux et des broderies un contraste caractéristique de l'art méroïtique.

Sur le flanc nord, tourné vers l'Égypte, le roi, également accompagné de son fils, est cette fois revêtu d'une tunique longue et coiffé de la double couronne des pharaons, tandis qu'Apédémak porte un sceptre ouas également égyptien. De ce sceptre partent des signes de vie, le dieu assumant sur ce côté son rôle de créateur. Il est cette fois suivi non seulement de dieux mais aussi de déesses, dont seules Satis et Isis sont encore reconnaissables. La bipartition du temple, entre le côté sud, associé à Koush, à la masculinité et à la guerre, et le côté nord, associé à l'Égypte, à la féminité et à la vie se retrouve dans d'autres temples, par exemple plus tard à Naga, et nous donne un aperçu saisissant de l'organisation duelle du monde selon les Méroïtes et de la façon dont Apédémak fédère ces deux pôles.

L'intérieur du temple, suivant la tradition égyptienne, est orné de décors en bas-relief, alors que l'extérieur présente des reliefs incisés. Malheureusement, ces derniers ne sont pas aussi bien conservés 


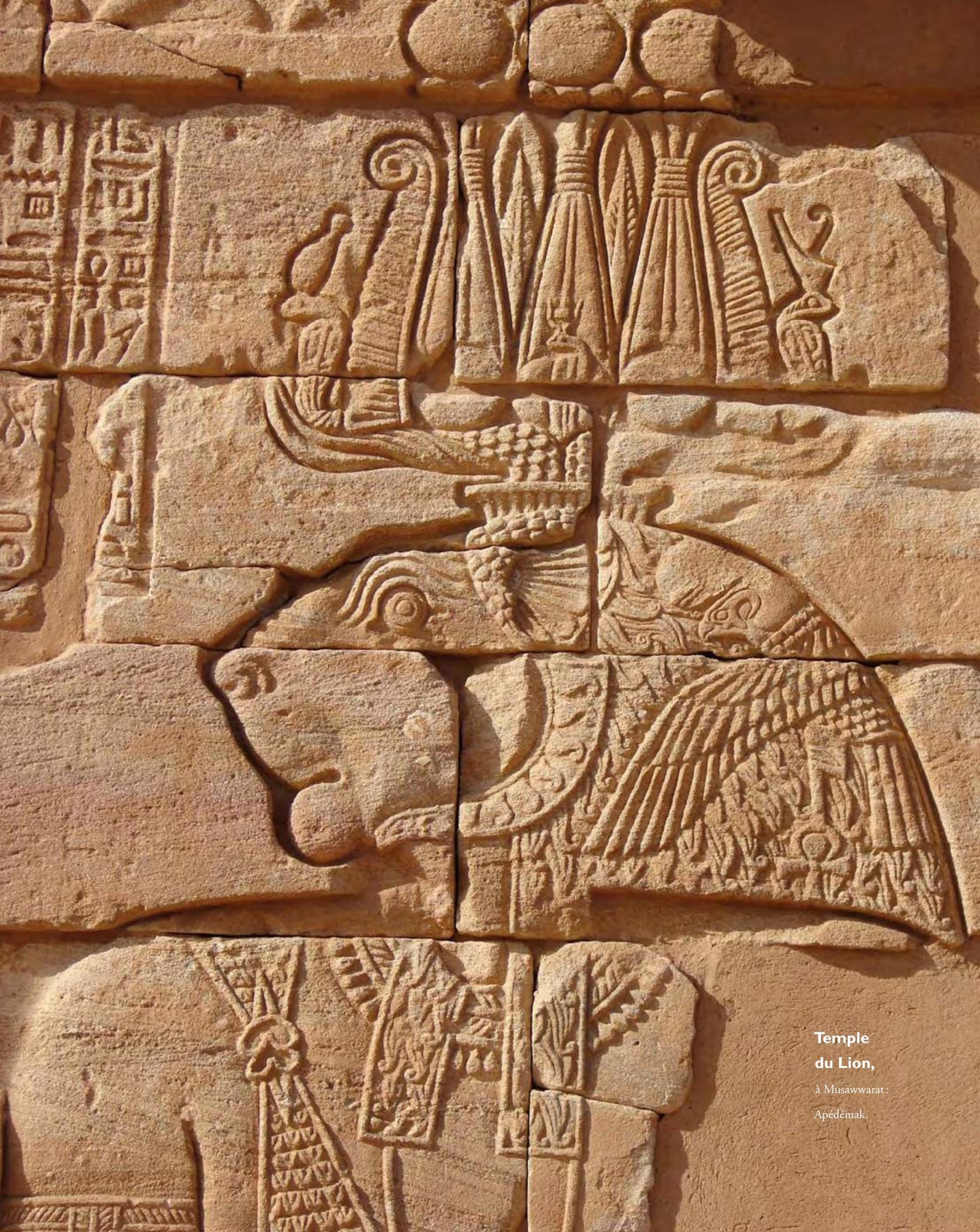


le Soudan

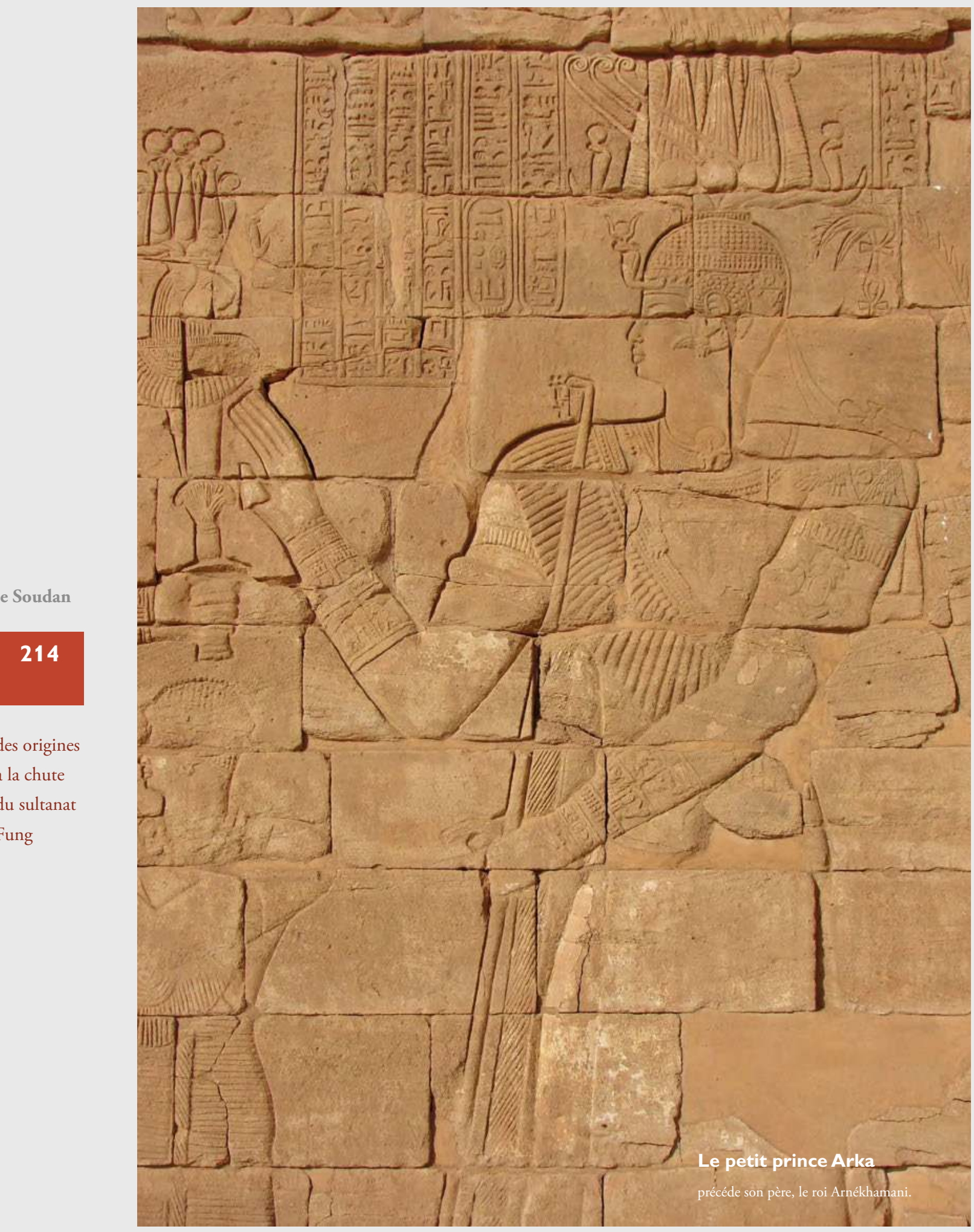

des origines à la chute du sultanat Fung 


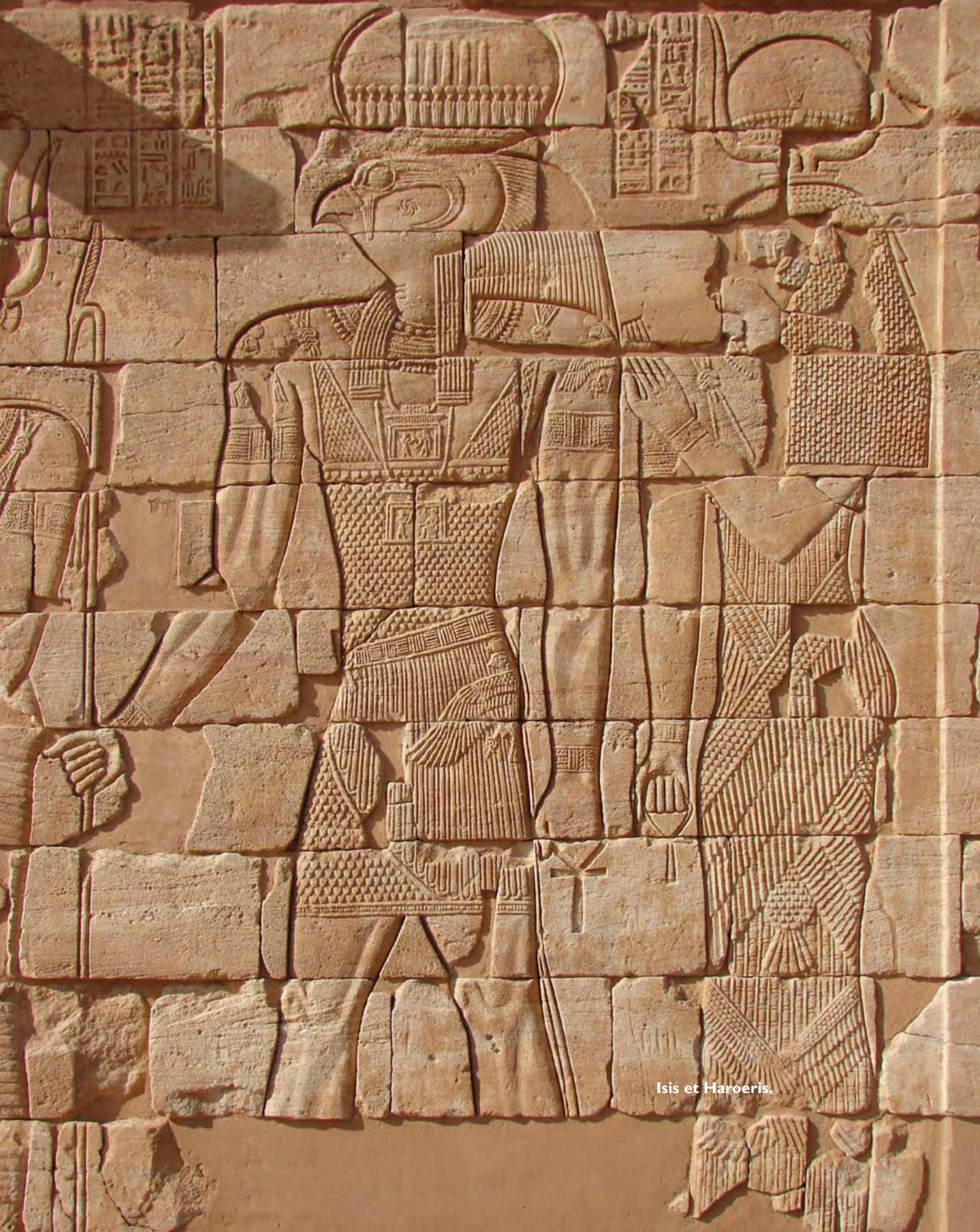




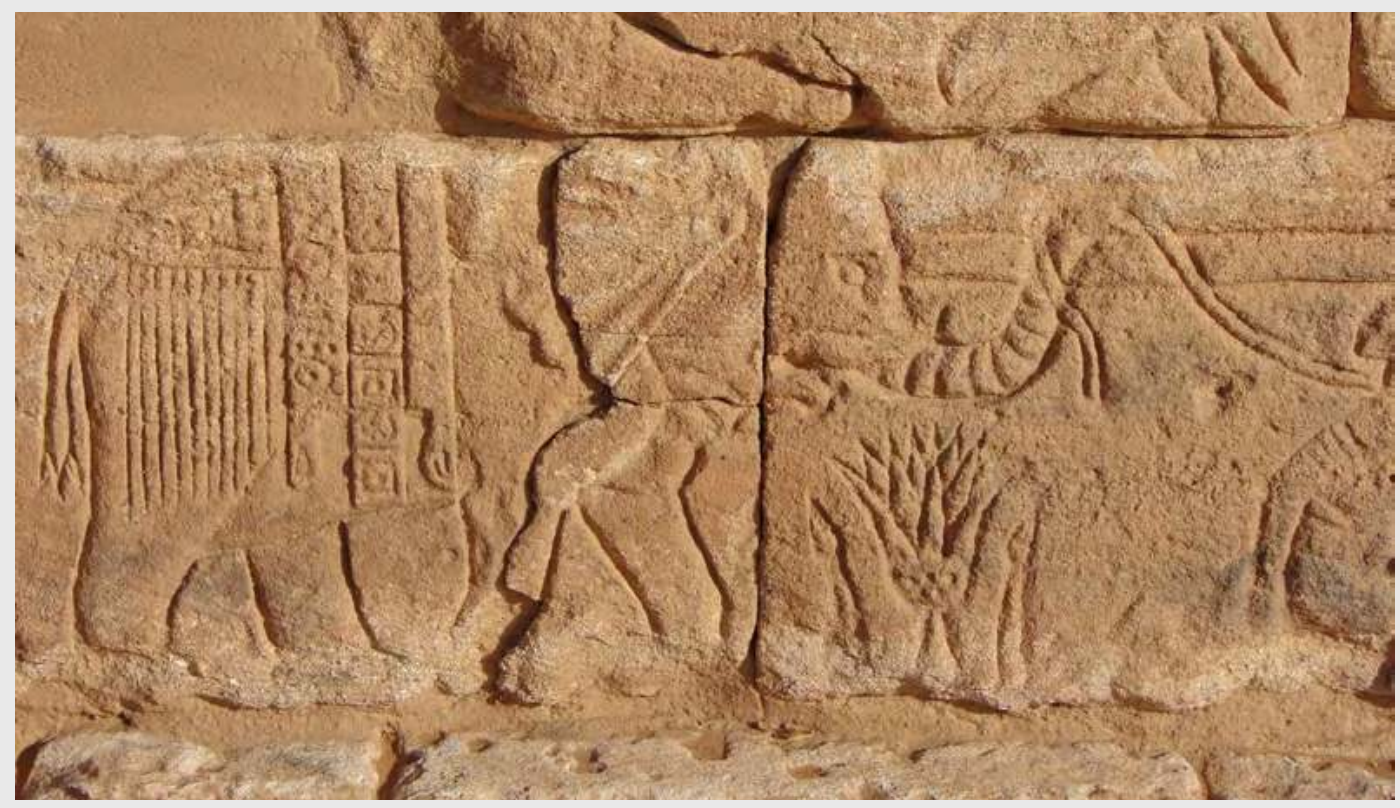

Temple du Lion : un éléphant de guerre tient un prisonnier entravé.

le Soudan

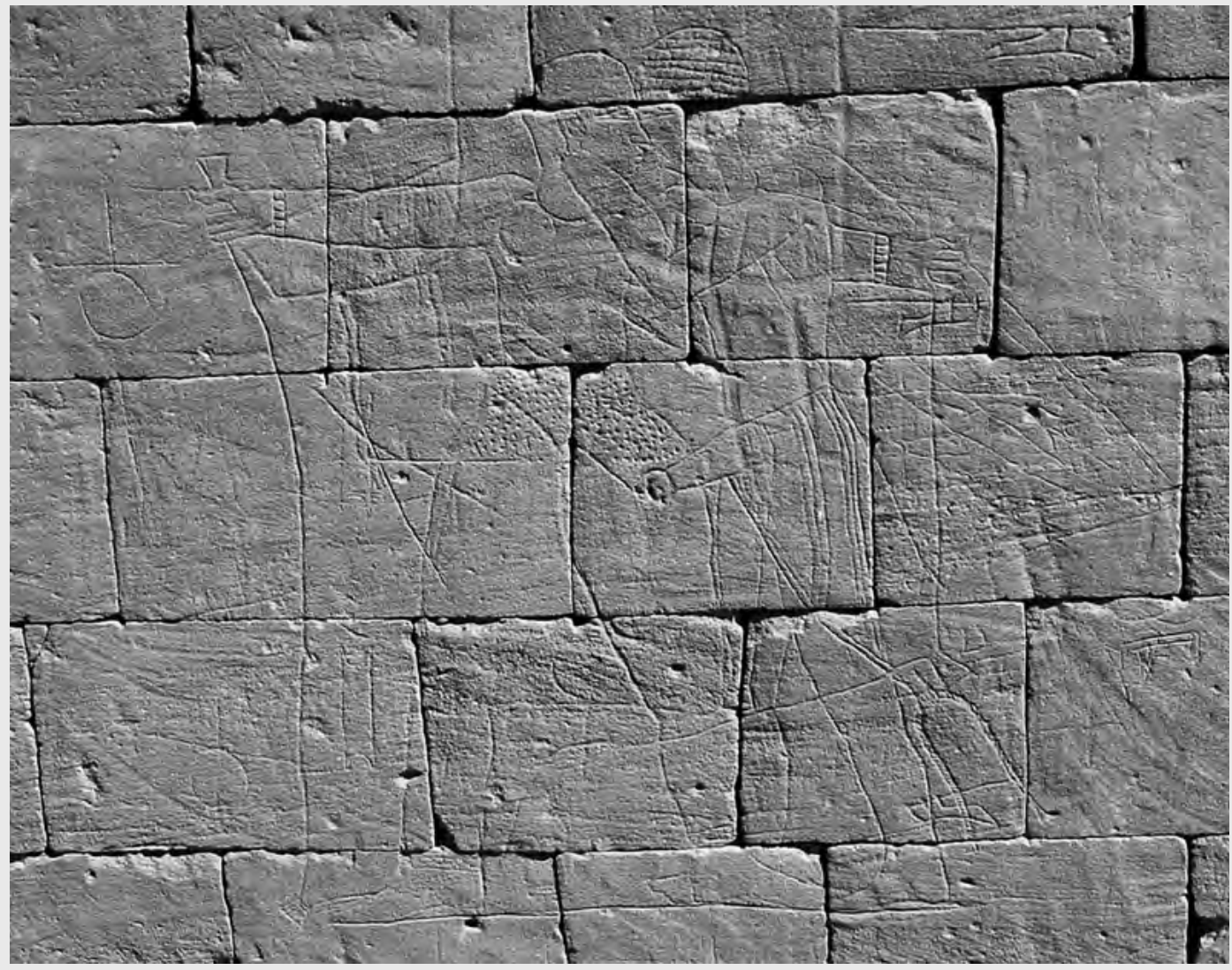

Graffito méroïtique érotique. 


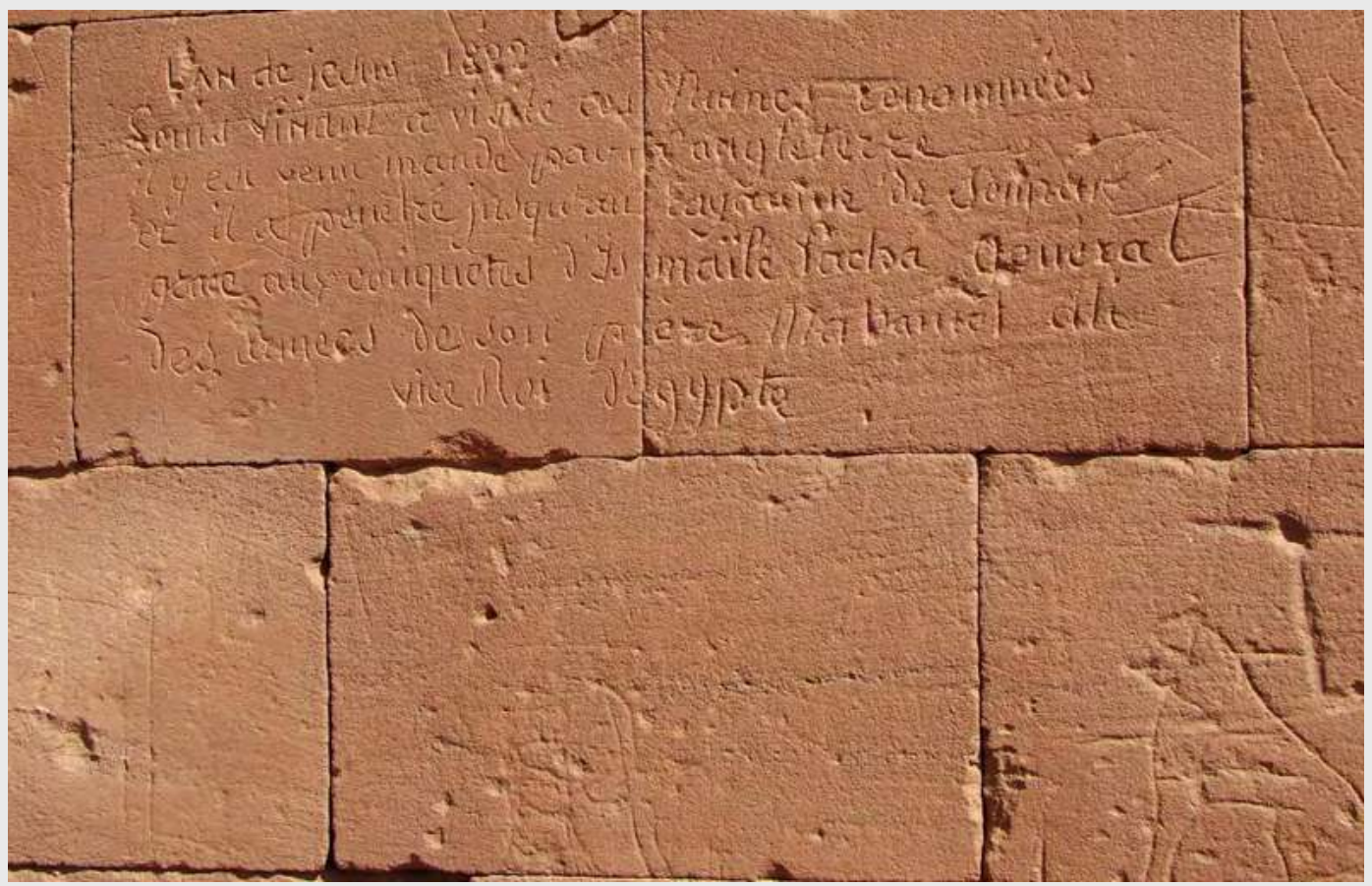

Graffito de Linant de Bellefonds: «L’an de Jésus 1822. Louis Linant a visité ces ruines renommées.

Il y est venu mandé par l'Angleterre et il a pénétré jusqu'au royaume de Sennar grâce aux conquêtes

d'Ismaïle (sic) Pacha Général des armées de son père Mohamed âli (sic) vice Roi d’Égypte.» (voir p. 209)

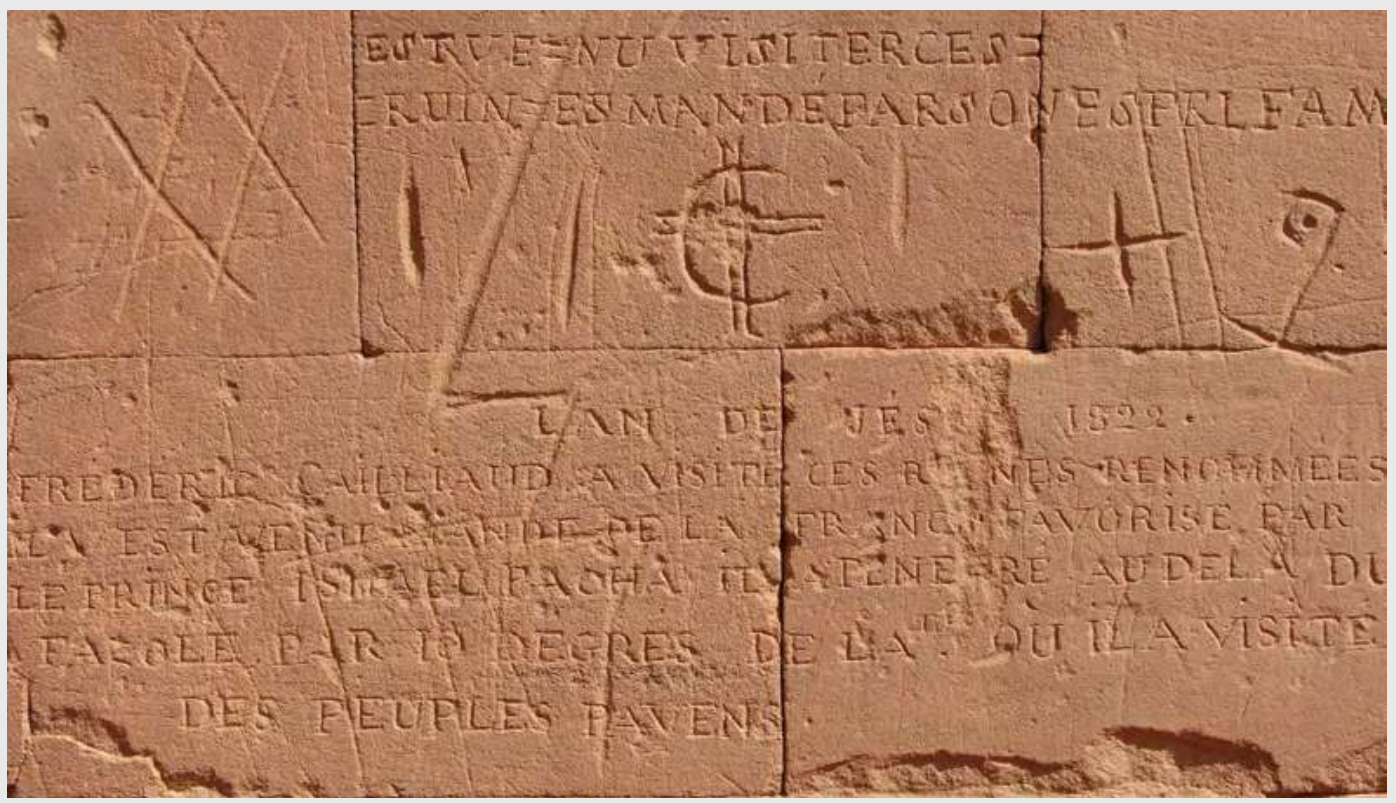

des temples dans

la savane

Graffito de Cailliaud : «L'an de Jés[us] 1822. Frédéric Cailliaud a visité ces ruines renommées.

Il y est venu mandé de la France. Favorisé par le Prince Ismaël Pacha il a pénétré au-delà du Fazole par 10 degrés de la[titude] où il a visité des peuples payëns.» (voir p. 210) 


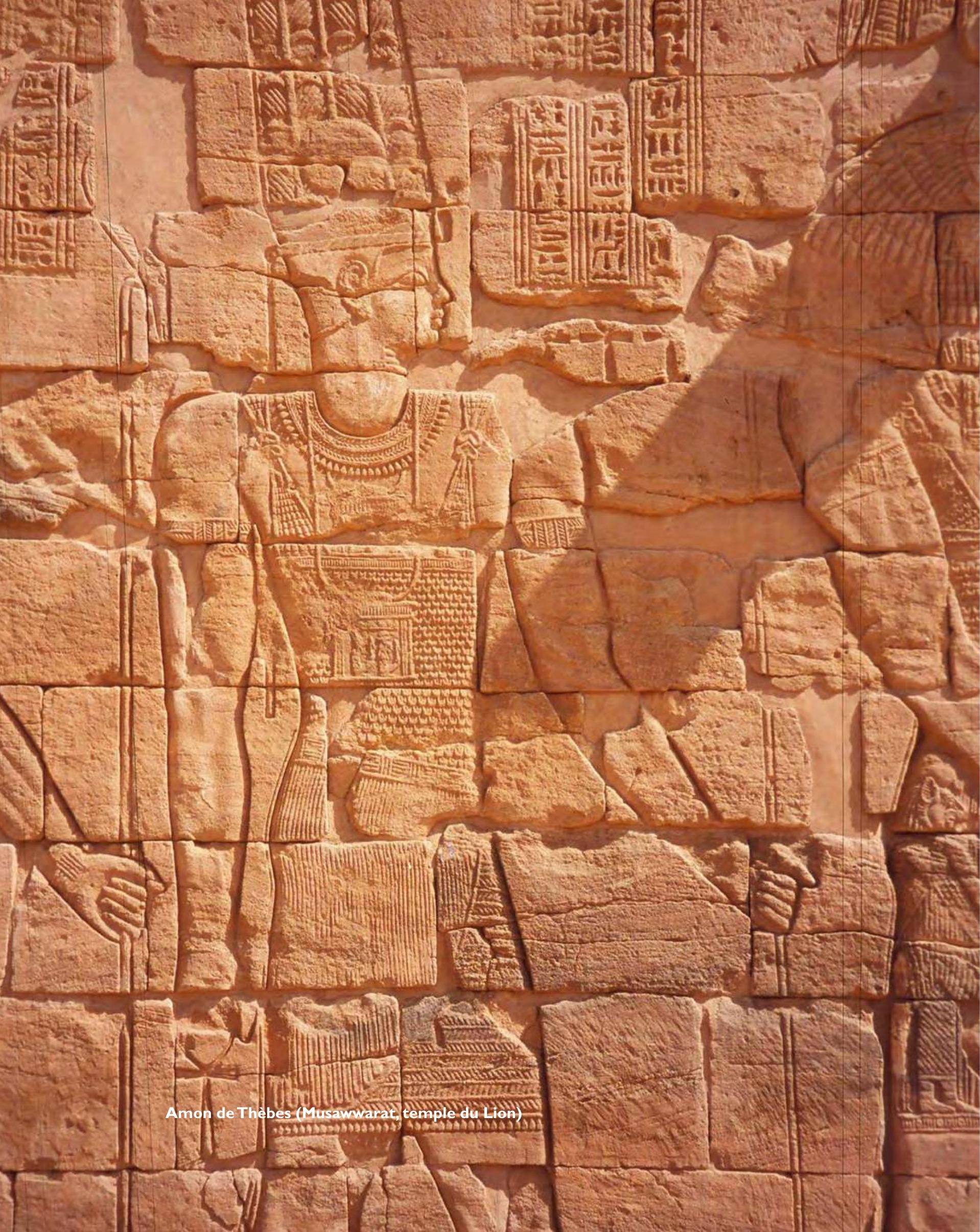




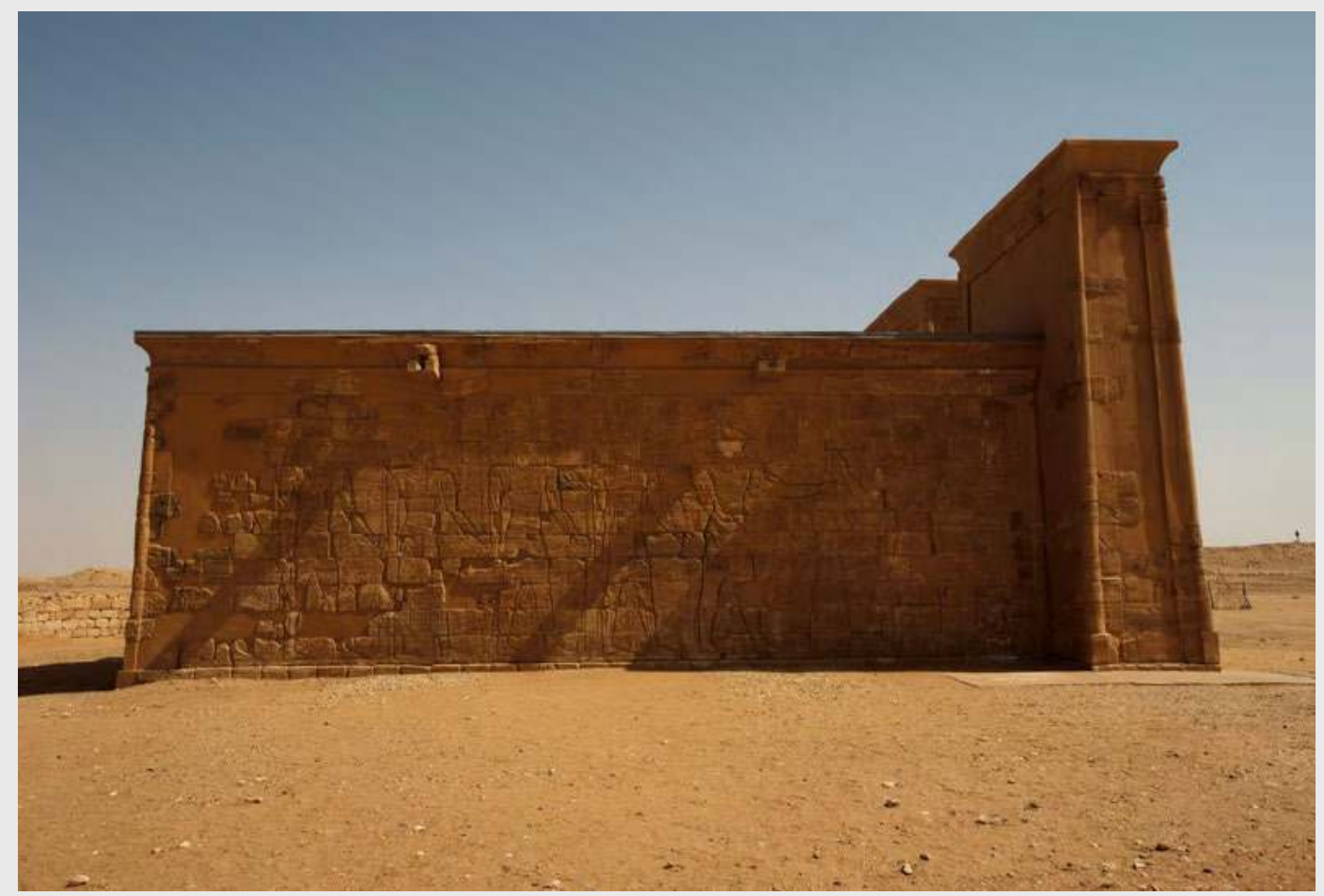

Temple du Lion de Musawwarat, face sud.

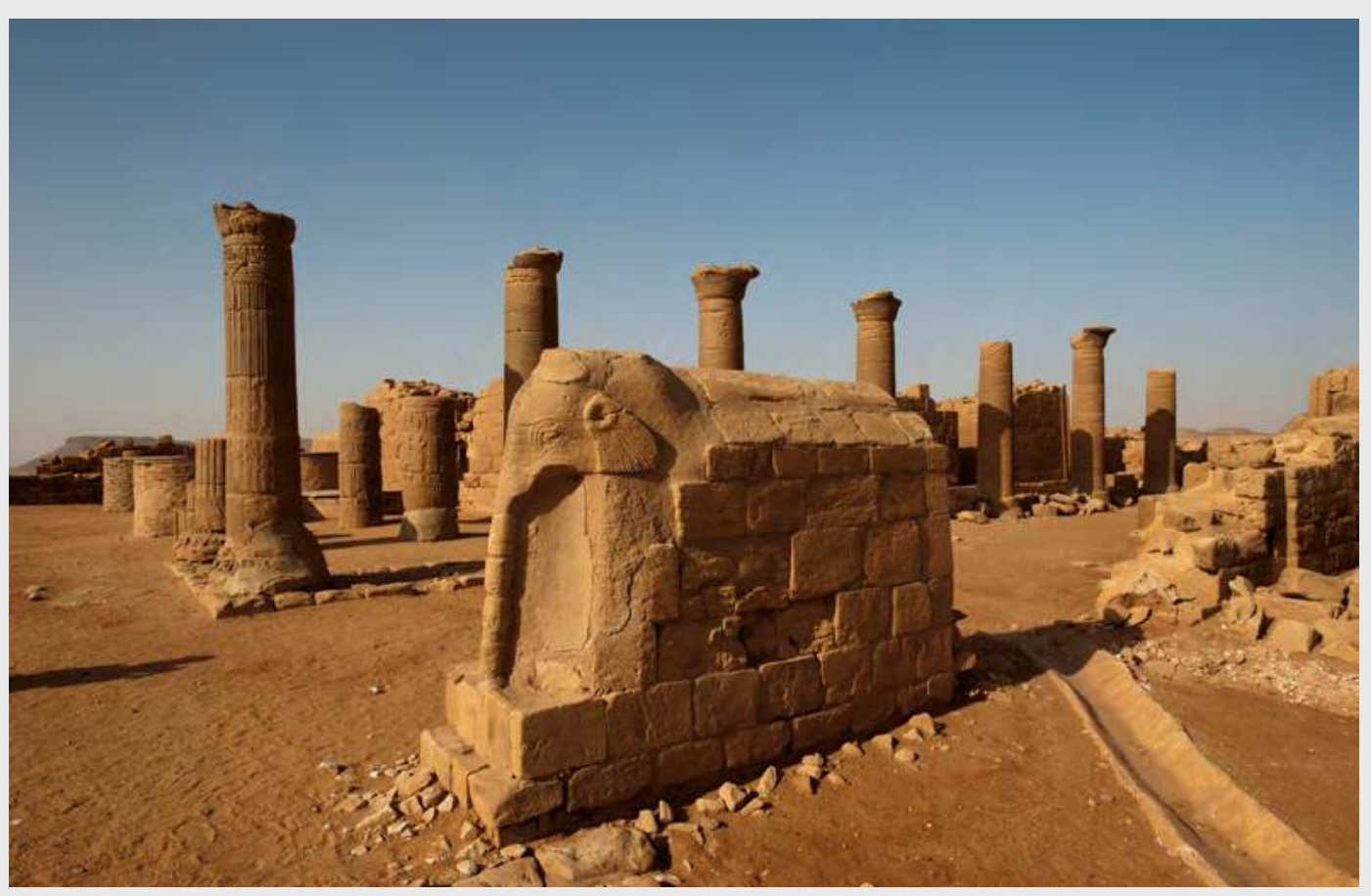

des temples dans

la savane

Grande Enceinte de Musawwarat,

fragment de mur en forme d'éléphant. 


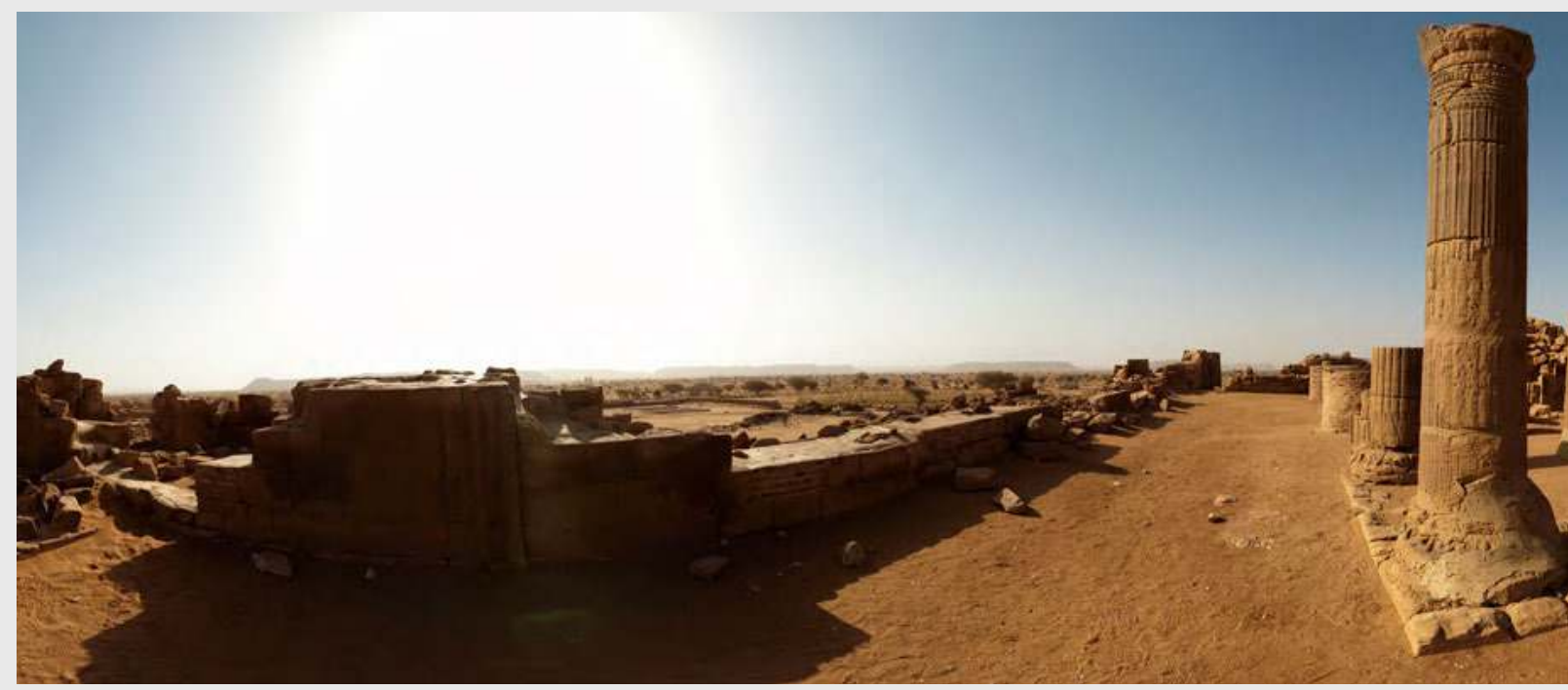

Grande Enceinte de Musawwarat: la terrasse centrale et le complexe 100.

le Soudan

220

des origines

à la chute

du sultanat

Fung

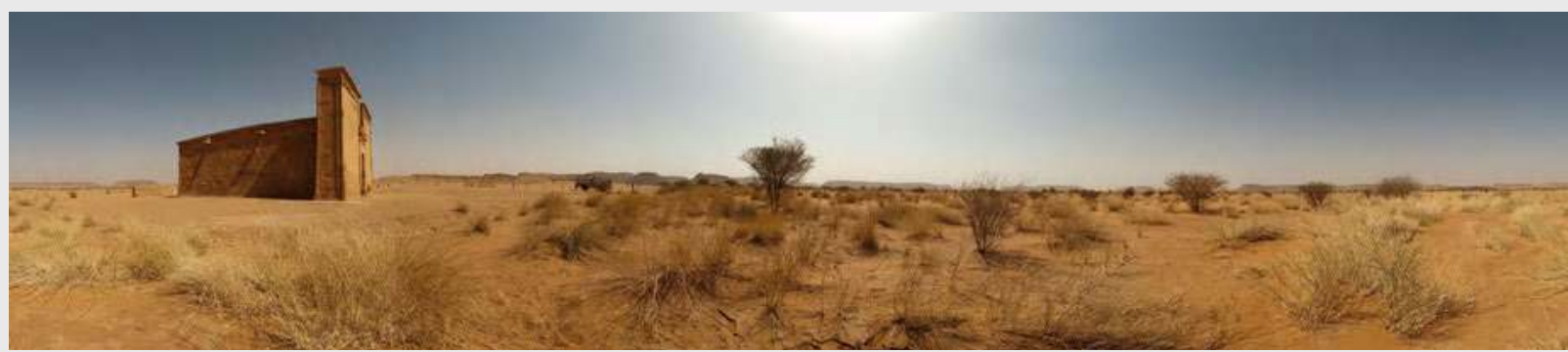

Le temple du Lion au centre de la plaine de Musawwarat.

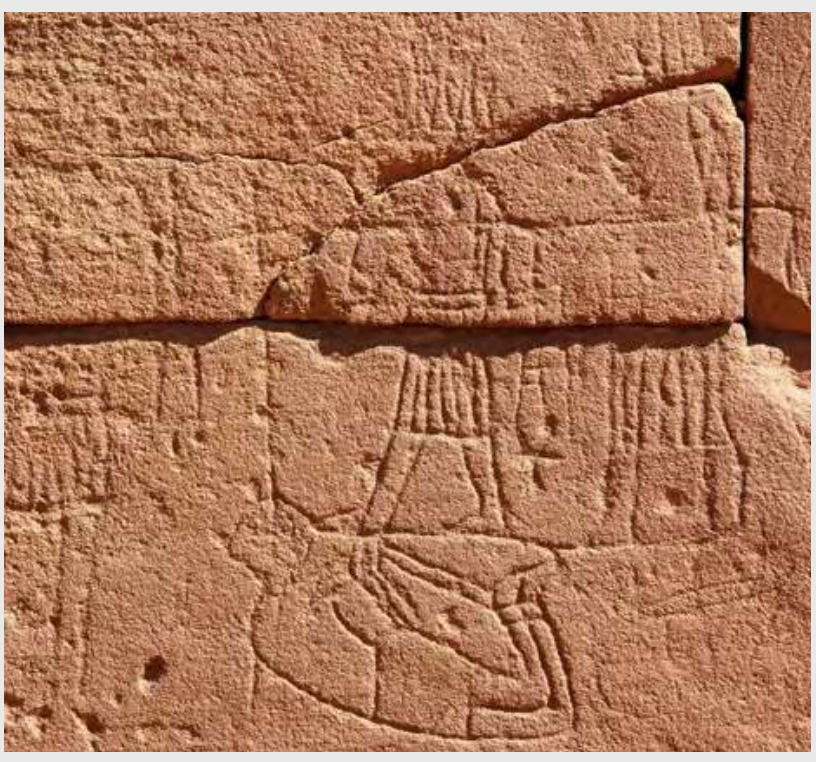

Apédémak piétinant un ennemi (Musawwarat, Grande Enceinte, graffito).

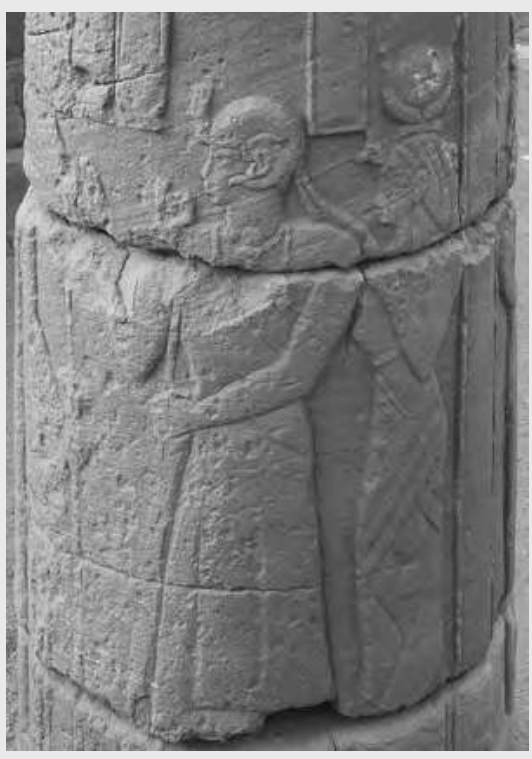

Arnékhamani et Isis (Grande Enceinte). 

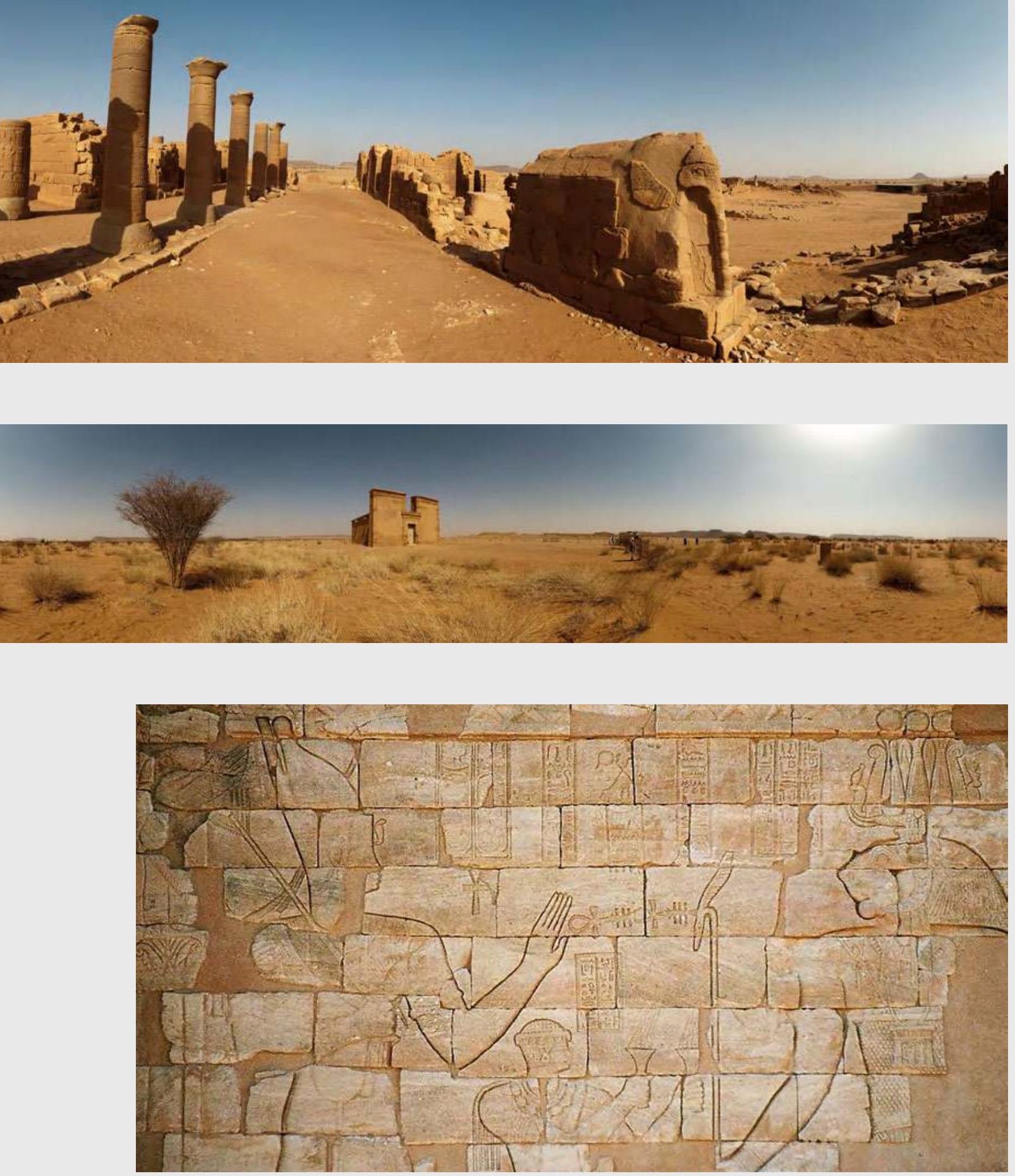

des temples dans

la savane

Arnékhamani en costume égyptien devant Apédémak (Musawwarat, temple du Lion). 


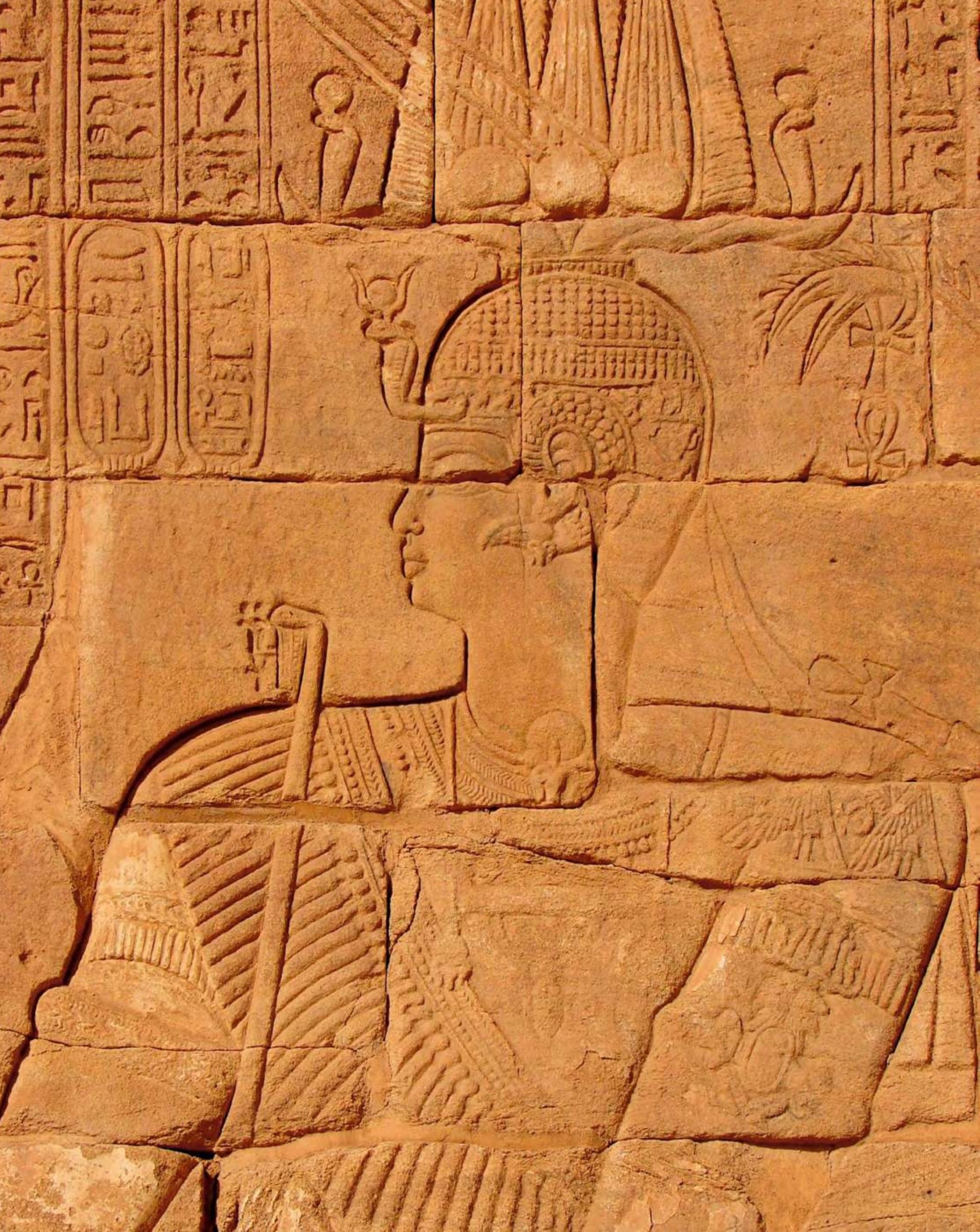


que les précédents. Ici, la dualité simple de l'extérieur est remplacée par un jeu de chiasmes complexes ordonnés cette fois autour d'Apédémak et d'Amon. Sur le mur du fond, derrière l'autel, était représenté le roi entre Amon à gauche et Apédémak à droite. Sous chacune des divinités sont encore visibles un lion et un éléphant. Le décor le plus inattendu est celui des colonnes, organisé en plusieurs registres. Des scènes énigmatiques y figurent, comme le dieu Bès jouant de la harpe devant un lion assis ou un homme attaqué par le même fauve sous un fourré de papyrus. Elles semblent en rapport avec le mythe de l'CEil du Soleil, un récit mythologique égyptien où la déesse-lionne Tefnout, issue de l'œil de Rê, s'enfuit en Nubie et en est ramenée par les ruses des dieux Thot et Onouris/Arensnouphis.

Plusieurs de ces scènes présentent, pour la première fois dans l'art méroïtique, une nette influence hellénistique, visible notamment dans le traitement du corps humain et les positions des personnages. Qui plus est, lors du remontage du temple, on s'est aperçu que sur les faces internes des tambours de colonnes figuraient des repères d'architecte sous la forme de lettres grecques. Si l'on ajoute qu'une grande partie des légendes gravées en hiéroglyphes égyptiens auprès des divinités est clairement influencée par les textes des temples ptolémaïques de Philae, il est certain qu’Arnékhamani a pu bénéficier de la collaboration de lettrés égyptiens et d'artistes grecs pour la construction du temple du Lion et éventuellement de la Grande Enceinte. On a ainsi la preuve que les relations avec l'Égypte lagide s'étaient améliorées depuis la réoccupation de la Basse-Nubie par Ptolémée II.

\section{Méroé et le commerce des éléphants de guerre}

À l'arrière du temple, sur le mur extérieur, étaient gravées deux scènes, aujourd'hui fragmentaires, où le roi effectuait des offrandes devant Apédémak et Shébo. Au registre inférieur, des éléphants de guerre couverts de leur caparaçon amènent des ennemis prisonniers devant le roi. L'animal est pourtant très rare dans l'iconographie méroïtique officielle, alors qu'il figure souvent dans les graffiti et les gravures rupestres qui mettent volontiers en scène la grande faune sauvage. Ses représentations à Musawwarat épuisent pratiquement la liste de ses attestations connues en contexte royal. Il ne fait en effet l'objet d'aucun culte et, s'il est ici associé à Apédémak, c'est en raison du caractère guerrier de ce dieu.

L'utilisation d'éléphants de guerre était une innovation récente

Temple du Lion, Musawwarat: le roi Arnékhamani. introduite par les royautés hellénistiques. Alexandre le Grand, après ses combats sur l'Indus où ses troupes avaient été confrontées à cette arme redoutable, avait fait venir en Perse des pachydermes et des cornacs indiens. Ses successeurs, notamment Séleucos en Syrie (qui couvrait alors 
tout le Moyen-Orient) et Ptolémée Ir en Égypte, se les étaient partagés. Mais lorsque les deux royaumes entrèrent en conflit, il ne fut plus possible aux Lagides, contrairement aux Séleucides, d'importer des éléphants indiens puisqu'ils auraient transité par le territoire ennemi. Ptolémée II décida donc de faire entraîner au combat des éléphants africains. Les Carthaginois avaient initié cette pratique quelques décennies auparavant avec des animaux capturés en Tunisie et dans l'Atlas, appartenant à une race aujourd'hui éteinte. Pour se procurer les pachydermes, alors nombreux dans le sud du royaume de Méroé, Ptolémée passa avec la royauté koushite des accords dont on ne connaît pas les termes mais qui devaient inclure des échanges, la monnaie étant inconnue des Méroïtes. Comme ces derniers ignoraient le dressage des éléphants, les Ptolémées envoyèrent des cornacs formés par les Indiens ainsi que des chasseurs spécialisés, dont nous possédons des bribes de correspondance et des graffiti en grec, notamment à Abou Simbel.

Sous le règne d'Arnékhamani, le commerce des éléphants battait son plein et constituait une source de revenus considérable pour Méroé. C'est dans ce contexte qu'il faut interpréter la présence du pachyderme à Musawwarat, non seulement dans les reliefs du temple du Lion mais aussi dans la Grande Enceinte où par exemple deux murs du temple central se terminent par une sculpture maçonnée en forme d'éléphant figuré grandeur nature. Le nom mérö̈tique même de Musawwarat (ce terme moderne désigne en arabe un "endroit dessiné»), Abore-pi, est un composé qui signifie «le lieu de l'éléphant». Il est possible, si ce toponyme est plus ancien que la construction du complexe religieux, qu'il ait également motivé la présence de l'animal dans son programme iconographique.

Les liens diplomatiques et commerciaux étroits avec la dynasdes origines à la chute du sultanat Fung tie lagide n'allaient toutefois pas durer. En l'espace d'une décennie, deux événements allaient les mettre à mal. Le 22 juin 217 av. J.-C., lors de la quatrième guerre de Syrie entre les royaumes lagide et séleucide, l'armée de Ptolémée IV Philopatôr engagea le combat contre celle d'Antiochus III à Raphia (aujourd'hui Rafah, entre l'Égypte et la bande de Gaza). Ptolémée IV disposait de 73 éléphants africains, alors qu'Antiochus alignait 102 éléphants indiens. C'était la première fois que de tels effectifs des deux espèces étaient face à face, et le résultat fut désastreux pour l'armée égyptienne. En effet, les éléphants de Méroé, une variété disparue de nos jours, étaient plus petits que les éléphants d'Asie. L'historien grec Polybe, dans son récit de la bataille de Raphia, raconte comment les pachydermes de Ptolémée furent saisis de terreur par la taille, les barissements et l'odeur de leurs congénères indiens. Ils refluèrent vers l'arrière, semant le chaos dans leur propre camp. Grâce au nombre supérieur 
de ses troupes, où pour la première fois avaient été incorporés des phalangistes égyptiens récemment formés, Ptolémée gagna la bataille, mais au prix de lourdes pertes au sein de sa cavalerie. L'utilisation d'éléphants africains fut abandonnée et Méroé perdit ainsi un commerce lucratif.

L'incorporation de troupes égyptiennes dans l'armée lagide eut toutefois une conséquence plus fâcheuse pour Ptolémée IV. Jusque-là soumise au joug macédonien, la population égyptienne releva la tête et des révoltes éclatèrent contre les nouveaux maîtres. En 205 av. J.-C., la Haute-Égypte entra en dissidence et, deux ans plus tard, les rebelles prirent Thèbes, où leur chef fut couronné pharaon sous le nom d'Horounnéfer (transcrit en grec Horronophris). Vers 199 lui succéda Ankh-Ounnefer (grec Chaonnophris), peut-être son fils, bien que la question soit débattue. Pendant vingt ans, la Haute-Égypte constitua à nouveau un royaume indépendant. Les Koushites profitèrent comme d'habitude des troubles en Égypte pour avancer leurs pions sur leur frontière nord. Ils fournirent un soutien militaire aux armées des rois thébains mais, en échange, ils reprirent la Basse-Nubie, d'où ils avaient été chassés sous Ptolémée II, et rétablirent la frontière du royaume au sud d'Assouan.

\section{Arkamani II, Adikhalamani et les temples de Basse-Nubie}

Pendant ce temps, à Méroé, Arkamani II avait succédé à son père Arnékhamani, peut-être au terme d'une régence assurée par sa reine-mère. Il s'agissait très probablement du prince qui figurait sous le nom d'Arka sur les murs du temple du Lion à Musawwarat. Malgré son jeune âge, il y était décrit comme prêtre d'Isis. Devenu roi, il ajouta d'ailleurs, ainsi que l'avait tardivement fait son père, l'épithète "aimé d'Isis» à sa titulature. Cette dernière, complexe et variable selon les sites, comporte des aspects «nationalistes» très marqués. Elle rappelle le passé glorieux de Koush : il y est décrit comme le «Koushite» (égyptien Kگ̌̌sy), reprise du nom de Kashta, père de Piankhy, et curieusement comme «la main vivante d'Amon». Cette épithète était en effet un des titres des divines adoratrices d'Amon, dites "main du dieu», et possédait originellement une connotation sexuelle: le dieu-créateur, unique et donc seul, ayant engendré par masturbation le premier couple divin, Chou et Tefnout, la divine adoratrice était appelée à stimuler l'éjaculation du dieu pour répéter la création originelle. Il est évident que cet aspect n'était pas pris en considération dans la titulature d'Arkanami II et qu'il était peut-être oublié, la fonction de divine adoratrice ayant été abolie trois siècles auparavant. Ce qui comptait, c'était que les plus puissantes d'entre elles, sous la XXV dynastie, avaient été Koushites (voir chapitre 5, p. 115 sq.). 
Et puis, dans la dernière en date de ses titulatures, celle qui figure sur la cuve funéraire renfermant son sarcophage dans la tombe Beg. N.7, le nom de couronnement du roi n'est plus égyptien. Pour la première fois depuis cinq siècles, il est rédigé en langue méroïtique, bien que transcrit en hiéroglyphes égyptiens. L'écriture cursive méroïtique existait depuis peu, mais seuls les signes sacrés, investis de pouvoirs magiques, pouvaient figurer sur le sarcophage. Or, l'écriture hiéroglyphique méroïtique, attestée un siècle plus tard, n'avait pas encore été inventée. Ce nom est $m k$-l-tk js-trk, "aimé du dieu, honoré (?) d'Isis» et représente donc une paraphrase, à défaut d'une traduction fidèle, des équivalents égyptiens «aimé d'Isis» et «élu de Rê» dans les autres titulatures de ce roi. Le choix de la langue méroïtique constitue en tout cas un précédent qui sera imité quelques décennies plus tard, quand elle prendra presque entièrement la place de la langue égyptienne.

Arkamani II s'empressa de laisser sa trace dans la Basse-Nubie reconquise en y édifiant temples et chapelles. Sur l'île de Philae, il poursuivit les travaux qu'avait entrepris Ptolémée IV avant la rébellion thébaine dans le petit temple dédié au dieu Arensnouphis. À Kalabcha, plus au sud, il entreprit l'édification du temple de Mandoulis. Ce dieu était considéré comme un fils d'Isis et arborait des formes diverses (oiseau à tête humaine ou homme à tête de lion) mais son culte était limité à la région. Son nom n'est pas égyptien et présente des variations orthographiques compatibles avec une origine koushite, mais on ne possède aucune attestation de lui plus au sud, ni dans les textes méroïtiques. Il fut particulièrement adoré plus tard, après que l'empereur Auguste eut fait agrandir son temple par les

des origines

à la chute

du sultanat

Fung Blemmyes, un peuple nomade de langue couchitique originellement installé dans le désert oriental. Enfin, à Dakka, une centaine de kilomètres au sud de Philae, Arkamani II continua les travaux entrepris sous Ptolémée IV dans le temple de Thot de Pnoubs. Comme Arensnouphis dont il peut emprunter l'aspect physique, Thot de Pnoubs était impliqué dans le mythe de l'Eil du Soleil selon lequel ils avaient tous deux, changés en singes, ramené par leurs ruses l'œil de Rê (la déesse Tefnout, dite aussi «la Lointaine») auprès de son père. Le nom de Pnoubs, en égyptien P 3 -nbs, «le jujubier", ne désigne pas ici la cité du même nom, l'actuelle Kerma, mais l'arbre lui-même qui semble avoir joué un rôle dans ce mythe que nous ne connaissons pas en totalité. Une gravure fameuse du temple de Dakka représente en effet un babouin sous un jujubier.

Qu'il s'agisse du culte d'Arensnouphis ou de celui de Thot de Pnoubs, les travaux d'Arkamani II témoignent de l'influence grandissante sur la royauté mérö̈tique du clergé de Philae. C'est probablement à son instigation que la construction des temples en question avait été entreprise par Ptolémée IV Philopatôr. La révolte de la Thébaïde n'avait pas permis 
de les achever, mais les prêtres de Philae obtinrent d'Arkamani, leur nouveau suzerain, qu'il continuât les travaux. C'est peut-être à leur demande expresse que les Ptolémées, lorsqu'ils prirent le relais après la reconquête de la BasseNubie, n'effacèrent pas les cartouches d'Arkamani II, donnant l'impression fausse d'une "collaboration" entre les deux royaumes dans l'édification de ces sanctuaires, une thèse que l'on a longtemps privilégiée. Il est vrai aussi que le nouveau souverain lagide, Ptolémée V Épiphane, soucieux d'éviter la répétition des conflits, tenta de se réconcilier avec la population des territoires nouvellement reconquis: la préservation des cartouches d'Arkamani peut être due aussi à cette politique de compromis. Du côté des Méroïtes, nous avons précédemment vu que les temples de Musawwarat avaient été bâtis, décorés et inscrits avec l'aide du clergé de Philae, dont l'influence à Méroé était donc effective dès le règne d'Arnékhamani. Son fils Arkamani II a manifestement continué cette collaboration. Le mythe de l'CEil du Soleil se retrouve d'ailleurs aussi bien dans le temple du Lion, à Musawwarat, que dans les temples d'Arensnouphi et de Thot en Basse-Nubie. Durant cette période, le clergé de Philae joue apparemment le même rôle de mentor que celui quavaient joué les prêtres d'Amon auprès de la XXV dynastie naissante. L'épithète "aimé d'Isis» adoptée tardivement par Arnékhamani et reprise par Arkamani II et son successeur est peut-être autant une imitation de la titulature de Ptolémée IV qu'un hommage à l'Isis de Philae.

Alors que la Thébaïde était encore indépendante pour quelques années, un nouveau souverain méroïtique, Adikhalamani, peut-être fils ou frère du précédent, entreprit à Debod, à vingt kilomètres au sud d'Assouan, la construction d'un petit sanctuaire dédié à Amon, là où se trouvait une ancienne chapelle ramesside. Le roi y est figuré présentant des offrandes à Amon et Mout, mais aussi aux protagonistes de la geste de l'"CEil de Rề: Onouris (ou sous ses autres formes Arensnouphis et Chou) et Tefnout. L'édifice fut agrandi par la suite par les Ptolémées puis les premiers empereurs romains et consacré également à Isis. Il fut offert par l'Égypte à l'Espagne en 1968, en récompense de son engagement dans la campagne de sauvetage des monuments de Nubie, et se trouve aujourd'hui dans un parc madrilène. Adikhalamani, comme son prédécesseur Arkamani II à Philae, Kalabcha et Dakka, y est représenté comme un pharaon égyptien, suivant un programme iconographique sans doute conçu à l'origine pour Ptolémée IV : ici, pas de costume tripartite ni même de calotte royale koushite. Adikhalamani est également attesté en Basse-Nubie sur une stèle à son nom retrouvée à Philae lors du démontage du temple en 1974-1975.

Mais la domination koushite sur la région ne devait pas durer. Malgré les renforts envoyés par Méroé, le pharaon thébain Hor-Ounnefer ne put tenir face à l'offensive lancée par Ptolémée V Épiphane contre 
la Thébaïde. À la fin d'octobre 186 av. J.-C., l'armée lagide défit ses dernières troupes et le captura après avoir tué son fils. Les Méroïtes furent chassés à nouveau de Basse-Nubie. Comme nous l'avons mentionné, Ptolémée $\mathrm{V}$, tirant leçon des erreurs du passé, ménagea la population égyptienne. Il confirma l'attribution au temple de Philae des revenus du Dodécaschène. Il inaugura même en personne, en 185 , la nouvelle chapelle qu'il avait fait construire à Philae pour Imhotep, le vizir et architecte du roi Djoser de la III ${ }^{\mathrm{e}}$ dynastie, plus tard divinisé et considéré désormais comme le fils du dieu memphite Ptah.

On a parfois suggéré qu'Adikhalamani n'ait été qu'un petit roi usurpateur de Basse-Nubie, car on a aucune trace de son nom au sud du royaume. Mais la mention d' «aimé d'Apédémak» accompagnant son nom à Debod le relie bien à la région méridionale. Le double cartouche du roi contient de plus des épithètes identiques ou proches de celles de son prédécesseur Arkamani II : «image de Rê», «élu des dieux», "aimé d'Isis». Il est vrai que l'on ne possède pas de monument funéraire à son nom. La pyramide qui suit chronologiquement celle d'Arkamani II à Méroé, Beg. N.9, est attribuée à un roi nommé Tabirqo, inconnu par ailleurs. La difficulté a été contournée par Reisner en proposant d'identifier Adikhalamani et Tabirqo. Cette solution est généralement acceptée. Toutefois, il serait possible d'attribuer la pyramide Beg. N. 8 à Adikhalamani. Elle contient en effet un reste de cartouche où seuls se lisent deux signes égyptiens: $m r$, "aimé", qui pourrait correspondre à son épithète Mry Js.t, "aimé d'Isis", ou à un retour à $M r y J m n$, "aimé d'Amon", et un $t$ qui conviendrait à la consonne méroïtique écrite $\underline{d}$ dans la transcription égyptienne du nom d'Adikhalamani (Jdhr-Jmn). Qui plus est, la tombe Beg. N. 8 se situe effectivement entre celles d'Arkamani II (Beg. N.7) et de Tabirqo (Beg. N.9). Malgré sa position dans le rang des sépultures, elle a été considérée par Reisner comme plus tardive que Beg. N.9 parce qu'elle comporte une innovation, à savoir une première chambre funéraire à quatre piliers au lieu de deux précédemment, et que cette disposition se retrouve dans les règnes qui suivent celui de Tabirqo. D'autre part, sa pyramide possède des coins plus élaborés, une caractéristique qui apparait dans les monuments postérieurs. Mais les dimensions réduites de la première chambre (deux piliers au lieu de quatre) de Beg. N. 9 ainsi que la taille modeste et la structure simple de sa pyramide s'expliquent peut-être par la mort prématurée de ce souverain, dont le nom n'apparaît sur aucun autre monument. La chapelle, pourtant bien conservée, ne présente ni relief ni inscription, ce qui est fort inhabituel et indique une situation d'urgence imprévue. En ce cas, Beg. N. 8 peut avoir accueilli Adikhalamani, tandis que Beg. N.9 serait celle de son successeur éphémère, Tabirqo. 


\section{La reine Nahirqo et l'attribution de la pyramide Beg. N. I I}

Si le nom du roi sur le mur de la chapelle de Beg. N. 8 est partiellement perdu, celui de la reine qui l'accompagne était en partie conservé jusqu'à récemment. Comme celle de la reine-mère Kanarta au commencement du royaume de Méroé, sa titulature se compose de deux noms méroïtiques transcrits en hiéroglyphes égyptiens, Nahirqo et [...]nntny (début manquant). Elle y est dite «aimée de Mout », l'épouse du dieu Amon. Reisner lui avait attribué la sépulture Beg. N.11, dont la pyramide et la chapelle sont les plus imposantes de toutes les tombes royales de Méroé. Sa chapelle est la seule qui comporte deux salles, précédée d'un haut portique où est représenté Horus, accompagné d'un chien, versant une libation. Les impressionnants reliefs des murs latéraux, foisonnants de détails, ont été prélevés durant la domination britannique. L'un se trouve dans le bâtiment d'entrée du musée de Khartoum, l'autre au British Museum. On y voit la reine, trônant en majesté, vêtue du costume tripartite des souverains méroïtiques, recevant offrandes et libations. Derrière elle est également assis un petit personnage masculin tenant une palme et touchant la couronne de la reine en signe de légitimation. Un groupe statuaire, représentant la souveraine debout et le même prince dans la même position, se trouve aujourd'hui au musée du Caire et est réputé avoir été exhumé dans la chapelle de Beg. N.11 par un officier égyptien au temps de l'occupation turque. Malheureusement, aucune inscription n'a été conservée sur les représentations de cette reine, ni dans les reliefs de la chapelle, où elles étaient peintes et ont disparu, ni sur le groupe statuaire.

Sur la foi de rapprochements stylistiques et iconographiques, l'égyptologue allemand Fritz Hintze avait proposé d'identifier la reine de Beg. N.11 avec Shanakdakhété, la commanditaire du petit temple F à Naga, situé sur la pente du gébel. Le cartouche de cette dernière y figure en effet en hiéroglyphes méroïtiques, précédé de son titre en égyptien: «le fils de Rê, maître des Deux Terres». L'usage du masculin pour qualifier une reine est courant dans les inscriptions en égyptien du royaume de Méroé et s'explique par l'influence de la langue méroïtique où il n'existe pas de genre grammatical. Dans les reliefs du temple $\mathrm{F}$, comme dans les scènes de Beg. N.11, la reine est accompagnée d'un prince qui porte la main à sa couronne en un geste de légitimation. Le principal problème de l'identification proposée par Hintze et largement relayée par les spécialistes jusqu’à nos jours réside dans la forme des hiéroglyphes méroïtiques. Sous le règne suivant, celui de Tanéyidamani, ces signes sont encore dans leur enfance, adoptant des graphies variables. Ce n'est qu'au $\mathrm{I}^{\mathrm{er}}$ siècle av. J.-C. qu'ils acquièrent leur forme canonique. Or, c'est celle que présentent justement les hiéroglyphes du cartouche de Shanakdakhété à Naga. Ils sont 
en fait semblables à ceux que l'on trouve dans les inscriptions de la reine Amanishakhéto, à la fin du Ir siècle av. J.-C. Nous sommes donc d'avis que le nom de Shanakdakhété est soit celui d'une souveraine ayant régné autour du début de l'ère chrétienne, soit un autre nom de la reine Amanishakhéto, dont la présence à Naga est attestée par quatre stèles trouvées récemment et qui disposait d'un palais royal non loin de là, à Ouad Ben Naga. La figuration à la fois en Beg. N. 11 et dans le temple F d'un prince accomplissant un geste de légitimation tient au statut particulier de ces reines, les Candaces, et se retrouve aussi bien dans la chapelle funéraire d'Amanishakhéto à Méroé (Beg. N. 6). Nous préférons donc revenir à la théorie de Reisner et faire de Nahirqo la souveraine de Beg. N.11. Si nos hypothèses sont justes, elle aurait été l'épouse d'Adikhalamani et aurait repris les rênes du royaume de Méroé à la mort prématurée de Tabirqo, peut-être son fils aîné. Son règne serait donc à placer aux alentours de $17 \mathrm{O}$ av. J.-C.

\section{Le statut de la Candace, mère du roi}

le Soudan

\section{0}

des origines

à la chute

du sultanat

Fung
Temple

du Lion,

à Naga :

la Candace

Amanitoré

(page 231)

et son fils,

le roi

Natakamani

(page 232).
Cette reine est considérée comme la première des "Candaces", mais le témoignage de Bion de Soles (voir ci-dessous, p. 234) permet de faire remonter le titre au début du royaume de Méroé. Le nom est connu à la fois en méroïtique, où il est diversement écrit $k t k e, k d k e, k t w e, k d w e$, et sous ses transcriptions égyptienne kntjky et grecque kandakê, qui restituent le «n» jamais noté devant une consonne en méroïtique. Son étymologie est inconnue. Le terme, contrairement à ce que l'on lit encore çà et là, ne semble pas dériver de $k d i$ (prononcé $/ \mathrm{kadi} /$ ), «femme», encore moins de kdise (prononcé /kadisə/), "sœur", qui ne comportent pas de consonne nasale, ainsi que le montrent les nombreux rapprochements que l'on peut effectuer avec les langues apparentées au méroïtique. Comme les inscriptions des cartouches de Beg. N.11 ont disparu (elles étaient simplement peintes), on ne peut certifier que ce titre y figurait, mais il est attesté aux premiers siècles avant et après notre ère pour les reines Amanirénas, Amanishakhéto et Amanitoré. L'institution dura sans doute très tard, puisqu'une stèle latine gravée par un visiteur venu de Rome, retrouvée à Musawwarat et récemment réétudiée, rend hommage à une reine inconnue que l'on doit replacer à la charnière des $\mathrm{III}^{\mathrm{e}}$ et $\mathrm{IV}^{\mathrm{e}}$ siècle apr. J.-C. Il est possible que les reines Bartaré et Kanarta, au début du royaume de Méroé, aient déjà bénéficié de ce statut. Contrairement à la situation qui prévalait en Égypte ancienne, où le pharaon est par essence un mâle et où les rares reines régnantes accèdent au trône dans des circonstances exceptionnelles (généralement en abusant, à l'instar d'Hatchepsout, de leur position de régente du royaume durant la minorité du successeur du roi défunt), à Méroé ces souveraines jouissent 



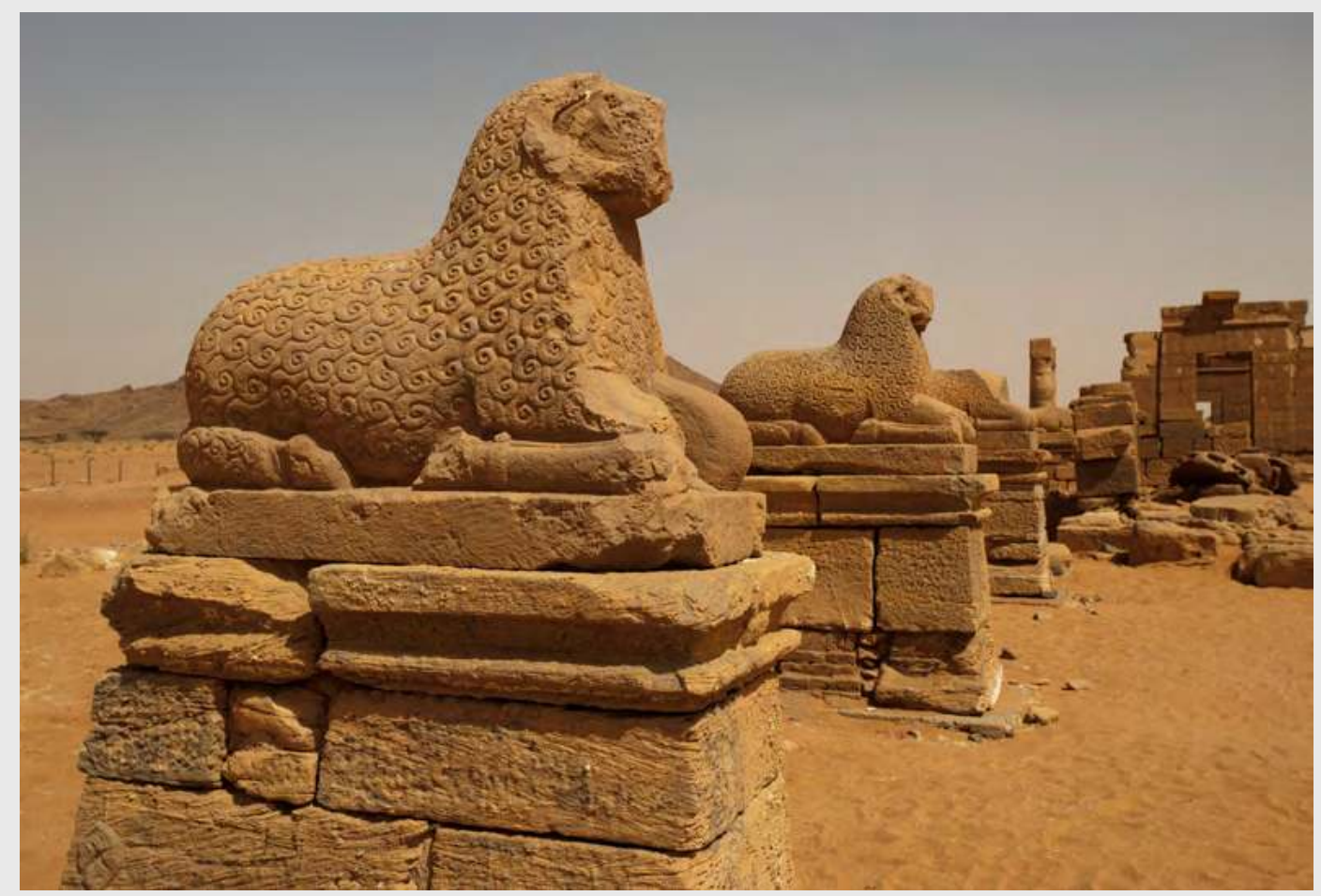

Allée de béliers du temple d'Amon à Naga.

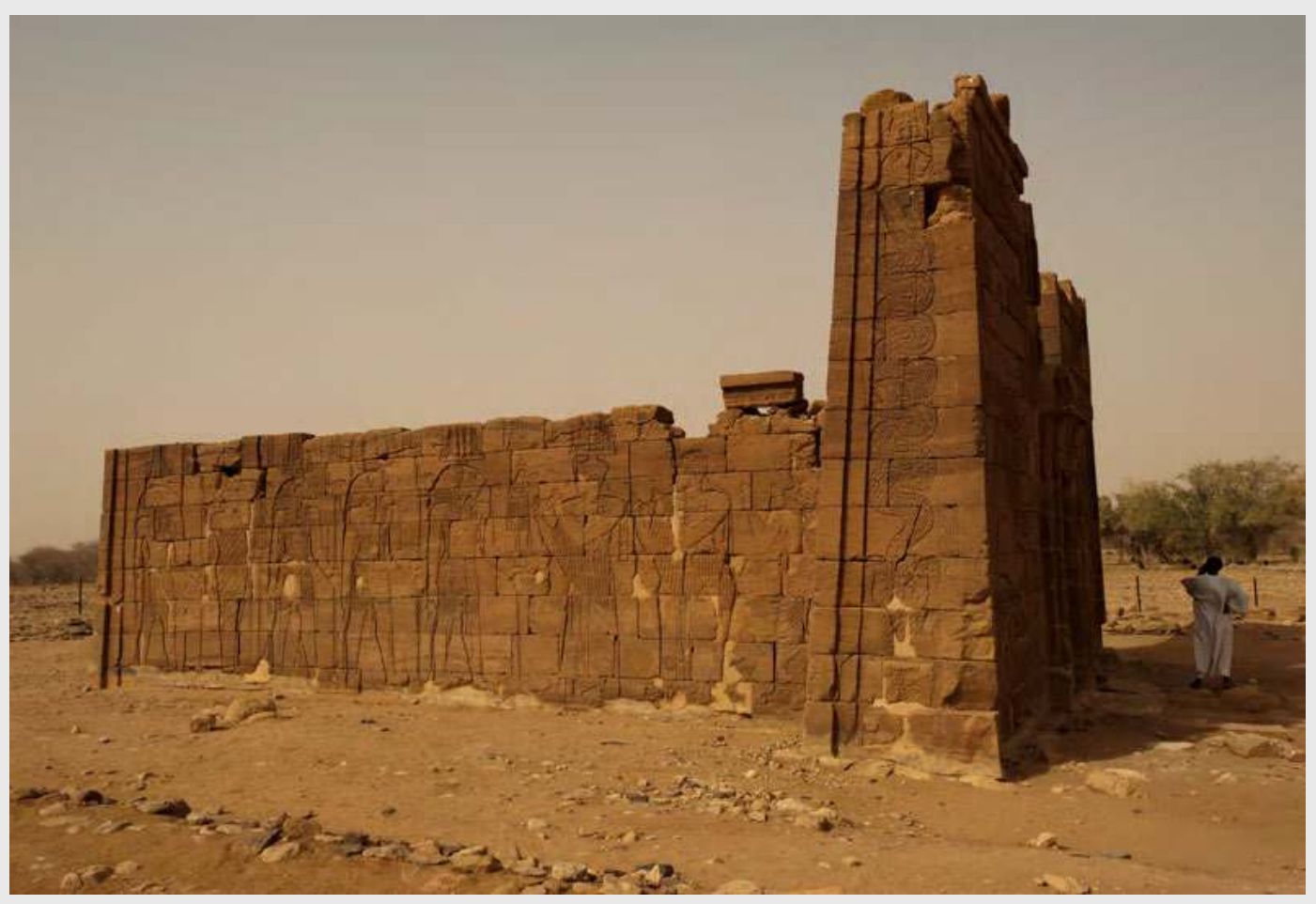

des temples dans

la savane

Temple d'Apédémak à Naga, côté sud. 
apparemment d'une complète légitimité. Elles sont d'ailleurs représentées comme des femmes, éventuellement armées et massacrant les ennemis, à l'instar d'Amanishakhéto sur le pylône de sa chapelle funéraire ou d'Amanitoré sur celui du temple d'Apédémak à Naga, et contrairement à une Hatchepsout qui se fait figurer en homme. Dans les textes méroïtiques où elles n'accompagnent pas un roi, elles sont nommées "qore», "souverain ", avant leur titre de Candace.

Toutefois, la possibilité pour une femme de monter sur le trône de Méroé n'implique pas, comme on l'a parfois extrapolé, que la civilisation mérö̈tique ait été régie par une sorte de matriarcat. Les fonctions administratives et religieuses sont ainsi l'apanage des hommes. On n'a aucune mention de reine régnante depuis la création du royaume koushite jusqu'à la fin de l'époque napatéenne, bien que la reine-mère dispose d'un rang élevé qui en fasse le deuxième personnage de l'État. Il ne semble pas qu'une fille puisse succéder à son père, comme aujourd'hui en Angleterre ou dans les pays nordiques. Il n'est donc pas exclu que l'institution des Candaces soit issue d'une extension du statut de régente. La Candace est assurément une reine-mère. Elle est figurée généralement comme une femme plantureuse, aux cuisses larges, aux fesses rebondies et aux seins tombants, et jamais comme une reine juvénile. Il ne s'agit pas, comme on le lit parfois, d'illustrer une conception «africaine» des canons de beauté féminine mais d'exalter sa maternité et sa maturité. D'autre part, on trouve dans les sources grecques une citation maintes fois reprise des Éthiopiques de Bion de Soles, un écrivain alexandrin qui avait voyagé à Méroé dans la première moitié du $\mathrm{III}^{\mathrm{e}}$ siècle (donc au début du royaume de Méroé) et selon lequel «les Éthiopiens ne

des origines

à la chute

du sultanat

Fung font pas état des pères de leurs rois, mais les donnent pour fils du Soleil. Ils appellent "Candace" la mère de chacun d'entre eux".

Dans deux inscriptions du temps de la Candace Amanirénas ainsi que sur les reliefs du temple de Naga, trois personnages sont cités à la tête du royaume: le roi, la Candace et un jeune homme portant le titre de $p q r$ ou $p k r$, «prince» (prononcé /bakora/). Le terme est généralement suivi de $t$, «suprême», ou de qorise, "du souverain », pour le distinguer d'autres princes de second rang ou même locaux qui sont attestés avec le même titre dans les textes de Basse-Nubie. Des rares sources méroïtiques, démotiques et grecques qui nous livrent des liens familiaux, il ressort que le roi est le fils de la Candace (Amanitoré et le roi Natakamani, Nawidémak et le roi Amanakhabalé). Le pqr aussi est fils de la Candace dans le seul cas documenté (Akinidad, fils d'Amanirénas), ce qui en ferait le fils du roi défunt et le frère du roi régnant. Le personnage qui se tient dans les scènes des chapelles funéraires aux côtés de la Candace et célèbre sa légitimité pourrait être le pqr. On notera que dans les peintures de la chapelle funéraire 
de la Candace Nawidémak à Barkal, c'est un autre prince, Etareteya, qui est debout devant la reine pour procéder à son encensement: il est effectivement précisé qu' «il est le frère du prince suprême ( $p k r-t r)$ ».

D'après les éléments, certes disparates et imprécis, dont nous disposons, il semble qu'à la mort d'un roi méroïtique, c'était à la fois son épouse et leur fils qui montaient ensemble sur le trône. Les titres, et sans doute les rôles, étaient toutefois différents: la reine-mère était la Candace, son fils le «souverain" (méroïtique qore). Il semble que, dans le cas où le fils venait à mourir jeune, la Candace prenait également le titre de «souverain». Dans le cas inverse, le plus fréquent, où la Candace décédait avant son fils, le roi régnait seul. Cette institution semble héritée des coutumes locales de la région de Méroé, ce qui explique qu'elle n'existait pas encore dans le royaume de Napata. Néanmoins, l'importance déjà accordée à la reinemère dans la tradition napatéenne a dû faciliter l'adoption de cette nouvelle institution. D'une part, c'est d'elle que le nouveau roi tenait sa légitimité. D'autre part, dans les textes d'Aspelta et d'Amannote-erike, elle est décrite comme «Isis qui se réjouit de voir son fils Horus apparaitre sur le trône de son père Osiris». Une fois son époux mort et devenu selon la tradition égyptienne un "Osiris", la reine-mère devenait, elle, une vivante Isis en charge $\mathrm{du}$ futur Horus. Le statut de régente trouvait donc une légitimation religieuse dans le mythe d'Isis, qui, après l'assassinat d'Osiris par son frère Seth, avait enfanté et élevé leur fils Horus dans les marais de Chemmis, jusqu’à ce qu'il puisse affronter l'usurpateur et récupérer la royauté de son père.

Toutefois, la situation est plus complexe qu'il n'y paraît, en bonne partie sans doute parce qu'il nous manque des éléments historiques. En effet, comment expliquer, si elles exercent la régence, que deux Candaces puissent succéder l'une à l'autre? Or, c'est apparemment le cas d'Amanirénas et d'Amanishakhéto, à la fin du ire siècle. Toutes deux ont le même pqr, Akinidad, qui semble n'avoir jamais régné, alors même qu'il dirigeait déjà les armées sous le règne d'Amanirénas et que son frère aîné, Téritéqas, était décédé après un règne probablement très court. Il ne fait pas de doute cependant, comme nous le verrons, que la Candace Amanishakhéto a eu un fils, représenté à ses côtés comme un jeune prince sur les bagues de son fameux trésor. Semblablement, nous ne savons pas comment, si le roi était mort avant elle, une Candace pouvait régner seule, puisque le roi défunt avait forcément un successeur mâle, proche ou plus éloigné. Elle aurait dû céder le pouvoir à ce dernier s'il était assez âgé. Dans le cas où il était encore mineur, elle aurait dû soit régner avec lui s'il était un autre de ses fils, soit s'effacer devant une nouvelle Candace s'il était le fils d'une autre femme. Faute d'information suffisante, nous sommes incapables pour l'instant de répondre à ces questions. 


\section{Tanéyidamani et la grande stèle du Gébel Barkal}

le Soudan

\section{6}

des origines

à la chute

du sultanat

Fung
Du règne de Nahirqo, nous ne possédons pas d'autre témoignage que son gigantesque monument funéraire. Il peut paraitre étonnant qu'une reine dotée d'une telle sépulture n'ait laissé de traces dans aucun temple, mais la construction de sa chapelle et de sa pyramide a vraisemblablement été supervisée par son fils et successeur, Tanéyidamani. Il semble d'ailleurs que les deux hypogées jumeaux de Nahirqo et de Tanéyidamani aient été construits simultanément. Le monument de la reine, surdimensionné, recouvrit ensuite une partie de la deuxième substructure prévue pour le roi, si bien que la pyramide de ce dernier est largement décalée au nord et se trouve désolidarisée de ses chambres souterraines. L'importance de la pyramide et de la chapelle de Nahirqo semble donc un hommage filial de Tanéyidamani, un roi puissant qui disposait de moyens importants. Après la parenthèse de l'indépendance de la Thébaïde, les contacts directs entre l'administration lagide et le royaume de Méroé avaient repris de plus belle et les échanges étaient à nouveau nombreux. Ainsi, parmi le mobilier fortement pillé de la tombe de Nahirqo figuraient des jarres portant en démotique la mention "vin d'Égypte».

Tanéyidamani était sans doute un fils cadet d'Adikhalamani et de la reine Nahirqo. Cette dernière aurait assuré la régence jusqu’à la majorité du nouvel héritier après la mort de Tabirqo, que l'on doit donc considérer comme le fils aîné, mort peu de temps après son accession au trône. Dans les débris de la chapelle de Tanéyidamani (pyramide Beg. N.12), deux fragments d'une table d'offrandes inscrite en cursive méroïtique livrent la fin du nom de son père. Hintze le translittérait [...]iwl, mais, étant donné le ductus archaïque des signes, le signe lu erronément « $w$ » est en fait un « $h »$. Le nom était donc sans doute $[A m n i-(a) t] i h l$, soit Adikhalamani, avec antéposition du nom d'Amon peut-être écrit par un groupe idéographique, comme il est fréquent dans les inscriptions archaïques. Le lien entre Nahirqo et Tanéyidamani est d'autre part établi par deux parallèles. Dans les reliefs de la chapelle de la reine-mère apparaît le prince héritier, conduisant les cérémonies en l'honneur de la défunte. À côté d'une de ses représentations figure en cursive méroïtique la séquence $T[n e] y i$, relevée par Lepsius. Il s'agit du premier élément de son nom, comme on le trouve pour le futur Arkamani II, appelé simplement Arka dans les reliefs du temple du Lion à Musawwarat, où il apparaît enfant devant son père. D'autre part, la reine Nahirqo elle-même, comme nous l'avons précédemment noté, possède en Beg. N. 8 un second cartouche terminé par -tny, transcription égyptienne du méroïtique tneyi. On ignore le sens précis de ce mot, pour lequel Hintze proposait «lion» mais qui est plus vraisemblablement un terme désignant une qualité royale comme la force ou le pouvoir. 
Contrairement à ses prédécesseurs, Tanéyidamani ne prit pas de nom de couronnement égyptien mais une épithète variable en méroïtique insérée dans un second cartouche. La pratique était connue, mais encore en hiéroglyphes égyptiens, pour certaines reines, Bartaré, Kanarta et Nahirqo. Son usage pour un roi marque une rupture supplémentaire avec la tradition égyptienne et napatéenne. Sur un cylindre de bronze retrouvé au Gébel Barkal, et qui doit dater du début de son règne, cette épithète est peutêtre Tneyi-Apedemk, où le nom du dieu Apédémak serait figuré par l'idéogramme du lion. Les hiéroglyphes méroïtiques, dont c'est ici la première attestation assurée, sont très maladroits: le choix de certains signes puisés dans le répertoire égyptien pour donner des équivalents aux signes cursifs est fondé sur une vague ressemblance formelle avec eux, qui néglige la valeur phonétique. Cette imperfection sera corrigée par la suite. Sur la lunette de sa grande stèle du Gébel Barkal, l'épithète suit le nom à gauche dans le même cartouche. Elle est cette fois inscrite en hiéroglyphes plus évolués, la stèle étant sans doute bien postérieure au cylindre de bronze. Elle se lit wte lxte, sans doute "doué d'existence» (wte "existence», traduit d'après le nara wud- «exister», est remplacé habituellement par pwrite "force de vie»). Elle transcrit l'épithète égyptienne usuelle, $d j$ ' $h \underline{h}$, «doué de vie», après le nom des pharaons. Cette «méroïtisation» de la formule ne sera pas généralisée par la suite, les inscriptions des temples continuant à l'inclure en langue et écriture égyptiennes. Mais elle montre avec quel enthousiasme les scribes accueillirent l'apparition d'une écriture hiéroglyphique méroïtique qui pouvait se substituer à l'égyptien.

Le règne de Tanéyidamani, que l'on présume long, se situe au milieu du $\mathrm{II}^{\mathrm{e}}$ siècle avant notre ère. Le souverain est largement attesté par des inscriptions diverses, toutes en méroïtique, retrouvées essentiellement à Méroé et au Gébel Barkal. Deux d'entre elles, une très belle plaquette votive de schiste rouge conservée à Baltimore et une statuette à tête de lion aujourd'hui au Louvre, indiquent la dévotion particulière que Tanéyidamani a montrée pour Apédémak. La plaquette provient d'ailleurs du temple de ce dieu à Méroé, sans doute érigé ou restauré par ce roi. Mais le monument le plus important est une grande stèle de granit $(158 \times 53 \mathrm{~cm})$ inscrite sur ses deux faces et ses deux côtés en cursive méroïtique. Retrouvée par Reisner à l'entrée du temple d'Amon au Gébel Barkal, contre le premier pylône, elle compte 161 lignes de texte, à comparer avec les 159 lignes de la Stèle de la Victoire de Piankhy ou les 161 lignes de la stèle du roi napatéen Harsiotef, toutes deux originellement érigées dans le même temple. Ces chiffres similaires ne sont pas un hasard: il s'agit à la fois d'imiter les grands ancêtres mais aussi de s'en démarquer en utilisant le méroïtique au lieu de l'égyptien, sans doute pour la première fois sur un tel support. Le cintre de la stèle 
présente, en un tracé assez fruste, le roi face au couple divin, Amon de Napata et Mout. Sur la moitié gauche, Tanéyidamani, vêtu d'une version légère du costume tripartite, offre deux colliers aux divinités. Sur la moitié droite, accompagné d'un chien, il abat rituellement un ennemi devant le couple divin. Contrairement aux stèles napatéennes, la double scène n'est pas symétrique, le roi étant chaque fois placé à droite d'Amon. Autre nouveauté: sous la ligne de sol figure un second registre où apparaissent quatre ennemis ligotés, à plat ventre autour de quatre arcs, symbole pharaonique des peuples vaincus. Le cintre du revers représente le roi debout, une palme à la main. Juché sur un ennemi gisant à terre, il est vêtu d'une dépouille de léopard et entouré d'Amon de Thèbes et Amon de Napata. Les dieux sont en relief incisé, tandis que le monarque est en bas-relief, ce qui laisse supposer que le décor n’ait pas été achevé.

Notre connaissance encore très partielle de la langue méroïtique ne permet pas actuellement de vraiment comprendre les chroniques des rois. Alors que les inscriptions funéraires, très stéréotypées, sont en bonne partie traduisibles, les grandes stèles royales, peu nombreuses, contiennent essentiellement des narrations, mettant en œuvre une morphologie variée et un vocabulaire riche et changeant au gré du récit. Les bribes de texte qui offrent prise à la traduction dans la stèle de Tanéyidamani peuvent, sous toutes réserves, se résumer comme suit. Après un protocole royal minimal, le récit commence par l'évocation d'un conflit avec un peuple ennemi. Les hommes sont tués, tandis que les femmes sont emmenées en captivité et le butin offert au temple d'Amon. Suit une liste de douze divinités pour lesquelles des sanctuaires ont été construits: plusieurs formes d'Amon, dont Amon de Napata, Amon de Thèbes et peut-être Amon de Pnoubs, Aqedise (dieu lunaire équivalant à Khonsou), Isis, Makedoke (littéralement: «le grand dieu ", autre forme d'Amon?) et peut-être Apédémak. Ensuite sont détaillées les offrandes faites aux dieux. Dans le passage suivant, très obscur, apparaît la mention d'un pqr qorise, un "prince royal» qui semble porter le nom de Tabibalé. Puis sont évoqués des déplacements à travers le royaume, qui permettent de rendre un culte à des divinités éloignées, comme Isis et Horus de l'«île de Saï». Le texte se termine par deux actions armées. Une nouvelle campagne militaire est lancée contre une tribu ou une faction rebelle dans la région de Napata, le butin étant donné à l'Amon local. Enfin est décrit l'écrasement d'une rébellion dont les chefs portent des noms méroïtiques: Akhatoné et son frère Nakharora. L'ensemble de la famille, détaillé par leurs liens de parenté, est soit massacré, soit asservi.

L'inscription suit donc le modèle napatéen, qui alterne généralement les campagnes militaires, la description des honneurs rendus aux dieux et les travaux effectués dans leurs temples. Toutefois, le texte 
ne semble pas commencer par le couronnement du souverain. Il n'y a également aucun repère temporel par années régnales, cette tradition égyptienne, déjà clairsemée dans la stèle de Nastasen au IV siècle, ayant été totalement abandonnée dans les chroniques royales méroïtiques. Le peu que nous comprenons comporte tout de même deux éléments importants. Le culte d'Amon de Napata reste une institution fondamentale dans le royaume de Méroé et ne paraît pas affaibli face à l'essor des divinités locales, notamment Apédémak. En second lieu, le pouvoir royal doit faire face non seulement aux incursions de tribus hostiles mais aussi à des oppositions internes, dont on ignore l'origine et l'ampleur. Tanéyidamani fut à sa mort inhumé aux côtés de sa mère, dans une tombe de dimension plus modeste (Beg. N.12) mais dotée d'une profonde chapelle aux murs tapissés de reliefs splendides et bien conservés (photographies p. 206-207). Le roi y apparaît en majesté, assis sur un trône de forme léonine, les pieds posés sur un support où sont peints aussi des lions. Il est vêtu du grand costume tripartite, il porte la couronne atef d'Osiris et il est couvert d'une incroyable profusion de bijoux, dont le plus notable est un grand sautoir auquel est fixée une statuette d'Amon de Napata à tête de bélier. Derrière lui se tient une petite Isis aux ailes déployées et une reine aux formes plantureuses tenant un sistre, sans doute la future reinemère. Malheureusement, aucune inscription n'est conservée: elles étaient très probablement peintes sur des placards qui, eux, sont encore visibles.

\section{Deux nécropoles royales en alternance, Méroé et Barkal}

Le renforcement de la présence royale dans le complexe d'Amon au Gébel Barkal correspond peut-être à un rééquilibrage entre les deux pôles du royaume, Napata et Méroé. On n'a pas en effet de traces en ce lieu des souverains précédents depuis Amanislo. Il est même assez probable que cette initiative royale ait impliqué de nouvelles alliances matrimoniales. À cette époque commence en effet à se développer un cimetière princier à Barkal Nord, à quelques centaines de mètres en contrehaut des anciennes pyramides de la dernière dynastie napatéenne. Une sépulture de grande dimension, Bar. 8, est érigée pour un membre important de la famille royale, peut-être une reine d'après un relief abîmé, le seul fragment retrouvé de la chapelle funéraire. Un peu plus tard, un prince est enterré sous la pyramide Bar. 5, qui se trouve être par un heureux hasard la mieux préservée de toutes les pyramides du Soudan. Les reliefs de la chapelle, qui étaient en très bon état lorsque Lepsius visita Barkal et les fit reproduire, nous montrent des scènes d'une grande qualité picturale, qui rappellent, à moindre échelle, celles des chapelles de Nahirqo et de Tanéyidamani à Méroé. Le prince est assis sur le trône au lion, sous un dais, protégé par les ailes d'Isis debout 
derrière lui. Il tient un sceptre et les insignes pharaoniques que sont le fouet (nekhakha) et la crosse (heqa). Un jeune membre de sa famille tend l'encensoir devant ses narines. Mais la ressemblance avec un souverain s'arrête là. Il ne porte ni le costume tripartite, ni la couronne, et n'arbore pas au front l'uraeus, le cobra réservé aux rois. En revanche, il tient un arc de grande taille, qui illustre peut-être la fonction militaire de certains des "princes royaux", dont l'exemple le plus fameux est Akinidad qui combattit les armées d'Auguste.

Lorsque Reisner dégagea ce second groupe de pyramides de Barkal, qui comprend aussi des sépultures de rois et de reine plus tardifs, et qu'il constata qu'il était contemporain de certaines tombes de Begrawwiya Nord, il imagina un «second royaume de Napata» qui aurait correspondu à une sécession du nord du royaume. On s'aperçut ensuite que les souverains de cette époque, qui va jusqu'au $\mathrm{I}^{\text {er }}$ siècle apr. J.-C., étaient aussi attestés dans le sud s'ils étaient enterrés à Napata, dans le nord s'ils étaient inhumés à Méroé, si bien que cette théorie fut vite abandonnée. L'explication la plus cohérente est de supposer qu’à partir du règne de Tanéyidamani, ou peu auparavant, la famille royale de Méroé renoua des alliances matrimoniales avec l'ancien clan royal de Napata, écarté de la lignée dynastique sous le règne d'Arkamani Ier-Ergaménès.

La situation s'est d'ailleurs compliquée dernièrement avec la découverte en 2012 à Sedeinga, lors des travaux de terrassement de la route bitumée passant sur la rive gauche du Nil, d'une grande tombe de format royal, contemporaine de Beg. N.11 (Nahirqo), Beg. N.12 (Tanéyidamani) et des origines à la chute du sultanat Fung Bar. 5 (prince inconnu). Elle présente en effet la même substructure à deux chambres, plus une niche funéraire, la première salle comportant quatre piliers et la seconde, deux. Les analyses au carbone 14 des charbons d'un encensoir ont confirmé une date autour de 150 av. J.-C. $( \pm 30)$. La tombe se situe au degré près à l'ouest du temple de la reine Tiyi, laquelle était réinterprétée à l'époque méroïtique comme une forme d'Isis. Comme à Méroé, elle est localisée largement à l'ouest des nécropoles locales. Il semble évident que quelque membre éminent de la famille royale ait désiré se mettre sous la protection de la déesse, loin de Méroé et même de Napata. Mais ce projet, pour une raison inconnue, avorta. La niche funéraire fut juste entamée dans le roc et aucune pyramide ne fut bâtie sur les appartements souterrains, pourtant très soigneusement taillés dans le grès. La tombe fut tout de même occupée (puis totalement pillée), mais sans doute pas par le royal défunt à qui elle avait été destinée.

Les souverains situés entre le milieu du II $^{\mathrm{e}}$ siècle av. J.-C. et le milieu $\mathrm{du} \mathrm{I}^{\mathrm{er}}$ siècle apr. J.-C. sont alternativement inhumés à Méroé (Begrawwiya Nord) et à Napata (Barkal Nord), sans que l'on puisse discerner les raisons 
qui orientèrent le choix de la nécropole. La succession chronologique des différents monarques est elle-même sujette à caution. Jusqu'à 30 av. J.-C., ils ne sont connus dans le meilleur des cas que par leurs noms. Outre la reine anonyme de Bar. 8 (voir ci-dessus), est attesté un roi dans un texte en égyptien citant un «Osiris (roi défunt), le roi de Haute et Basse-Égypte Nqyrjnsn» sur un fragment de table d'offrandes retrouvé en Beg. N.13, la pyramide de grande taille située à côté de celle de Tanéyidamani. Le nom, peut-être Nakidenasene (?) en méroïtique, comporte une finale -sen connue chez ses lointains prédécesseurs napatéens Nastasen et Gatisen/Aktisanès. Les reliefs de la chapelle funéraire de Beg. N.13 sont étroitement imités de celle de Tanéyidamani. Le monarque, coiffé de la couronne atef d'Osiris, est assis devant les officiants de ses funérailles, qui lui présentent hommage et offrandes. Il est protégé par les ailes d'Isis et suivi de la reine, son épouse.

Le rang de pyramides sud-nord dans le cimetière de Begrawwiya Nord étant alors arrivé au bord du plateau, les monuments suivants furent érigés sur les points les plus élevés de la frange ouest-est dominant la plaine. La pyramide la plus proche de Beg. N.13 est Beg. N.2O. Un fragment de la chapelle portant un nom d'Horus en égyptien, $K 3-N h t$, «taureau puissant...», a été vu et recopié par Lepsius. Ce retour aux titulatures traditionnelles est remarquable, même si l'orthographe de l'inscription est rudimentaire. En revanche, cette partie du nom d'Horus, commune à tant de rois depuis Piankhy et également fréquente chez les pharaons lagides, ne nous apporte aucune information sur la position chronologique du règne. Les reliefs du mur sud de la chapelle, aujourd'hui perdus mais copiés par l'équipe de Lepsius, sont de toute beauté. Le roi assis est encensé par le prince héritier, reconnaissable à son collier à grosses boules. Il est protégé par Isis, suivie de tout le reste de la famille royale: épouse, princesse et petit prince. La représentation du roi rappelle le prince de Bar. 5 : il tient comme lui un arc, un long sceptre ainsi que le fouet et la crosse des pharaons. Mais il porte le costume tripartite des souverains et la calotte koushite, curieusement entourée d'un large diadème où quatre paires de cobras sont fixées. Une grande corne de bélier derrière l'oreille, recourbée sur sa joue, rappelle les figurations royales napatéennes. L'ensemble manifeste une qualité digne des reliefs de la chapelle de Tanéyidamani mais s'en démarque nettement. Les deux sépultures, Beg. N.13 et 20, par leur taille et leur décor, témoignent de deux règnes prospères qu'il faut placer approximativement entre 120 av. J.-C. et la première moitié du siècle suivant.

Un autre souverain est connu en dehors d'un contexte funéraire pour cette période. Il est représenté et nommé sur un graffito d'une carrière de grès près du Gébel Suweigat, quelque cinq kilomètres au nord du Gébel Barkal. C'est en bonne partie de cet endroit que provient le grès utilisé pour 
le Soudan

242

des origines

à la chute

du sultanat

Fung

les pyramides de Barkal, selon l'actuel directeur des Antiquités du Soudan, Abdelrahman Ali Mohamed, qui étudia cette carrière dans le cadre de sa thèse sur les matériaux de construction des nécropoles royales de la région de Napata. Le graffito, de bonne facture, figure un souverain dont le costume est couvert d'une peau de léopard, une palme à la main, debout devant Amon de Napata à tête de bélier assis sur un trône. On possède un parallèle exact sur le revers de la grande stèle de Tanéyidamani retrouvée au Gébel Barkal (voir ci-dessus, p. 238). Ici, toutefois, le monarque est suivi d'une petite princesse jouant du sistre. La scène est traversée par une inscription sur trois lignes, partiellement arasée, appelant la bénédiction d'Amon de Napata sur le roi. Son nom, suivi du titre qore "souverain", se lit difficilement $\mathrm{P}[\ldots]$ khedateqo. Si la lettre manquante est bien un «t», comme il le semble, on peut reconstruire "Patakhedateqo", mais sans certitude. Le nom rappelle certains anthroponymes égyptiens tardifs commençant par $P_{\mathcal{J}-d j-\text {, }}$ "celui qu’a donné...", mais il serait étrange qu’un souverain méroïtique ait porté un tel nom. La graphie des signes rappelle d'assez près celle de la grande stèle de Tanéyidamani, ce qui ajoute un élément pour voir en ce roi un de ses proches successeurs. Sa sépulture, que la présence du graffito dans les carrières suggère de situer à Barkal, n'est pas localisée et doit compter parmi les monuments non attribués faute d'inscriptions. Ces quatre souverains, la reine de Bar. N. 8, les deux rois de Beg. N.13 et 20 et Patakhedateqo, sont les seuls pour lesquels on possède une trace entre le règne de Tanéyidamani, mort probablement vers 130-120 av. J.-C., et l'avènement de Téritéqas, situé sans doute peu de temps avant 30 av. J.-C. Ce siècle sur lequel nous ne disposons que de peu de données précises semble avoir été une ère de paix et de prospérité. Aucun conflit n'est par exemple attesté avec l'Égypte ptolémaïque, qui continue à administrer la Basse-Nubie sans heurts particuliers. Toutefois, durant le règne de Téritéqas, le royaume de Méroé va à nouveau entrer dans les tumultes de l'histoire méditerranéenne.

\section{Téritéqas, Amanirénas et Akinidad la guerre entre Méroé et Rome}

Le 12 août 30 av. J.-C., Cléopâtre VII, dernière souveraine d'Égypte, se donna la mort à Alexandrie, un an après la bataille d'Actium où sa flotte et celle de son amant Marc-Antoine avaient été défaites. Octave, vainqueur, annexa l'Égypte, désormais intégrée dans l'Empire romain. Il y nomma un gouverneur, le premier "préfet d'Alexandrie et d'Égypte", en la personne de Cornélius Gallus, un ami proche. Celui-ci acheva la conquête romaine du pays en s'emparant de la région de Thèbes, qui était aussitôt entrée en rébellion, et poursuivit jusqu'en Basse-Nubie. 
Il fit ériger à Philae, en date du 17 avril 29, une stèle trilingue (latin, grec, égyptien hiéroglyphique) où il commémorait ses victoires et expliquait la nouvelle organisation de la région. Le Dodécaschène, les douze schènes $(128 \mathrm{~km})$ d'Assouan à Maharraqa, comprenant les temples de Philae, restait partie intégrante de l'Égypte sous domination romaine. Le Triacontaschène, les trente schènes $(320 \mathrm{~km})$ entre Maharraqa et Faras sur la deuxième cataracte, était désormais placé sous la direction d'un gouverneur local (tyrannos) qui lèverait l'impôt pour Rome. Le royaume de Méroé devenait un État allié (dans la version grecque) ou vassal (dans la version latine, comprise uniquement des Romains), après que Cornélius Gallus eut rencontré les «envoyés du roi d'Éthiopie».

Le roi en question était très probablement Téritéqas, dont le nom est connu par deux textes méroïtiques, un graffito du temple de Dakka, rédigé vers 25 av. J.-C., et une stèle ovale assez fruste du temple d'Isis à Méroé, conservée au musée de Liverpool. Sur cette dernière, le roi apparaît seul face à la déesse, tendant la main vers elle en un geste de salut, tandis qu'elle dirige vers lui un signe de vie fixé au bout d'une longue palme. Deux inscriptions méroïtiques d'origine figurent derrière les personnages. Une troisième, sans doute ajoutée plus tard sous la scène et très abrasée, proclame: "C'est le souverain Téritéqas, c'est le [?] de la Candace Amanirénas et d'Akinidad.» On le considère traditionnellement comme l'époux d'Amanirénas, bien que l'on n'ait aucune preuve de ce lien matrimonial. Mais selon notre interprétation de la position de la Candace dans les institutions du royaume (voir ci-dessus, p. 230 sq.), Téritéqas serait plutôt le fils d'Amanirénas et d'un roi au nom inconnu auquel il aurait succédé. Le "prince royal» (pqr qorise) Akinidad, qui allait jouer un rôle éminent dans la suite des événements, serait donc le frère cadet de Téritéqas.

Les relations amicales entre Octave, devenu en 27 av. J.-C. l'empereur Auguste, et le premier préfet d'Égypte allaient toutefois s'envenimer, Cornélius Gallus étant soupçonné de s'appuyer sur la nouvelle province, source inégalable de richesses et de puissance, pour assouvir des ambitions personnelles. Rappelé à Rome, il fut déchu de ses fonctions et se suicida. Un second préfet, Aelius Gallus, fut nommé en 26 av. J.-C. Mais à peine s'était-il installé, qu'Auguste l'envoya en expédition dans la péninsule arabique, le remplaçant à Alexandrie par un nouveau préfet, Caïus Pétronius. Aelius Gallus partit pour l'Arabie en emmenant la moitié des légions stationnées en Égypte, dégarnissant en bonne partie la protection de la frontière sud. La suite nous est racontée par le géographe et historien grec Strabon, d'après des informations de première main. Il avait en effet accompagné Aelius Gallus, son ami, peu après son investiture, dans un voyage jusqu’à la frontière égypto-méroïtique. 


\section{La guerre entre Rome et Méroé}

extrait de la Géographie de Strabon, xvII.1.53-54

Gonflés de présomption par le départ d'une partie des troupes stationnées en Égypte pour suivre Aelius Gallus dans sa campagne contre les Arabes, les Éthiopiens attaquèrent la Thébaïde et une garnison de trois cohortes à Syène (Assouan). Ils parvinrent à prendre Syène, Éléphantine et Philae au terme d'un assaut soudain, en asservirent les habitants, et renversèrent même les statues de César (Auguste). Alors Pétronius les attaqua avec moins de dix mille fantassins et huit cents cavaliers contre trente mille hommes. Il les contraignit tout d'abord à se réfugier dans la ville éthiopienne de Pselchis (actuelle Dakka) et envoya une ambassade pour réclamer ce qui avait été pillé et demander des comptes sur les raisons pour lesquelles ils avaient commencé la guerre. Comme ils répondirent qu'ils avaient été lésés par les nomarques (collecteurs d'impôts), il leur répliqua que ce n'était pas ceux-là les maîtres de la région, mais César.

Ils demandèrent trois jours pour délibérer, mais comme ils

le Soudan

244

des origines

à la chute

du sultanat

Fung n'avaient rien fait de ce qu'il fallait, il attaqua et les força à se battre. Il les mit rapidement en fuite en raison de la faiblesse de leur tactique et de leur armement. Ils avaient en effet de grands boucliers oblongs en peau de bœuf non tannée et comme moyens de défense des haches, certains des épieux, certains aussi des glaives. Les uns furent repoussés dans la cité, d'autres s'enfuirent dans le désert, d'autres trouvèrent refuge dans les nombreux îlots en franchissant le lit du fleuve, car en raison du courant il n'y avait guère de crocodiles. Parmi eux se trouvaient aussi les généraux de la reine Candace qui régnait de notre temps sur les Éthiopiens, une femme hommasse qui avait perdu un œil. Tous ceux-là, Pétronius les capture vifs, après avoir traversé sur des radeaux et des bateaux, et les envoie immédiatement à Alexandrie, puis il se dirige vers la cité (Pselchis/Dakka) et s'en empare. Si l'on ajoute aux prisonniers le grand nombre de ceux qui tombèrent au combat, le chiffre de ceux qui en réchappèrent se trouva être extrêmement réduit.

De Pselchis, Pétronius arriva à Premnis (actuelle Qasr Ibrim), une cité fortifiée, après avoir traversé les dunes où l'armée de Cambyse, prise dans une tempête de sable, avait été ensevelie. Il attaqua et s'empara de la citadelle au premier assaut, et après cela s'élança vers Napata. C'était la résidence royale de Candace, et son fils s'y trouvait, alors qu'elle-même s'était installée dans un endroit proche. Bien qu'elle eût envoyé une délégation pour demander un traité d'amitié et qu'elle eût rendu les captifs de Syène ainsi que les statues, il marcha sur Napata, d'où le prince s'était enfui, 
et la détruisit complètement. Il réduisit la population en servitude et revint sur ses pas avec son butin, jugeant trop difficiles d'accès les régions situées plus en avant. Il fit améliorer les défenses de Premnis, y plaça une garnison avec des provisions pour quatre cents hommes pendant deux ans et s'en revint en Alexandrie. Quant aux captifs, il vendit les uns comme butin, en envoya mille autres à César, qui venait de rentrer de Cantabrie, d'autres enfin périrent de maladie.

Pendant ce temps, Candace marcha avec plusieurs dizaines de milliers d'hommes sur la garnison (de Premnis). Pétronius partit à la rescousse et parvint à arriver le premier devant la garnison. Il renforça les défenses du lieu en multipliant les équipements militaires. Alors que les Éthiopiens voulaient parlementer, il leur enjoignit de parlementer avec César. Comme ils répondirent qu'ils ne savaient pas qui était César et comment ils devaient accéder à lui, il leur accorda une escorte. Ils arrivèrent à Samos, où se trouvait César, qui de là s'apprêtait à partir pour la Syrie, ayant envoyé Tibère en Arménie. Après qu'ils eurent obtenu tout ce qu'ils demandaient, il leur fit même remise du tribut qu'il leur avait imposé.

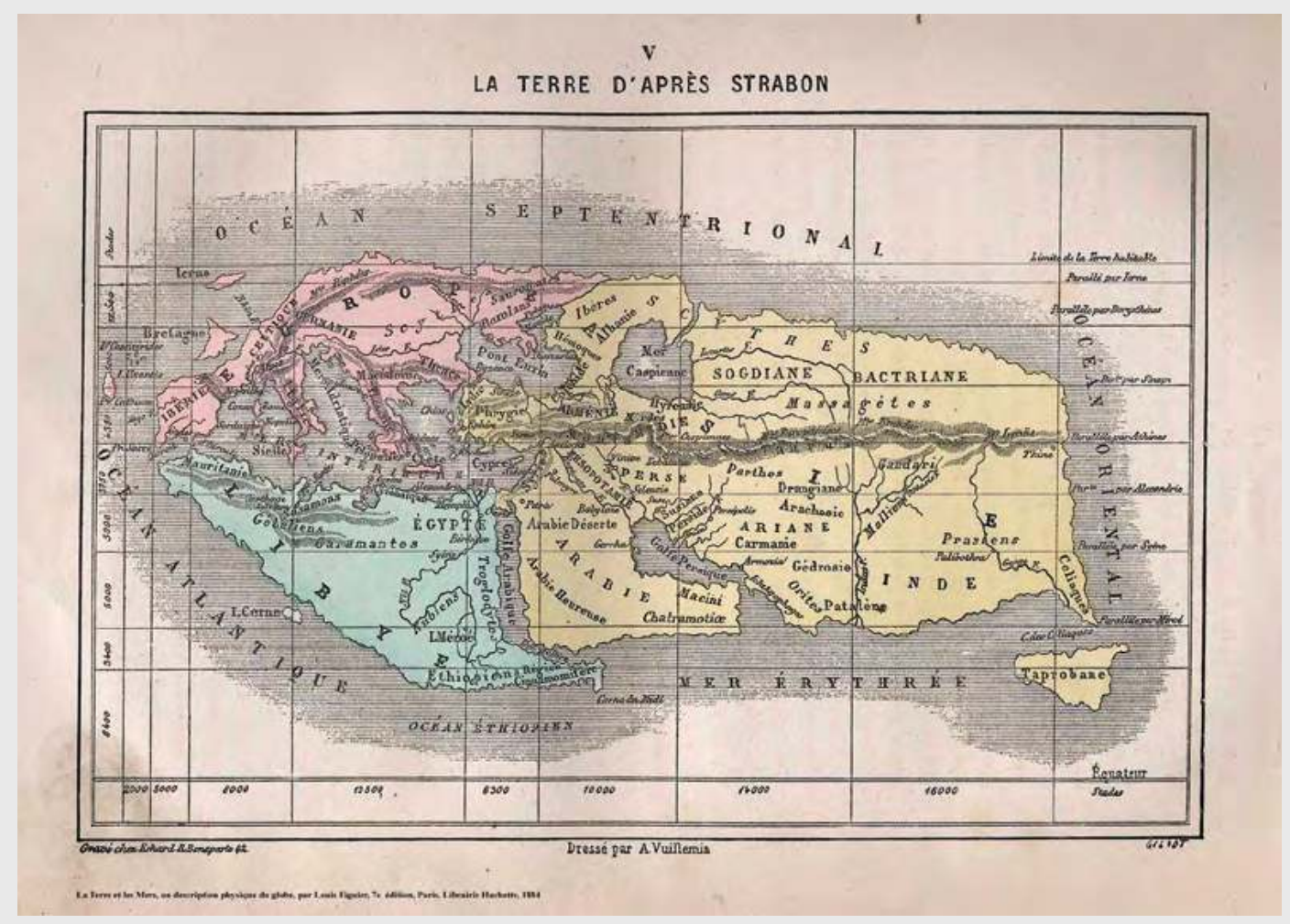

La Terre, d'après Strabon, in Louis Figuier, La Terre et les mers, ou description pysique du globe,

$7^{\mathrm{e}}$ édition, Paris, 1884 (carte dressée par A. Vuillemin). 
Le récit de Strabon est le plus précis qui nous soit parvenu de la guerre entre les Méroïtes et les Romains parmi les sources gréco-romaines (Pline l'Ancien et Dion Cassius en parlent brièvement). Certains détails sont confirmés par la géographie, comme le raccourci par le désert entre Qasr Ibrim (Premnis) et Dakka (Pselchis), qui évite la boucle que fait le Nil autour de Korosko. D'autres le sont par l'archéologie. C'est ainsi que les fouilles britanniques à Qasr Ibrim ont mis au jour à la fin des années 1970 des centaines de boulets de catapulte au pied des remparts, destinés à empêcher l'approche de l'armée de la Candace lors de sa tentative de reprise de la cité. L'un d'entre eux portait même une inscription en grec: "Ça te suffit, Candace?» écrite par un légionnaire facétieux. Hans Barnard, qui a publié ces projectiles, en rapproche les commentaires tracés à la craie sur les missiles par les pilotes britanniques qui bombardaient l'Allemagne lors de la Deuxième Guerre mondiale, comme: "Voilà pour toi, Adolph!». Enfin, d'autres éléments du récit nous permettent de reconstituer la chronologie des faits. Aelius Gallus partit d'Égypte avant l'été de l'an 25 av. J.-C., son départ déclenchant la révolte du Dodécaschène et le raid des Méroïtes sur Assouan. La première campagne de Pétronius fut achevée au retour d'Auguste de Cantabrie, en Hispanie, à la fin de l'an 24. La deuxième attaque des Méroïtes sur Qasr Ibrim doit coïncider avec la fin des vivres amassés pour deux ans, soit en l'an 22. Le traité de Samos s'est conclu lorsqu'Auguste résida pour la seconde fois sur cette île grecque, durant l'hiver 21-20. En revanche, d'autres éléments du récit de Strabon sont étranges. Dans la description de la panoplie hétéroclite des

des origines

à la chute du sultanat Fung Méroïtes, nulle mention n'est faite de l'arc, une arme à laquelle ils excellaient. Semblablement, on a peine à croire qu'ils aient ignoré qui était César Auguste. Tout porte à croire en effet que de tout temps la monarchie koushite était bien informée de ce qui se passait en Égypte.

Mais surtout, on s'est interrogé à juste titre sur le bilan réel de l'expédition de Pétronius. Strabon est riche de détails sur le début du conflit, sans doute en raison de sa proximité avec Aelius Gallus, lui-même probablement bien renseigné sur les développements de la situation dont son départ était en partie responsable. Or, les premiers événements de 25 av. J.-C. ne constituent en fait qu'une révolte des habitants du Triacontaschène face aux impôts que font peser sur eux les Romains et non pas encore l'affrontement direct entre le pouvoir royal méroïtique et les armées de Pétronius. Sur la suite des opérations, Strabon se fait beaucoup moins précis, et on peut soupçonner quelque exagération des faits en faveur des Romains de la part de ses sources. L'historienne Inge Hofmann a essayé de démontrer qu'il était matériellement impossible à Pétronius, depuis Alexandrie, d'avoir mené toutes ces opérations militaires, atteint Napata et rejoint Alexandrie 
durant le court espace de temps qui sépara la révolte du Triacontaschène du retour d'Auguste de son expédition ibérique, soit entre 4-5 mois (estimation basse) et 6-7 mois (estimation haute), alors que le simple trajet d'Assouan jusqu'à Napata demandait deux mois à une armée. Si, dans la chronique de son règne laissée par Auguste (Res gestae Divi Augusti), l'empereur affirme que Napata "a été atteinte», ce qui pouvait être le fait d'éclaireurs ou d'espions envoyés par Pétronius, il n'indique pas expressément, contrairement à Strabon, qu'elle a été rasée. La prise de Napata semble confirmée une centaine d'années après les faits par Pline l'Ancien et au début du $\mathrm{III}^{\mathrm{e}}$ siècle par Dion Cassius dans sa monumentale Histoire romaine. Le récit de ce dernier est dans l'ensemble un résumé de Strabon, mais il ajoute que «Pétronius, ne pouvant ni avancer plus loin en raison du sable et de la chaleur, ni rester dans le pays dans de bonnes conditions avec toute son armée, se retira en emmenant la plupart de ses hommes».

Qu'il ait eu lieu ou non, le sac de Napata, l'ancienne capitale restée métropole religieuse, ne pouvait cacher que l'objectif principal des Romains programmé de longue date dans la stèle de Cornélius Gallus, à savoir la prise de Méroé, n’avait pas été atteint. L'aveu de cette semi-défaite se lit entre les lignes dans la chronique d'Auguste, qui ajoute dans le passage cité plus haut que Napata est "proche de Méroée, une proximité pourtant toute relative ( $350 \mathrm{~km}$ par les pistes). La contre-offensive de la Candace, moins de deux ans après la première campagne, montre bien que l'expédition de Pétronius n'avait pas entamé les forces du royaume de manière significative. Qui plus est, la forteresse de Qasr Ibrim fut réoccupée par les troupes méroïtiques après le traité de Samos, et la découverte à Méroé, sous le seuil du temple M 292, de la tête d'une des plus belles statues de bronze connue d'Auguste montre que le butin des villes pillées par les Méroïtes n'avait pas été entièrement rendu, ce qui était pourtant une des premières exigences de Pétronius. Le traité de Samos conclu avec Auguste en 21/20 est étonnamment favorable au royaume koushite. La frontière fut remontée en deçà du Triacontaschène et aucun tribut ne fut exigé. Tous ces faits indiquent que la campagne contre le royaume de Méroé (comme d'ailleurs celle que mena simultanément Aelius Gallus en Arabie) n'avait pas rencontré le succès escompté.

\section{La guerre contre Rome vue par les Méroïtes}

Il serait évidemment du plus grand intérêt pour les historiens aussi bien de Rome que de Méroé de connaitre le point de vue des Méroïtes sur ce conflit. Or, on possède quatre inscriptions relatives à cette guerre, qui sont malheureusement toutes écrites en méroïtique, une langue qui n’est que partiellement comprise. 
le Soudan

\section{8}

des origines

à la chute

du sultanat

Fung
Toutefois, nos récentes recherches ont permis d'affiner les quelques informations que l'on peut en tirer. Les deux premières sont des graffiti gravés sur les murs du temple de Dakka, l'antique Pselchis. Les deux autres sont des stèles royales érigées dans le sud du royaume.

Le premier graffito de Dakka n'est certes pas une ouvre d'art. Enserré dans un grand cartouche un peu bancal surmonté de deux hautes plumes, gravé en caractères peu soignés, il contient un protocole initial qui cite le roi Téritéqas, la Candace Amanirénas et le prince Akinidad suivi du locatif Sek-te, "à Pselchis (Dakka)». Trois propositions très abîmées donnent les noms de peuples ennemis dont les hommes furent tués et les femmes asservies. Le texte se termine par la mention de son commanditaire: "Akhamora étant stratège (gouverneur de province)", détail important car il s'agit du nom mérö̈tique du nouvel administrateur établi par la royauté méroïte pour remplacer le gouverneur que les Romains avaient mis à la tête du Triacontaschène. Le second graffito de Dakka, en partie effacé, ne cite qu'Akinidad et semble dédier son butin à Isis.

De 1909 à 1914, le Britannique John Garstang dirigea pour le compte de l'université de Liverpool des fouilles de grande ampleur à Méroé. Durant la dernière saison, il se déplaça de trois kilomètres au sud, sur le site de Hamadab, où il dégagea les ruines d'une cité périphérique. Elle comportait un temple de briques, précédé d'un pylône flanqué de deux grandes stèles en grès, inscrites en cursive méroïtique. Celle de gauche était dans un bon état de conservation, à l'exception de la partie supérieure cintrée, porteuse de l'image gravée du souverain devant les dieux, qui avait été partiellement arasée, ne laissant voir que les pieds des personnages. Le texte était néanmoins intact. L'autre stèle était par contre très abîmée. Le cintre était également brisé et, surtout, la majeure partie de l'inscription était fortement érodée. Garstang fit transporter la première en Angleterre.

Acquise par le British Museum où l'on peut la voir aujourd'hui, elle est constituée d'un bloc de grès massif de 3,5 tonnes. Elle mesure $258 \mathrm{~cm}$ de hauteur et $100 \mathrm{~cm}$ de largeur. Elle porte 42 lignes de texte en cursive méroïtique. La partie restante du cintre montre une scène d'adoration divine en deux volets symétriques. Sur la gauche, une reine méroïtique en sandales à grandes boucles, suivi d'un prince reconnaissable à ses pieds nus, rend hommage à un dieu vêtu d'un pagne simple, vraisemblablement Amon. Sur la droite, les mêmes font face à une déesse porteuse de la croix de vie, sans doute la déesse Mout, parèdre d'Amon. Sous cette scène figure une ligne de prisonniers entravés que les personnages foulent ainsi aux pieds. Le protocole initial (lignes. 1-2) livre l'identité des deux personnages royaux: "Alors qu’Amanirénas, le souverain, la Candace, celle qui les subjugue (?), régnait et qu'Akinidad était prince ( $p q r)$ et vice-roi...» 
La stèle présente donc une Candace et un prince, soit la même configuration du pouvoir que celle décrite par Strabon lors du conflit, et l'on savait par l'étude paléographique dont Griffith avait jeté les bases que le texte se situait dans un espace chronologique "archaïque» qui incluait cette période. Le passage qui suit immédiatement (lignes 2-5), bien que largement incompréhensible, déclencha l'intérêt des méroïtisants. Il contient en effet trois mots qui ont orienté l'interprétation vers le conflit entre Rome et Méroé: Qes, Armeyose et Armi. Dans une première étude, Archibald H. Sayce, l'épigraphiste de la mission Garstang, proposait de voir dans ces mots les noms respectifs de Koush, des Romains et de Rome. Le nom de Rome en méroïtique est en effet connu dans les textes postérieurs sous la forme Arome. Griffith reprit l'analyse du texte qu'il publia en 1916. Il admit la traduction de Qes par «Koush», d'Armi (selon lui une variante ancienne d'Arome) par «Rome» et suggéra que Armeyose fût un calque du grec Rhomaios, "Romain». Qui plus est, il avait identifié peu de temps auparavant les mots "homme» et «femme», ce qui lui permettait d'avancer pour un passage récurrent une traduction approximative, «tuant les hommes, asservissant les femmes", bien qu'il ne pût rendre compte en détail de la syntaxe de la proposition. Cette mention en forme de bilan de campagne, qui revient plusieurs fois dans le texte (avec parfois des chiffres précis pour le nombre d'hommes et celui de femmes), était une preuve supplémentaire de la teneur militaire du texte. Pour plusieurs décennies, on tint comme établi que la stèle dite "d'Akinidad " était bien la version méroïtique de la guerre contre Rome.

Mais les études qui suivirent montrèrent que l'identification par Sayce et Griffith de l'ennemi des Méroïtes comme "romain" sur la base du terme Armi devait être abandonnée. Le mot semble en effet une désignation archaïque du Triacontaschène. La première stèle de Hamadab et le premier graffito de Dakka sont étroitement liés. La principale différence est la présence de Téritéqas dans le graffito et son absence dans la stèle. L'hypothèse traditionnelle selon laquelle il serait décédé après l'assaut des Méroïtes sur la Basse-Nubie semble la meilleure explication. Le prince Akinidad fut alors délégué comme commandant de l'armée de Koush par la Candace Amanirénas. Les deux textes décrivent la guerre non pas comme une importante expédition contre les Romains mais simplement comme l'écrasement de plusieurs tribus rebelles, selon la tradition des stèles napatéenne tardives. L'une de ces "tribus», basée à Pselchis, est citée sous le nom d'Arobe (peut-être prononcé /arumbe/) qui pourrait désigner les Romains et être une forme archaïque du mot Arome, "Rome». La question de la souveraineté sur Armi, le Triacontaschène, est cependant présente dans l'introduction de la première stèle de Hamadab. Que cette question 
le Soudan

250

des origines

à la chute

du sultanat

Fung n'ait probablement pas été réglée par les prétendues négociations entre Cornélius Gallus et les émissaires du roi de Méroé quatre ans auparavant se devine d'après la remarque de Pétronius aux Méroïtes dans le récit de Strabon: "Ce n'étaient pas ceux-là [les collecteurs d'impôt] les maîtres du pays, mais César." Le texte cite également comme chef des ennemis d'Armi capturés par les Méroïtes (seulement 32 hommes et 137 femmes) un certain Kouper, connu par ses deux fils Pétéisé et Pahor. Ceux-ci s'étaient en effet noyés dans le Nil. Or, ce genre de mort était une raison suffisante, selon le témoignage d'Hérodote, pour qu'ils soient divinisés. Tous les noyés, bien évidemment, ne recevaient pas de sanctuaire en dur. Mais dans ce cas précis, sans doute en hommage à l'ancien allié de Rome, Caïus Pétronius fera plus tard ériger à Dendour un temple aux fils de Kouper. La première stèle de Hamadab et les graffiti de Dakka décrivent donc le début de la guerre: Akinidad ravage le Triacontaschène, fait prisonnier Kouper, le gouverneur nommé par les Romains, ainsi que plusieurs hommes et femmes. Après quoi il marche contre trois différents centres cultuels et administratifs du Dodécaschène, décrits chacun comme un peuple ennemi dans la tradition koushite. Le premier était Pselchis (moderne Dakka), où était peut-être stationnée une garnison romaine. Un nouveau gouverneur de province, Akhamora, est nommé par Akinidad, qui remonte peu après sur Napata.

Nous avons ci-dessus signalé qu'il existait une seconde stèle à Hamadab. Placée par Garstang à l'entrée de la cité royale de Méroé, elle disparut à une époque indéterminée. Selon le service des Antiquités, elle aurait été réinhumée à Méroé, mais, d'après les gardiens de ce site, elle aurait été transportée dans les magasins du musée national de Khartoum. C'est effectivement là qu'elle a été retrouvée en 2006. Elle a été ensuite installée dans les salles d'exposition, où nous avons pu en faire une étude nouvelle en février 2007. Le monument comporte 32 lignes inscrites. Comme la première stèle de Hamadab, elle n'a conservé que la partie inférieure de la lunette, montrant les pieds des personnages dans une scène similaire. Toutefois, la déesse se trouve à gauche et le dieu Amon, à droite, enlace la Candace selon un geste bien connu dans la tradition royale égyptienne. La représentation semble en relation directe avec celle de la première stèle en raison de leur symétrie. Qui plus est, elle en constitue la suite, puisque, précédemment, la reine se tenait encore à l'écart du dieu. La frise de prisonniers, sous les pieds des personnages, est totalement arasée, au point que l'on peut se demander si elle a jamais été exécutée ou si elle n'a pas fait l'objet d'un martelage.

L'inscription était dès la découverte très érodée. Elle ne comporte pas de protocole complet. La mention du prince Akinidad avec son titre de pqr qorise, "prince royal», à la première ligne ne s'accompagne pas de celle 
de la Candace Amanirénas. Cette absence de protocole confirme les déductions que l'on pouvait faire de la scène gravée, à savoir que la seconde stèle de Hamadab constitue la suite de la première. Le texte commence de manière abrupte par une proposition que l'on peut traduire: «Ce sont les captifs Tameya." Ce mot a été récemment identifié sur une petite stèle de Naga, où il barre la figure gravée d'un captif romain, reconnaissable à son type physique européen, son casque et son ceinturon. Bien évidemment, on regrette fort de ne plus pouvoir vérifier que les prisonniers de la frise sur la seconde stèle de Hamadab étaient originellement du même type que le Romain de Naga. Aux lignes 3-4, on lit le passage suivant (où le premier verbe est inconnu): «Des Tameya, j’ai [?] chaque homme, j’ai razzié chaque femme et chaque garçon.» Il semble bien que l'on tienne enfin le récit détaillé de la guerre tant recherché. Le terme «Tameya» apparaît en effet plusieurs fois dans la suite du texte, montrant qu'il ne s'agit pas d'un simple accrochage mais d'une campagne narrée en continu. Évidemment, le passage traduit fait penser à la prise d'Assouan par les Méroïtes et à la réduction en esclavage de sa population selon le récit de Strabon. Malheureusement, le mauvais état de conservation du texte et notre connaissance lacunaire de la langue méroïtique nous empêchent de comprendre la plus grande partie du récit. Mais des toponymes apparaissent, dans le même ordre que chez Strabon: Éléphantine (?), Assouan, Napata puis Qasr Ibrim. Tous ces éléments sont les seuls en rapport avec la guerre contre les Romains que nous avons pu actuellement identifier, mais ils nous paraissent assez convaincants pour avancer que le récit méroïtique de ce conflit a bien existé et qu’il figure sur cette stèle si malencontreusement mutilée. Il ne permet pas en revanche de savoir si Pétronius a effectivement atteint Napata, car la mention de cette ville figure dans un contexte obscur.

La deuxième stèle de Hamadab ressemble plus à une réécriture de l'ensemble du conflit qu'à une simple suite de la première stèle. L'importance qu'y joue le prince Akinidad seul, contredite par le texte de Strabon qui met la Candace au premier plan, est peut-être motivée par des considérations politiques et pose à nouveau la question de sa position dans la lignée de succession. Tous ces témoignages méroïtiques, en tout cas, citent l'ensemble des opérations militaires. Or, les règles implicites de la propagande antique veulent que la défaite, lorsqu'elle est totale, ne laisse pas de traces dans les annales. Elle est exorcisée par le silence des sources du côté des vaincus. Par contre, une semi-défaite, ainsi que l'a été par exemple la bataille de Qadesh entre Ramsès II et l'Empire hittite, sera commémorée comme une victoire, les aspects négatifs étant soigneusement tus. C'est de toute évidence le cas de la guerre entre Rome et Méroé. Nous avons précédemment lu entre les lignes des sources gréco-latines que la campagne 
le Soudan

252

des origines

à la chute

du sultanat

Fung

de Pétronius n'avait sûrement pas été un succès complet. Avec les textes de Hamadab et de Dakka, nous en avons la confirmation, puisqu'elle paraît avoir été considérée par les Méroïtes comme une victoire.

De fait, il semble que la politique de modération adoptée par Auguste lors des négociations qui aboutirent au traité de Samos fut payante, puisque les conflits de Méroé avec l'Empire romain cessèrent pour des siècles. Les bonnes relations avec le puissant voisin du nord sont attestées par l'existence de contacts réguliers, assurés sans doute par des ambassadeurs qui portent le nom méroïtique d'apote Arome-li-se, "envoyé auprès de Rome» (c'est-à-dire auprès du pouvoir romain en Égypte). L'équipement des tombes royales de Méroé comporte également des objets précieux d'importation méditerranéenne, notamment des bronzes qui sont probablement des cadeaux diplomatiques ou le fruit des échanges qui avaient repris avec le nord sur une plus grande échelle, l'Empire romain étant un marché bien plus vaste que ne l'était l'Égypte. La demande en bêtes sauvages (notamment pour les jeux du cirque) et en produits de luxe (ivoire, plumes d'autruche, peaux de fauves, esclaves africains) fut multipliée. Méroé restait plus que jamais un "couloir vers l'Afrique», selon le mot de l'archéologue W.Y. Adams, car il n'existait pas encore de voies de pénétration vers les régions subsahariennes à l'ouest du continent, qu'elles fussent par mer ou à travers le désert, qui ne put être aisément franchi avant l'introduction du chameau dans la région, au Moyen Âge. En retour, les importations en provenance de la Méditerranée dans le royaume de Méroé devinrent plus nombreuses, exerçant notamment dans le domaine des arts plastiques et de la céramique une influence considérable. L'art méroïtique, qui était jusqu'alors un mélange de traditions locales et égyptiennes, incorpore une troisième composante gréco-romaine qui, à partir du premier siècle de notre ère, fait jeu égal avec les concepts hérités de la culture napatéenne.

\section{La Candace Amanishakhéto et la réorganisation de la Basse-Nubie}

On ignore où furent inhumés le roi Téritéqas et la Candace Amanirénas. On a proposé pour le premier la tombe Beg. N. 21, dont les reliefs inachevés pourraient s'expliquer par l'urgence de la situation dans un contexte de guerre. Mais d'autres solutions sont possibles à Méroé (Beg. N.14) ou au Gébel Barkal (Bar.2). Dans tous les cas, les sépultures sont anépigraphes. La Candace, sa mère, ne semble pas lui avoir longtemps survécu. Elle est attestée en compagnie seulement du prince Akinidad sur la première stèle de Hamadab et un petit autel portatif de bronze retrouvé à Kawa. Dans les deux cas, elle porte, en plus du titre de "Candace», celui de qore, «souverain ", pris 
(ou repris) à la mort de Téritéqas. Bien que, là aussi, on n’ait aucune inscription attestée, on attribue à Amanirénas la pyramide de Barkal no 4 , l'une des mieux conservées et des plus grandes du groupe nord. Les reliefs, simples mais d'excellente facture, représentent une reine protégée par Isis et encensée par un prince. Sur le mur nord, elle porte la calotte koushite surmontée de la couronne hathorique des épouses royales connue depuis la reine égyptienne Tiyi, mais, sur le mur sud, elle arbore le pschent, la double couronne des pharaons. Ces deux figurations s'accordent bien avec son double titre de Candace et de souverain. Le trousseau funéraire, qui comporte des verreries romaines du début de l'Empire, confirme pour ce tombeau une date qui s'accorde à celle de son règne. Sachant que les deux Candaces qui l'ont suivie sur le trône ont des sépultures parfaitement identifiées, la pyramide Bar. 4 semble bien avoir été la dernière demeure d'Amanirénas.

La succession de cette reine est un mystère. En effet, son fils Akinidad, auréolé dans les chroniques méroïtiques de Hamadab de son rôle éminent dans le conflit contre les Romains, était toujours en vie. Toutefois, c'est une autre Candace, Amanishakhéto (écrit Amanishakhété dans quelques inscriptions), qui monta sur le trône. Dans les débris sur le sol de sa chapelle ont été retrouvés des fragments de deux ou trois tables d'offrandes inscrites, qui ont conduit certains chercheurs, comme Fritz Hintze, à reconstruire en partie le nom de ses parents. Malheureusement, la graphie des signes et le type des formules employées sont plus tardifs d'un siècle et demi au moins. Ces tables d'offrandes, dont l'une est assurément royale, ont donc plutôt été déplacées ou proviennent d'une éventuelle réutilisation de la tombe. Aussi ignorons-nous la filiation d'Amanishakhéto. Comme son avènement s'est toutefois fait dans la continuité avec le règne précédent, on peut proposer, selon notre conception du rôle de la Candace, qu'elle ait été la grande épouse royale de Téritéqas et régente de son fils. Il reste toutefois inexplicable qu'Akinidad, si c'est bien lui que cite Strabon comme fils de la Candace (mais on voit mal comment il pourrait en être autrement), n'ait pas été couronné non seulement au décès de Téritéqas mais, de plus, à la mort d'Amanirénas.

Il est assez probable que la Candace Amanishakhéto se soit maintenue sur le trône jusqu'au début du $\mathrm{I}^{\mathrm{er}}$ siècle de notre ère. Outre son imposant monument funéraire à Méroé, elle est attestée en effet par un grand nombre d'inscriptions à travers tout le royaume, depuis Qasr Ibrim, au nord, jusqu’à Naga, au sud. Au début de son règne, elle y est accompagnée du même prince ( $p q r)$ Akinidad que la Candace Amanirénas. C'est notamment le cas sur une large stèle retrouvée à Qasr Ibrim (ancienne Primis, Premnis chez Strabon), dans la citadelle que Pétronius avait fortifiée et où il avait établi une garnison pendant deux ans. Selon les termes du traité de Samos, 
elle fut, comme le reste du Triacontaschène, évacuée par les Romains qui se retirèrent sur la nouvelle frontière nord, vers Hiéra Sycaminos (actuelle Maharraqa). Le texte méroïtique est largement incompréhensible et d'ailleurs mal conservé, la stèle ayant servi de pavement dans la cathédrale copte édifiée plus tard en ce lieu. Le protocole initial se lit: «Amanishakhéto étant souverain et Candace, Akinidad étant prince.» Les Romains (Tmeye) y sont deux fois cités, ainsi que plusieurs officiels méroïtiques: il semble bien que ce document atteste donc la réorganisation du Triaconstaschène après le départ de la garnison romaine, ainsi que l'établissement du culte d'Amon (Amnp) et d'Isis "Maîtresse du Sud» (Nbeyrose, de l'égyptien Nb.t rsy). Le nom d'Akinidad apparaît encore une fois dans un cartouche en hiéroglyphes méroïtiques, au côté de celui d'Amanishakhéto, sur des blocs de grès ayant servi à la restauration du grand temple de Kawa, puis il disparait: dans les autres inscriptions, Amanishakhéto est seule et continue d'assumer les titres de «souverain» et de "Candace».

$\mathrm{Si}$, comme nous le supposions précédemment, elle est montée sur le trône comme régente de son fils, on n'a aucune trace écrite de ce dernier, peut-être mort trop jeune pour régner. On possède en revanche des témoignages iconographiques. Parmi les bagues du trésor découvert dans la pyramide d'Amanishakhéto, sur lequel nous reviendrons, plusieurs possèdent des chatons gravés où est souvent figurée la reine, seule ou accompagnée de divinités. Sur l'un d'eux, elle trône face à Amon à tête de bélier, également assis. Elle est coiffée d'un scorpion à tête d'Isis surmontant la calotte koushite, comme son aïeule Nahirqo dans sa chapelle de la pyramide Beg. N.11, et elle pose sur les genoux du dieu un enfant au front paré d'un cobra royal. des origines à la chute du sultanat Fung Sur un autre chaton, elle est assise sur un lit matrimonial en compagnie d'un roi de Méroé, reconnaissable à son costume tripartite et son double uraus (cobra royal). Elle porte la même coiffure au scorpion et tend au roi un petit prince dont le statut est cette fois simplement signalé par la «mèche de l'enfance», une tresse unique conservée sur un crâne rasé.

Les très nombreuses stèles et inscriptions connues au nom d'Amanishakhéto entraient très certainement dans un programme de restauration des édifices cultuels et royaux, mais l'intense activité architecturale développée sous le règne conjoint d'Amanitoré et de Natakamani, quelques décennies plus tard, a sans doute oblitéré les travaux entrepris sous sa direction, dont seuls nous restent les quelques blocs du grand temple d'Amon de Kawa, sans doute restaurés par elle, et son palais de Ouad Ben Naga. On possède ainsi deux petites stèles à son nom et des fragments de deux autres, toutes d'une très grande qualité d'exécution, retrouvées en 1999 et 2000 dans le temple d'Amon de Naga, ce qui laisse supposer qu'elle a fait construire ou rénover en ce lieu. Mais l'ensemble du bâti actuellement en place 
et la totalité des reliefs datent du règne d'Amanitoré et Natakamani. Il n'est toutefois pas impossible, comme nous le verrons, qu'il faille lui attribuer le temple F, un petit édifice perché sur le flanc de la montagne de Naga. Si tel est le cas, les quatre stèles pourraient provenir de ce bâtiment.

Amanishakhéto fit notamment construire (ou rénover) un imposant palais à Ouad Ben Naga, non loin de Méroé. Sur un plan carré de près de $60 \mathrm{~m}$ de côté, cet édifice doté de deux étages, construit sur une série de caissons et de magasins, comportait une cour centrale à ciel ouvert qui permettait la diffusion de la lumière et la circulation de l'air, créant une sorte de climatisation naturelle dans l'édifice. L'ensemble était richement décoré de peintures géométriques et de reliefs sur stuc, parfois recouverts encore d'une mince feuille d'or. Les magasins servaient à entreposer non seulement les denrées mais aussi les produits de luxe destinés à l'exportation dont la royauté avait le monopole: on y a retrouvé notamment des défenses d'éléphants. Il semble avoir servi de modèle pour les résidences royales des règnes suivants, particulièrement ceux de Natakamani, dont des exemples sont connus à Napata et à Mouweis. La multiplication de ces résidences royales, y compris dans des centres de moyenne importance comme Mouweis, semble montrer que les souverains, bien que basés à Méroé, avaient l'habitude de se déplacer à travers le royaume de palais en palais, à la manière de la royauté française à l'époque de la Renaissance.

C'est sans doute sous le règne d'Amanishakhéto que fut mise en place une réorganisation de la Basse-Nubie qui devait rester inchangée jusqu'au départ des cohortes romaines au $\mathrm{III}^{\mathrm{e}}$ siècle de notre ère. Le Dodécaschène (entre Assouan et Maharraqa) était officiellement rattaché à l'Empire romain et protégé par des garnisons détachées par le préfet d'Égypte. Dans les faits, il s'agissait d'une zone tampon administrée en commun par les principaux complexes religieux, Philae, Pselchis (moderne Dakka) et Talmis (moderne Kalabcha) et placée sous la direction d'un «stratège» (en méroïtique pelmos). Aux différents échelons de cette administration se trouvaient des notables issus de grandes familles locales où se mêlaient Méroïtes et Égyptiens, alliés par des liens matrimoniaux, et qui cumulaient les fonctions religieuses et séculières. Bien qu'ayant partiellement délégué leur pouvoir sur la région, les Romains eurent à cœur d'encourager et de financer l'agrandissement des temples de Basse-Nubie, où leurs empereurs furent représentés sous les traits de pharaons. Un vaste programme architectural et iconographique couvrant la majorité des complexes religieux fut lancé sous le règne d'Auguste. Une cour monumentale entourée de colonnades devant le temple d'Isis fut inaugurée à Philae. À Debod, le temple d'Amon autrefois érigé par le roi méroïtique Adikhalamani fut agrandi et consacré à Isis. À Kalabcha, le petit sanctuaire 
laissa place à un temple monumental et son dieu local, Mandoulis, y fut associé aux principaux dieux d'Égypte et de Nubie. À Dakka, le temple de Thot fut agrandi et devint un important lieu de pèlerinage. Nous avons vu précédemment que Pétronius, vers 10 av. J.-C., fit bâtir à Dendour un temple aux fils divinisés de l'infortuné Kouper, le gouverneur nommé par Cornélius Gallus et capturé par Akinidad lors de la guerre avec Rome. Ce petit sanctuaire, offert par l'Égypte aux États-Unis en récompense de leur participation au sauvetage des monuments de Nubie en 1963-1964, se dresse aujourd'hui au Metropolitan Museum of Art de New York.

Le Triacontaschène (entre Maharraqa et Faras) avait été rendu aux Méroïtes par le traité de Samos en 20-21 av. J.-C. Il était administré par un officiel qui portait le titre méroïtique de pesto (écrit pesti sous le règne d'Amanirénas et peseto à partir du $\mathrm{I}^{\mathrm{er}}$ siècle apr. J.-C.). Le mot est d'origine égyptienne, mais son étymologie est discutée. Il est connu en grec sous la forme psentês, simple transcription du méroïtique, et traduit en égyptien par p3-š-nsw, "le fils royal», le titre officiel des anciens vicerois de Koush (voir chapitre 4, p.85 sq.) que les pharaons du Nouvel Empire déléguaient à la tête de la Nubie. S'il n'est pas certain que ce dernier soit l'étymon du terme pesto, il n'en reste pas moins qu'il s'accorde avec le contenu de la fonction: une délégation du pouvoir royal en Nubie, rendue nécessaire par la grande distance qui séparait la province du pouvoir central. Le premier pesto fut certainement Akinidad, le fils d'Amanirénas qui combattit contre les Romains et qui porte ce titre jusqu'à l'avènement d'Amanishakhéto. Rappelé assez vite à Méroé, il fut remplacé par un administrateur de famille non royale, établi à la limite sud du Triacontaschène, des origines à la chute du sultanat Fung à Faras. Le premier attesté est un dénommé Tasémérékha (le nom est de lecture incertaine). Il est connu uniquement par la table d'offrandes funéraire retrouvée à proximité de sa tombe à Faras, dont l'inscription présente des graphies qui correspondent au premier siècle av. J.-C. Son probable successeur, également enterré à Faras, s'appelait Khalalakharora et semble avoir connu une longue carrière, jalonnée de titres aussi bien administratifs que sacerdotaux. La paléographie de l'inscription de son épitaphe laisse supposer qu'il fut inhumé dans la première moitié du $\mathrm{I}^{\mathrm{er}}$ siècle de notre ère. Il est le premier à porter le titre de "vice-roi en Akine» (pesto Akine-te-l) par lequel ses successeurs seront régulièrement désignés. "Akine» est la nouvelle désignation de la province, tirée du nom de la cité de Mirgissa, à proximité de la deuxième cataracte, qui s'appelait en égyptien «Iken » et qui est sûrement la localité nommée Acina sur la liste de toponymes nubiens du géographe romain Pline l'Ancien. Par la suite, les monuments des pestol peseto furent érigés au nord du Triacontaschène, à Karanóg, qui était apparemment le nouveau siège de l'administration du vice-roi. 
Bien que son règne, contrairement à celui d'Amanirénas, semble avoir été une ère de paix et de prospérité, Amanishakhéto entretint l'image guerrière de son prédécesseur. On doit déplorer que son monument le plus important soit en grande partie détruit. Il s'agit d'une stèle en forme d'obélisque, inscrite en méroïtique cursif sur ses quatre faces, qui a été découverte en 1911 devant le deuxième pylône du grand temple d'Amon de Méroé. Sa taille originelle devait avoisiner les trois mètres, mais seules les dernières lignes sont conservées aujourd'hui, ainsi qu'une multitude de petits fragments impossibles à raccorder. Elle semble faire état de campagnes militaires, comme ses équivalents napatéens et méroïtiques et, du moins sur la partie conservée, dénombrer des prisonniers en grand nombre: sur la face $\mathrm{A}$, le chiffre des jeunes gens et des jeunes filles razziés s'élève à 1538 , sur la face B sont comptabilisés 1032 hommes et 2673 femmes. Il semble, d'après l'occurrence du nom divin dans le récit, que ce butin humain était offert à Amon, mais il est très probable que les plus solides de ces malheureux soient entrés dans les transactions avec l'Empire romain où les esclaves noirs étaient très recherchés.

Même les stèles de dévotion d'Amanishakhéto rappellent par leur iconographie les expéditions militaires de la Candace et de ses prédécesseurs. Ainsi, la première des quatre petites stèles de Naga précédemment citées représente la reine amenée par-devant le dieu Apédémak par son épouse, la déesse Amésémi. Sous la scène figure une frise de prisonniers, pour une fois très détaillés. Tous sont de type africain sauf le premier qui, comme nous l'avons précédemment noté, est un soldat romain désigné comme un «Blanc» (Tameya) par une légende en méroïtique: Tmey-l-o, "c'est un Tameya». Bien entendu, il est assez peu vraisemblable que de nouveaux conflits aient eu lieu avec les armées d'Auguste ou de Tibère sans laisser de traces dans les sources gréco-latines, et le prisonnier n'est là que comme un rappel des combats du règne précédent.

\section{La pyramide d'Amanishakhéto et son trésor}

La représentation la plus emblématique d'Amanishakhéto comme femme de guerre figure sur le pylône de sa chapelle funéraire à Méroé (Beg. N. 6). De part et d'autre de la porte, sous son nom gravé en hiéroglyphes, elle apparaît en costume tripartite de souverain méroïtique (tunique, châle et cordelière). Sur le côté nord (le côté "féminin", celui de la Candace), elle porte un diadème orné d'une haute égide à l'effigie du bélier d'Amon et surmonté d'un rapace, faucon d'Horus ou milan d'Isis dont les ailes éployées protègent ses tempes. Ses joues sont scarifiées de trois traits verticaux, comme celles de la déesse Amésémi, épouse d'Apédémak. 


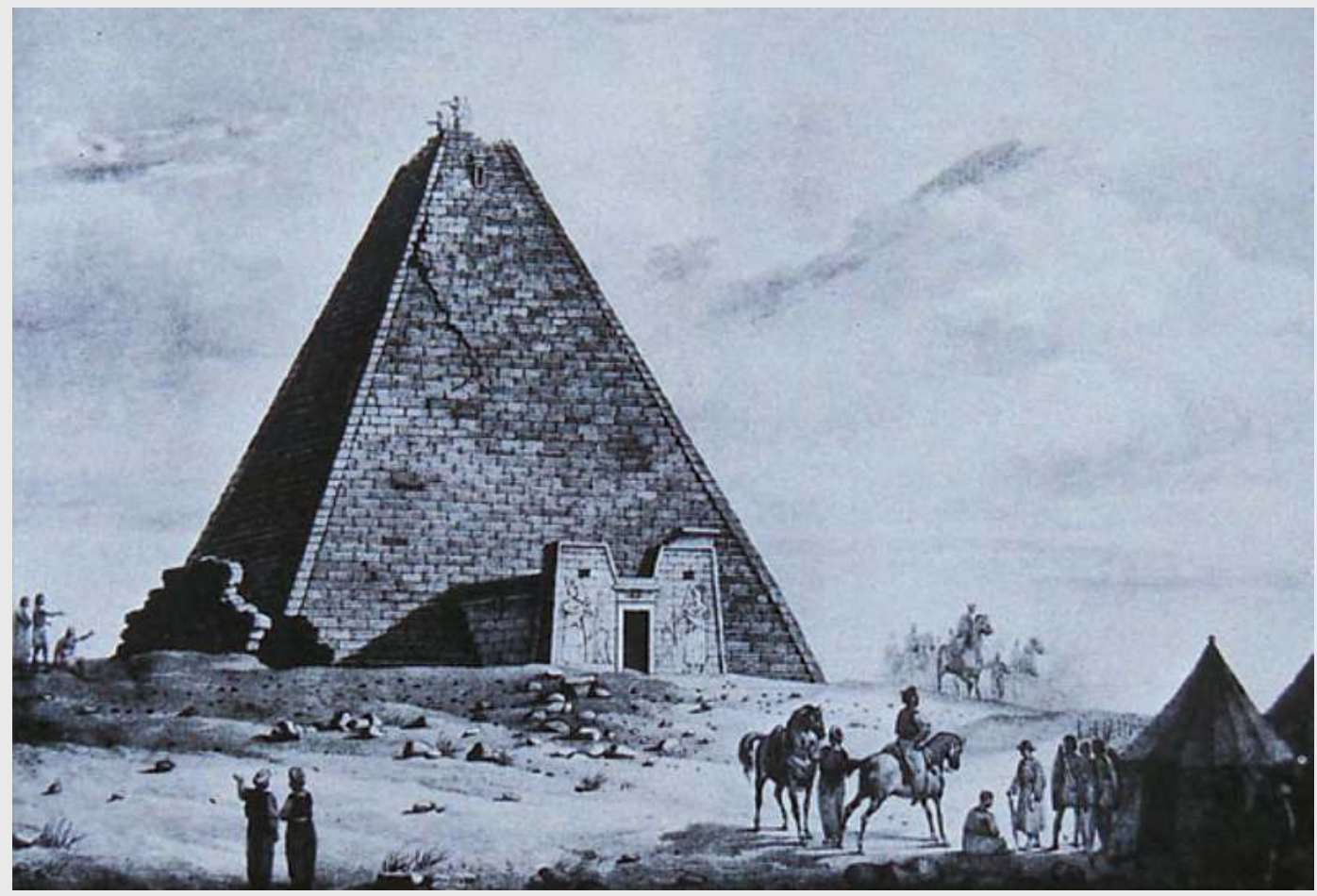

le Soudan

La pyramide d'Amanishakhéto dessinée par Frédéric Cailliaud en 1822.

258

des origines

à la chute

du sultanat

Fung

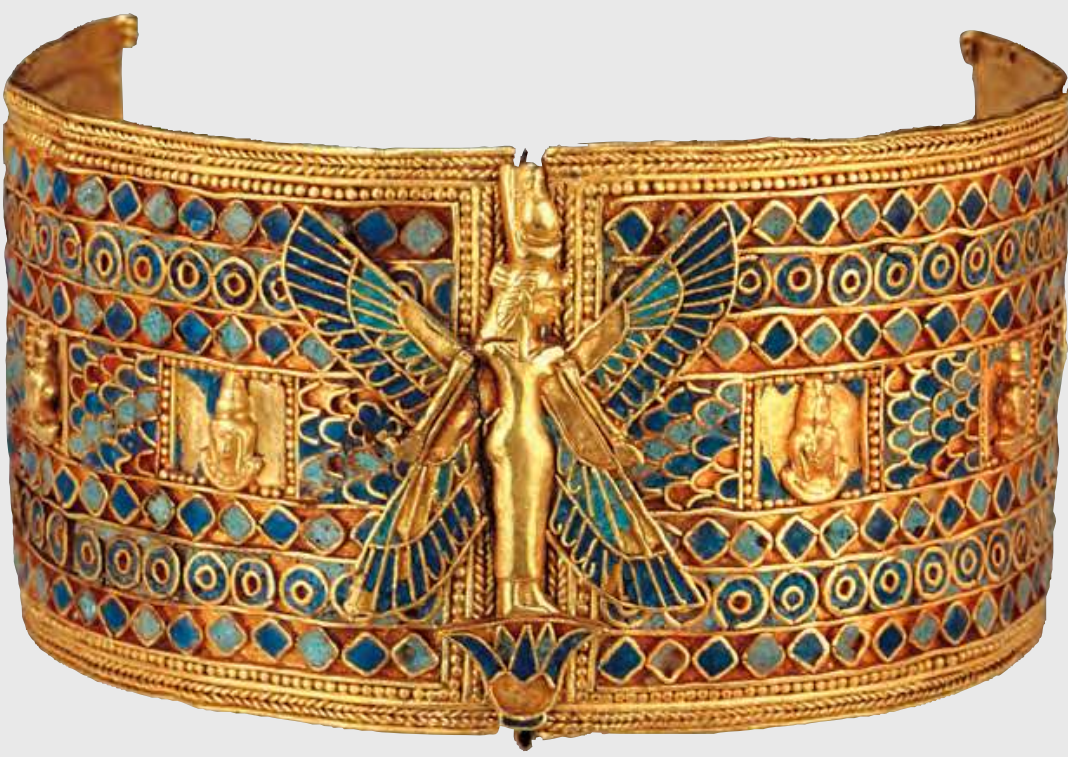

Bracelet en or et pâte de verre colorée, hauteur 4,5 cm, Munich, SsÄK, Ant. 2455. Ce bracelet était porté au bras ou à l'avantbras et était attaché par un lien de cuir ou de tissu. Au centre, une déesse Mout - épouse d'Amon — aux quatre ailes déployées et coiffée de la dépouille de vautour, surmontée de la couronne de Haute et Basse Egypte, marque l'articulation du bracelet. 

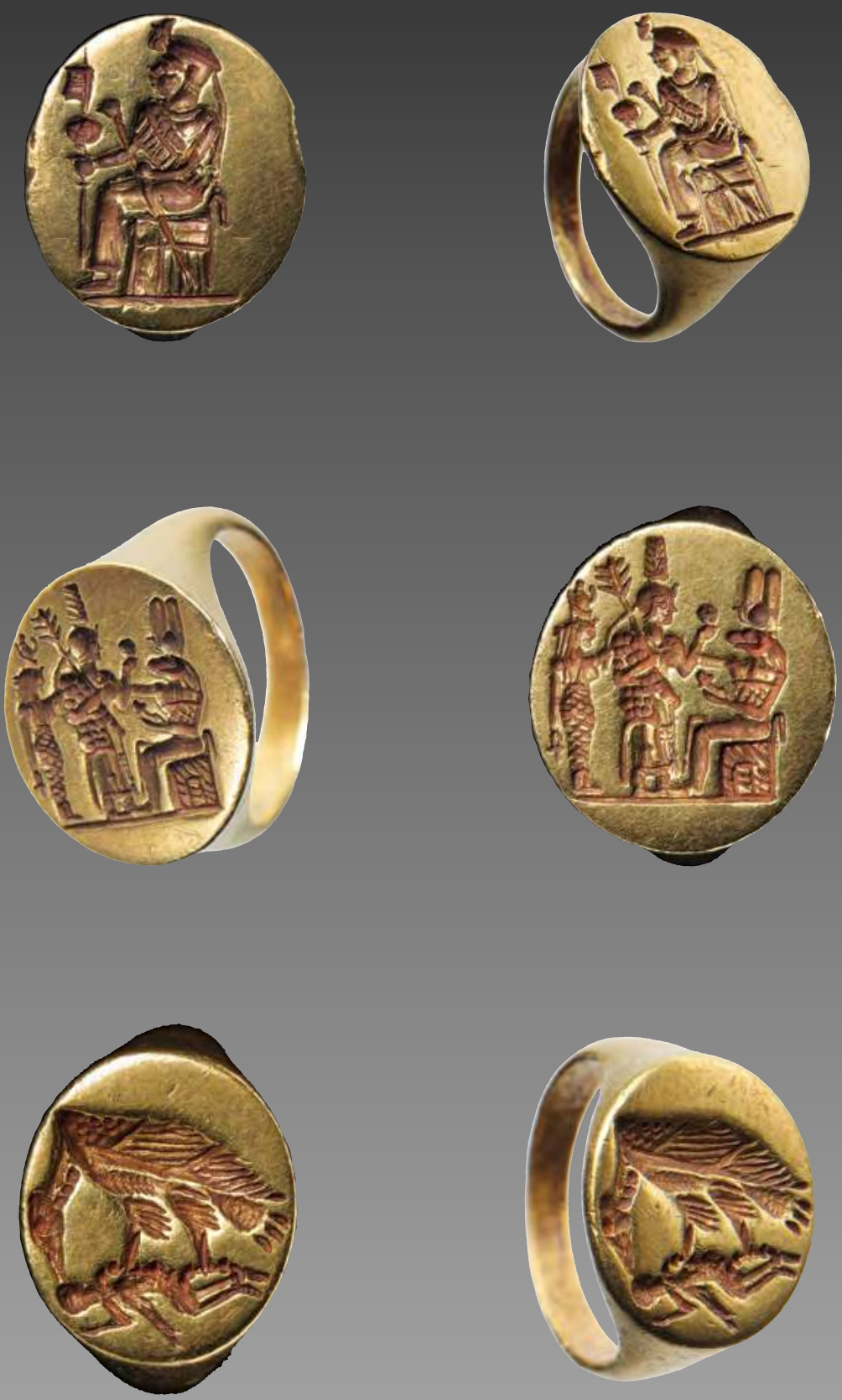

Bagues cachets à intaille, or, hauteur de 1,75 à 5 cm, Berlin, ÄMP 1696, 1723 et 1720 .

Plus de cinquante bagues cachets ont été trouvées dans la chambre funéraire d'Amanishakhéto, dont trois paires représentant la naissance divine, l'élection et de couronnement de la reine. Sur ces bagues, on distingue également les représentations d'Amon du Gébel Barkal, d'Amon de Méroé et d'Amon de Kawa. En général, Isis est coiffée d'une couronne hathorique et tient une palme: c'est donc l'Isis de Méroé — associée ici à Amon, ce qui est sans parallèle en Égypte. 
Sur le côté sud (le côté "masculin », celui du souverain), elle arbore la grande couronne hemhem, conjuguée avec la double plume et le disque solaire du dieu Amon-Rê, un diadème à deux cobras royaux, une corne de bélier autour de l'oreille et elle tient un grand arc. Mais, dans les deux cas, elle pousse devant elle une cohorte d'ennemis entravés d'une corde dont elle tient fermement l'extrémité, tout en dardant sur eux une longue pique acérée. Tout aussi spectaculaire est son apparence physique: elle est représentée comme une femme obèse, avec un double menton, trois plis de graisse sur le cou, des bras pleins et un fessier incroyablement proéminent. Ses longs ongles acérés rappellent à dessein les griffes d'une lionne. Ajoutée au récit de Strabon qui peignait Amanirénas comme une «femme hommasse qui avait perdu un œil» et qui dirigeait elle-même ses armées, cette représentation d'Amanishakhéto a beaucoup contribué dans les ouvrages de vulgarisation au mythe de la Candace comme guerrière barbare.

La pyramide de la reine fut bâtie sur un emplacement où s'élevait deux siècles plus tôt une autre pyramide royale (Beg. N. 53) désormais sans doute écroulée et qui avait probablement appartenu à Arnékhamani. Celle d'Amanishakhéto était autrefois la mieux conservée des monuments de Begrawwiya Nord. Elle culminait à plus de $28 \mathrm{~m}$ de hauteur et dominait la nécropole. Il ne nous reste malheureusement, pour témoigner de la splendeur de cet édifice, qu'une gravure de l'ouvrage de Frédéric Cailliaud qui la visita en avril 1821 et publia son Voyage à Méroé cinq ans plus tard. En 1830, un aventurier italien de Bologne, Giuseppe Ferlini, qui avait été engagé comme médecin militaire au service du khédive d'Égypte et était basé à Khartoum, entreprit dans la nécropole royale, avec quelques ouvriers, des "fouilles archéologiques" comme on l'entendait à l'époque, c'est-à-dire une chasse au trésor. Après avoir fait démolir pierre par pierre deux petites pyramides tardives et n'y avoir rien trouvé de monnayable, il s'attaqua à la plus haute, celle d'Amanishakhéto, qu'il fit presque entièrement détruire. Il prétend dans un opuscule publié plus tard avoir trouvé un bol de bronze rempli de bijoux dans le bâti de la pyramide, mais il semble qu'il ait ainsi voulu ou égarer les pistes d'autres chercheurs de trésor, ou se dédouaner de la destruction du monument. C'est très probablement de la chambre funéraire que proviennent les fameux bijoux de la reine que Ferlini arriva à vendre en deux lots aux rois Louis ${ }^{\text {er }}$ de Bavière en 1839 et Frédéric-Guillaume II de Prusse en 1844. Du fait de cette séparation, ils sont conservés les uns au musée Égyptien de Berlin, les autres au musée d'Art égyptien de Münich.

Le trésor était d'après le catalogue original composé de 10 bracelets, 66 bagues et anneaux, 6 colliers, une chaîne, 54 amulettes, 4 clochettes, 26 perles, 2 camées et 4 intailles, la plupart en or, argent, pierres 
fines et pâte de verre. L'une des difficultés que rencontra Ferlini pour vendre son butin tenait à l'aspect composite des bijoux qui mêlaient la tradition égyptienne, d'importantes influences hellénistiques (notamment les camées et intailles) et quelques caractéristiques locales. Un des meilleurs exemples de cet improbable mélange est un anneau-écusson en or et pâte de verre, destiné à être fixé sur la coiffure royale. À l'anneau de fixation est suspendue une égide figurant un large collier, surmontée de deux yeux oudjat (l'œil d'Horus considéré comme une protection magique) avec au centre le buste du dieu Shébo, certes coiffé de la double couronne égyptienne mais avec un visage souriant modelé selon les canons grecs. Sur le bord inférieur du collier sont accrochés dix cauris d'or qui évoquent les traditions africaines. À lui seul, ce petit bijou de 3,7 cm de largeur est un concentré d'art méroïtique, mêlant les trois cultures égyptienne, méditerranéenne et soudanaise.

La succession d'Amanishakhéto reste obscure. Sur les reliefs des murs sud et nord de sa chapelle funéraire, la Candace trône en majesté, entourée de personnages non identifiés qui portent des palmes. Derrière elle est assis un prince qui porte la main sur sa couronne en un geste de légitimation, une scène que nous avons déjà décrite dans la chapelle de la reine Nahirqo, plus d'un siècle et demi auparavant. Devant elle figurent trois personnes: un homme de haute taille, un prince très semblable à celui qui est assis derrière elle et une princesse. Sur le mur sud, le prince procède à l'encensement de la souveraine. Aucune des inscriptions, originellement peintes sur des panneaux stuqués disposés au-dessus des personnages, n'est malheureusement conservée. On peut supposer que le prince héritier, son épouse et deux autres princes, dont éventuellement le $p q r$ qui a peut-être succédé à Akinidad, sont représentés. On devrait donc penser qu'un roi, peut-être le plus grand des trois hommes, a remplacé la Candace sur le trône. Mais aucun nom ne nous est parvenu.

\section{L'énigme de la reine Shanakdakhété}

La situation est d'autant plus complexe que c'est probablement à cette époque qu'il faut replacer la reine Shanakdakhété à qui on a longtemps attribué la pyramide Beg. N.11 de Méroé, construite vers 170 av. J.-C., et que nous avons précédemment rendue à la reine Nahirqo. Parmi les édifices cultuels du site de Naga figure un petit temple rectangulaire d'une douzaine de mètres de longueur, bâti en hauteur sur le flanc du Gébel Naga. Très ruiné, il comporte sur ses murs intérieurs des gravures difficilement reconnaissables, couvertes de millénaires de graffiti divers. Il faut dire qu'étrangement les scènes sont sommairement gravées en relief incisé, alors que la tradition égyptienne, généralement respectée dans le royaume 
le Soudan

\section{2}

des origines

à la chute

du sultanat

Fung napato-méroïtique, réserve ce type de relief aux décors extérieurs, tandis que les décors intérieurs sont exécutés en bas-relief. Les murs extérieurs, dont l'enduit est partiellement conservé, ne comportent aucune figuration gravée. On peut donc se demander si ce petit bâtiment a jamais été terminé. Il s'agit probablement, comme le temple du Lion de Musawwarat, d'un sanctuaire consacré à Apédémak et à Amon. Les scènes du mur sud-ouest, les mieux conservées, représentent une Candace et un prince debout devant Apédémak, assis sur un trône figurant un éléphant (rappel des reliefs de Musawwarat) et suivi de la déesse Amésémi, sa compagne. Le même couple royal honore plus loin la triade koushite, Amon à tête de bélier devant Mout et Khonsou. D'un côté de l'entrée on distingue la Candace assise sur un trône et, de l'autre, le prince debout. Cette double figure de la royauté, reine et prince, a été comparée par les archéologues aux reliefs de la chapelle de la reine inhumée en Beg. N.11 à Méroé, et la pyramide a été dès lors attribuée à la Candace du temple F, Shanakdakhété, alors même que plusieurs autres Candaces sont représentées en compagnie d'un prince.

Au fond du temple, une niche est flanquée de deux inscriptions symétriques, aujourd'hui presque totalement détruites, mais relevées par Fritz Hintze en 1958. Elles sont en hiéroglyphes égyptiens, à l'exception du cartouche de la reine Shanakdakhété qui est inscrit en hiéroglyphes méroïtiques. Le cartouche est unique, ne contenant que le nom de naissance, ce qui s'accorde aux usages du règne de la reine Amanishakhéto. De plus, comme nous l'avons signalé lors de notre passage sur la reine Nahirqo, les graphies des signes ne correspondent pas aux plus anciens hiéroglyphes méroïtiques connus, sous le règne de Tanéyidamani, mais à celles du $\mathrm{I}^{\mathrm{er}}$ siècle de notre ère. Qui plus est, certains hiéroglyphes égyptiens du texte adoptent la forme des hiéroglyphes méroïtiques de cette période. Un indice, certes infime, relie ces deux inscriptions à Amanishakhéto et à la Candace suivante, Nawidémak: la reine y est dite en égyptien "douée de vie", suivant la formule habituelle. Mais au lieu que l'expression soit suivie de la mention la plus courante: «comme Rê pour toujours», on lit une variante rare $m r^{\prime} n b$, "chaque jour». Contrairement aux règles de l'écriture égyptienne, le signe du disque solaire $\left(r^{\circ}\right)$ ne remplit pas l'espace disponible, laissant le cadrat à moitié vide. Il est constitué d'un cercle minuscule placé derrière la tête de la chouette (l'hiéroglyphe $m$ ) qui précède. Or, dans plusieurs exemples du cartouche d'Amanishakhéto et dans le seul que nous possédons pour la reine Nawidémak, c'est ainsi qu'est écrite la lettre méroïtique " $m$ » : une chouette flanquée d'un petit cercle qui n'a pas de fonction phonétique. Cette graphie particulière ne se retrouve ni avant ni après ces deux règnes. 
Une première hypothèse consiste donc à voir en Shanakdakhété une Candace ayant régné entre Amanishakhéto et Nawidémak. Dans ce cas, elle aurait pu avoir été inhumée sous la pyramide royale ${ }^{\circ} 10$ de Barkal, construite pour une reine inconnue et datant de cette époque. Une autre solution, qui nous semble plus simple, serait que Shanakdakhété ne soit qu'un autre nom d'Amanishakhéto. Shanakadakhété signifie "Shanaka l'a enfantée», Shanaka étant le nom local de la déesse Mout, tandis que "Amanishakhéto" (variante Amanishakhété) se traduit probablement "Amon l'a conçue». Mout et Amon étant époux, les deux noms peuvent être interprétés comme les deux aspects d'une même filiation, ainsi que dans le nom du roi napatéen Senkamanisken, transcription égyptienne d'un composé méroïtique signifiant "Shanaka et Amon l'ont (?) conçu». Cette hypothèse aurait l'avantage d'expliquer que quatre stèles au nom d'Amanishakhéto aient été retrouvées dans le temple d'Amon de Naga, alors que l'on n'a pas trace par ailleurs de constructions diligentées par cette reine sur ce site. Les stèles ont pu être transportées sous le règne d'Amanitoré et Natakamani du temple F dans le temple d'Amon qui venait d'être construit. On comprendrait mieux également qu'elles représentent toutes les quatre la Candace en compagnie de la déesse Amésémi, épouse d'Apédémak, deux divinités auxquelles le temple $\mathrm{F}$ a été en partie consacré, alors qu'elles sont quasiment absentes du temple d'Amon.

\section{La reine Nawidémak et les tribulations de sa statue d'or}

Le souverain attesté de manière assurée après Amanishakhéto est à nouveau une Candace, la reine Nawidémak. Selon notre théorie du rôle de la Candace, il faut supposer que s'est intercalé entre elles un roi — voire deux si Shanakdakhété est distincte d'Amanishakhéto —, mais nous n'en avons aucune trace écrite. La position chronologique de Nawidémak dans la première moitié $\mathrm{du} \mathrm{I}^{\mathrm{er}}$ siècle de notre ère est inférée d'une part par la localisation de sa sépulture à Barkal Nord (Bar.6) et l'architecture de sa pyramide et de son hypogée, d'autre part par les graphies des signes dans les inscriptions qui portent son nom et qui la situent clairement entre les règnes d'Amanishakhéto et d'Amanitoré. Son nom comprend le mot $m k$, «dieu» ou «déesse», en dernière position, là où d'autres comportent le nom d'Amon (Tanéyid-amani, Téqoride-amani), mais il ne peut actuellement être traduit avec assurance. Sa pyramide est l'une des plus larges de Barkal et la seule que l'on puisse attribuer à un règne précis grâce aux textes de sa chapelle. Les reliefs des murs nord et sud, stuqués et peints, avaient lors de la visite de l'expédition prussienne en 1844 conservé leurs couleurs. Ils sont malheureusement totalement détruits aujourd'hui, et les planches des Denkmäler 
de Lepsius en sont l'unique témoignage qui nous soit parvenu. La reine y apparaît seule sur son trône, contrairement aux Candaces qui l'ont précédée et qui sont toujours accompagnées d'un prince anonyme assis sur un second siège. Elle est protégée par Isis, qui étend sur elle ses ailes, et encensée à l'aide d'un long brûle-parfum tendu sous ses narines par un prince. Un texte en cursive méroïtique décrit ce dernier comme «Etareteya, le frère du prince suprême (pqr-tr)». Le nom de la reine apparaissait au-dessus de sa représentation sur le mur nord dans un cartouche abîmé se lisant $N[\ldots] d m k$. Aussi fut-il longtemps restitué sous une forme erronée, "Naldamak», jusqu’à ce que les philologues Hintze puis Macadam rétablissent la bonne lecture, "Nawidémak», à l'aide d'autres documents.

L'un de ces documents a connu une étonnante destinée depuis sa découverte fortuite en 1948 au Gébel Barkal. Il s'agissait d'une statuette de la reine Nawidémak, originellement d'une vingtaine de centimètres, qui pour son malheur avait été réalisée dans un matériau qui excite les pires convoitises, l'or. L'œuvre représentait la reine debout sur un socle gravé d'une inscription en cursive, vêtue du costume royal tripartite et tenant deux objets disparus. Il est assez probable qu'elle appartenait au trousseau funéraire de la sépulture de la reine, située non loin du là, qu'elle avait été enfouie dans le sable par un pilleur de tombes antique, peut-être dérangé dans sa coupable besogne, et qu'elle n'avait jamais été récupérée. Elle fut découverte par une petite fille du hameau de Barkal, Amina Babiker, qui faisait brouter ses chèvres près du temple. Rapportée au village, la statuette fut démembrée: le socle en fut détaché, les deux jambes furent désolidarisées en dessous du genou et peut-être également la tête, jamais retrouvée. Ce trésor devint l'enjeu de rivalités entre

des origines

à la chute

du sultanat

Fung familles et l'affaire finit par être rapportée à la police. Les autorités punirent les auteurs des dégâts d'une amende, payée si rapidement que l'on soupçonna que la jambe droite, disparue, avait servi à acquérir la somme exigée. Le service des Antiquités, alors dirigé par le Britannique P.L.Shinnie, rétribua la petite fille au poids de l'or sur le marché local. La statuette, ou plutôt ce qui en restait, entra dans les collections du musée de Khartoum.

Shinnie écrivit un court article sur cette découverte dans Kush, la revue des Antiquités soudanaises. Faute d'inscription, le socle ayant disparu, il attribua hypothétiquement la statuette à la reine Amanitoré, ce qui est tout à son honneur car elle ne régna que quelques années plus tard. Tout aurait pu en rester là si l'affaire n'avait pas connu un autre rebondissement. En 1961, un riche Américain, amateur de pièces de joailleries anciennes, Melvin Gutman, prêta sa collection pour une exposition à l'Allen Memorial Art Museum, à Oberlin (Ohio). Un catalogue fut rédigé pour l'occasion par Ch. Parkhurst, directeur du musée. La pièce $\mathrm{n}^{\circ} 164$ attira l'attention d'un des conservateurs: il s'agissait d'une fine 


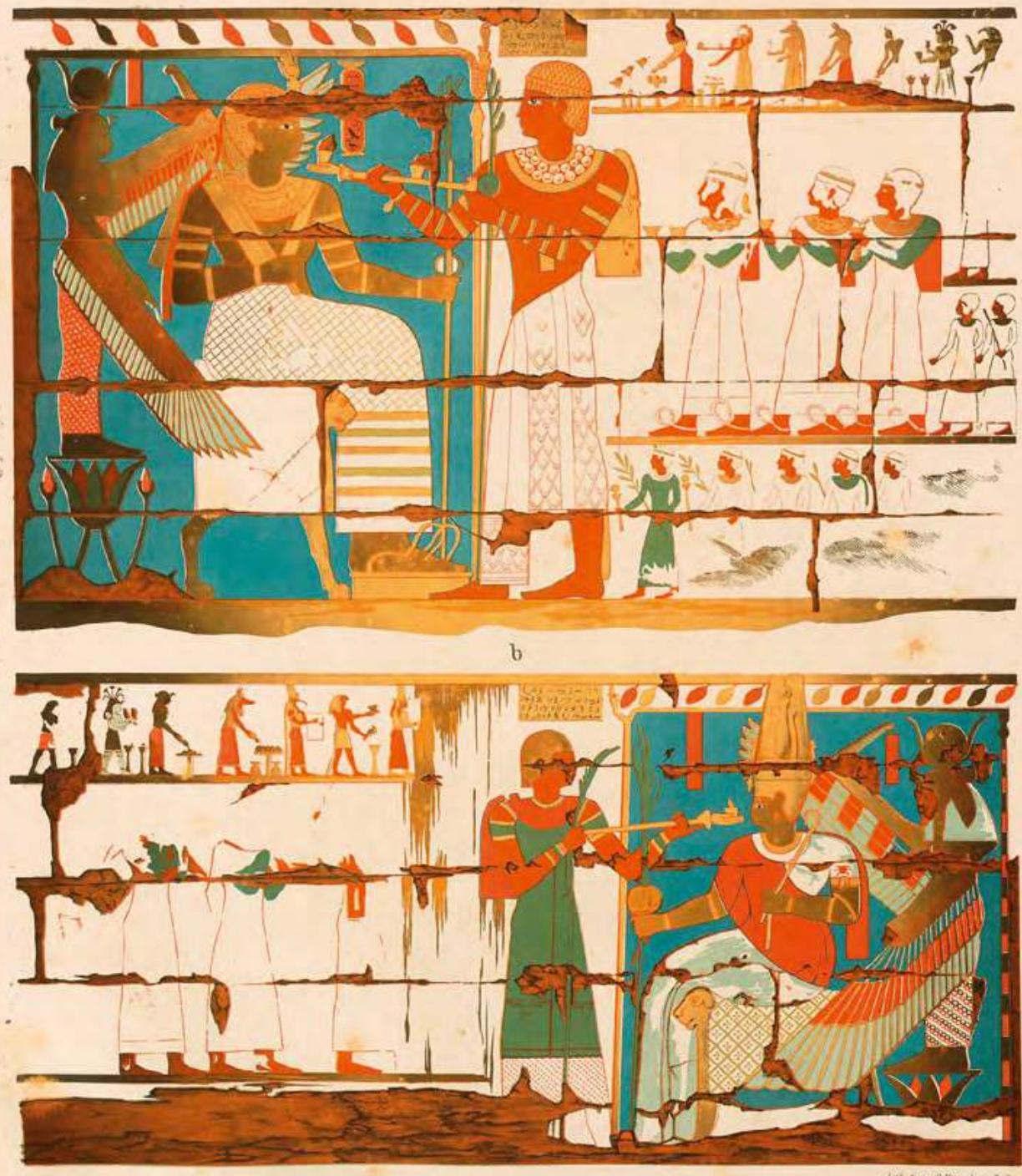

Barkal. Nördliche Pyramidengruppe. Pyr: 15. a. Nordwand. b. Westwand.

La reine Nawidémak, chapelle de la pyramide Barkal 6,

d'après Carl Richard Lepsius, Denkmäler aus Aegypten und Aethiopien, vol. V, pl. 19. 


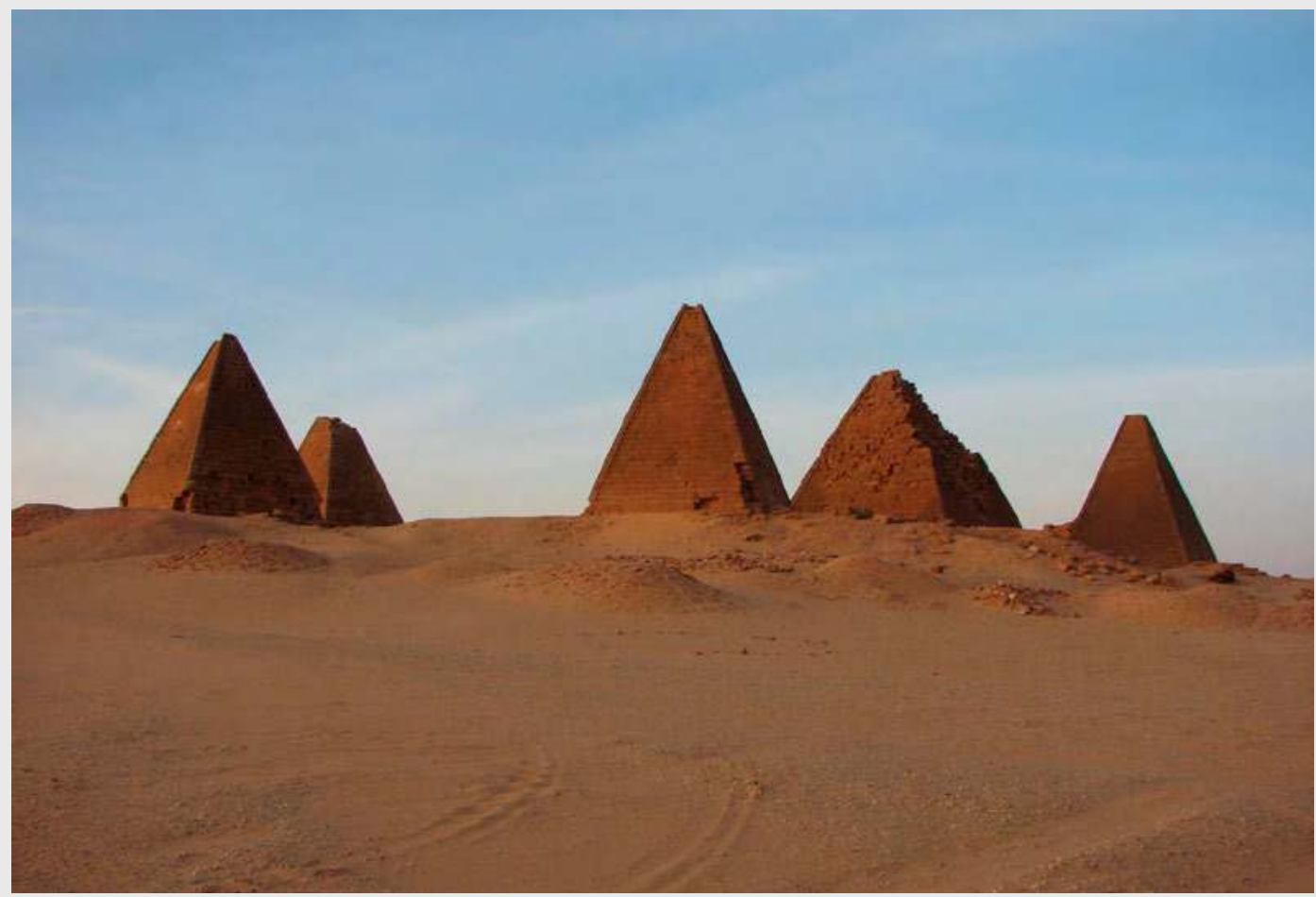

le Soudan

Gébel Barkal, pyramides du groupe nord.

266

des origines à la chute du sultanat Fung

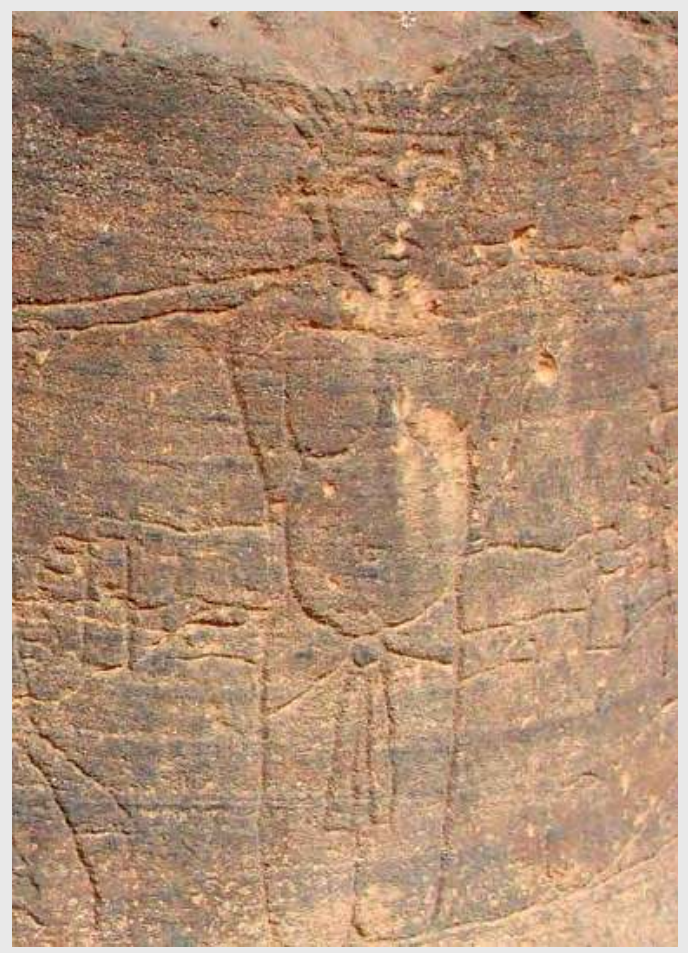

Gébel Barkal, piédestal méroïtique.

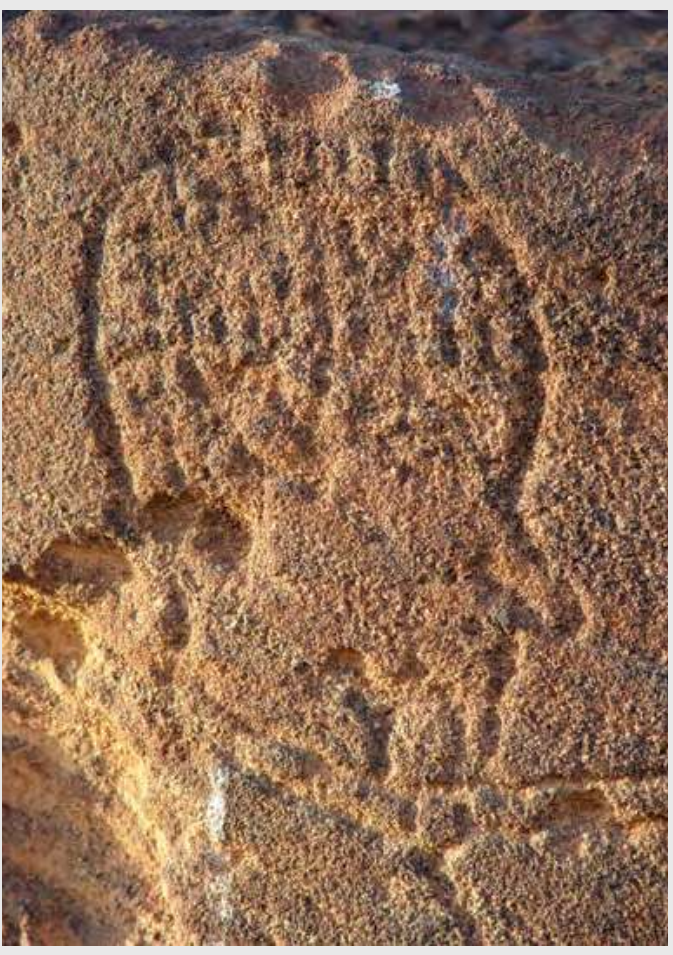

Gébel Barkal, piédestal méroïtique, prisonnier libyen [?]. 
plaquette en or, gravée de signes méroïtiques, de 5,7 × 3,2 cm. L’objet fut signalé à M. F. Laming Macadam, un des meilleurs spécialistes américains du Soudan. Des traces d'arrachement en deux endroits montraient que cette plaquette était à l'origine le socle d'une statue dont on l'avait détachée. Macadam comprit immédiatement qu'il s'agissait de la statuette trouvée à Barkal. Il publia un long article intitulé Queen Nawidemak dans le bulletin du musée. L'inscription, en grande partie toujours intraduisible, est une prière à Amon de Napata, appelé à favoriser de ses dons la reine Nawidémak. Elle est désignée par le titre de qore, "souverain », et non "Candace», ce qui laisse supposer qu'elle régnait seule.

Comment le socle de la statuette, sans aucun doute vendu par les villageois, avait-il fait son chemin jusqu'à la collection de Melvin Gutman? L'amateur new-yorkais l'avait acquis d'un autre collectionneur bien plus fameux, Robert Garrett. Fils d'une riche famille du Maryland, né en 1875 et décédé en 1961, Robert Garrett gagna la célébrité en remportant les médailles d'or du lancer du disque et du poids aux premiers Jeux Olympiques modernes de 1896, et accessoirement deux médailles d'argent en saut en hauteur et en longueur. Ayant repris la banque familiale, il consacra une grande partie de sa fortune à collectionner des œuvres d'art, particulièrement des manuscrits anciens, et à parrainer des fouilles archéologiques. Mais comment avait-il acquis le socle d'or? On l'ignore. Après la mort, en 1967, de Melvin Gutman, sa collection fut mise en vente chez Sotheby's à New York en octobre 1969. L'acquéreur du socle est inconnu et on perd alors la trace de l'objet qui a sans doute poursuivi son incroyable odyssée à travers le monde. La statue, quant à elle, fut volée à Khartoum dans les années 1990 et ne fut jamais retrouvée. Depuis lors, tous les objets d'or sont gardés sous coffre au musée national du Soudan.

\section{Amanakhabalé et les hafirs du Kéraba}

Bien qu'aucun prince clairement désigné comme son héritier n'apparaisse à ses côtés dans les reliefs de sa tombe, Nawidémak avait un fils qui lui succéda. Plusieurs fragments jointifs de deux tables d'offrandes royales, retrouvés à Méroé et provenant de la pyramide Beg. N.2, conservent, sur l'une, en cursive méroïtique, la mention d'un souverain (qore) "enfanté par Nawidémak», sur l'autre, en méroïtique hiéroglyphique, le nom de ce roi bien connu, Amanakhabalé. À l'exception d'un cône de bronze portant ses cartouches retrouvé à Kawa, tous les témoignages de son règne sont attestés dans la région de Méroé où il fut d'ailleurs inhumé, contrairement à sa mère qui reposait à Barkal près de Napata. Nous n'avons pour l'heure aucune explication certaine de ces alternances entre Méroé et Barkal comme lieu de sépulture 
le Soudan

\section{8}

des origines

à la chute

du sultanat

Fung des souverains. Elles ne résultent pas de changements dynastiques, ainsi que le montre le cas de Nawidémak et d'Amanakhabalé. On suppose qu'au sein de la famille royale existaient depuis le début du $\mathrm{II}^{\mathrm{e}}$ siècle av. J.-C. deux lignées, l'une originaire de Méroé, l'autre de Napata. Ce pourrait être la raison de ces changements de lieu d'inhumation, les souverains reposant au plus près de leurs ancêtres soit à Napata, soit à Méroé. Mais comme on ignore la généalogie précise des souverains (et parfois même leurs noms) durant cette période, il est impossible de vérifier cette théorie.

Amanakhabalé (et non Amanikhabalé, comme on le trouve souvent transcrit à tort) est le premier d'une petite série de souverains et de princes à porter un nom où apparaît une mystérieuse hypostase d'Amon, Amanakh (écrit Amnxe ou Mnxe). Le dieu Amon, en méroïtique Amani (Amni ou Mni), est adoré sous un grand nombre de formes locales dans le royaume de Méroé: Amon de Napata (Amnpte), Amon de Karnak (Amnp, confondu avec le précédent), Amon de Thèbes (Amnote ou Amni Note), Amon de Pnoubs (Amnbse), Amon de Méroé (Amni Bedewite), etc. On ignore en revanche quelle est l'origine d'Amanakh, qui n'est pour l'heure attesté que dans ces quelques noms royaux ou princiers.

Deux inscriptions, l'une sur le cône de bronze de Kawa, l'autre sur un lion de grès de Basa, présentent le nom de ce roi dans un double cartouche. Évidemment, on songe immédiatement à un double nom, celui reçu à la naissance et celui pris au couronnement, comme on en a maints exemples à l'époque napatéenne et au début du royaume de Méroé. Mais le second cartouche n'est pas en égyptien et varie d'une inscription à l'autre. Sur le cône, on y lit wtemroso, une paraphrase méroïtique de l'épithète habituelle des pharaons, "doué de vie». La même formule avait déjà utilisé par Tanéyidamani dans le second cartouche de sa grande stèle du Gébel Barkal. Le premier cartouche du cône de Kawa comprend le titre méroïtique qor, "le souverain», au-dessus du nom du roi. Sur le lion de Basa, on lit dans le premier cartouche le nom du roi, dans le second le titre égyptien «roi de Haute et Basse-Égypte», suivi du groupe qor et de trois signes de vie égyptiens. Il ne s'agit donc pas d'un nom de couronnement mais de titres et d'épithètes qui remplissent artificiellement un second cartouche hérité des usages anciens mais dont la fonction est oubliée ou considérée comme caduque. Il faudra attendre les règnes suivants pour retrouver de véritables noms de couronnement égyptiens.

Amanakhabalé a peut-être effectué des travaux dans un des temples de Kawa, comme semble l'indiquer le cône de bronze à son nom qui paraît avoir originellement coiffé un mât à oriflamme devant le premier pylône. Mais c'est surtout dans le Kéraba, la partie occidentale de la région du Boutana, que se concentrent les vestiges connus de son activité. 
À Naga, tout d'abord, un fragment de récipient en pierre à son nom a été trouvé en 1958 par un gardien. Il proviendrait, sans certitude, du temple d'Amon, où il pourrait avoir été déplacé en même temps que les stèles d'Amanishakhéto. Il indique en tout cas la continuité du culte à Naga sous le règne d'Amanakhabalé. Entre Naga et Méroé, le site de Basa abritait un temple et un palais, aujourd'hui réduit à des tertres qui n'ont jamais été fouillés. Un grand hafir («réservoir» en arabe local) permettait, comme à Musawwarat, de fournir en eau le complexe cultuel. De nombreuses sculptures en grès en ornaient les bords, notamment deux statues de grenouilles et cinq de lions assis. Elles ont été transportées au musée de Khartoum à la fin des années 1960, ainsi que d'autres provenant de l'entrée du palais. Les lions forment désormais une allée monumentale qui mène à la salle d'exposition, et les grenouilles ont été placées aux deux extrémités du bassin creusé dans les jardins. Les batraciens (en fait une espèce de crapaud) sont les représentations de la divinité égyptienne Héqet, déesse de l'eau et de la fécondité. Les lions sont évidemment associés à Apédémak, dieu-créateur mais aussi guerrier divin: l'un des fauves tient d'ailleurs entre ses mâchoires un ennemi vaincu qu'il s'apprête à dévorer. Sur un autre sont gravés les cartouches du roi Amanakhabalé, signant la fondation ou la rénovation du complexe de Basa. Enfin, au sud-est de Basa, à Umm Usuda, se trouve un autre réservoir bordé de statues de lions et de béliers. Une grande stèle brisée comporte un texte en cursive méroïtique, originellement gravé sur les quatre faces. Le nom du souverain qui la fit ériger est perdu, mais les graphies des signes correspondent exactement à celles, très caractéristiques, du règne d'Amanakhabalé. On peut penser qu'Umm Usuda, avec Basa et d'autres sites qui restent à découvrir, faisait partie d'une ceinture de complexes cultuels et de relais pour la population nomade bâtis par ce souverain dans le Kéraba.

Le monument le plus connu d'Amanakhabalé est une petite stèle en stéatite, une pierre à la fois compacte et facile à tailler, ce qui a permis à l'artiste une profusion de détails difficiles à exécuter sur du grès. Elle mesurait originellement plus de $50 \mathrm{~cm}$ de hauteur. Découverte dans le temple d'Amon de Méroé durant les fouilles réalisées par John Garstang en 1911, elle était brisée en deux morceaux non jointifs. La partie supérieure est actuellement conservée à Khartoum; la partie inférieure, dite «stèle Touraïeff ", est au musée de l'Ermitage à Saint-Pétersbourg. Cette dernière avait été achetée pour la collection archéologique impériale, Garstang ayant financé en partie ses fouilles par la vente des objets découverts. Le cintre représente deux scènes symétriques : à gauche, Amanakhabalé devant Mout et, à droite, devant l'Amon-Rê koushite à tête de bélier. Le roi, vêtu d'une tunique brodée à l'effigie d'un faucon et coiffé comme Amon de deux hautes plumes autour d'un disque solaire, posées sur la calotte koushite, 
offre des colliers aux deux divinités. L'ensemble rappelle fortement l'iconographie des stèles napatéennes, mais plusieurs détails montrent l'influence de l'Égypte romaine, notamment le trône du dieu, orné d'un sphinx assis de style grec. Le texte, malheureusement en partie perdu, est gravé avec grand soin et figure parmi les rares inscriptions méroïtiques à présenter d'indéniables qualités calligraphiques. Il commence non par la nomination du souverain mais par celle de son épouse: "C'est l'épouse, c'est Kaditede [...] le roi [Amakha]balé.» Bien que seules les deux dernières syllabes du nom royal soient conservées, il n'y a pas de doute sur son identité. Le reste du texte, sur la "stèle Touraïeff», est une sorte de litanie comprenant de courtes prières identiques adressées à différentes divinités, notamment Aritene, hypostase d'Amon-Rê (sans doute Rê-Harakhty) et Mout. Néanmoins, une traduction est actuellement impossible. La mention d'un «enfant» (tdxe, littéralement «enfanté») dans le texte, la position de l'épouse royale en tête de l'inscription et peut-être le ventre gonflé de la déesse Mout laissent supposer que la stèle contient des prières pour la santé d'un héritier à venir.

Si tel est bien son contenu, les suppliques de la stèle Touraïeff furent exaucées. Les reliefs très érodés de la chapelle de la pyramide Beg. N.2, sous laquelle fut inhumé le roi, le représentent assis en costume royal tripartite, face à non moins de quatre princes reconnaissables à leur collier à grosses boules. L'un, le plus grand, procède à l'encensement, suivi par trois autres de petite taille, tandis qu'un cinquième, minuscule, est debout aux côtés du monarque. Le roi est protégé par Isis, juchée sur un lotus comme dans les reliefs de la

des origines

à la chute

du sultanat

Fung chapelle de Nawidémak et ceux de Beg. N.10. Derrière lui se trouvent deux femmes aux formes opulentes sur deux registres superposés. Comme le règne suivant est celui, conjoint, de la Candace Amanitoré et du roi Natakamani, il est tentant de voir en l'une des femmes la future reine-mère, dans le prince thuriféraire le futur roi Natakamani et dans les trois petits personnages qui le suivent les trois princes royaux (pqr qorise) qui ont successivement complété le trio royal dans l'iconographie du règne à venir.

\section{Le couple royal Amanitoré et Natakamani, mère et fils}

Avec l'avènement d'Amanitoré et Natakamani s'ouvre une ère d'extraordinaire prospérité dans le royaume de Méroé. Aucun souverain depuis le règne de Taharqo, sept siècles plus tôt, n'avait à ce point couvert le territoire koushite de temples et de palais. Eu égard à la profusion de réalisations architecturales, on peut penser que leur règne fut aussi de longue durée. De nombreux auteurs, jusqu'à récemment, l'ont situé des deux côtés du début de notre ère ou dans les premières années du I ${ }^{\text {er }}$ siècle apr. J.-C. 
Inge Hofmann, une des meilleures spécialistes de la chronologie méroïtique, l'a replacé dans la seconde moitié du $\mathrm{I}^{\mathrm{er}}$ siècle de notre ère dans un ouvrage paru en 1978. Ses arguments, fondés sur la situation des monuments funéraires d'Amanitoré et de Natakamani, ainsi que sur les importations méditerranéennes dont les dates peuvent être précisées, ont convaincu la plupart des historiens actuels de Méroé. L'étude de la paléographie, c'està-dire l'évolution des tracés des signes dans l'écriture méroïtique, nous permet également de placer les deux corégents plusieurs décennies après le règne d'Amanirénas, la Candace qui affronta les armées de Pétronius en 25-24 av. J.-C., dont les séparent au moins trois souverains connus par des inscriptions (Amanishakhéto, Nawidémak et Amanakhabalé), et sans doute deux de plus dont nous ignorons les noms. On peut donc situer avec une certaine confiance le règne d'Amanitoré et de Natakamani approximativement entre 50 et 80 de notre ère.

Un autre argument en faveur de cette chronologie a été avancé sur la base du récit par différents auteurs latins et grecs d'un épisode remarquable du règne de l'empereur Néron. Vers 62-63 apr. J.-C., il envoya une petite expédition, dirigée par deux centurions, le long du Nil afin d'en chercher les sources. Le problème des sources de ce fleuve a été une des grandes questions scientifiques de l'Antiquité, qui a passionné des générations d'écrivains grecs depuis Hérodote et ne fut résolue que dans les années 1860. Le but de cette expédition était très certainement dénué d'ambitions militaires contre Méroé, contrairement à ce que rapporte, cent cinquante ans plus tard, l'écrivain grec Dion Cassius. Si Pline l'Ancien parle des centurions comme des exploratores, c'est-à-dire de manière ambiguë "des explorateurs" ou "des éclaireurs", selon Sénèque, qui était un des intimes de l'empereur jusqu'à sa disgrâce et son suicide en 65 , Néron les avait bien envoyés "pour rechercher les sources du Nil» (ad investigendum caput Nili). Le fait que les explorateurs romains se soit aventurés de manière certaine bien au-delà du royaume de Méroé, au péril de leurs vies, prouve également que l'État koushite n'était pas visé en priorité. Voici le récit que fait Sénèque, dans ses Questions naturelles, à l'occasion d'un développement sur l'existence d'un grand lac au centre du continent africain:

《U'ai entendu moi-même les deux centurions que César Néron, épris de vérité au-dessus de toutes les autres vertus, avait envoyés pour rechercher les sources du Nil. Ils racontèrent qu'ils avaient accompli un long voyage et que, aidés par le roi d'Éthiopie et recommandés par lui auprès des souverains voisins, ils étaient arrivés dans les régions les plus reculées. "Enfin nous sommes parvenus, dirent-ils, à d'immenses marécages, auxquels les indigènes ne connaissaient aucune issue et dont personne n'aurait pu espérer sortir. La végétation et les eaux sont à ce point mêlées que l'on ne peut 
se frayer un chemin à travers cette eau, ni à pied, ni en bateau, parce que seule une petite embarcation pour une personne unique peut flotter sur ce marécage boueux et encombré. Là, dirent-ils, nous avons vu deux rocs, dont les flots s'échappaient avec une force immense."

Il n'y a pas de doute, d'après la description précise des centurions, qu'ils étaient parvenus à cette gigantesque étendue marécageuse en amont de Malakal, saturée de plantes aquatiques, que l'on appelle aujourd'hui le Sudd («barrage» en arabe) et qui obligea les explorateurs anglais en quête des sources du Nil au XIX ${ }^{\mathrm{e}}$ siècle à passer par l'Afrique de l'Est. En revanche, les deux rochers d'où sortait le fleuve sont, sinon une invention, du moins une reprise du mythe rapporté par Hérodote, selon lequel sa source se trouvait entre deux rochers nommés Crophi et Mophi. Par ce petit mensonge ajouté à d'indéniables réalités, les centurions dissimulaient l'échec de leur mission.

L'expédition est aussi décrite par le géographe Pline l'Ancien, contemporain des faits. Il ne parle pas du Sudd mais fournit quelques détails sur les distances, la végétation, la faune et les habitants. Méroé y est décrite comme une petite ville avec peu de bâtiments mais un temple d'Amon, ce qui laisse supposer que les Romains furent peut-être reçus par prudence dans une localité périphérique comme el-Hassa/Damboya ou Mouweis, de préférence à la cité royale. Mais, surtout, Pline rapporte que le souverain qui les accueillit était une reine, Candace, «dont le nom était transmis de reine en reine depuis de nombreuses années». Ce désaccord entre Sénèque et Pline, pourtant tous deux contemporains de l'expédition et tous deux des origines à la chute du sultanat Fung bien informés, a été expliqué par l'existence d'une corégence à Méroé. Or, le règne conjoint d'Amanitoré et Natakamani en offre le meilleur exemple connu. Il est possible que les centurions aient été reçus par les corégents et que Sénèque, dont le récit est centré autour des sources du Nil, ait négligé de mentionner la reine, tandis que Pline, qui connaissait mieux le royaume de Méroé par les descriptions grecques de Dalion, Aristocréon et Bion de Soles, lui accorde la prééminence.

On a souvent hésité sur le lien de parenté entre Natakamani et Amanitoré, ce qui revient à s'interroger sur la place de la Candace dans la royauté méroïtique. Malgré les sources grecques qui présentent d'une même voix la Candace comme "mère du roi", certains spécialistes les voyaient plutôt époux, d'autres frère et sœur, voire les deux à la manière de Ptolémée II Philadelphe et Arsinoé II. Nos recherches récentes permettent ici de lever le voile sur leur parenté. Les deux souverains sont en effet nommés dans deux graffiti consécutifs en démotique (égyptien tardif) du temple de Dakka, au sud de Philae, qui avaient jusqu'à présent été lus sans examen critique. Deux officiels du Dodécaschène, la région semi-autonome 
de Philae, y ont fait inscrire une sorte d' "attestation d'offrandes» à l'intention d'Isis afin qu'elle donne la vie aux "pharaons " pour services rendus au temple. Le second graffito date l'inscription de l'an 3 «du roi Aqrakamani (J'qrgзmnう) et de la reine Naytal $(N y t l)$, sa mère». Griffith, qui a publié et traduit les deux graffiti d'après la copie d'un original perdu, signale à la fois la mauvaise qualité de la rédaction du scribe égyptien (un certain Harmakhis qui a signé le graffito) et celle du copiste moderne. Aussi, plutôt que d'inclure dans la liste des monarques de Koush, comme nos prédécesseurs, deux noms royaux qui n'apparaissent nulle part ailleurs, nous semble-t-il préférable d'envisager que le deuxième graffito comporte des maladresses, commises soit par le scripteur sur ces noms étrangers, soit par le copiste moderne, soit plus vraisemblablement les deux. Nous nous sommes appuyé sur les avis éclairés des démotisants Michel Chauveau et Damien Agut-Labordère, que nous remercions.

Le segment écrit ou lu üqr-était sans doute à l'origine $n t$, l'aspect général des deux groupes étant assez proche en démotique et quasiment identique si on fait précéder le nom d'un souverain d'une ouverture de cartouche. Dans ce cas, le nom du roi n'est pas Aqrakamani (J'grgumnj) mais Natakamani (Ntg3mnj), pour lequel on connait une autre transcription avec " $g$ » $(N t g-J m n)$. Pour la reine, la correction est plus importante: il faut en effet supposer qu'un " $m$ » initial a été omis par le scribe et que la lettre finale est un " $r$ » et non un " $l$ », la différence entre les deux signes démotiques étant assurée par l'ajout pour « $l$ » d'un petit trait, réduit sur la copie à un point qui n'était sans doute qu'une éraflure dans la pierre. Le nom aurait donc dû être $<M>n y t r$, soit Amanitoré, généralement écrit sans le « $a$ » initial en méroïtique (Mnitore). Ainsi, au prix de quelques corrections mineures, les deux corégents inconnus du texte, qui ne sont mentionnés dans aucun autre document, deviennent le couple de souverains les plus fameux de l'histoire méroïtique. Cette simplification ajoute un fort élément de vraisemblance en faveur de notre thèse.

La date de ces deux graffiti a fait débat. Selon les démotisants qui ont publié le texte, Griffith en 1937 et Burkhardt en 1985, le graffito présente une paléographie qui le place avant la fin du I $^{\text {er }}$ siècle de notre ère (Griffith) ou entre la fin du $\mathrm{I}^{\text {er }}$ et le début du $\mathrm{II}^{\mathrm{e}}$ siècle (Burkhardt). L'historien László Török préfère une date beaucoup plus ancienne, vers 30 av. J.-C., car c'est la dernière période où le Dodécaschène a été sous la juridiction directe des Méroïtes. Mais d'une part, c'est une date pour laquelle nous connaissons déjà deux souverains, Téritéqas et la Candace Amanirénas; d'autre part, il n'est pas besoin que le clergé de Dakka ait été sous domination koushite pour qu'il ait consenti, dûment rétribué, à désigner comme «rois» les souverains méroïtiques et à dater l'inscription 
d'après leur règne. Si l'on rectifie les noms comme nous le suggérons, une fourchette entre 60 et 70 apr. J.-C., correspondant au début du règne conjoint d'Amanitoré et de Natakamani, tombe parfaitement dans l'intervalle suggéré par les démotisants. Outre cet aspect chronologique, les deux graffiti confirment qu'Amanitoré est bien la mère de Natakamani et non sa femme ou sa sœur. Probablement épouse d'Amanakhabalé après Kaditédé, elle serait également la mère des trois princes ( $p q r)$ qui apparaissent successivement dans les reliefs des temples construits sous son règne, Arikankharor, Arakakhataror et Shorkaror. Déjà représentés aux côtés de Natakamani dans les scènes funéraires de la chapelle d'Amanakhabalé, comme nous l'avons suggéré, ils seraient donc les frères de Natakamani et non ses fils. Parmi les noms de cette famille royale, seul celui du roi est compris : il signifie "Amon (est) puissant» et correspond à l'anthroponyme égyptien fréquent Amen-nakht. Les trois princes partagent la même terminaison -(a)ror qui désigne probablement «l'enfant mâle».

\section{Les temples d'Amanitoré et Natakamani}

le Soudan

274

des origines

à la chute

du sultanat

Fung

Le programme architectural mis en œuvre par le couple de corégents est d'une ampleur sans précédent. À l'exception des grands complexes dynastiques à Napata et Méroé - où il est clair que le travail d'Amanitoré et Natakamani consista à réaménager l'espace existant —, il est souvent difficile de savoir si les temples furent restaurés, reconstruits ou bâtis de neuf, car il ne subsiste aucune trace d'édifices plus anciens. C'est le cas à Naga où il est possible qu'aient existé des constructions antérieures là où se dressent aujourd'hui le temple d'Amon et celui d'Apédémak. Il serait en effet étrange que le site n'ait comporté que le petit temple $\mathrm{F}$ au nom de Shanakdakhété, bâti à flanc de montagne, et rien en contrebas, sur les berges du Wadi Awatib qui se prêtaient bien mieux à la construction d'édifices religieux, pour lesquels un cours d'eau, fût-il symbolique, était requis. Mais aucun vestige de bâtiments antérieurs au règne d'Amanitoré et Natakamani n’a pu y être mis en évidence, peut-être parce qu'ils ont été rasés pour faire place nette.

C'est le dieu Amon qui fut le principal bénéficiaire des travaux entrepris sur l'ensemble du territoire de Koush et que nous allons détailler du nord au sud. Un temple aujourd'hui disparu lui fut dédié à AmaraEst. Ses colonnes, relevées par Lepsius, comportaient sur quatre registres des scènes d'adoration semblables à celles du temple d'Amon de Naga et des inscriptions en hiéroglyphes méroïtiques identiques, sinon que le prince ( $p q r$ ) Shorkaror y remplace Arakakhataror. Sur l'île de Saï, Vincent Francigny a identifié et publié en 2011, parmi les vestiges architecturaux 
gisant à l'est de la forteresse ottomane, deux fragments d'abaques et des fûts de colonnes ayant appartenu à un temple méroïtique similaire à celui d'Amara. Les parties inférieures des trois cartouches de Natakamani, Amanitoré et un prince dont le nom se termine par -ror, comme les trois connus, figurent sur les abaques. À Tabo, sur l'île d'Argo située au sud de Kerma, le couple royal fit aménager une nouvelle cour dans le temple d'Amon construit par Taharqo.

Au Gébel Barkal, les chantiers des corégents furent particulièrement nombreux. Une seconde cour avec son pylône d'entrée fut ajoutée devant le grand temple d'Amon que Piankhy avait fait construire huit siècles auparavant (B 500), ainsi qu'un nouveau dromos (allée monumentale) où furent déplacés les béliers que le Conquérant avait fait transporter depuis Soleb. À l'est, un petit temple (B 561) a été découvert durant l'hiver 20142015 par l'équipe de l'archéologue américain Timothy Kendall. Il s'agit vraisemblablement d'un mammisi (sanctuaire consacré à la naissance d'enfants royaux) car il est orné de décors étroitement imités du mammisi principal de Philae, notamment des frises de génies apotropaïques aux formes fantastiques protégeant le jeune Horus. Il comprend des colonnes historiées identiques à celles de Naga et d'Amara. Même si les tambours supérieurs où figuraient les cartouches royaux ont disparu, il ne fait pas de doute, d'après la partie conservée des inscriptions qui répètent les formules connues à Naga et Amara, qu'ils renfermaient les noms d'Amanitoré et Natakamani. Il est toutefois plus vraisemblable d'après les données architecturales que les corégents ont rénové un temple existant depuis longtemps et ne l'ont pas bâti de neuf. On leur doit également la restauration du temple de Barkal B 1100 où, selon Kendall, qui l'a fouillé en 2000-2002, s'effectuait originellement le couronnement des rois. Enfin, au sud-est du site, un grand palais méroïtique est depuis 1978 dégagé par l'équipe italienne de l'université La Sapienza de Rome. Une stèle fragmentaire, au nom de Natakamani (sur la partie disparue), de la «Candace Amanitoré» et du "prince Arikankharor» y a été découverte en 1984.

Au sud de la cinquième cataracte, sur le site de Dangeil où depuis 2000 travaille une équipe anglo-soudanaise sous la direction de Salah elDin Mohammed Ahmed et Julie Anderson, un important temple d'Amon a été mis au jour. Peut-être originellement construit par Taharqo, il fut entièrement rebâti sous le règne des corégents. Il comporte notamment les mêmes colonnes historiées que celles de Naga ou d'Amara, mais, comme dans le temple B 561 de Barkal, conservées trop bas pour que les cartouches soient visibles. Toutefois, des fragments de grès retrouvés dans les débris portaient bien les noms de la Candace Amanitoré et du roi Natakamani. À Méroé, comme au Gébel Barkal, ils agrandirent le temple principal 
du dieu Amon en y aménageant une nouvelle cour à l'avant du complexe. Au centre de cette cour fut édifié un reposoir pour les barques sacrées utilisées lors des processions. Il semble que les statues de béliers du dromos en grès sombre que l'on peut voir aujourd'hui devant le temple datent aussi de leur règne: elles comportent la même toison à bouclettes que celles de Naga, une caractéristique que l'on ne trouve pas ailleurs. Également à Méroé, c'est au couple royal que l'on associe la reconstruction des «Bains royaux", un édifice comprenant une sorte de piscine interne, entourée de statues hellénisantes, et dont la fonction (bains ou sanctuaire consacré aux divinités des eaux) reste encore indéterminée. Toujours à Méroé, les petits temples situés le long de l'allée processionnelle qui mène au temple d'Amon, M 720, KC 102 et KC 104, ont livré des fragments de peinture sur enduit qui nous préservent les noms d'Amanitoré et Arikhankharor (en transcription égyptienne) et un saisissant portrait de la Candace, pour une fois en couleur, sobrement coiffée d'un bandeau à égide d'Isis.

À Mouweis, un site urbain au sud de Méroé fouillé depuis 2007 par une équipe du musée du Louvre, le cartouche fragmentaire d'un des princes, soit Arakakhataror, soit Arikankharor, retrouvé dans le temple, signe également le règne des corégents. Un palais royal situé au sud du site a été dégagé par Michel Baud et Marc Maillot. Architecturalement très proche de celui du Gébel Barkal, il est également attribuable à Natakamani, bien qu'aucune inscription n'y ait été retrouvée. À proximité de Mouweis, à Ouad Ben Naga, là où la reine Amanishakhéto avait fait édifier un palais, le couple royal construisit un temple consacré à la déesse Isis. Dans ce temple figuraient trois reposoirs de barques, dont le plus beau fut rapporté au musée de Berlin par Lepsius. Gravé sur ses quatre faces, il comporte des inscriptions en égyptien, mentionnant la Candace et le roi, ainsi que leurs cartouches en méroïtique hiéroglyphique audessus de leurs représentations. Ce monument joua un rôle important dans le déchiffrement effectué en 1911 par Griffith, puisque les noms royaux y figuraient en deux écritures, égyptienne et méroïtique. Enfin, bien que les preuves absolues manquent, le dernier état de construction de la Grande Enceinte de Musawwarat, notamment la décoration des colonnes du sanctuaire central, le temple 100, a été récemment attribué à Natakamani par les archéologues qui y ont travaillé.

Mais c'est à Naga que l'on peut voir dans toute sa splendeur l'activité architecturale du règne. Situé à près de $160 \mathrm{~km}$ de Khartoum, c'est souvent le premier site que découvrent les rares touristes qui viennent au Soudan. Après avoir parcouru une piste sablonneuse d'une quarantaine de kilomètres à travers une savane arborée ponctuée de grands acacias, où l'on s'attendrait à rencontrer girafes, éléphants et lions, et qui y étaient effectivement 
présents à l'époque (les derniers lions sont attestés vers 1830), on débouche au pied d'un sombre gébel où s'élèvent les temples pharaoniques les plus méridionaux d'Afrique et les mieux conservés du Soudan. L'absence de ville moderne à proximité et le défilé des troupeaux, que viennent abreuver, à un profond puits situé au centre du site, les populations nomades de la région, ajoutent à la magie du lieu. Trois grands édifices s'élèvent en bordure du Wadi Awatib, un oued rarement en eau: le vaste temple d'Amon au nord et, au sud, la chapelle d'Hathor et le temple d'Apédémak. Un peu plus haut sur la pente du gébel est situé le petit temple de la reine Shanakdakhété que nous avons précédemment évoqué. Contrairement à Musawwarat, Naga était une véritable ville, avec des bâtiments administratifs, un habitat et une nécropole. Elle possédait trois hafirs (réservoirs) qui permettaient de stocker l'eau des pluies durant la saison sèche.

Le temple d'Amon était originellement le moins bien conservé des trois édifices bâtis sous Amanitoré et Natakamani. En 1993, le musée égyptologique de Berlin obtint la concession du site de Naga et se lança dans un vaste chantier, doté d'importants moyens, mêlant travaux archéologiques et restauration du monument, sous la conduite du professeur Dietrich Wildung et de sa directrice des fouilles, Karla Kröper. Comme les temples d'Amon en Égypte ou ceux de Napata et Méroé, l'édifice est bâti sur un plan axial est-ouest. L'allée monumentale, qui comportait, de part et d'autre d'une chapelle-reposoir pour les barques sacrées, deux alignements de six statues de béliers sur socle, fut la première partie du temple à être remontée.

De cette allée, on accède par un pylône de grès et de briques à la salle hypostyle où seule une colonne était restée debout, jusqu’à ce que l'équipe berlinoise, en 2004-2005, remontât les sept autres qui gisaient en tronçons sur le sol. Puis se succèdent le pronaos et, flanqué de deux magasins, le petit sanctuaire, où fut retrouvé, encore en place, un support de naos en grès. Transporté au musée de Khartoum et remplacé dans le temple par une copie en plâtre, il est gravé sur ses quatre faces d'images des divinités accomplissant le sema-taouy («l'union des Deux Terres»): sur les faces ouest et est, Horus et Thot lient les plantes de la Haute et Basse-Égypte autour d'un poteau central portant les cartouches en hiéroglyphes méroïtiques de la reine Amanitoré et du roi Natakamani; sur les deux autres faces, les dieux du Nil accroupis sur le registre inférieur répètent le même geste autour des cartouches bilingues, au nord, de Natakamani, dont le nom de couronnement égyptien est Kheper-ka-Rê, au sud, d'Amanitoré, appelée Mery-ka-Rê. Sur le registre supérieur apparait le souverain, suivi des «âmes de Pé et de Nékhen", esprits des ancêtres royaux, exécutant l'étonnante danse hénou (en position accroupie comme dans les danses russes), associée 
aux traditions les plus anciennes de la royauté pharaonique. Derrière le mur du sanctuaire s'élève un petit "contre-temple», avec un espace sacrificiel et un unique bélier tourné vers la montagne.

Le temple d'Amon de Naga est inspiré des temples, égyptiens ou napatéens, qui existaient sur le territoire de Koush. Le support de naos est ainsi clairement démarqué de celui que le roi Atlanersa avait fait placer dans son temple du Gébel Barkal. Parmi les inscriptions égyptiennes, seules celles qui légendaient les personnages ont été recopiées, avec toutefois de grossières maladresses: ainsi Thot, "seigneur de l'Ogdoade", c'est-à-dire des huit divinités d'Hermopolis, fut réduit à «seigneur des six », deux traits étant manquants. Horus, le "grand dieu», devint «le dieu bon", ce qui est habituellement une épithète du pharaon, parce que le signe '3 "grand" dans le texte d'Atlanersa est confondu avec le signe $n f r$, «bon». Les âmes de Nékhen devinrent les âmes de «khe», le filet d'eau représentant la consonne " $n$ " ayant été oublié à l'initiale (comme dans le naos d'Atlanersa) et à la finale. Toutefois, une telle méconnaissance de l'égyptien, à vrai dire presque inutilisé à Méroé depuis près de deux siècles, n'est pas systématique durant ce règne. Le reposoir de barque de Ouad ben Naga, par exemple, ainsi que les chapelles funéraires d'Amanitoré et d'Arikankharor à Bégrawwiya comportent des textes égyptiens assez longs, certes de type tardif mais généralement corrects.

Dans d'autres cas, la différence avec les modèles anciens est volontaire et témoigne d'une adaptation plutôt que d'une déformation. Les temples du Nouvel Empire et, plus rarement, d'époque tardive comportent des origines à la chute du sultanat Fung souvent, sur le linteau de la première porte, une scène symétrique figurant le pharaon devant la divinité, accomplissant une course dite «aux vases et à la rame». Très ancienne, elle est probablement liée aux rites d'arrivée de la crue du Nil. D'un côté, le roi brandit le vase ḩs utilisé pour les libations, de l'autre côté un aviron et le signe $h p$, une pièce de batellerie archaïque, d'usage inconnu, ressemblant à une équerre. On trouvait cette scène en Nubie, par exemple à l'entrée du grand temple d'Abou Simbel ou sur un bloc effondré du temple de la reine Tiyi à Sedeinga.

Sur le linteau de la première porte du temple d'Amon de Naga, on décida de la faire figurer, mais en l'adaptant. Le signe $h p$ fut remplacé par le fouet royal nekhakha, de forme assez semblable, le vase hs par une aiguière à bec plus répandue dans le culte méroïtique, et l'aviron disparut. Les deux scènes, l'une devant Amon de Thèbes à tête humaine, l'autre devant Amon de Naga à tête de bélier, tout en restant symétriques, furent unifiées: le roi tiendrait le vase et le fouet aussi bien à droite qu'à gauche. Mais, surtout, il fallait que soit présent sur un pied d'égalité l'ensemble de la famille royale: le souverain, la Candace et le prince Arakakhataror, 
représentés comme une trinité dans le temple d'Amon. Or, il était difficile de figurer la Candace, vêtue de la robe à fourreau d'Isis, courant à grandes enjambées comme Ramsès II à Abou Simbel. Pour lui conserver sa majesté, on décida que la marche serait plus digne que la course. Finalement, les trois personnages furent représentés marchant vers Amon avec, seule concession aux modèles égyptiens, le talon de la jambe arrière légèrement levé, alors que le pied du pharaon est habituellement à l'équerre dans les courses traditionnelles. Sur les linteaux intérieurs, qui comportent des scènes d'offrandes plus conventionnelles aux deux Amon, les talons des personnes royales touchent la ligne de sol.

L'ensemble des textes du temple d'Amon, à l'exception des titres royaux et des noms de couronnement, est en méroïtique hiéroglyphique et constitue le corpus le plus nombreux rédigé dans cette écriture qui nous soit parvenu. Le retour des noms de couronnement égyptiens, qui avaient connu une éclipse de près de deux siècles, doit être interprété non comme une imitation de l'Égypte, où d'ailleurs cette pratique avait disparu sous les empereurs au profit de titres romains transcrits en hiéroglyphes, mais comme un retour aux sources de l'histoire koushite. Le nom égyptien d'Amanitoré, Mery-ka-Rê, «l'âme de Rê est aimée», est repris de la titulature d'Aspelta. Celui de son fils Natakamani, Kheper-ka-Rê, «l'âme de Rê est en devenir» est emprunté au roi méroïtique Arnékhamani, tandis que celui du prince royal Arakakhataror, Ankh-ka-rê, «l'âme de Rê est vivante», avait été le nom de couronnement d'Anlamani, frère et prédécesseur d'Aspelta, puis de Nastasen, et sera repris par son frère, le prince royal Arikankharor. Tous ces points montrent que le règne des corégents ne constitue pas seulement une période de frénésie architecturale mais aussi une ère de renouveau idéologique et intellectuel qui avait très probablement été amorcée sous la Candace Amanishakhéto et se poursuivra jusqu'au début du II siècle.

Plus encore que dans le temple d'Amon de Naga, c'est dans celui d'Apédémak qu'apparaît l'ampleur de ce renouveau. Le sanctuaire de ce dieu, situé de l'autre côté du wadi, semble avoir été construit ex nibilo par les corégents puisqu'il ne comporte pas de soubassements plus anciens. Tout laisse pourtant à croire qu' il existait dès le $\mathrm{II}^{\mathrm{e}}$ siècle av. J.-C. un temple consacré au dieu-lion sur le site, autre que le petit édifice décoré sous Shanakdakhété, le temple F. L'hymne du dieu sur les murs de son sanctuaire à Musawwarat mentionne en effet un «Apédémak de Toulakaté». Or ce toponyme (écrit Tolkte) est le nom méroïtique de Naga. Le temple F, de date trop tardive, de taille réduite et de localisation très marginale sur la pente du gébel, peut difficilement avoir été le lieu de culte principal du dieu-lion, dont les traces restent donc à découvrir sur le site. À l'instar du temple F et de celui de Musawwarat, le temple d'Apédémak de Naga 
se présente comme un bâtiment rectangulaire à salle unique, contrastant avec l'architecture égyptienne du temple d'Amon qui aligne le long d'un axe est-ouest une succession de différents espaces sacrés. Sa façade, tournée vers le gébel, est constituée d'un pylône solidaire des murs, comme dans les chapelles funéraires royales (photographies p.231-233). C'est d'ailleurs à celle de la reine Amanishakhéto à Bégrawwiya que fait penser le décor, qui met en scène le massacre des ennemis par le roi et la Candace. Sans doute l'une et l'autre scène sont-elles inspirées du premier pylône du temple d'Isis à Philae, où le roi lagide Ptolémée XII Néos Dionysos est représenté de façon symétrique sur les deux môles exécutant les guerriers ennemis.

La position des souverains méroïtiques à Naga est plus statique qu’à Philae, parce qu'il n'était pas possible ou souhaitable, comme nous l'avons vu déjà dans le temple d'Amon, de représenter la Candace effectuant un large pas dans sa robe à fourreau. Il n'en reste pas moins que la symétrie de la scène renvoie à la parfaite égalité entre les deux corégents, un thème central dans l'iconographie du temple. De façon plus systématique encore que dans le temple du Lion à Musawwarat, l'édifice est scindé en deux parties: la moitié nord renvoie à la féminité, à la Candace et à l'Égypte, tandis que la moitié sud est consacrée à la masculinité, au roi et à Koush. Ainsi, sur le môle nord du pylône apparaît la Candace Amanitoré, massacrant les ennemis tenus par leur chevelure autour d'une pique centrale, une scène connue en Égypte depuis les toutes premières dynasties mais réservée aux rois. Comme avant elle Amanishakhéto, Amanitoré est représentée comme une femme aux rondeurs exagérées. Au-dessus d'elle, des origines à la chute du sultanat Fung ainsi que sur le pylône de Philae, plane la déesse-vautour Nekhbet. À ses pieds, un lion lance ses griffes contre la grappe d'ennemis qu'elle tient fermement. Sur le môle sud, c'est le roi Natakamani qui accomplit le massacre des ennemis. Il est survolé par le dieu-faucon Horus et accompagné également d'un lion qui attaque à la gorge un guerrier nouba tombé à terre. Les deux scènes sont légendées en méroïtique hiéroglyphique, donnant les noms et titres du souverain et de la Candace et appelant sur eux deux les bénédictions d'Apédémak, seigneur du lieu.

Sur les tranches extérieures du pylône figure une étonnante représentation de cette divinité, un serpent à buste et tête de lion, coiffé de la couronne hemhem et dont les anneaux empilés en volutes régulières sortent d'une touffe d'acanthe tout à fait hellénistique. Les murs extérieurs latéraux présentent la triade royale, Natakamani, Amanitoré et le prince royal Arikankharor face à une procession de divinités. Sur le mur sud, le défilé est exclusivement masculin: Apédémak face au roi, puis Horus, Amon de Napata, Aqedise (le dieu-lune équivalant à l'Égyptien Khonsou) et enfin Amon de Pnoubs. Le roi et la Candace sont tous deux habillés du costume 
tripartite et coiffés de la calotte koushite. Sur le mur nord, en revanche, ils sont figurés comme Isis et Osiris, elle portant un disque solaire entre deux cornes de vaches, lui la haute mitre dite atef du premier roi mythique de l'Égypte. Face à eux, des divinités purement féminines, cette fois: Isis, Mout, Amésémi, Hathor et Satis. C'est toutefois sur l'arrière du temple, face à l'est, que l'on trouve la plus extraordinaire représentation divine de tout l'art méroïtique. Vers cette divinité s'avancent depuis le nord la Candace, accompagnée du prince qui était peut-être trop jeune pour être catégorisé comme «masculin", depuis le sud le roi Natakamani, également suivi d'Arikankharor. Le dieu Apédémak est au centre du mur et tourne un premier visage léonin vers la Candace et un second vers le roi. Une troisième tête est figurée de face, vers le spectateur. Semblablement, à l'aide d'une première paire de bras, le dieu présente à gauche un bouquet à la reine Amanitoré et soulève le coude de la Candace en signe de légitimation. À l'aide d'une seconde paire de bras, il accomplit les mêmes gestes à droite envers le roi Natakamani.

Il s'est évidemment trouvé quelques esprits imaginatifs pour rapprocher ce dieu à trois têtes et à quatre bras des divinités hindoues traditionnelles. Or on n'a absolument aucun élément qui puisse suggérer une influence à si longue distance, sachant que même les rivages de la mer Rouge étaient en dehors de la domination méroïtique. Mais surtout, c'est méconnaître la motivation religieuse et politique de cette singulière représentation: sur le plan théologique, le dieu Apédémak appartient à la fois au côté féminin et au côté masculin, assurant par ce mélange la fécondité qui permet la création. Sur le plan idéologique, il est le protecteur de la Candace et du souverain, placés ainsi exactement à parité. La multiplication des têtes et des bras symbolise ces différents aspects du dieu.

L'intérieur du temple, comme à Musawwarat, comporte des bas-reliefs qui conjuguent l'héritage égyptien et l'influence grecque. On y voit ainsi deux représentations de dieux barbus figurés de face, correspondant aux divinités lagides Zeus-Amon et Sérapis. Au registre supérieur du mur nord, une image de dieu solaire assis sur un trône, à la tête présentée de face et entourée de rayons, pourrait être une figuration d'Hélios, éventuellement assimilé au dieu méroïtique du Soleil, Masha, bien connu par les textes mais dont on ne possède aucune représentation certaine. Ce mélange d'influences se retrouve dans la chapelle d'Hathor, précédemment dénommée le «kiosque romain", qui s'élève à l'ouest du temple d'Apédémak. Ce bâtiment à colonnes, autrefois un peu courtaud, a retrouvé des proportions élégantes depuis que l'équipe de Berlin l'a débarrassé de la gangue d'alluvions qui emprisonnait son quart inférieur. La façade orientale, la mieux conservée, présente une porte d'entrée typiquement méroïtique, avec sa découpe trapézoïdale. Elle est décorée de frises gigognes 
de cobras royaux entourant le disque solaire, empruntées à l'architecture égyptienne. Quatre colonnes à chapiteaux composites soutiennent cette façade qui s'ouvre de chaque côté de la porte sur deux fenêtres voûtées plus romaines qu'hellénistiques. On a longtemps pensé que cet édifice était très tardif, car on rapprochait son style particulier du kiosque de Trajan à Philae ( $\mathrm{II}^{\mathrm{e}}$ siècle apr. J.-C.) ou de la porte de Dioclétien sur le même site (III $-\mathrm{IV}^{\mathrm{e}}$ siècle apr. J.-C.). En fait, il y a quelques années, nous avons pu dater paléographiquement $\mathrm{du} \mathrm{I}^{\mathrm{er}}$ siècle de notre ère un graffito méroïtique d'adoration à la déesse Mout, gravé à l'intérieur du temple sur des blocs d'origine. Il est maintenant admis par les archéologues du site que cette chapelle, qu'une statue découverte récemment lors du nettoyage de la base a permis d'attribuer à la déesse Hathor, est contemporaine des temples d'Amon et d'Apédémak et appartient donc au programme architectural lancé à Naga par Amanitoré et Natakamani.

\section{Les princes royaux de Natakamani ont-ils régné ?}

le Soudan

\section{2}

des origines

à la chute

du sultanat

Fung

S'il paraît clair que la Candace est la mère du roi en exercice, et ce point est démontré dans le cas d'Amanitoré et Natakamani par la relecture du graffito de Dakka (voir supra, p. 272 sq.), la position du «prince royal» (méroïtique $p q r$ ) reste une question difficile. Akinidad par exemple a été au siècle précédent le $p q r$ de deux Candaces, Amanirénas et Amanishakhéto, sans régner pour autant lui-même, alors que, selon le témoignage de Strabon, il était le fils d'Amanirénas. Semblablement, on connaît trois $p q r$ successifs durant le règne d'Amanitoré et Natakamani, figurés avec eux en une triade royale: Arikankharor dans le temple d'Apédémak de Naga, Arakakhataror dans le temple d'Amon de Naga et Shorkaror dans le temple d'Amon d'Amara. Selon le précédent d'Akinidad, il est vraisemblable qu'il s'agisse de fils d'Amanitoré et donc de jeunes frères de Natakamani. Tous trois sont représentés à la suite du couple de corégents dans les temples, et les deux premiers au moins disposent d'un nom de couronnement égyptien, Ankh-ka-Rê, inscrits dans un cartouche à côté de leur nom méroïtique. À Naga, au-dessus des cartouches d'Arikankharor, apparaissent les titres égyptiens nsw-bjty <nb>t3.wy, "roi de Haute et Basse Égypte, maître des Deux Terres» et, au-dessus des cartouches d'Arakakhataror, ntrnfr bjty nb t3.wy, «le dieu bon, roi de Basse-Égypte, maître des Deux Terres", soit dans les deux cas une véritable titulature de pharaon. Néanmoins, le prince est bien le troisième dans l'ordre protocolaire, après le roi et la Candace. Contrairement à eux deux, dans les temples de Naga, il ne porte pas de couronne mais un simple diadème et n'arbore jamais le costume royal tripartite. 
On possède deux monuments où Arikankharor et Shorkaror figurent seuls en position royale, mais dans l'un et l'autre il leur manque certains des insignes du pouvoir suprême. Le premier est représenté accomplissant le massacre rituel des ennemis sur une très belle plaquette trouvée à Méroé et conservée au Worcester Art Museum. Une Victoire ailée, coiffée d'un long plumet typiquement méroïtique mais munie d'ailes aux épaules et aux talons comme la déesse grecque dont elle est inspirée, tend une palme réinterprétée en chasse-mouches au-dessus du prince. De l'autre côté, une divinité disparue lui présente une nouvelle grappe d'ennemis entravés. Si la scène est royale, Arikankharor ne porte toutefois pas le costume des souverains et sa coiffure consiste en un diadème orné non du double cobra qu'arborent rois et Candaces mais de l'effigie d'Apédémak, sous forme d'une tête de lion surmontée de la couronne hemhem.

Shorkaror, quant à lui, est attesté dans une gravure monumentale non loin de la frontière sud-est du royaume, au Gébel Geili, entre Khartoum et Kassala. Dans ce lieu désolé, sur le flanc d'un rocher rarement éclairé faisant face à la falaise, le prince est figuré armé d'une pique, d'un arc, et ceint d'une épée dans son fourreau. Deux cartouches érodés donnent son nom et un titre peu lisible (mnslhe?) et de signification inconnue, si du moins la lecture est correcte. Comme surgissant d'une nuée, le buste d'un dieu solaire de type gréco-latin (peut-être Hélios), représenté de face et couronné de rayons, lui tend une grappe de prisonniers à massacrer et un bouquet d'épis de sorgho. D'autres ennemis, disloqués, tombent du ciel, tandis que d'autres encore, ligotés, sont alignés sous les pieds du prince. Mais, à l'instar d'Arikankharor, le prince Shorkaror ne porte pas le costume des souverains et sa calotte koushite s'orne non du double cobra, mais d'une tête d'animal, sans doute à nouveau un lion, coiffée de la couronne hemhem. Dans ces deux représentations, les princes sont investis d'une partie seulement de la puissance royale: ils agissent en chefs d'armée et reçoivent l'appui des dieux dans leur mission de défenseurs du royaume. Ce rôle militaire du $p q r$ avait déjà été souligné dans les chroniques du siècle précédent où Akinidad menait les troupes méroïtiques à l'assaut des Romains. Mais il ne donne pas pour autant aux "princes royaux» de légitimité au trône. Bien que ce point soit débattu, il ne semble pas, au vu de la documentation actuelle, que Shorkaror ait régné. Si des fouilles futures mettaient au jour un document où il serait désigné comme qore «souverain", cette position serait bien sûr révisée.

Le seul de ces trois princes dont la sépulture soit connue est Arikankharor, qui fut inhumé sous la pyramide Beg. N. 5 à Méroé. Bien qu'assez petite, elle est dotée d'une chapelle profonde aux murs décorés de très beaux reliefs, où le défunt affronte le jugement d'Osiris dans la plus complète des scènes de psychostasie (pesée de l'âme) que nous ait léguées 
l'art koushite (voir p.205). Il est possible qu'elle ait été inspirée par un exemplaire du Livre des Morts égyptien, où elle est souvent représentée en détail. Sur le mur sud, Arikankharor est mené au tribunal par la déesse Maât puis assiste à la pesée de son cœur dans une grande balance régulée par Horus et Anubis. Thot enregistre les résultats, face à Osiris assis sur un trône et précédé de la Dévoreuse, le monstre composite qui aurait avalé le cour si la pesée n'avait pas été favorable. Sur le mur nord, Arikankharor, désormais justifié, est enlacé par la déesse de l'Occident et prend place sur le trône au lion, encensé par un autre prince et recevant les offrandes aux défunts glorifiés. Le programme iconographique de la chapelle d'Arikankharor est tout à fait singulier dans la nécropole de Méroé. Dans la plupart des chapelles, en effet, la pesée de l'âme est juste évoquée par une balance placée au milieu d'autres détails sur le mur ouest, tandis que sur le mur sud est représenté le défunt (ou la défunte) assis sur le trône au lion et attendant son jugement face aux offrandes propitiatoires. Également insolite est l'absence de la déesse Isis, protectrice habituelle du défunt. En fait, ces singularités n'ont peut-être été possibles que parce qu'Arikankharor ne disposait pas d'un plein statut royal. Il ne porte d'ailleurs pas de couronne mais un simple diadème orné d'un cobra unique, fixé sur une perruque ronde.

Arikankharor est considéré comme le premier en date des princes à avoir occupé le statut de $p q r t r$, «prince suprême», durant le règne des corégents. Il semble certain qu'il est décédé avant la reine-mère Amanitoré, dont la tombe occupe la dernière place possible pour un souverain, quoiqu'exiguë, dans la rangée ouest des pyramides de Bégrawwiya

des origines

à la chute

du sultanat

Fung Nord. Les sépultures des deux autres princes ne sont pas identifiées, mais la suggestion faite par l'égyptologue viennoise Inge Hofmann de leur attribuer les deux petites pyramides Beg. N. 14 et Beg. N.15, totalement au nord de la rangée ouest et situées sur une extension étroite de la barre rocheuse la plus élevée, correspond bien à la «crise du logement » qui a touché la fin du règne des corégents. Ces deux tombes ne comportant plus d'inscriptions qui, selon le témoignage de Lepsius, étaient originellement peintes sur enduit, il n'est pas possible de prouver qu'elles furent bien les dernières demeures des deux princes.

La pyramide de la Candace Amanitoré, Beg. N.1, située sur le rebord sud de la crête rocheuse, est bien conservée. Elle est étonnamment petite pour une si grande reine, mais sa position ne permettait pas l'édification d'un vaste monument en surface. Le fait que l'on ait tenu malgré cela, qu'il s'agisse de la volonté de la reine ou de son fils Natakamani, à édifier son tombeau en cet endroit est un indice de plus pour faire d'Amanitoré l'épouse du roi Amanakhabalé, inhumé à côté en Beg. N. 2. Comme pour son fils Arikankharor, les reliefs de sa chapelle font preuve d'originalité. 
Contrairement à la tradition, elle n'est pas représentée sur le mur sud assise sur le trône au lion recevant les hommages et les offrandes dans l'attente du jugement d'Osiris. Ce sont en fait des scènes de ses funérailles qui sont figurées: l'enlèvement du corps sur la barque sacrée du dieu-faucon Sokar, portée à dos d'homme et encensée par un prince, le transport sur le Nil et la dépose du catafalque dans la chambre funéraire où deux Isis accomplissent les libations rituelles. Dans chacune des scènes, son cercueil est accompagné par le dieu Sokar, guide des défunts dans l'Au-delà, sous forme de faucon momifié. Le jugement d'Osiris est simplement suggéré par une petite balance où est pesée l'âme au chevet du catafalque. Le mur nord, plus conforme à la tradition, montre la reine justifiée, assise sur le trône au lion et protégée par Isis. On notera que, dans tous ses portraits, la Candace est modestement coiffée de la couronne hathorique des grandes épouses royales égyptiennes, comme Tiyi ou Néfertari, et non de celles que portent les souverains, hmhm ou pschent. Comme dans la chapelle d'Arikankharor, les scènes sont accompagnées de citations des textes funéraires égyptiens gravées en hiéroglyphes, renouant avec une pratique interrompue depuis le règne d'Arkamani II, trois siècles auparavant.

Nous ignorons si le roi Natakamani a longtemps survécu à sa mère, faute de textes complets où il soit cité sans elle. À son décès, il fut inhumé sur une colline isolée au nord-est de Bégrawwiya, totalement à l'opposé de la Candace Amanitoré. Cette position a beaucoup été discutée: on en fit soit le résultat d'une brouille familiale, soit le désir que les deux sépultures «embrassent » l'ensemble de la nécropole royale. En fait, comme nous l'avons vu, il n'y avait plus de place sur la ligne de crête la plus élevée de Bégrawwiya Nord. Il fallait donc se résoudre, ou à localiser la nouvelle sépulture en contrebas, comme on le fera aux règnes suivants, ou à la bâtir au même niveau que les autres, mais sur une colline plus éloignée. C'est cette seconde option, plus conforme peut-être au statut d'égalité entre les corégents, qui fut choisie.

Curieusement, deux hypogées parallèles de dimensions comparables furent creusés mais seule la tombe située à l'est, Beg. N.22, se vit complétée par une pyramide et une chapelle. L'autre fut toutefois utilisée, sans doute plus tardivement et pour un membre secondaire de la famille royale puisqu'aucune superstructure ne fut érigée. Peut-être avait-elle été prévue originellement pour Amanitoré afin que mère et fils reposent côte à côte, mais, en ce cas, on changea d'avis avant la mort de la Candace. La chapelle funéraire de Natakamani en Beg. N.22 présente des reliefs moins élaborés que ceux d'Amanitoré ou Arikankharor. On y voit le roi en costume royal méroïtique, assis en majesté sur le trône au lion sur les murs nord et sud, à l'ouest encensant Osiris suivi d'Isis. Un détail cependant 
le Soudan

\section{6}

des origines

à la chute

du sultanat

Fung

est significatif, surtout si l'on considère que la construction de la chapelle est généralement l'œuvre du successeur du défunt: aucune reine n'est présente dans les scènes conservées de la chapelle funéraire. L'institution de la Candace va en effet connaître dans les deux règnes suivants une moindre importance.

\section{De l’ombre à la lumière : le roi Amanakharéqérem}

Ce souverain est un des meilleurs exemples des progrès rapides et constants de notre connaissance de l'histoire de Méroé, si partielle soit-elle encore. Son nom était inconnu il y a quarante ans. Il est maintenant considéré comme un des grands rois bâtisseurs de la période méroïtique classique et son visage retrouvé est exposé aux yeux de millions de visiteurs au musée de Berlin. Il n'est pas certain qu'il ait directement succédé à Natakamani. Sa position relative par rapport à Amanitenmomidé, lui aussi un des successeurs immédiats du corégent, n'est en effet pas élucidée. Mais il est constant qu'Amanakharéqérem a complété, à Naga, au Gébel Barkal et peut-être à Tabo, les constructions principales érigées sous le règne de Natakamani et que le style des gravures est étroitement inspiré des représentations de ce souverain.

Durant la domination turco-égyptienne du Soudan, une statue de bélier inscrite en méroïtique fut dégagée en 1863 par Johannes Dümichen dans les ruines de la cathédrale de Soba, sur le Nil Bleu, lors de la seconde expédition égyptologique prussienne. Le fameux Gordon Pacha, gouverneur du Soudan nommé par le khédive d'Égypte, la fit transporter, dit-on, dans les jardins de son palais de Khartoum. Bien que fortement endommagée, la statue était de belle facture. Elle imite les anciens modèles égyptiens, notamment les béliers du temple construit par Taharqo à Kawa, car son pelage est rendu par un motif en écailles et non en grosses boucles, comme les béliers de Naga. Alors que ces derniers sont anépigraphes, celui de Soba était inscrit. Une bande courante, très abîmée, gravée en hiéroglyphes méroïtiques et égyptiens sur la base du monument, livrait le nom fragmentaire du roi dédicataire du temple dont il provenait. Dans ses Meroitic Inscriptions en deux tomes publiées en 1911 et 1912, Griffith, qui venait de déchiffrer l'écriture méroïtique, lui accorda le numéro 1, puisqu'elle était la plus méridionale des inscriptions rédigées dans cette langue. Elle porte encore aujourd'hui, dans le Répertoire d'épigraphie méroïtique (REM), le numéro Remooo1. Dümichen et Griffith ne doutèrent pas que la cathédrale de Soba eût été bâtie sur les ruines d'un temple méroïtique, et cette opinion prévalut jusqu'aux fouilles de Soba par les Britanniques au début des années 1980, qui ne trouvèrent pas d'installation antérieure à la période chrétienne. Le cartouche brisé du souverain ne livrait que la seconde 
partie de son nom [...]reqerem, et c'est sous cette forme qu'il fut inclus dans les listes royales de Koush. Sur des critères extrêmement ténus, Hintze data ensuite son règne du $\mathrm{II}^{\mathrm{e}}$ siècle apr. J.-C. et lui attribua même une sépulture à Méroé, la pyramide Beg. N. 30, où aucune inscription n'avait conservé le nom du royal occupant.

Or, en 1975, à une vingtaine de kilomètres au sud de Méroé, dans un lieu-dit appelé Giblab, des agriculteurs qui creusaient un canal d'irrigation découvrirent un bélier très semblable. Le site était connu depuis les premiers voyageurs européens, notamment Frédéric Cailliaud, qui y avait décrit des restes de statues et de bâti en briques. L'inscription de la base n'était guère mieux conservée que celle du bélier de Soba. Cette fois, c'était la fin du cartouche qui était manquante. L'archéologue P. L. Shinnie, qui avait été appelé sur le site depuis Méroé où il fouillait alors, fit bien le lien entre le bélier de Soba et cette statue, mais il lut le nom du roi «Amankheremy». En revanche, le cartouche du nom de couronnement égyptien, manquant sur le bélier de Soba, était présent, et Shinnie proposa de le lire "Nebmaâtrê", ce qui avait été celui du grand pharaon Amenhotep III dont les monuments, notamment à Soleb, étaient encore visibles sur la terre de Koush. Or, un roi méroïtique avait porté ce nom de couronnement, mais son nom de naissance était peu lisible. Ses deux cartouches apparaissaient sur un objet assez étrange, une sorte de demi-sphère décorée en pierre trouvée par Reisner au Gébel Barkal, qu’on nomma "Omphalos de Napata" par comparaison avec l'"Omphalos de Delphes», une pierre conique du temple grec censée représenter le "nombril» (grec omphalos) du monde. Il a été établi depuis lors que cet objet était en fait un naos en forme de hutte traditionnelle qui contenait une statuette divine et qui devait à l'origine s'orner d'un cobra dressé à l'avant, évoquant ainsi la silhouette caractéristique du Gébel Barkal.

En 1999, l'archéologue allemand Steffen Wenig publia un article au titre humoristique, Ein “neuer" alter Königsname ("Un "nouveau” vieux nom royal»), qui montrait que les rois du bélier de Soba, du bélier de Giblab et du naos de Napata étaient un seul et même souverain, dont le nom devait être lu "Amanikharéqérem ". C'était presque exact, à la nuance

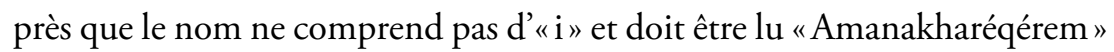
et même, en toute rigueur, "Amanakharéqéréma". Il ne contient pas le nom simple d'Amon (Amani), mais d'une de ses hypostases, Amanakh, que nous avons évoquée précédemment dans le nom du roi Amanakhabalé. D'après les parallèles avec les langues nubiennes, les plus proches du méroïtique, le groupe Amanakh-are-qerema pourrait signifier «Amanakh, tu es noir» et correspondrait à un nom donné à la naissance, peut-être selon les caractéristiques physiques de l'enfant, augmenté par la suite du nom 
divin, peut-être au moment du couronnement. Le nom de la Candace Amanirénas (de Amani-are-nase) offrirait, toujours d'après le nubien, un parallèle convaincant, signifiant "Amon, tu es long(ue)». Mais on doit garder à l'esprit que ces traductions, dans l'état actuel de notre connaissance du méroïtique, restent très fragiles.

L'identification de ce roi précéda de peu la découverte de ses constructions. En 1999, Vincent Rondot ouvrit une nouvelle fouille française sur le site où avait été trouvé le second bélier et qui s’avéra être appelé localement «el-Hassa». En quelques saisons, un temple de briques de grandes dimensions fut dégagé. L'analyse architecturale montra qu'il avait été construit en trois étapes, dont la plus importante correspondait au règne d'Amanakharéqérem. Outre le bélier retrouvé en 1975, un autre mieux conservé apparut en 2001 et, lors de la fouille de l'allée monumentale en 2008, trois autres furent découverts en place. De cette manière, l'ensemble de l'inscription bilingue, appelant en égyptien et en méroïtique le dieu local Amon de Tabakha à donner la vie au roi, put être reconstitué. Tabakha était le nom méroïtique du lieu aujourd'hui appelé el-Hassa. Or, il apparaissait déjà sur le bélier de Soba, ce qui prouvait que la statue avait été amenée par voie fluviale depuis el-Hassa pour être réutilisée sur le site chrétien, peut-être comme figure de l'Agneau mystique, après avoir été amputée de la statuette du roi nichée entre les pattes avant de l'animal. Devant les temples d'Amon à Naga et Méroé semblablement, la figure de Natakamani a été détachée volontairement du corps des béliers. Les statuettes de Naga ont été récemment retrouvées dans plusieurs cachettes à l'intérieur du temple d'Amon, en

des origines

à la chute

du sultanat

Fung compagnie de restes biologiques qui ont permis de dater l'enfouissement d'une période très tardive, au $x^{\mathrm{e}}$ siècle de notre ère, en pleine époque chrétienne. Les murs du temple d'el-Hassa étaient couverts de mortier, malheureusement très dégradé, mais un pan, au sud de l'édifice, conservait les formes rebondies d'une reine, sans doute la Candace du règne, dont le nom n'a pas été conservé. Les annexes du temple, comportant notamment un palais cérémoniel, sont en cours de dégagement. La fouille s'étendra prochainement vers l'est, où se trouve, à moins d'un kilomètre, sur le site appelé Damboya, un palais résidentiel comme à Ouad Ben Naga et Mouweis.

Pendant ce temps, à Naga, l'équipe du musée de Berlin dirigée par le professeur Wildung contribuait elle aussi à la résurrection du roi Amanakharéqérem. En 1998, un médaillon de pierre gravé en méroïtique au nom du roi, suivi de l'épithète wtemroso, équivalant de l'égyptien $d j$ ' $n h$, «doué de vie», était retrouvé dans le temple d'Amon. Jusqu'alors, on ne disposait pour ce roi que d'inscriptions en hiéroglyphes méroïtiques, qu'il est difficile de dater en raison de la relative stabilité de cette écriture et du maigre corpus que nous disposons. Or, cette fois, le texte était rédigé 
en cursive, dont l'évolution est plus marquée et mieux documentée. $\mathrm{Au}$ vu de la forme des signes, il n'était plus possible de dater le règne d'Amanakharéqérem de la fin du $\mathrm{II}^{\mathrm{e}}$ siècle de notre ère (on avait suggéré vers 190 apr. J.-C.), mais il fallait le remonter d'un siècle dans le passé. Je proposai donc une date autour de 80-90 apr. J.-C., qui est largement acceptée aujourd'hui. Ce souverain devenait dès lors un des successeurs directs de Natakamani, et la suite allait le confirmer. En effet, en 2004, Dietrich Wildung et Karla Kröper commencèrent à dégager, au nord-est du temple d'Amon, un édifice dont les ruines avaient déjà été signalées par les voyageurs du XIx ${ }^{e}$ siècle, Cailliaud et Lepsius, le temple Naga 200. Il apparut qu'il s'agissait d'un monument assez semblable au temple d'Apédémak de Naga. Il se présente en effet comme un quadrilatère de dimensions modestes $(15 \times 16 \mathrm{~m})$, avec un pylône d'entrée solidaire des murs. En revanche, l'intérieur est aménagé comme un temple égyptien avec deux salles successives ouvrant sur un sanctuaire composé de trois chapelles. Il était précédé d'une chapelle-reposoir et d'un autel monumental.

L'ensemble était orné de reliefs magistralement exécutés, dont la qualité fit même croire un moment qu'ils avaient servi de modèle au temple d'Apédémak, alors que la succession chronologique des deux édifices est bien inverse. Ainsi, sur deux blocs jointifs montrant le bas du buste royal, c'est avec une délicatesse extrême que sont rendus la légère mollesse du cou, le modelé du menton, et la sensualité des lèvres épatées et finement ourlées. Préservée sur trois fragments, une tête de lion à l'attaque, mufle retroussé et crinière hérissée, est un autre chef-d'œuvre, inspiré du réalisme de la sculpture gréco-romaine. Il s'agit de l'animal emblématique d'Apédémak, accompagnant le roi lors du massacre rituel des ennemis, comme sur le pylône du temple de Natakamani.

À la différence de ce dernier, le souverain est toujours seul face aux divinités dans le temple Naga 200: ici, ni Candace ni prince royal. Le pylône présente ainsi une scène symétrique du massacre des ennemis où seul le roi est chaque fois figuré, abattant les peuples vaincus devant l'image d'un dieu adjuvant. Comparé aux temples de Natakamani et Amanitoré sur le même site, celui d'Amanakharéqérem semble témoigner du retour à une royauté non partagée, entièrement centrée sur la figure du roi. Une autre particularité tient à la division des murs longs en scènes séparées. Sur le mieux conservé, le mur extérieur ouest, une première scène campe le roi honorant Apédémak et sa compagne Amésémi. Pour la première fois apparaît entre eux deux un personnage divin qui doit être leur enfant mais dont le nom ne nous est pas parvenu. Amanakharéqérem, comme dans les chapelles funéraires royales, est protégé par Isis qui étend sur lui ses ailes. Le visage de la déesse est remarquablement calqué sur les portraits 
du roi. Une deuxième scène le montre face à Amon à tête de bélier suivi de Mout, mais leur fils Khonsou est séparé d'eux dans une troisième scène où, enserré à la manière du dieu Ptah dans un naos, il reçoit l'hommage du souverain. Les parties les mieux conservées de ce mur ont fait l'objet d'un prêt de longue durée au musée Égyptien de Berlin, où elles ont été reconstituées sur les murs de la salle consacrée aux antiquités du Soudan. Ces reliefs qui égalent et souvent surpassent en qualité les œuvres du temps d'Amanitoré et de Natakamani montrent que la "Renaissance méroïtique» qui avait caractérisé les arts, les constructions et le climat intellectuel à l'époque des corégents s'est perpétuée sous leurs successeurs.

Au Gébel Barkal également, les fouilles récentes ont mis en évidence la continuité entre ces règnes. On se souvient que l'activité d'Amanakharéqérem dans le grand temple d'Amon était attestée par la présence du naos dit "Omphalos de Napata». En 2014, à l'est du temple d'Amon, l'équipe de Timothy Kendall a mis au jour une chapellereposoir au nom du même souverain devant ce qui, l'année suivante, allait être identifié comme un temple (B 561) restauré sous Amanitoré et Natakamani. Bâtie en pierre alors que le temple correspondant l'avait été en briques cuites, cette chapelle comportait des reliefs en majorité disparus illustrant la procession de la barque divine. Sur un des linteaux a été retrouvé le cartouche d'Amanakharéqérem "vivant éternellement». Étonnamment, le nom est transcrit en hiéroglyphes égyptiens et non méroïtiques. Ce détail, ajouté au choix du nom de couronnement Nebmaâtrê, au plan classique du temple Naga 200, au pelage en écailles

des origines

à la chute

du sultanat

Fung et à la base inscrite des béliers d'el-Hassa, témoigne des tendances archaïsantes très perceptibles dans les réalisations du règne.

L'activité d'Amanakharéqérem durant un règne que l'on doit supposer long et florissant ne se limite pas à ces sites. À Doukki Gel/Kerma, où les traces des rois de Méroé sont malheureusement rares, sans doute en raison des destructions que ce site a connues, les fragments d'une ou de plusieurs plaquettes décorées et gravées à son nom ont été retrouvés dans le temple méroïtique. C'est peut-être à ce roi, enfin, que nous devons les deux statues colossales de Tabo qui, transportées à Khartoum, furent érigées le long des salles d'exposition du musée national du Soudan. Selon l'analyse récente de Vincent Rondot, elles doivent être datées du début $\mathrm{du} \mathrm{II}^{\mathrm{e}}$ siècle de notre ère. Celle de gauche représenterait le prédécesseur du roi régnant, dont le pschent s'orne d'une couronne de lauriers à étoile centrale caractéristique des défunts glorifiés dans l'Égypte romaine contemporaine; celle de droite, le roi vivant, flanqué le long de sa jambe du petit prince héritier figuré en Harpocrate (Horus-l'enfant). De manière très prudente, en l'absence d'inscriptions qui auraient nommé 
ces personnages royaux, Vincent Rondot suggère de les attribuer au règne du roi Amanakharéqérem, notamment en raison de l'archaïsme dont elles témoignent, les sculpteurs ayant essayé de renouer avec la grande statuaire napatéenne, mais sans succès puisque l'une des statues se fendit et qu'elles ne furent jamais érigées devant le pylône du temple de Tabo. Une autre caractéristique de ce groupe est l'accent mis sur la lignée mâle, du prédécesseur à l'héritier. Or, cette préoccupation, après un siècle de pouvoir partagé entre souverain, Candace et prince royal, semble avoir déjà dicté le décor extérieur du temple Naga 200. Ce serait donc un indice supplémentaire pour attribuer les deux colosses au règne de ce souverain.

\section{Les souverains du II $^{\mathbf{e}}$ au début du III siècle des noms et des pyramides...}

On ignore où fut inhumé Amanakharéqérem, même s'il est très probable que ce fut à Méroé et non à Barkal, où aucun enterrement royal ne semble s'être fait après celui de la reine Nawidémak, à partir de la première moitié $\mathrm{du} \mathrm{I}^{\mathrm{er}}$ siècle de notre ère. Les hypothèses qui ont été émises avant la nouvelle datation de son règne à la fin du $\mathrm{I}^{\text {er }}$ siècle (Beg. N.30, 37 ou 41) ne sont évidemment plus recevables, puisqu'elles reposaient sur la succession chronologique des sépultures royales en fonction de leurs caractéristiques architecturales. Nous n'en voyons aucune qui soit pleinement satisfaisante. Toutefois, il serait assez logique qu’il ait été inhumé en Beg. N.16, une sépulture dont la superstructure a été remaniée par la suite mais dont l'hypogée, malgré les pillages, a livré aux fouilleurs les restes d'un splendide trousseau funéraire, comportant notamment des cloches de bronze gravées, de nombreux bracelets d'or et un jeu de plaques d'argent représentant des divinités armées.

Son règne correspond en effet à la période où, le rang ouest des pyramides de Bégrawwiya Nord étant complet, les souverains inaugurèrent un second rang parallèle situé en contrebas et à l'est du précédent. La taille de ces monuments, réduite de moitié par rapport aux structures érigées par leurs prédécesseurs, ainsi que le recours fréquent à la brique et non plus à la pierre, témoignent d'une économie amoindrie par rapport aux siècles précédents. Semblablement, l'intervention royale dans les complexes religieux paraît se limiter à des restaurations de piètre qualité. Il semble qu'un tremblement de terre de grande magnitude se soit produit au tournant des $\mathrm{I}^{\mathrm{er}}$ et $\mathrm{II}^{\mathrm{e}}$ siècle, abattant les colonnes de la salle hypostyle du temple d'Amon à Naga ainsi que l'autel monumental de l'approche du temple d'el-Hassa. Or, dans un cas comme dans l'autre, on ne reconstruisit pas. À el-Hassa, seul le bâtiment principal du temple à Amon d'el-Hassa fut restauré. 
Quant à Naga, il semble que le site fut laissé en l'état et plus ou moins abandonné. Ainsi, les souverains dont les noms apparaissent dans les chapelles funéraires ou sur des tables d'offrandes retrouvées dans les décombres de leurs pyramides ne sont pas attestés en dehors de la nécropole. Bien que les fouilles à venir puissent nous réserver quelques bonnes surprises, comme on l'a vu pour le roi Amanakharéqérem, on n'a, pour l'heure, pas mis au jour de temples bâtis ou reconstruits datant de ces règnes.

Les premières tombes royales de cette nouvelle rangée sont Beg. N.16, 17 et 18. Considérée comme la plus ancienne, Beg. N.16 est énigmatique. Il s'agit d'une petite pyramide de briques qui a clairement été l'objet d'aménagements ultérieurs. La chapelle se trouve en effet à l'intérieur de la pyramide, ce qui est tout à fait inhabituel. De plus, un monument beaucoup plus tardif, Beg. N.36, a été construit immédiatement à l'est, oblitérant les rayons du soleil levant sur cette chapelle. Dans la première chambre funéraire de Beg. N.16, située juste sous la pyramide Beg. N.36 et largement ouverte par les pilleurs, deux tables d'offrandes ont été retrouvées lors des fouilles de George Reisner. Elles proviennent évidemment de chapelles proches à l'entrée desquelles elles étaient originellement déposées. Elles comprennent les formules royales habituelles qui appellent Isis et Osiris à abreuver le défunt de lait et non d'eau, comme pour les particuliers.

À juger par la paléographie, la plus ancienne appartenait à un souverain nommé Amanitaraqidé, l'autre à un défunt beaucoup plus tardif appelé Aryesbokhé. Notons au passage que rien ne permet d'assurer le sexe de ces défunts, la langue méroïtique ne possédant pas de genre et le texte ne présentant aucun détail autre que la filiation et les bénédictions finales. L'hypothèse la plus répandue serait qu'Amanitaraqidé ait régné au début $\mathrm{du} \mathrm{II}^{\mathrm{e}}$ siècle de notre ère et soit l'occupant de Beg. N.16. Il serait donc le successeur direct d'Amanakharéqérem. Toutefois, si le mobilier de la tombe s'accorde avec une telle datation, la table d'offrandes d'Amanitaraqidé présente une paléographie bien plus tardive. De plus, les noms de son père, Pisakara, et de sa mère, Amanakhadoké, ne renvoient à aucun souverain connu au début du II $^{\mathrm{e}}$ siècle. Eu égard au contexte très perturbé dans lequel a été trouvée la table d'offrandes d'Amanitaraqidé, il serait plus plausible de voir en lui un roi ou une reine de la fin du II siècle.

Le successeur le plus probable d'Amanakharéqérem est le roi Amanitenmomidé, qui partage avec lui le même nom de couronnement, Nebmaâtrê, et fut inhumé en Beg. N.17. On ne peut toutefois pas être certain que ce souverain, qui n'est actuellement pas attesté autre part que dans la nécropole, n’ait pas régné en premier. Les scènes de sa chapelle funéraire, de grande qualité, sont en partie inspirées de celles de Natakamani. Sur le mur sud, le monarque, vêtu du costume royal tripartite mais la tête 
couverte, comme Natakamani, de l'antique coiffure dite «némès» des pharaons égyptiens, est assis sur le trône au lion, protégé par Isis, et reçoit l'encensement d'un prince. Sur le mur ouest, consacré traditionnellement à la transformation en Osiris du défunt justifié au tribunal divin, il est également assis sur le trône, dans la même tenue, suivi d'Isis, qui étend sur lui ses ailes, et reçoit une libation de lait effectuée par Anubis et Nephtys. Cette scène habituellement réservée à des registres secondaires occupe ici tout l'espace, ce qui semble inspiré des décors des tables d'offrandes. Sur le mur nord, enfin, au lieu de l'apparition en gloire du souverain justifié, on a adapté la scène du mur ouest de la chapelle de Natakamani, où le roi rendait hommage à Osiris: Amanitenmomidé, identifié par ses deux cartouches surmontés du titre égyptien de «roi de Haute et Basse-Égypte, maître des Deux Terres », est cette fois en costume de pharaonique, coiffé de la double couronne, et accomplit devant Osiris trônant en majesté l'antique rite égyptien «d'amener les veaux», souvent représenté dans les scènes funéraires méroïtiques. Il est suivi de deux théories de porteurs de palmes et d'un troupeau de bovins dont les cornes sont artificiellement déformées, suivant des usages encore vivants chez les peuples nilotiques. Cette scène du mur sud est clairement inspirée, outre les références égyptiennes, par les reliefs de la chapelle de la reine Nahirqo (Beg. N.11), exécutés trois siècles auparavant. Les panneaux décorés des murs nord et sud de Beg. N. 17 furent détachés en 1844 par Lepsius lors de l'expédition prussienne puis transportés en Allemagne: le panneau sud est actuellement visible au musée de Berlin mais le panneau nord, autrefois au musée Égyptien de l'université de Leipzig, fut détruit dans les bombardements de la cité en décembre 1943.

Dans la chambre funéraire de Beg. N.17 furent trouvés trois crânes. En 1954, ils furent examinés par un anthropologue du Peabody Museum de Harvard, où ils sont toujours conservés. Le spécialiste affirma qu'il s'agissait de deux jeunes femmes et d'un homme d'environ 30 ans. Mais on a quelques raisons de douter de cette conclusion : l'identification du sexe à partir d'un crâne, surtout jeune, est très controversée aujourd'hui. D'autre part, rien ne prouve qu'il s'agisse des occupants initiaux de la sépulture et non d'inhumations plus tardives, la réutilisation d'anciens hypogées étant très répandues, dans les derniers siècles du royaume de Méroé et à l'époque postmérö̈tique. Par ailleurs, le même anthropologue analysa également des fragments de crâne trouvés dans la tombe du roi napatéen Harsiotef à Nouri (voir chapitre précédent, p. 156 sq.) et en tira la conclusion qu'il s'agissait d'un homme d'environ vingt-cinq ans. Or ce souverain est l'un des rares dont le règne soit décrit dans une chronique précise, datée de sa trentecinquième année sur le trône et rédigée avant sa mort, si bien qu'il n'y a aucune chance qu'il soit décédé avant l'âge de cinquante ans. 
Entre les grands monuments d'Amanitenmomidé et celui de la Candace Amanakhatashan s'intercalent chronologiquement deux petites pyramides, Beg. N. 40 et 41, dont Reisner trouva les chapelles trop ruinées pour en donner une reproduction. La taille réduite des sépultures laisserait penser qu'il s'agit plutôt de princes que de rois. Mais Lepsius, qui était passé sur le site soixante-dix ans auparavant, aborde dans son journal en quelques mots les décors des chapelles, qui étaient alors mieux visibles, et décrit les défunts comme des rois. Il signale notamment le cobra à large couronne sur le front du souverain en Beg. N. 41. Sur le mur du fond (mur ouest), dit-il, ils présentent une offrande à Osiris, ce qui s'accorde avec la typologie des décors que l'on trouve en Beg. N.18. En Beg. N.41, une inscription méroïtique en cursive très fragmentaire, gravée entre deux personnages secondaires de la procession funéraire et préservée par un moulage de Lepsius, donne les titres de l'un d'entre eux. Sa paléographie correspond au milieu du $\mathrm{II}^{\mathrm{e}}$ siècle, ce qui confirme la position chronologique des monuments.

Le règne suivant, si l'on suit la disposition des sépultures dans la nécropole, doit être attribué à une Candace, Amanakhatashan, dont le nom méroïtique (peut-être Amanakhatasene) est transcrit en égyptien sur les murs de sa chapelle funéraire de Beg. N.18 dans un cartouche précédé d'un nom de couronnement effacé dont ne subsiste que l'hiéroglyphe «Rê». On ignore sa filiation mais il est possible qu'elle ait été l'épouse du roi attesté en Beg. N. 41 et soit donc séparée d'Amanitenmomidé par une génération. Comme Amanakharéqérem et plusieurs autres personnages royaux ou princiers à partir du premier siècle, son nom méroïtique contient la forme du dieu Amon appelée Amanakh, ici suivie d'un élément de sens inconnu qui était déjà présent dans les noms des rois Nastasen et Gatisen/Aktisanès.

La reine est désignée, sans marque de féminin comme il est cou-

des origines

à la chute

du sultanat

Fung rant dans les textes égyptiens de Méroé, par les titres de «fils de Rê, seigneur des apparitions» et de "roi de Basse et Haute-Égypte, maître des Deux Terres». Semblablement, la déesse Isis, qui la couvre de ses ailes, est légendée en égyptien «Isis, elle protège son fils», ce que l'on doit corriger en «sa fille». Elle apparaît enveloppée dans le manteau royal et ceinte de la large écharpe du costume tripartite, sans l'embonpoint habituel avec lequel sont représentées les Candaces, mais son genre féminin est attesté par la dépouille de vautour ajoutée sur sa calotte koushite. Sur le seul relief reproduit, celui du mur sud, elle est assise sur le trône au lion, sous lequel sont placés les «neuf arcs» figurant les peuples ennemis, comme précédemment sous les trônes d'Amanitoré et Natakamani. Deux inscriptions mérö̈tiques cursives qui nomment des personnages secondaires appartenant à la procession funéraire permettent, grâce à la paléographie des signes, de placer ce règne au milieu du $\mathrm{II}^{\mathrm{e}}$ siècle de notre ère. Un autre texte, également 
en cursive méroïtique, figure sur des blocs extérieurs de cette pyramide et peut être daté approximativement de la même époque. Il évoque le sacrifice commémoratif de trois bœufs et de quatre vaches, sans doute effectué dans les années qui ont suivi l'inhumation.

Une inscription très similaire, mais où le nombre de vaches immolées s'élève cette fois à vingt-quatre, se trouve sur la pyramide Beg. N.19, celle du roi Tarékéniwal. Cette pratique consistant à commémorer un sacrifice post mortem par une inscription gravée à l'extérieur sur le monument est attestée uniquement en Beg. N.2 pour le roi Amanakhabalé, cent ans auparavant, avec une formulation un peu différente, et pour ces deux souverains dans deux textes semblables, à un chiffre près. Elle atteste leur proximité chronologique, que l'on peut également déduire de la position proche des deux pyramides sur le deuxième rang de Bégrawwiya Nord. Comme on connait le nom de la grande épouse royale de Tarékéniwal, Amanakhalika, il est plausible qu'Amanakhatashan ait été la mère de ce monarque et ait exercé la fonction de Candace, marquée par ses titres royaux égyptiens. Leurs deux monuments funéraires, bien que de taille modeste comparés à ceux des siècles précédents, comportent une décoration de grande qualité qui témoigne d'une époque encore prospère.

Le portique de la chapelle de Beg. N. 19 est bien conservé et montre le roi effectuant le massacre rituel des ennemis, comme celui de la reine Amanishakhéto en Beg. N. 6, deux siècles auparavant. Tarékéniwal porte un pagne et une tunique ajustée couverte d'écailles comme une armure et ornée de bandes brodées d'images divines. Il est coiffé d'un diadème arborant un cobra à tête de bélier couronnée, dont les rubans flottent sur ses épaules. Il porte une mentonnière, habituelle sur les portraits royaux depuis l'époque de Natakamani et sans doute adaptée de la jugulaire des casques grecs et romains. D’une main, il tient un arc et une pique à laquelle est attachée une grappe de quatre ennemis miniatures dont les pieds battent dans le vide; de l'autre, il lève une hache de combat pour les abattre. Au-dessus de lui est inscrit dans un cartouche son nom en hiéroglyphes méroïtiques, suivi de l'élément qo: "c'est», "voici». Il est surmonté des titres égyptiens de « roi de Haute et Basse-Égypte» et de "maître des Deux Terres». Il n'y a pas de second cartouche contenant un nom de couronnement égyptien, contrairement à ses prédécesseurs. Les reliefs intérieurs du mur sud de la chapelle sont très fortement inspirés de ceux du mur ouest de la chapelle d'Amanitenmomidé (Beg. N. 17) : ils montrent Anubis et Nephtys effectuant une libation devant le souverain assis sur le trône au lion sous lequel figurent les neuf arcs.

Le successeur de Tarékéniwal fut sans doute son fils, Ariténéyesbokhé, inhumé en Beg. N.34, où fut retrouvée sa table d'offrandes. Elle indique qu'il était le fils de Tarékéniwal et d'Amanakhalika, sans doute 
la reine enterrée tout à côté de son époux en Beg. N. 32. Son nom semble le premier d'une série de trois rois tardifs qui comporte la séquence-yesbokhé (écrit yesebohe), Ariténé-yesbokhé, Aryesbokhé et Yesbokhé-Amani. Il s'agit d'une forme verbale construite sur le substantif bohe qui désigne un "chef» et qui était transcrite piankhy en égyptien (voir "La stèle du roi Nastasen", p.179-181). Le sens du nom royal est donc probablement "Ariténé l'a fait chef» ou "Ariténé règne en chef», Ariténé étant la forme méroïtique du dieu solaire égyptien Harakhty. La pyramide et la chapelle de Beg. N.34 ont été trouvées en ruines, mais des blocs appartenant à son pylône ont été découverts in situ par Reisner, puis en 1977-1978 par l'archéologue allemand Fritz Hinkel qui restaura un bon nombre de monuments funéraires à Bégrawwiya. Les deux blocs de Reisner contiennent les cartouches du roi surmontés de ses titres en égyptien, identiques à ceux de son père. Contrairement à lui, il dispose d'un nom de couronnement, Kheper-ka-Rê, emprunté à ses ancêtres Arnékhamani et Natakamani. À côté de chaque paire de cartouches se tient un cobra à tête de bélier couronnée qui devait se trouver sur la coiffure de deux figures royales disparues. Les fragments mis au jour par Hinkel complètent partiellement ces blocs: ils présentent le roi massacrant ses ennemis en deux scènes symétriques gravées sur les deux môles du pylône de la chapelle, comme son père en Beg. N.19.

On doit sans doute placer une génération plus tard le roi Amanitaraqidé dont la table d'offrandes, retrouvée dans la chambre funéraire de Beg. N.16, provient sans doute de la chapelle de Beg. N.36, située juste au-dessus (voir début de cette section). La paléographie de l'inscription indique une date à la fin $\mathrm{du} \mathrm{II}^{\mathrm{e}}$ ou au commencement $\mathrm{du} \mathrm{III}^{\mathrm{e}}$ siècle de notre ère. Il y est présenté comme le fils d'un nommé Pisakara et d'une femme appelée Amanakhadoké, deux personnes sans doute royales dont on ignore le lieu d'inhumation. Les reliefs du mur nord de la chapelle de Beg. N. 36 figurent un roi assis sur le trône au lion, en costume tripartite et diadème à urœus, encensé par un prince suivi d'une reine.

C'est au début du $\mathrm{III}^{\mathrm{e}}$ siècle qu'un troisième rang de pyramides fut inauguré à Bégrawwiya Nord, à l'est du précédent, sans doute par les trois pyramides Beg. N.30, 29 et 28. Dans les ruines de la pyramide Beg. N. 29, Lepsius retrouva une table d'offrandes gravée en écriture hiéroglyphique méroïtique, qu'il rapporta à Berlin. Assez curieusement, il ne la publia pas dans ses Denkmäler. On soupçonne qu'il ait voulu la garder inédite afin de pouvoir se réserver une éventuelle étude en vue du déchiffrement de l'écriture méroïtique, qu'il ne trouva jamais le temps de mener à bien. C'est en effet la seule table d'offrandes complète en méroïtique hiéroglyphique et, comme ses formules sont presque identiques à celles des autres tables d'offrandes royales en cursive, elle permettait d'établir 
une correspondance signe à signe entre les deux écritures. C'est ce que fit Griffith, qui la publia en 1911 après l'avoir étudiée à Berlin. Elle joua donc un rôle crucial dans son déchiffrement des signes méroïtiques. Elle est dédiée à un roi non attesté par ailleurs, Takide-Amani. Son père, Adéqétali, et sa mère, Napatadakhéto, sont également inconnus. L'historien L. Török considère que ces deux derniers ne sont pas issus de famille royale, parce que leurs noms n'incluent pas celui d'une divinité. Mais on peut citer les noms d'une bonne douzaine de rois, depuis Alara jusqu’à Tarékéniwal, où n'apparaît aucun nom de dieu. Par ailleurs, le nom de la mère de Takide-Amani, Napatadakhéto, signifie "Napata l'a enfantée» et, plutôt qu'une simple allégorie de l'antique cité royale, Napata doit ici être la déesse tutélaire de la ville, de même qu'en Égypte Ouaset était celle de Thèbes.

En fait, qu'il s'agisse d'Amanitaraqidé ou de Takide-Amani, le principal problème vient de ce que leurs ascendants ne sont pas connus par ailleurs, contrairement à Ariténé-yesbokhé dont le père, Tarékéniwal, était attesté en Beg. N.19. Or, dans les bribes de généalogie que l'on peut reconstituer pour les lignées royales de Koush, on n'a aucun exemple de monarques qui ne soient pas fils ou filles de roi. Il est évidemment probable qu'il y ait eu des usurpateurs, comme dans tous les royaumes anciens, mais on ne peut bien entendu en faire une règle et évincer des listes royales les noms des parents de souverains attestés uniquement sur les tables d'offrandes de leur enfant. Une autre solution serait de supposer que le successeur du monarque défunt ait pu dans certains cas être choisi parmi ses neveux ou ses cousins, comme le fut Taharqo sous la XXV dynastie (mais il était tout de même un fils cadet du roi Piankhy). Ce type de succession collatérale, de l'oncle au neveu, est bien attesté en Nubie pour de nombreuses charges sacerdotales ou administratives. Dans le cas d'Amanitaraqidé, son

père Pisakara et sa mère Amanakhadoké pourraient avoir été inhumés en Beg. N. 38 et 37, comme le supposait Dunham dans sa publication des fouilles de Reisner. Mais pour ce qui est des parents de Takide-Amani, seule Beg. N. 30, érigée pour un roi, pourrait être attribuée à son père Adéqétali s'il était avéré qu’il ait régné.

\section{Basse et Moyenne-Nubie aux premiers siècles de notre ère}

Autant les sources écrites méroïtiques ou égyptiennes sont rares et laconiques au centre $d u$ royaume à partir du règne d'Amanakharéqérem, autant elles sont nombreuses et volubiles au nord, entre Philae et Sedeinga. La situation est paradoxalement inversée par rapport à l'époque précédente, où la quasi-totalité des textes sont issus du Soudan central. Trois facteurs conjugués expliquent cet état de fait: le repeuplement de la Basse-Nubie, 
le Soudan

\section{8}

des origines

à la chute

du sultanat

Fung la densité des fouilles archéologiques et les caractéristiques locales des textes funéraires. Tout d'abord, il est généralement admis que la Basse-Nubie a connu de très importantes fluctuations démographiques entre le premier millénaire av. J.-C. et le début de notre ère. À l'époque napatéenne et au méroïtique ancien et classique, la zone est très largement dépeuplée. Le fait est d'ailleurs constaté par Pline l'Ancien qui attribue cette dépopulation à la "guerre entre les rois", c'est-à-dire aux conflits qui opposèrent Méroé aux Ptolémées, et il en dédouane ainsi l'expédition de Pétronius. Toutefois, le phénomène est plus ancien que l'époque lagide et remonte à la fin de la domination égyptienne.

L'archéologue Williams Y.Adams, qui fut l'un des plus actifs lors de la campagne de sauvetage de la Nubie submergée et qui examina en détail cette question, est catégorique: "En archéologie, l'"argument par le silence" est rarement sans risque, mais quand une région de plus de 300 milles de longueur a été examinée pouce par pouce et que les prospections ont relevé des centaines de sites datant du second millénaire av. J.-C. et du premier millénaire apr. J.-C., mais moins d'une douzaine pour le millénaire qui les sépare, je crois que l'on peut parler avec confiance d'un dépeuplement général.»

Adams admet que, parmi les rares sites des périodes napatéenne et méroïtique ancienne, figurent d'importants centres royaux, égyptiens ou koushites, comme à Dakka, Debod ou Qasr Ibrim. Selon lui, il s'agit non d'agglomérations conséquentes mais d'établissements où les deux États rivaux "montrent leur drapeau, c'est-à-dire proclament leur souveraineté» face au pouvoir adverse, ce qui correspond effectivement à la politique menée sur cette zone-frontière durant toute l'Antiquité. On suit moins Adams lorsqu'il attribue la raréfaction des sites d'habitat à une baisse des eaux du Nil. Cette hypothèse est en effet contredite par les relevés de hauteur de crues effectuées par les Égyptiens, notamment durant les dynasties libyennes. On se souvient également du record atteint sous l'an 6 de Taharqo (voir chapitre 6, p. 156 sq.). Le repeuplement de la Nubie aux premiers siècles de notre ère serait en partie dû selon Adams à l'introduction de la saqieh, la roue à eau, depuis l'Égypte. Ici aussi, les preuves matérielles manquent: certains spécialistes estiment que ce dispositif d'irrigation n'a pas été adopté en Nubie avant l'époque chrétienne, où elle est alors abondamment attestée.

Une autre hypothèse d'Adams, souvent reprise par la suite, doit être sûrement abandonnée. Il propose en effet que les nouveaux arrivants aient été des colons nubiens (c'est-à-dire des Noubas, locuteurs de langues nubiennes), encouragés par les rois de Méroé dont ils seraient ainsi devenus les sujets. Cette théorie s'appuie sur des arguments linguistiques discutables sur lesquels nous reviendrons dans le chapitre 9 (voirp.374sq.) mais 
dont on peut déjà dire qu'ils supposent dès l'antiquité la présence, entre la première et la troisième cataracte, d'une forme archaïque de nubien dont le descendant est encore parlé aujourd'hui. Pourtant, sur le plan historique, il ne fait pas de doute que la population de la Basse et Moyenne-Nubie des premiers siècles de notre ère constituait un ensemble homogène de langue et de culture méroïtique. D'une part, on n'y a pas retrouvé de cimetières qui attestent une culture parallèle différente, et aucun texte méroïtique de Basse ou Moyenne-Nubie ne semble contenir de noms de personnes et de lieux de langue nubienne. D'autre part, à supposer, comme le fait Adams, que ces Nubiens se soient acculturés au terme d'un long séjour plus au sud dans le royaume et soient ainsi devenus «invisibles» aux archéologues, on ne voit pas comment ils auraient abandonné leurs coutumes propres mais conservé leur langue, alors que c'est généralement l'inverse qui se produit quand une culture est ainsi phagocytée.

La théorie originelle d'Adams, c'est-à-dire le repeuplement de la Basse-Nubie aux Ir ${ }^{\text {er }}-I^{\mathrm{e}}$ siècles de notre ère après une longue période d'étiage démographique, est difficilement contestable, bien que les causes de ces fluctuations restent obscures. Mais, plutôt qu'une origine exogène, il faut privilégier une remontée vers le nord de population méroïtique, ce que suggèrent d'ailleurs à l'unisson les rares études d'anthropologie physique consacrées à la question. Les grandes familles du Triacontaschène, qui fournirent les principaux administrateurs de la région, aiment d'ailleurs à rappeler dans leurs textes funéraires leurs liens avec des "princes royaux» issus sans doute des lignées dynastiques de Méroé.

La quantité importante de textes découverts en Basse-Nubie est aussi une conséquence des prospections et des fouilles effectuées au début du $\mathrm{xx}^{\mathrm{e}}$ siècle pour anticiper les rehaussements de l'ancien barrage d'Assouan, puis de la campagne de sauvetage des monuments de Nubie lancée par l'Unesco lors de l'érection du haut barrage au début des années 1960. Plus de trente nations répondirent en effet à l'appel, permettant un quadrillage extensif du terrain archéologique. C'est ainsi que la quasitotalité des cimetières méroïtiques de la région furent fouillés en l'espace de soixante ans, livrant plus de trois cents stèles funéraires et tables d'offrandes inscrites. Cette abondante moisson a été majoritairement effectuée sur les sites de Karanóg et Shablul (fouilles anglo-américaines sous la direction de D. Randall-MacIver), de Qasr Ibrim (fouilles britanniques de l'Egypt Exploration Society dirigées par J.M. Plumley), de Nag Gamus (fouilles espagnoles sous la direction de M. Almagro), d'Arminna (fouilles américaines dirigées par W. K. Simpson et B. G. Trigger), du Gébel Adda (fouilles américaines sous la direction de A.J.Mills et N.B. Millet) et de Faras (fouilles britanniques dirigées par F.Ll. Griffith). Il faut ajouter 
pour la Moyenne-Nubie une quarantaine de textes découverts plus récemment dans les fouilles françaises de la nécropole de Sedeinga et du cimetière méroïtique d'élite de l'île de Saï.

La richesse des informations apportées par ces documents méroïtiques retrouvés en Basse et en Moyenne Nubie tient à une évolution des textes funéraires spécifique à la région septentrionale du royaume. Au sud, les épitaphes se contentent de donner le nom du défunt et de ses deux parents et enchainent immédiatement sur les bénédictions finales priant Isis et Osiris d'accorder nourriture et boisson dans l'Au-delà. Même pour les rois, la mention du titre qore, "souverain", est rarissime, leur statut étant exprimé par des bénédictions spécifiques. En revanche, au nord, une section plus ou moins développée a été ajoutée entre la filiation et les bénédictions. Dénommée "description", elle donne une liste des fonctions exercées par le défunt ("description individuelle») et ses liens de parenté avec des personnes jugées importantes, généralement des notables locaux mais parfois de hauts dignitaires du royaume ("description relative»). Elles peuvent comporter, plus rarement, des passages dits «biographiques» qui détaillent des faits d'armes ou des états de service. C'est de cette "description" que proviennent la plupart de nos informations sur la société en Nubie mérö̈tique aux premiers siècles de notre ère.

Sur l'extrême nord de la Nubie, c'est-à-dire le Dodécaschène, entre Assouan et Maharraqa, nos sources d'information principales sont les nombreux graffiti en égyptien (démotique), grec et méroïtique inscrits sur les murs du temple d'Isis à Philae et de Thot à Dakka. Il s'agit de textes d'adoration aux divinités, dits "proscynèmes» d'après leur nom grec, mais qui, lorsqu'ils sont rédigés par des Méroïtes, incluent de nombreux détails, contrairement aux courtes prières laissées par les Égyptiens. Nous avons précédemment vu que le Dodécaschène était devenu à partir du traité de Samos en 21 av. J.-C. une zone tampon semi-autonome, officiellement partie de l'Égypte romaine mais placée de facto sous l'autorité du haut-clergé des temples de Philae, de Kalabcha, de Dakka et de Dendour. L'Empire était représenté par des garnisons romaines, incluant parfois des soldats d'origine locale qui y furent stationnées jusqu'au $\mathrm{III}^{\mathrm{e}}$ siècle de notre ère. Le pouvoir exécutif était en fait tenu par des lignées d'origine mérö̈tique. L'une d'entre elles, que l'on appelle la «famille Wayekiye», d'après le nom de deux de ses membres principaux, cumule des fonctions importantes, administratives et cultuelles, à la fois dans le Dodécaschène et le Triacontaschène, la région plus au sud jusqu'à la deuxième cataracte. Cette lignée est attestée entre le début du $\mathrm{II}^{\mathrm{e}}$ siècle et celui du IV siècle sur huit générations par de longs graffiti à Philae et Dakka ainsi que par trois textes funéraires de Médik, près de Ouadi es-Seboua et du Gébel Adda. 


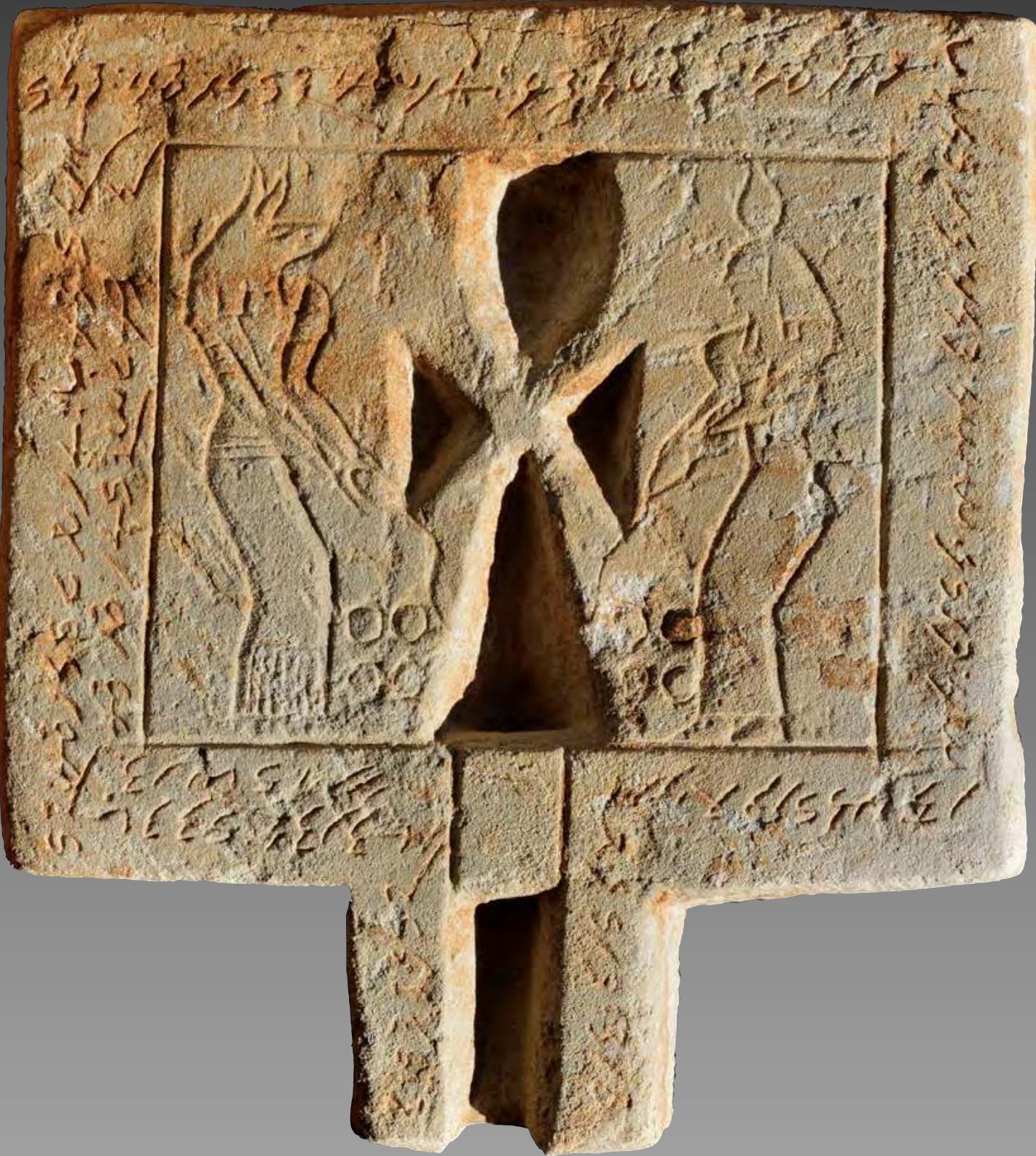

Table d'offrandes de Malitabelito, 

min $x^{4}(2)+2(x-1) 2$

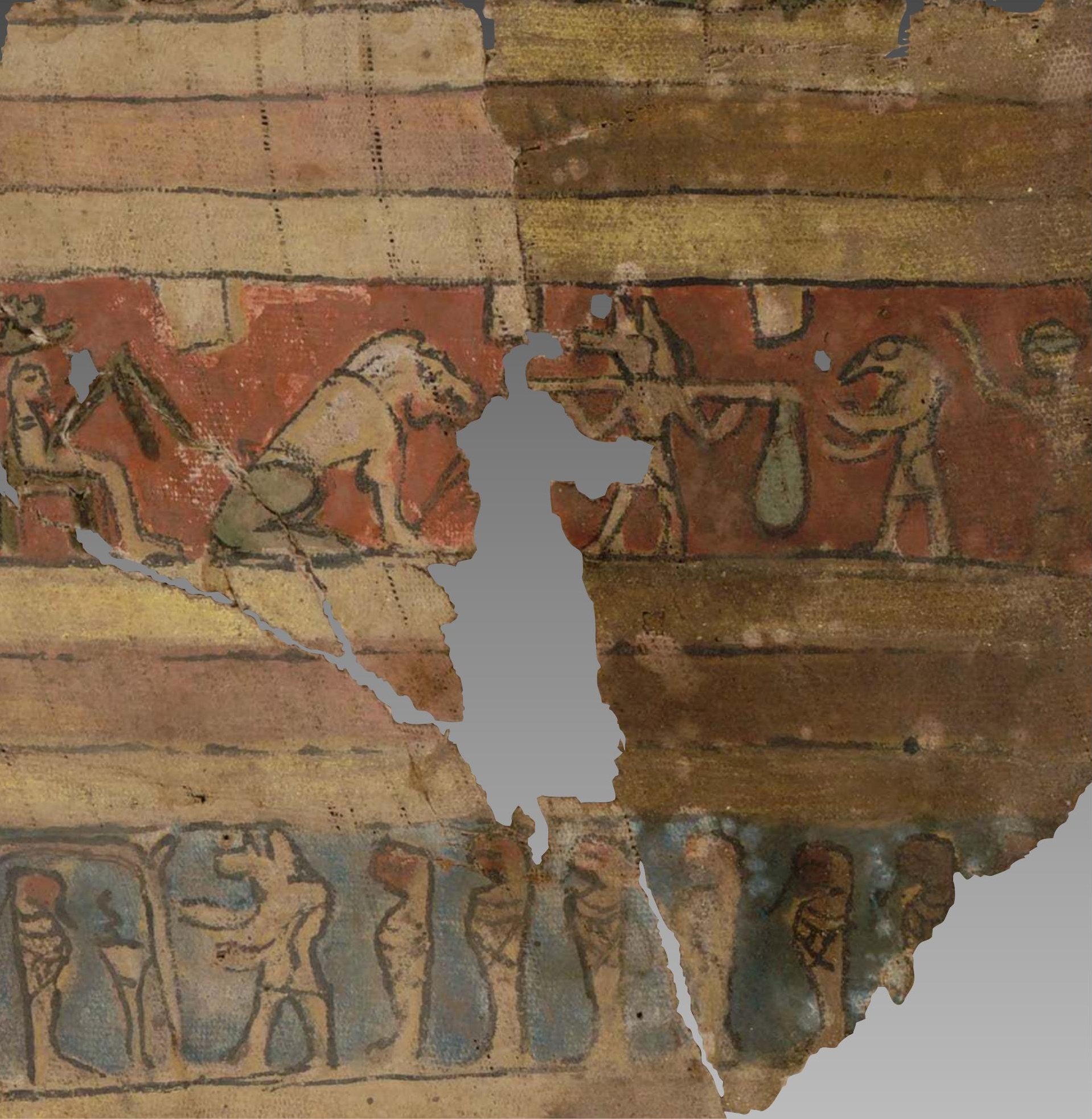


Psychostasie,

toile de sarcophage méroïtique provenant de Sedeinga, image numérisée par Arkhênum.
Confinée au début dans des fonctions sacerdotales en rapport avec le culte d'Isis de Philae, cette famille acquiert à partir du $\mathrm{III}^{\mathrm{e}}$ siècle des responsabilités plus importantes qui en font les représentants du souverain de Méroé dans le Dodécaschène et le Triacontaschène. Deux de ses membres éminents, Manitawawi et son neveu Hornakhtiotef II, au milieu du III $^{\mathrm{e}}$ siècle, sont ainsi "prophètes d'Isis», "administrateurs (du temple) d'Isis», "agents du roi dans le Pays de Nubie», "princes héréditaires de Takompso », "scribes royaux de Koush, qui connaissent les levers des cinq étoiles vivantes (planètes) et calculent les heures des éclipses du Soleil et de la Lune».

L'un des plus sûrs témoignages des liens étroits qu'entretenait cette administration locale avec le pouvoir central méroïtique nous est donné par un proscynème en démotique inscrit dans le temple de Dakka pour Qoréné, frère de Hornakhtiotef II, qui demande à Thot de l'«amener sain et sauf jusqu'à Méroé» et de lui accorder «la faveur de Pharaon, notre chef, et de ses gens", afin qu'il puisse "apporter la dîme annuelle». Le même Qoréné, fils de Wayekiye, a inscrit sur le mur du temple d'Apédémak à Naga un proscynème, le plus méridional des textes démotiques, ce qui prouve qu'il est bien arrivé, à cette occasion ou une autre, à Méroé, prenant même le temps de visiter les sanctuaires de la région.

Peu après 220 apr. J.-C., les légions romaines du Dodécaschène s'étaient en effet retirées massivement vers le nord, bien que ce ne fût que sous le règne de Dioclétien, en 298 , que les troupes quittèrent officiellement la frontière égyptienne. L'historien grec Procope, qui rapporte les faits (avec quelques confusions) au milieu du vie siècle, explique ce retrait par le faible rendement en taxes de la région, qui ne compensait pas les frais nécessaires pour entretenir des garnisons si lointaines. Il incrimine également les attaques récurrentes de peuples nomades, les Blemmyes et les Noubades, mais évoque un accord avec Rome livrant à ces derniers le Dodécaschène, alors que l'on sait qu'ils n'en devinrent les maîtres qu'au milieu du v viècle, après la chute de Méroé. C'est probablement avec les Koushites que fut passé ce pacte qui leur laissait la région, à charge pour leur roi de protéger les complexes religieux et de contrer les incursions des nomades qui menaçaient aussi le sud du territoire égyptien sous domination romaine. Plusieurs ambassades, sur lesquelles nous reviendrons, furent à cet effet dépêchées par le souverain méroïtique à Philae.

Le Triacontaschène, la région des 30 schènes $(128 \mathrm{~km})$ plus au sud, de Maharraqa jusqu'à la deuxième cataracte, était, comme nous l'avons vu précédemment, partie intégrante du royaume de Méroé depuis le traité de Samos. Elle était administrée par un gouverneur, le vice-roi de Nubie, en méroïtique peseto, qui, à partir du début de notre ère, avait son siège à Karanóg, à une soixantaine de kilomètres au nord d'Abou Simbel. 
Les vice-rois étaient choisis, sans doute par le pouvoir central, dans certaines familles de haut rang établies dans le Triacontaschène mais apparentées de manière lointaine au clan royal.

Une stèle de la fin du $\mathrm{III}^{\mathrm{e}}$ siècle, malheureusement très abîmée, trouvée à Faras et conservée à Oxford, nous préserve partiellement une liste de vice-rois de la même lignée. Le défunt, Makhéye, lui-même adjoint d'un vice-roi, détaille en effet les titulaires de cette fonction auxquels il était apparenté par sa lignée maternelle: Karinakarora, Nétéwitarora, [...]ye (début perdu), Khawitarora, Malotona, [...] tanidé, Abratoye, Makhésé, Amanibélilé, Téwinéye. Quatre d'entre eux sont aussi attestés par leurs textes funéraires de Karanóg: Nétéwitarora, Khawitarora, Malotona et Abratoye. Ordonnée chronologiquement, la liste de la stèle de Makhéye couvre sans doute plus d'un siècle. Nétéwitarora (ou Nétéwitara), le second de la liste initiale, a dû mourir à la fin du II $^{\mathrm{e}}$ siècle, à en juger par la paléographie de son épitaphe. Abratoye est bien connu par deux proscynèmes de Philae datés de 253 et 260 apr. J.-C. et il est suivi de trois autres vice-rois. Cette lignée compte également à son origine trois "princes royaux» (méroïtique pqr qorise), ce qui semble indiquer qu'elle est issue, au moins à haute date, du sang dynastique de Méroé. Aucun texte funéraire de "prince royal » n’a en effet été retrouvé en Basse-Nubie, alors qu'il n'est pas rare que des dignitaires de la région en citent parmi leurs ancêtres. Une stèle un peu plus tardive (début du IV siècle), trouvée à Arminna Ouest et rédigée pour deux défunts, frère et sœur, mentionne "des princes», non nommés, dans leur lignée maternelle et trois vice-rois inconnus par ailleurs, Akinara, Maléqoli et Shadéwali. Il semble qu'il s'agisse ici d'une famille différente et moins puissante que la précédente, même si elle compte aussi quelques prestigieux ancêtres.

La fonction de vice-roi ne paraît pas avoir été proprement héréditaire. Si le choix des vice-rois se faisait, probablement sur décision royale, dans les grandes familles du Triacontaschène, aucun d'entre eux n'était fils du peseto précédent et un seul, Khawitarora, cite un vice-roi, Litakarora (absent de la liste de Makhéye), dans sa lignée maternelle. En revanche, tous ont exercé auparavant d'autres fonctions dans les deux hiérarchies sacerdotale et administrative qui n'étaient pas séparées. Les textes funéraires de Basse-Nubie détaillent en effet la carrière des dignitaires en partant des fonctions les plus prestigieuses, normalement les dernières exercées, jusqu'aux premières, les moins élevées. C'est ce que l'historien L.Török appelle le cursus honorum, "course aux honneurs", par référence aux carrières programmées des hauts magistrats romains. Le vice-roi Malotona, un de ceux qui mentionnent le moins d'étapes, a ainsi été "prêtre pur d'Amon en chef" (womnise kroro), puis "grand-prêtre (?) à Napata» (beliloke Npte-te), avant d'être nommé «vice-roi de Nubie» (peseto Akine-te). 
Les textes funéraires de Basse et de Moyenne-Nubie regorgent de titres divers (plus de 150 actuellement attestés), dont beaucoup ne sont pas traduits ou le sont imparfaitement. Certains sont empruntés clairement à l'égyptien, souvent en incluant l'article de la langue d'origine, tel pelmos, «stratège» (de l'égyptien $p 3 m r-m s^{\varkappa}$, «le général»), qui désigne, comme en Égypte tardive, un gouverneur de nome (province). Le terme peut être d'ailleurs complété: pelmos adb-li-se, "stratège du nome», ou pelmos ato-li-se, "stratège du Nil», ce dernier recouvrant plutôt une fonction en rapport avec les processions fluviales en l'honneur d'Isis. Le titre de xrpxne, "maire», à l'origine "commandant», est un emprunt plus ancien à l'égyptien hr $r p$, «administrer». On trouve ainsi xrpxne Phrse-te «maire de Faras» ou xrpxne Atiye-te, «maire de Sedeinga ». Les relations avec les contrées environnantes étaient assurées par des ambassadeurs qui portaient le titre méroïtique d'apote, emprunté à l'égyptien $w p w t j$, «messager». C'est surtout avec l'Égypte romaine que les contacts diplomatiques étaient les plus fréquents, effectués par l'apote Arome-li-se, "ambassadeur auprès de Rome», ce qui n'obligeait pas le titulaire à des voyages au-delà de la région d'Assouan.

L'administration des temples était l'affaire du perite, «agent» (del'égyptien tardif $p 3 r t$, de même sens), et du plsn, "administrateur" (de l'égyptien tardif $p 3 m r$-šn). Dans le domaine sacerdotal, il semble que la plus haute fonction était celle de beloloke ou beliloke, un mot purement méroïtique signifiant peut-être "grand-prêtre» et généralement associé au culte d'Amon de Napata. Les Égyptiens avaient plusieurs catégories de prêtres, dont principalement les "prophètes» ( $(h m-n t r)$, les plus haut placés, et, au bas de la hiérarchie, les "prêtres purs" $\left(w^{\prime} b\right)$. Le premier de ces titres est passé en méroïtique sous la forme ant (prononcé/annata/). C'est le plus courant et il s'applique à tous les cultes: ant Wos-se, "prêtre d'Isis", ant Mni-se, "prêtre d'Amon", ant Mnp-se, "prêtre d'Amon de Napata", ant $M s$-se, "prêtre de Masha (le Soleil)", etc. Curieusement, le mot égyptien pour "prêtre pur» ne semble s'être maintenu que dans le composé womnise "prêtre pur d'Amon" (de l'égyptien w'b Jmn), parfois suivi de l'adjectif $l h$ «grand", ou (a)kroro, signifiant peut-être «premier». Ce n'est plus alors une dignité subalterne mais un titre prestigieux, souvent porté par les vice-rois. La multiplicité des mentions de fonctions sacerdotales dans les textes funéraires laisse supposer que chaque localité de Basse-Nubie disposait de temples en activité à côté des temples égyptiens en pierre souvent ruinés, mais presque aucun n'a été retrouvé. Leur bâti de briques, fragile et facilement réutilisable, explique sûrement ce vide archéologique. Celui de Qasr Ibrim, où était adoré Amon de Primis (Amni Pedeme-te), fait exception. Les fouilles britanniques de l'Egypt Exploration Society y ont mis au jour un important sanctuaire méroïtique, héritier du temple bâti par Taharqo 
au viI ${ }^{\mathrm{e}}$ siècle av. J.-C. C'était notamment un lieu de pèlerinage où étaient rendus des oracles. Transcrits sur des bandes de papyrus et recopiés sur des ostraca (tessons) ou des morceaux de cuir, ils étaient soigneusement gardés comme talismans.

Au sud du Triacontaschène, on ne connaît pas de manière sûre quelles étaient les régions administratives du royaume. Le seul témoignage est sujet à caution. Il s'agit des représentations des nomes (divisions territoriales) de Basse-Nubie et de Koush sur les murs du temple d'Isis à Philae. Une version date du règne de Ptolémée II Philadelphe (283-246 av. J.-C.), l'autre de Ptolémée VI Philomêtôr (180-145 av. J.-C.). Bien que chaque région soit symbolisée par une divinité particulière comme celles qui, en Égypte, personnifient les nomes, il est probable que seules les localités importantes et surtout connues des Égyptiens soient ici figurées et non les divisions administratives officielles. La Basse-Nubie (de la première à la deuxième cataracte) en comporte en effet sept, alors que le vaste territoire en amont de la boucle du Nil n'en compte que trois, Napata, Méroé et Kenset. La Haute-Nubie est représentée par Pnoubs (Kerma) et Kawa. La Moyenne-Nubie (de la deuxième à la troisième cataracte) en compte deux: Sedeinga sur la rive gauche et, sur la rive droite, Ta-Ouadj (la «terre verte»), sans doute nommé ainsi en raison de la teinte verdâtre du désert causée par la présence d'oxyde de cuivre. Curieusement, l'île de Saï, principauté autonome sous le royaume de Kerma et seul évêché de la région à l'époque chrétienne, ne figure dans aucune des deux listes. Sedeinga est le chef-lieu de la région, probablement depuis l'essor de la XXVe dynastie, puisque le petit temple bâti sous

des origines

à la chute

du sultanat

Fung Amenhotep III pour la reine Tiyi fut rénové et agrandi sous le règne de Taharqo, au début du viI ${ }^{\mathrm{e}}$ siècle. Il s'effondra peu après, probablement par suite de mouvements telluriques qui eurent raison de fondations trop fragiles. L'adoration de la reine divinisée ne disparut pas complètement mais subsista sous la forme d'un culte à Isis dont le temple reste à découvrir. Les textes funéraires méroïtiques de Sedeinga font en effet mention plusieurs fois de cette déesse, qui dispose en ce lieu de prêtres nommés ateki ou ateqi et d'autres appelés semte. Une stèle tardive du temple d'Apédémak à Méroé, au nom de Yesbokhé-Amani, un des derniers souverains, mentionne encore une Isis et un Horus de Sedeinga en parallèle avec les formes de ces divinités honorées à Philae.

Sedeinga et sa région étaient dirigés par des princes locaux qui, nous l'avons vu, disposaient d'un lieu d'inhumation à part sur une colline située à l'écart de la grande nécropole, le secteur ouest. Leurs prédécesseurs napatéens y avaient fait bâtir de vastes pyramides qui étaient alors ruinées. L'habitude se répandit sur le site, à l'époque méroïtique tardive, 


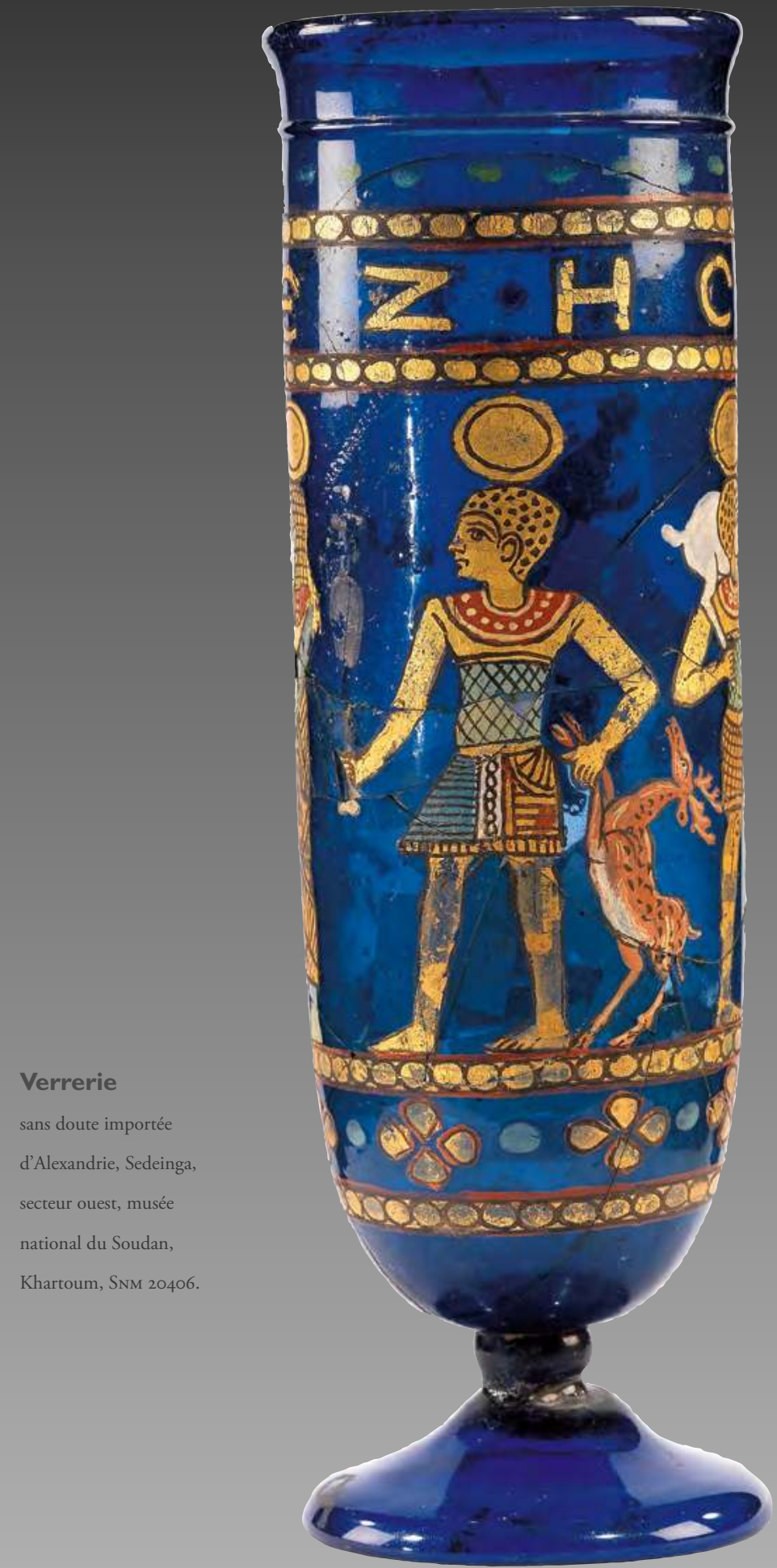




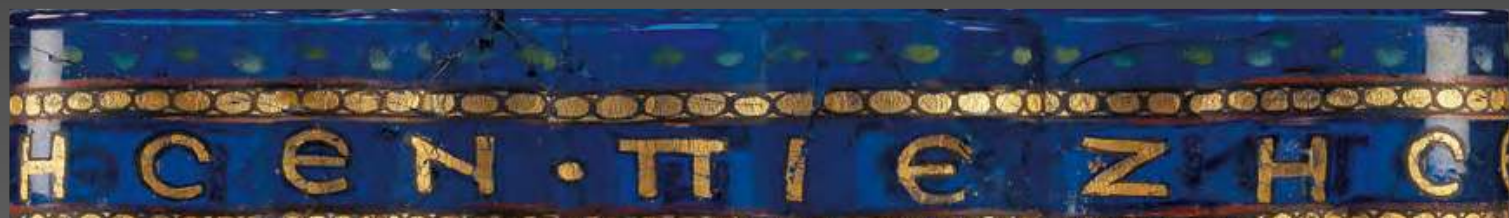

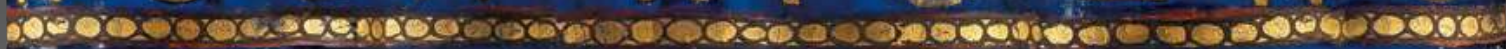
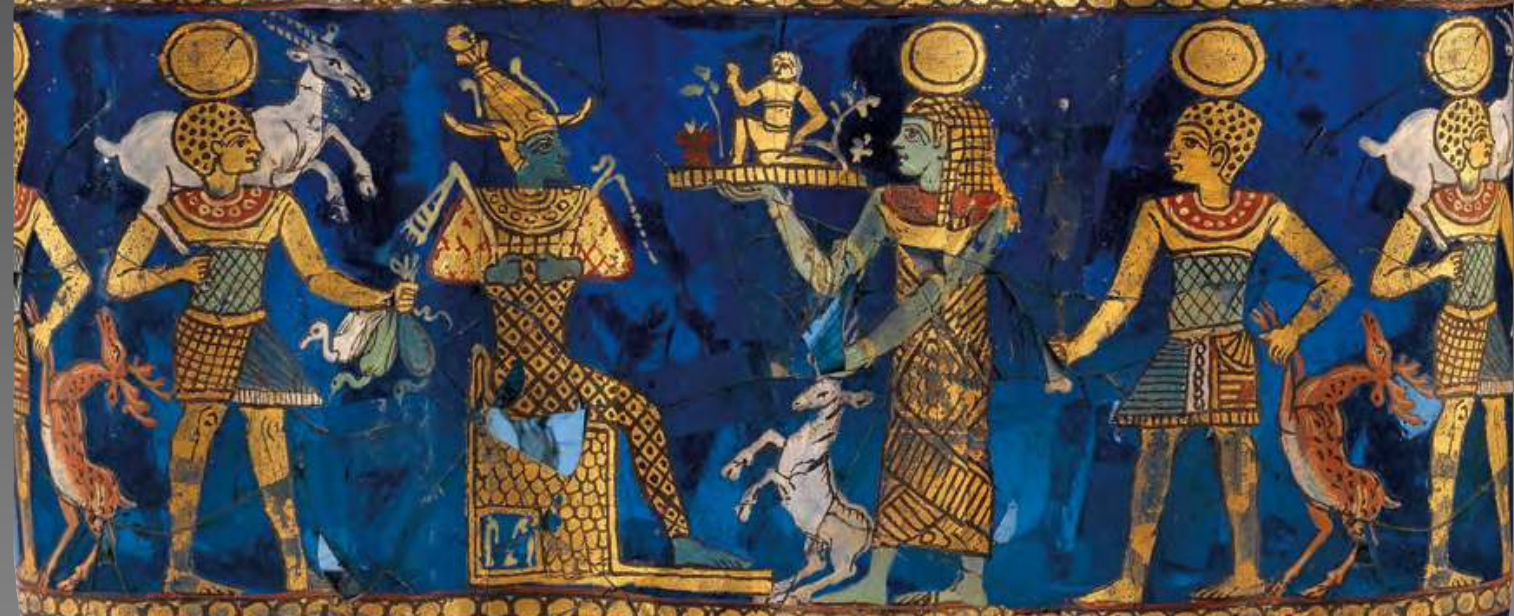

pover a Poo

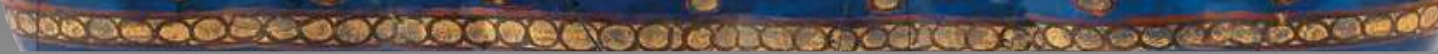

Verrerie

sans doute importée

d'Alexandrie,

déroulé, Sedeinga

secteur ouest, musée

national du Soudan,

Khartoum, SNM 20406 
de réutiliser les caveaux anciens vidés par les pillages et de construire immédiatement à l'est de la pyramide originelle un nouveau monument comportant une chapelle funéraire neuve. C'est ce que l'on appelle des "pyramides couplées", bien que les deux bâtiments soient d'époque différente. Le même procédé a récemment été mis en évidence dans le secteur II de Sedeinga. Ces pyramides secondaires sont de taille inférieure et de facture moins soignées que les pyramides originelles. Cette pratique laisse supposer un certain déclin, économique ou démographique de la cité, qui a son parallèle à Méroé où les monuments funéraires des souverains, à partir du $\mathrm{II}^{\mathrm{e}}$ siècle de notre ère, décroissent en taille et en qualité. Il semble que seule la Basse-Nubie connaisse à cette époque une période florissante, profitant sans doute de sa situation frontalière avec l'Égypte romaine. Toutefois, le déclin supposé de Sedeinga est tout relatif: les fouilles du secteur ouest ont mis au jour, malgré les pillages, des trousseaux funéraires luxueux, incluant des verreries de toute beauté, sans doute importées d'Alexandrie, et des bagues d'or et d'argent aux chatons ornés de motifs où se mêlent les traditions koushite et gréco-romaine. On a supposé qu'une des sources principales de la richesse des princes de Sedeinga provenait de sa position au débouché des pistes du désert occidental sur le Nil, ce qui leur permettait d'encaisser des taxes importantes sur le commerce caravanier.

Parmi la dizaine de textes funéraires découverts sur le secteur ouest, un ensemble exceptionnel nous donne un aperçu du clan princier qui gouvernait Sedeinga. Quatre inscriptions (stèle, table d'offrandes, seuil et linteaux inscrits) proviennent d'une petite chapelle ajoutée devant la pyramide secondaire WT2. Elles commémorent un prince nommé Natemakhora qui dirigeait la région dans la seconde moitié du II ${ }^{\mathrm{e}}$ siècle de notre ère. Son cursus honorum indique qu'il a exercé les fonctions de stratège (gouverneur) du nome, d'aribet (peut-être responsable des taxes) à Sedeinga, d'atxmo (titre obscur) à Amara, de "premier prêtre pur d'Amon" et enfin de «sleqene à Sedeinga ", sans doute "chef de district», un titre relativement subalterne en Basse-Nubie mais qui, ici, désigne apparemment la plus haute fonction locale. Natemakhora rappelle par ailleurs ses liens de parenté avec des ancêtres et parents prestigieux. Bien qu'il soit lui-même né à Sedeinga, dont il est un «bon habitant" (mlomrse Atiye-te), il compte parmi ses ancêtres de hauts personnages de la région de Méroé, dont un "prince royal" et "un aleke (titre) à Naga». Les dernières lignes de ces textes sont des indications biographiques plus générales. «Il a administré ce nome (Sedeinga) et Ta-Ouadj", c'est-à-dire la région située sur l'autre rive du Nil, comme nous l'avons vu ci-dessus. Il s'est acquitté de ses tâches à la satisfaction de tous: "C'était un homme de valeur aux yeux de son supérieur, du souverain et du dieu.» Enfin, il mentionne 
apparemment un pèlerinage officiel effectué en tant que chef du nome auprès de l'Isis de l'Abaton, face à l'île de Philae. L'ensemble de ces textes montrent que Natemakhora disposait d'un statut très similaire à celui du peseto, le vice-roi de Basse-Nubie, dont il ne dépendait probablement pas encore. Toutefois, moins d'un siècle plus tard, il semble que, face à la dégradation de la situation due aux incursions des Noubas, Sedeinga fut intégré dans une vaste province septentrionale dirigée par le vice-roi Abratoye (vers 260 apr. J.-C.). Celui-ci, d'après sa stèle funéraire, proclamera sa suzeraineté "depuis la Basse-Nubie jusqu'à Ta-Ouadj" mais sera de surcroît contraint d'engager le combat contre les tribus noubas sur le sol même de Sedeinga. La cité de Tiyi, qui longtemps avait bénéficié de sa position au débouché des pistes caravanières du désert, en subira cette fois de fâcheuses conséquences, les mêmes chemins ayant aussi servi à l'ennemi pour gagner la vallée du Nil.

\section{Téqoride-Amani et les ambassades de Méroé à Philae}

le Soudan

\section{0}

des origines

à la chute

du sultanat

Fung

Le roi Téqoride-Amani est le seul souverain de Méroé dont on connaisse la date d'accession au trône, en 248-249 apr. J.-C., grâce à une inscription démotique de Philae datée conjointement de son règne et de celui de l'empereur romain Trébonien Galle. Le texte, une très longue prière (proscynème) à Isis gravée sur la porte d'Hadrien, fourmille de détails de grande valeur historique, bien que l'interprétation n'en soit pas toujours simple. Il est daté du 10 avril 253 et relate deux ambassades successives de Sasan, envoyé du roi Téqoride-Amani (en démotique Tqrrmn, avec la transcription habituelle par un $r$ égyptien $\mathrm{du} / \mathrm{d} /$ méroïtique rétroflexe entre voyelles). Le nom du dignitaire, autrefois lu "Pasan», a récemment été rectifié et figure sous la forme «Sasan» dans une nouvelle étude du texte publiée en 2009 par Jeremy Pope.

Sasan était "scribe royal en chef" (méroïtique qorene akroro) et "grand envoyé auprès des Romains", et c'est en cette qualité qu'il convoya à Philae, deux années de suite, dix talents d'or offerts par le souverain au clergé d'Isis. Le roi l'avait de plus chargé de prendre part en son nom aux cérémonies en l'honneur de la déesse et de son époux Osiris (notamment aux plus importantes, les fêtes annuelles de Khoïak), de procéder aux sacrifices rituels et de régaler par des festins les prêtres de Philae. Son second séjour ne dura pas moins de six mois, de novembre à avril. Il était entouré de personnages connus par ailleurs grâce à leurs proscynèmes: Wayekiye (deuxième $\mathrm{du}$ nom), gouverneur du Triascontaschène, Qoréné, dont nous avons mentionné dans la section précédente les allers-retours vers Méroé pour apporter la dîme, et Abratoye, le vice-roi de Nubie, désigné du reste en démotique 
par le titre pharaonique ancien de «fils royal» (voir chapitre 4, p. 85 sq.), qui fit le voyage depuis Karanóg sur l'ordre du souverain durant les deux séjours de l'ambassadeur. Chacun d'entre eux, y compris Sasan, ajouta au présent royal une quantité d'or pour la confection d'objets de culte destinés à la déesse. L'ambassadeur du roi était également chargé de cadeaux diplomatiques destinés à "César», l'empereur de Rome, sans doute confiés à des représentants du préfet d'Égypte dans la région d'Assouan.

Le fait que le proscynème soit daté in fine du règne de Trébonien correspond, semble-t-il, à une période de passage de relais où le pouvoir romain s'exerçait encore autour de Philae. Deux autres proscynèmes de Méroïtes, datés de 260, sept années plus tard, indiquent que la situation avait évolué vers un renforcement de l'influence koushite sur la région. Ils sont en effet inscrits non en démotique mais en grec, la langue officielle de la partie orientale de l'Empire romain. Leurs auteurs sont à nouveau le viceroi Abratoye et un ancien intendant du temple de Philae, Tami, envoyé en tant que "très honorable ambassadeur» du roi de Méroé. Comme précédemment, Abratoye avait dû accompagner l'émissaire du souverain à Philae. Les deux textes, qui sont avant tout des proscynèmes adressés à «Isis aux milliers de noms", nous éclairent peu sur le contenu de la mission, mais celui de Tami indique que «revenant après sept ans, il a fait la paix» et qu'il a procédé à l'investiture d'un prêtre d'Isis. Il est difficile de savoir si la première affirmation doit être replacée dans un contexte officiel ou personnel, mais la nomination d'un prêtre à Philae revêt une importance politique: elle était précédemment du ressort des autorités égyptiennes.

On ne peut garantir que l'ambassade de Tami s'est effectuée sous le règne de Téqoride-Amani, dont on connaît la date d'accession au trône, dix ans auparavant, mais non celle de sa mort. Sa table d'offrandes, retrouvée par Reisner à l'angle de la chapelle de la pyramide Beg. N. 28, indique que sa mère s'appelait Araqatan-makas et son père, Téritanide. Une fois de plus, aucun des deux n'est attesté comme souverain et l'hypothèse d'une succession collatérale pourrait expliquer ce fait. Son nom méroïtique signifie sans doute "celui qu'il a fait roi, Amon». Il est le dernier des monarques de Méroé pour lequel on possède un nom de couronnement, Kheper-ka-Rê, imité de celui de Natakamani deux siècles plus tôt et inscrit dans le premier d'un double cartouche sur le mur sud de sa chapelle funéraire en Beg. N.28, le second contenant son nom méroïtique en écriture hiéroglyphique. Le roi, selon la tradition la plus fréquente, y est représenté assis sur le trône au lion, protégé par les ailes d'Isis tenant la plume de Maât en signe de justification du défunt et encensé par un prince. Au-dessus de ce dernier, sur le mur nord, figuraient son nom et ses titres en cursive, mais les trop nombreuses lacunes 
le Soudan

\section{2}

des origines

à la chute

du sultanat

Fung ne permettent pas de l'identifier. Il est suivi d'une femme légendée (avec lacunes) comme "So [..]wo [...]eti, la grande épouse royale», et d'un second personnage féminin de haute taille, puis d'une procession de femmes sur deux registres. Sur le mur nord, le prince thuriféraire est seul face au roi, mais un défilé d'hommes, sur trois registres, se trouve derrière lui. Tous les participants, sauf l'officiant, portent des palmes, associées à Méroé aux cérémonies en l'honneur des rois défunts.

Le roi Téqoride-Amani est également cité sur trois cubes de grès sombre, sans doute des socles de statues, retrouvés par Garstang dans le temple d'Apédémak à Méroé. Le nom du dieu-lion y apparaît en tête, suivi de celui du souverain sur lequel les bienfaits divins sont appelés. Ces inscriptions témoignent d'une dévotion royale ininterrompue, même à cette période tardive, envers le dieu-créateur auxquels étaient déjà consacrés les temples bâtis par Arnékhamani à Musawwarat cinq siècles auparavant. De manière générale, le règne de Téqoride-Amani semble encore une période de stabilité où le souverain tient son territoire au sud comme au nord, accroît son pouvoir et, par ses luxueux présents répétés au temple d'Isis de Philae, fait montre de sa richesse à la lisière d'un monde romain en recul.

Lorsque Lepsius visita Méroé en 1844, il se livra, sinon à de véritables fouilles, du moins à quelques dégagements. C'est ainsi qu'il trouva en Beg. N.28 une table d'offrandes inscrite en méroïtique cursif qu'il rapporta dans les collections du musée de Berlin et attribua au roi inhumé en ce lieu. Ce n'est que soixante-dix ans plus tard que fut découverte par Reisner celle de Téqoride-Amani, le véritable possesseur de la tombe. La table d'offrandes de Berlin présente plusieurs difficultés. Le nom du défunt, tout d'abord, est sans doute orthographié de manière fautive, si bien que deux lectures sont possibles: Tmlqordemni (vocalisé Tamalaqorade-Amani) ou Tmelordemni (Tamélorade-Amani). Ensuite, sa mère Araqatan-makas est la même que celle de Téqoride-Amani, tandis que le nom de son père, Arotanide, tout en ressemblant à Téritanide, père de Téqoridémani, est différent.

De plus, sur cette stèle, la formule de filiation maternelle est redoublée, ce qui est généralement interprété comme signalant un deuxième mariage. Tamalaqorade-Amani (ou Tamélorade-Amani) serait donc un demi-frère $d u$ roi Téqoride-Amani... ou une demi-sœur, car on ignore le sexe du défunt, le méroïtique ne connaissant pas de genre grammatical. Quant à son statut royal, il n'est pas certain. Les méroïtisants, Griffith le premier, ont généralement distingué les souverains par l'emploi de formules spécifiques, dites $\mathrm{K}$ et $\mathrm{L}$, au lieu des habituelles A et B. Dans les formules de bénédiction qui concluent les textes funéraires méroïtiques, on appelle généralement Isis et Osiris à fournir aux défunts 
de l'eau (formule A) et du pain (formule B). Mais dans les tables d'offrandes royales, c'est une qualité de pain particulière (formule $\mathrm{K}$ ) et du lait (formule L) qui sont demandés aux dieux.

Or, il s'est passé à Méroé ce qui est arrivé dans de nombreuses civilisations: les prérogatives des souverains ont été peu à peu réclamées par le clan royal, puis par les puissants du royaume. C'est ainsi qu'en Égypte la pyramide, l'embaumement, les textes funéraires se sont étendus petit à petit de la personne du pharaon à la famille royale, puis à tous ceux qui en avaient les moyens. Dans le royaume méroïtique, les formules de bénédiction royales $\mathrm{K}$ et $\mathrm{L}$ se trouvent ainsi sur plusieurs tables d'offrandes $\mathrm{du}$ cimetière de Bégrawwiya Ouest où, depuis le $\mathrm{III}^{\mathrm{e}}$ siècle av. J.-C., étaient enterrés les membres subalternes de la famille royale et peut-être, comme à l'époque napatéenne, les administrateurs de la région de Méroé.

Certains spécialistes, notamment Inge Hofmann, ont supposé que ces tables d'offrandes avaient été déplacées depuis le cimetière nord pour être réutilisées dans des enterrements tardifs. Considérés comme des souverains, ces défunts, Amanakhedoli, Mashaqadakhel, Patrape-Amani, Amanipilade, ont donc été ajoutés sur les listes royales publiées dans des ouvrages récents sur la simple foi de leurs formules funéraires. Certes, on a un exemple de tombe très tardive dans un cimetière privé de la ville de Méroé où, par superstition, le défunt s'est entouré de tables d'offrandes glanées çà et là dans les monuments voisins. Mais il paraitt invraisemblable que l'on ait déplacé des tables d'offrandes depuis la nécropole royale dans le cimetière ouest, distant de près d'un kilomètre, alors que tant d'autres étaient disponibles dans les monuments ruinés de la même nécropole. De plus, certaines de ces tables d'offrandes retrouvées dans le cimetière ouest, d'après leur paléographie, datent de la même époque que les sépultures à proximité desquelles elles ont été retrouvées. Enfin, la plupart de ces souverains supposés sont à peu près contemporains de Téqoride-Amani, ce qui mènerait à une inflation considérable de rois en un espace de temps restreint, soit la seconde moitié du III siècle. Il est donc plus rationnel et plus économique de penser que ces princes du cimetière ouest n'ont jamais régné, mais ont simplement adopté, à partir de cette époque, les formules auparavant réservées aux monarques.

Il est de même probable que le possesseur de la table d'offrande de Berlin trouvée dans la tombe de Téqoride-Amani soit, non un souverain, qui disposerait alors d'une sépulture propre, mais un demi-frère ou une demi-sœur du roi, peut-être enterré(e) à ses côtés. Dans les nécropoles provinciales, notamment à Karanóg, Saï, Sedeinga, il est courant que plusieurs membres d'une même famille partagent la même tombe. On trouve au Gébel Adda, à Karanóg, des exemples de textes funéraires rédigés pour deux personnes, souvent des frères ou des sœurs. Il est également possible 
que Tamalaqorade-Amani (ou Tamélorade-Amani) ait été une des épouses de Téqoride-Amani, conformément à la coutume pharaonique et napatéenne des mariages royaux consanguins.

\section{Les incursions des Noubas et l'expansion d'Axoum}

le Soudan

314

des origines

à la chute

du sultanat

Fung

On a longtemps avancé avec beaucoup de précaution que les tribus noubas et le royaume abyssin d'Axoum étaient à l'origine de la chute de Méroé, vers 350 apr. J.-C. La réanalyse des sources textuelles et archéologiques fait désormais de cette hypothèse une certitude. Toutefois, leur action destructrice commence à se faire sentir dès les siècles précédents. Les Noubas sont un ensemble de tribus nomades situées à l'origine dans le Darfour et le Kordofan. Sur le plan linguistique, leurs langues sont les plus proches du méroïtique, ce qui laisse supposer une ascendance commune entre le sixième et le troisième millénaire, probablement dans le bassin inférieur du Wadi Howar, à l'ouest de la boucle du Nil. L'établissement du puissant royaume de Kerma vers 2450 av. J.-C. les a vraisemblablement empêchés, lors de la dessiccation du désert occidental, de se réfugier comme les Koushites dans la vallée du Nil. On suppose qu'ils ont pu subsister dans le Kordofan entre le milieu du troisième millénaire et la fin du premier millénaire avant notre ère, une période où l'aridité de la région s'installe progressivement. Au quatrième siècle av. J.-C., les rois napatéens Harsiotef et Nastasen relatent des campagnes militaires dirigées contre les Makha $(M b)$, où l'on peut reconnaître les ancêtres des Noubas (voir chapitre 6, p. 156 sq.). Les Méroïtes, rappelons-le, utiliseront deux termes pour les désigner: un premier, neutre et précis, Mho, "Maghu» (napatéen $M b$ ), dérivé du nom qu'ils se donnaient (que l'on peut reconstruire comme Magur ou Magi), et un second, péjoratif et imprécis, Nob, «Nouba», qui signifie en méroïtique "esclaves» et pouvait à l'occasion être employé pour d'autres populations. Les expéditions de Harsiotef et de Nastasen contre les Makha sont d'ailleurs des campagnes offensives et sans doute assez lointaines pour razzier bétail et main-d'œuvre servile.

Au début du $\mathrm{III}^{\mathrm{e}}$ siècle av. J.-C., les Noubas, selon le savant alexandrin Ératosthène, constituent un "grand peuple» (grec mega ethnos), une qualification où l'adjectif doit être interprété en termes de démographie. Ils vivent selon lui "en Libye», c'est-à-dire, d'après la tradition des géographes antiques, à l'ouest du Nil et non sur le territoire libyen actuel, et ce "depuis Méroé jusqu’aux méandres (du fleuve)». Cette dernière précision doit être rectifiée ou du moins clarifiée. Il est en effet exclu que les Noubas aient pu prospérer dans la Bayouda entre Méroé et Napata, un territoire crucial pour les Méroïtes puisque les pistes reliant leurs deux capitales 
y passaient. Il faut plutôt comprendre "entre la latitude de Méroé et celle de la grande boucle du Nil », c'est-à-dire dans la région du Wadi el-Melik qui, jusqu'à l'époque moderne, a servi de voie de passage privilégiée entre le Darfour, le Kordofan et le Nil. Toujours selon Ératosthène, ils sont "divisés en plusieurs royaumes», bien que la proximité de leurs langues supposent qu'ils ont dû longtemps former une unité ethnique. Dans les premiers siècles de notre ère, ils sont en tout cas dispersés sur un large espace entre l'ouest de la Basse-Nubie et la Gézira, au sud de Khartoum, à en juger par la localisation de leurs incursions.

La première mention connue des Noubas (Nob) dans les textes méroïtiques - si c'est bien eux et non de simples «esclaves» qui sont cités - se trouve au dos d'une statue d'Isis placée dans le temple d'Amon du Gébel Barkal et aujourd'hui conservée à Berlin. Elle est contemporaine $\mathrm{du}$ règne de Tanéyidamani, vers 170-15O av. J.-C. Le contexte du mot n'est pas clair mais la mention récurrente de l'«ouest» (teneke) et peut-être le verbe «tuer» (ked-d) laissent supposer qu'il s'agit d'opérations armées. Plus tard, au $\mathrm{I}^{\text {er }}$ siècle av. J.-C., le contenu militaire ne fait pas de doute. Un support d'oriflamme du temple d'Amon de Napata, en forme de statuette de bronze, figure un ennemi ligoté, à la chevelure hérissée surmontée d'une longue plume. Sur son ventre est gravée l'inscription qo qore Nob-o-l-o: "Celui-ci est le roi des Noubas». Au Ir siècle de notre ère, la table d'offrandes du pesto Khalalakharora, retrouvée à Faras, contient un passage où il apparaît que le vice-roi de Nubie a réprimé une attaque des $M$ ho contre Koush, "tuant l'homme et asservissant la femme» (singulier à sens collectif), selon la phraséologie habituelle. Sur les tables d'offrandes de Basse-Nubie $\mathrm{du}$ III ${ }^{\mathrm{e}}$ siècle, les mentions de combats contre les Noubas se multiplient dans des passages biographiques, indiquant le nombre de chefs capturés ou tués. La stèle funéraire du vice-roi Abratoye (vers 270) contient un long paragraphe qui décrit ses campagnes en Basse-Nubie ou à Sedeinga: «Il a tué 50 Noubas [...] il a tué 40 chefs nobas.» Encore plus tard, à la fin du III siècle, même la représentation d'une ambassade méroïtique à Philae, sur laquelle nous reviendrons, est prétexte à recenser les ennemis abattus. La figure du vice-roi Békemetéli y est ainsi légendée d'une inscription qui se termine par: «C'est le stratège du nome. Il a tué 537 Nobas.»

Bien entendu, c'est toujours le terme péjoratif Nob, «Nouba», qui est utilisé dans ces passages de teneur guerrière. Le terme neutre $M h o$, "Maghu ", réapparaît peu après, et justement dans des circonstances plus diplomatiques, sur deux textes funéraires du début du Ive siècle. Une stèle de Faras commémore en effet un certain Maluwitara, dignitaire dont la généalogie mêle de hauts lignages de la même cité et de l'île de Saï. Son cursus honorum indique qu'il a par trois fois exercé la fonction 
le Soudan

\section{6}

des origines

à la chute

du sultanat

Fung d'ambassadeur (apote), d'abord auprès de la contrée de Khalité, de localisation inconnue, puis auprès du pays des Maghu (apote Mheyo-se) et enfin auprès des Romains. L'autre stèle, originaire du Gébel Adda, est contemporaine ou légèrement postérieure. Elle comporte un passage biographique qu'il serait encore périlleux de traduire mais où est assurée la mention d'un certain "Tarutikhi, roi des Maghu» (Trotihi qore Mho-li-se-l). Le nom de ce souverain comporte sans doute le verbe vieux-nubien taru "honorer". Il semble donc qu'à partir du IV siècle, les Noubas aient passé un cap: ils n'étaient plus seulement des ennemis que l'on repoussait, mais un pouvoir établi avec lequel on était contraint de traiter. On ignore en revanche où se trouvait ce royaume nouba: sur les marches de l'État méroïtique ou déjà sur une portion de son ancien territoire? Lacte final de cette irrésistible progression des Noubas sera, quelques décennies plus tard, le remplacement de l'administration méroïtique par leurs propres élites.

Méroé était non seulement menacée à l'ouest mais aussi à l'est, par l'ascension du royaume d'Axoum. Depuis probablement le deuxième millénaire avant notre ère, les peuples sud-sémitiques du Yémen avaient commencé à coloniser des portions de l'actuelle Éthiopie. Au viII ${ }^{\mathrm{e}}$ siècle av. J.-C., une première entité politique dite "pré-axoumite", le Da'mot, est fondée par des colons originaires du royaume de Saba dans le Tigray et en Érythrée autour des cités de Yéha et Axoum. Vers le début de l'ère chrétienne est créé l'Empire d'Axoum qui mêle aux origines sabéennes des éléments locaux et des influences hellénistiques, comme le montrent les langues dans lesquelles sont rédigées ses inscriptions, à savoir le sabéen, le guèze et le grec. Depuis le port d'Adoulis, au sud de l'actuelle Massaoua, en Érythrée, se développe un commerce transcontinental dont se fait l'écho un texte grec anonyme, le Périple de la mer Érythrée, qui recense les ports de la mer Rouge et de l'océan Indien. Axoum exporte des produits africains, notamment de l'ivoire et des animaux vivants, des épices, de l'encens et de la myrrhe. Il importe en grande quantité toute sorte de produits manufacturés originaires du monde méditerranéen et des Indes. Pour sécuriser ce commerce rentable et étendre leur pouvoir, les rois d'Axoum s'emparent aux III $^{\mathrm{e}}$ et $\mathrm{IV}^{\mathrm{e}}$ siècles de vastes portions de la côte et conquièrent de l'autre côté de la mer Rouge, dans l'actuel Yémen, les royaumes de Himyar et de Saba, d'où avaient émigré une partie de leurs ancêtres. Dans l'arrière-pays érythréen jusqu'à la frontière avec le royaume mérö̈tique, ils soumettent diverses tribus, dont les Bedjas, cousins des Blemmyes qu'avaient combattus les rois napatéens.

L'Empire d'Axoum est un pouvoir récent, beaucoup plus dynamique et ouvert sur le monde contemporain que le royaume de Méroé confiné sur la vallée du Nil et engoncé dans les traditions pharaoniques 
millénaires. Le grec, la lingua franca du Moyen-Orient dans l'Antiquité tardive, est d'usage fréquent à Axoum, et c'est une des langues dans lesquelles sont inscrits les textes officiels. Le christianisme, en plein essor à cette époque, y est considéré avec bienveillance et deviendra au milieu du IV $v^{e}$ siècle la religion d'État. Enfin, les rois axoumites introduisent un dispositif dont le royaume méroïtique s'était étonnamment passé, la monnaie. Il faudra attendre au Soudan la fin de la période médiévale pour qu'elle entre en usage, alors que l'Égypte l'avait déjà adoptée dès la domination perse. Les échanges se faisaient sur le principe du troc, bien qu'il existât des unités de référence basées sur un poids de métal précieux pour estimer la valeur d'une marchandise, comme le chât ou le deben dans l'Égypte antique, mais, à Méroé, apparemment empruntées au voisin ptolémaïque.

Un graffito méroïtique du $\mathrm{II}^{\mathrm{e}}$ siècle av. J.-C., inscrit sur un mur de la Grande Enceinte de Musawwarat par un chasseur, figure un lévrier attrapant un lièvre et ajoute ce commentaire optimiste: "Puisse ce chien me rapporter trois talents." Bien qu'il s'agisse de talents de cuivre, la somme reste coquette. Le mot écrit $t l t$ et prononcé /talanta/ est emprunté au grec talanta, "talents», et aussi attesté dans des inscriptions plus tardives. Mais ce procédé ne pouvait rivaliser avec la commodité qu'apportait l'existence d'une monnaie sonnante et trébuchante. Moins d'une trentaine de pièces ptolémaïques et romaines ont été retrouvées sur le territoire actuel du Soudan, ce qui indique bien que la monnaie, fûtelle importée, n’avait pas cours dans le royaume de Méroé. À Axoum, les premières pièces, en or, argent et bronze, sont frappées sous le règne du roi Endoubis, vers 270 apr. J.-C.

Mais le commerce axoumite avec le monde méditerranéen battait son plein bien avant cette introduction dont elle était plutôt une conséquence et permettait à l'Empire romain d'acquérir les produits convoités de l'Afrique par voie maritime, un chemin plus sûr et plus rapide que les pistes caravanières qui reliaient Méroé à l'Égypte. Cette concurrence est probablement l'une des causes du déclin des élites méroïtiques, tant royales que provinciales (sauf en Basse-Nubie), qui se devine par la taille et la qualité décroissante des monuments funéraires dans la nécropole royale de Begrawwiya Nord et les cimetières de Sedeinga. S'y ajoutait l'insécurité causée par les incursions et les raids des tribus noubas et blemmyes qui devait considérablement affecter les transports caravaniers. Enfin, la maind'œuvre servile, que les rois de Napata et des premiers siècles de Méroé se procuraient aisément par des razzias sur les populations noubas, était plus difficile à acquérir, ces tribus étant apparemment plus belliqueuses et mieux organisées. Dans une économie fondée non sur un véritable commerce mais, comme en l'Égypte pharaonique, sur la concentration 
des biens entre les mains des élites politiques et religieuses et leur redistribution vers la population, tous ces nouveaux développements ont eu un effet délétère qui explique la chute rapide du royaume de Méroé, affaibli, vers le milieu du IV siècle.

\section{Les derniers souverains de Méroé}

le Soudan

\section{8}

des origines

à la chute

du sultanat

Fung

Nous disposons pour les derniers des monarques de Méroé, dont les règnes s'étendent sur une période de 70 à 80 ans avant la chute complète du royaume, de cinq pyramides (Beg.N.24-27 et 51), d'une ancienne pyramide transformée en chapelle (Beg. N.16) et de quatre noms, Aryesbokhé, Maloqorébar, Talakhide-Amani et Yesbokhé-Amani. Il est pour l'heure impossible de faire correspondre les trois derniers de ces noms avec des sépultures précises et d'établir entre eux une succession chronologique assurée.

Les tombeaux de cette époque correspondent à la partie sud du troisième rang de pyramides. Ils sont aujourd'hui réduits à de simples kôms de briques cuites et nous sommes limités aux descriptions et aux rares fac-similés des Denkmäler de Lepsius et de la publication des fouilles de Reisner. Aucun de leurs noms, sans doute peints et non gravés, n’a été conservé. La pyramide Beg. N. 51 est peut-être la première en date parmi elles. Le mur sud de la chapelle, reconstitué au musée de Boston, montre des reliefs de facture inégale, dont la meilleure partie présente le souverain sur le trône au lion, protégé par Isis et recevant une libation de lait versée devant lui par Anubis et Nephtys. La scène et ses détails attestent une nette influence de la chapelle du roi Tarékéniwal, tandis que la procession qui la continue à gauche est réalisée en simple relief incisé de manière assez grossière. Malheureusement, les cartouches gravés au-dessus du roi sont vides, probablement parce que les noms y étaient peints et ont été totalement effacés par l'érosion. Sur le mur sud, en partie effondré quand les relevés furent effectués, le roi est également assis sur le trône et reçoit l'hommage d'une procession de femmes conduite par une Candace aux larges épaules et aux seins tombants, porteuse d'une longue palme. Les fragments d'une table d'offrandes en faïence ont été retrouvés dans les décombres de la pyramide, mais l'inscription méroïtique partielle, qui cite la mère et le père d'un défunt, peut être datée sur des bases paléographiques et grammaticales du début du $\mathrm{I}^{\mathrm{er}}$ siècle de notre ère et ne correspondait pas originellement à cette sépulture.

La pyramide Beg. N. 24 a été brièvement décrite par Lepsius, peu avant son effondrement complet. Elle appartenait à un roi représenté sur le mur ouest de la chapelle effectuant une offrande face à Osiris assis en majesté. Les murs sud et nord figuraient, comme habituellement, le monarque 
sur le trône au lion, sans qu'aucun autre détail ne nous soit parvenu. La pyramide Beg. N. 25 était mieux conservée lorsqu'elle fut fouillée par Reisner. C'est la plus grande du groupe et sa chapelle était précédée d'un portique. Un fac-similé de la publication des fouilles représente la scène du mur sud: un roi vêtu de l'habit tripartite et couronné de la calotte koushite, protégé par la déesse Isis, reçoit l'encensement d'un prince. On retrouve d'après les notes de Lepsius un décor similaire dans les restes de la chapelle de Beg. N. 27, totalement détruite lorsque Reisner arriva à Méroé. Le savant allemand note que, sur le mur nord, apparaît devant le roi une "grosse femme» représentée plus grande que tous les autres personnages. Il s'agit sans doute de l'épouse royale, devenue reine-mère à la mort du roi.

La pyramide Beg. N.26 est justement celle d'une Candace, peut-être la même. Les restes de la chapelle la présentent assise sur le trône au lion, recevant l'hommage d'un prince qui tend d'une main l'encensoir vers ses narines, tout en effectuant une libation de l'autre main. La scène est légendée d'extraits de textes funéraires en hiéroglyphes égyptiens dont les bribes restantes semblent correctes, y compris à cette époque tardive (la dernière inscription dans cette écriture, totalement isolée, à Philae, date de 394).

La souveraine, sans doute la dernière des Candaces, pourrait être celle que cite une courte inscription latine retrouvée à Musawwarat sur un mur de la Grande Enceinte. Le bloc, détaché par Lepsius et rapporté à Berlin, était supposé avoir été détruit durant les bombardements de la Seconde Guerre mondiale. Heureusement, il fut récemment retrouvé dans les collections et publié à nouveau par le nubiologue Adam Łatjar. Ce document constitue la plus méridionale de toutes les inscriptions latines. Elle fut gravée le 15 avril d'une année inconnue par un certain Acutus, venu de Rome (venit [a]b Urbe mense Apr. die xv) et souhaite bonne fortune à la reine pour de nombreuses années (Dominae reginae in multos annos feliciter). Selon cette nouvelle analyse, le texte date du début $\mathrm{du} \mathrm{IV}^{\mathrm{e}}$ siècle au plus tôt, notamment en raison du comput simple des jours du mois et non plus calculé en calendes, nones et ides. La paléographie confirme une telle datation.

Les derniers ensembles funéraires de Bégrawwiya ne semblent pas témoigner d'une déliquescence du pouvoir central, bien que ni la taille des monuments, ni la solidité du bâti, ni la qualité des décors ne puissent rivaliser avec les fastes des siècles passés. Le nombre de pyramides conservées, cinq en tout, laisserait supposer de longs règnes si l'on pense qu'ils remplissent l'espace entre le règne de Téqoride-Amani et la chute de Méroé au milieu du Iv ${ }^{\mathrm{e}}$ siècle. Il est donc possible que ces sépultures correspondent à la fin du $\mathrm{III}^{\mathrm{e}}$ siècle et au début $\mathrm{du} \mathrm{IV}^{\mathrm{e}}$, tandis que les souverains 
des dernières décennies, en raison d'un contexte troublé, auraient éventuellement réutilisé des caveaux anciens. Nous verrons en effet que c'est probablement le cas du roi Aryesbokhé

Parmi les rares noms royaux qui nous ont été conservés pour cette époque, Maloqorébar et Talakhide-Amani sont associés dans le plus étonnant ensemble d'inscriptions méroïtiques du temple d'Isis à Philae. Dans la deuxième (et non la troisième, comme on le lit souvent) des salles de la colonnade orientale située entre les deux pylônes, a été grossièrement incisée la représentation d'une procession de dignitaires méroïtiques venus en ambassade à Philae. On se souvient que précédemment, en 252-253, le roi Téqoride-Amani avait dépêché sur l'île d'Isis un émissaire chargé de présents nommé Sasan. Mais alors que ce dernier avait pu bénéficier d'un excellent graveur pour exécuter avec soin une longue inscription en démotique, cette fois-ci les prêtres de Philae ne purent ou ne voulurent pas mettre un bon artisan à la disposition de l'ambassade. Elle dut se contenter d'un des scribes de l'expédition pour inciser maladroitement, en deux défilés, les figures des dignitaires et les accompagner de légendes mentionnant leurs titres non plus en démotique, qu'il ne devait pas maîtriser, mais en méroïtique cursif. La paléographie indique la fin du $\mathrm{III}^{\mathrm{e}}$ siècle ou le début du $\mathrm{IV}^{\mathrm{e}}$.

Au milieu d'une des deux processions est inscrit le plus long des textes qui ne décrit pas un personnage mais détaille les présents du pouvoir royal de Méroé aux dieux, particulièrement Isis et Osiris de Philae et de l'Abaton, le sanctuaire de l'île de Biggeh située immédiatement à l'ouest. Le texte indique au début les personnes royales qui ont commandité l'ambassade: "L’enfant Maloqorébar (et) le souverain Talakhide-Amani. " Les spédes origines à la chute du sultanat Fung cialistes du mérö̈tique ont longtemps débattu de ce passage, notamment parce que le premier éditeur du texte, Griffith, avait malencontreusement segmenté les mots de manière erronée. Il faut dire que le scribe antique avait utilisé une ponctuation assez parcimonieuse. En conséquence, au lieu de qore Thidmni, "le souverain Talakhide-Amani», Griffith avait découpé * qore-t Lhidmni, "celui du souverain, Lakhidamani». Comme le terme "enfant», tdxe, qui désigne le fils ou la fille "enfanté(e)» par une mère, n'était pas encore bien analysé, le personnage de Lakhidamani se trouva considéré comme une reine, éventuellement une Candace, mère d'un roi nommé Maloqorébar, et fut ajouté comme tel sur les listes royales figurant dans les publications. En fait, c'est la découverte en 2012, par la mission soudano-canadienne dirigée par K. Grzymski, d'une inscription de Méroé contenant clairement l'expression Tlhidemn[i]qor "le souverain Talakhide-Amani» qui a permis de confirmer le bon découpage du texte de Philae. Il s'agit là aussi d'un graffito tracé à la diable sur un bloc aujourd'hui détaché, situé derrière le sanctuaire du grand temple d'Amon, à proximité 
de l'enceinte de la cité royale. Assez mal conservé, il contient au début un certain nombre de bienfaits (la vie, la force, etc.) demandés aux dieux pour le monarque, mais le reste du texte est obscur et souvent illisible.

La nouvelle segmentation du graffito de Philae ne résout pas, néanmoins, tous les problèmes. Qui est en effet Maloqorébar, qualifié d'«enfant» et précédant même le nom du souverain? Son nom, signifiant peut-être "beau ( $m l o$ ) est le garçon (ar) des souverains (qoreb)", le désigne comme un prince. Il semble que Talakhide-Amani, qui utilise à Philae comme à Méroé le titre de qore, "souverain», est bien un roi et non une reine. En cas de régence, l'enfant serait en effet désigné comme «roi » et sa mère comme "Candace», d'après les rares précédents dont nous disposons. Le nom même de Talakhide-Amani signifie «il donne la victoire, Amon» et fait écho au nom Talakhamani, «il est victorieux, Amon», que portait un roi napatéen sept siècles plus tôt. Il n'est pas impossible que Maloqorébar ait été un héritier attendu et fêté après sa naissance par une action de grâce à Isis de Philae, à qui fut envoyée une délégation. Sa position en tête de l'inscription s'expliquerait alors plus aisément. Toutefois, on ne peut être sûr qu'il ait jamais régné, son nom n'étant pas attesté ailleurs que dans le graffito de Philae.

Le dernier roi de Méroé dont le règne ait laissé des témoignages muliples est Yesbokhé-Amani. Son nom signifie "Amon l'a fait chef» ou "Amon règne en chef» et devrait sans doute être rectifié en Amani-Yesbokhé. Dans l'écriture égyptienne, les noms de dieux sont toujours placés au début des cartouches royaux par un procédé que l'on appelle «antéposition honorifique». De plus, ces noms divins sont souvent rejetés, pour les mettre en valeur, au début de la phrase que constitue le nom royal, si bien qu'ils sont aussi au début de la forme oralisée. Ainsi, $R^{\prime}-m s-s(w)$, «Ramsès", signifie "C'est Rê qui l'a engendré», avec emphase sur le nom du dieu. Sans ce rejet, le groupe devrait être oralisé * $M s-R^{-}-s(w)$ selon l'ordre habituel de l'égyptien classique (verbe/sujet/objet). Mais cette emphase n'est pas systématique, si bien que l'on n'est pas toujours certain de la forme exacte à l'oral d'un nom royal: le successeur de Chéops est ainsi parfois appelé Djedefrê ou Râdjedef. On dispose parfois de transcriptions en grec ou en babylonien qui permettent de rétablir l'ordre de prononciation. Ainsi, le nom de couronnement d'Amenhotep III, Nebmaâtrê, "Rê est possesseur de justice», est écrit $R^{\prime} M 3^{\prime} . t n b$, mais la position exacte des éléments dans le groupe oralisé est assurée par la transcription babylonienne Nimmuriya connue par la correspondance diplomatique entre l'Égypte et le Levant. L'antéposition honorifique est également utilisée dans le royaume koushite lorsque les noms sont transcrits en égyptien, mais généralement pas lorsqu'ils sont écrits en mérö̈tique. Ainsi, Natakamani est écrit Jmn-ntk ou Jmn-Ntg en transcription 
le Soudan

\section{2}

des origines

à la chute

du sultanat

Fung égyptienne, mais Ntkmni en écriture méroïtique, aussi bien hiéroglyphique que cursive. À l'imitation de l'égyptien, des phénomènes d'emphase sont également possibles, avec un rejet du sujet, non au début de la séquence mais à la fin, l'ordre syntaxique du méroïtique (sujet/objet/verbe) étant l'inverse de l'égyptien. Si l'on ajoute que l'écriture méroïtique hiéroglyphique se lit dans le sens inverse des hiéroglyphes égyptiens, on ne s'étonnera pas que les scribes aient pu être perdus. C'est ce qui doit expliquer que, pour le roi Yesbokhé-Amani, on ait deux versions: Yesbokhé-Amani sur deux de ses textes, Amani-Yesbokhé sur les deux autres, dont celle qui est probablement la dernière inscription rédigée en méroïtique hiéroglyphique pour un roi de Méroé. Figurant sur un lion de grès qui provient de Qasr Ibrim, elle a été récemment publiée par Jochen Hallof. Cette statue, retrouvée sur ce site par J. Plumley en 1966, a été transportée au musée de la Nubie à Assouan où l'on peut la voir aujourd'hui. Le texte, gravé assez maladroitement sous la crinière de l'animal, proclame: "C'est Amani-Yesbokhé, le souverain aimé d'Amon de Napata.»

La datation de ce monarque peut être précisée. Deux graffiti tardifs identiques à son nom ont été inscrits sur les murs du passage de la porte dite d'Hadrien à Philae, au-dessus de la représentation de MarcAurèle en pharaon. Le texte en méroïtique cursif, assez court, commence par «C'est le souverain Yesbokhé-Amani» et se termine par «il est sous la protection d'Isis». Il s'agit très probablement d'une usurpation volontaire de l'image de l'empereur romain, d'ailleurs simplement légendé par

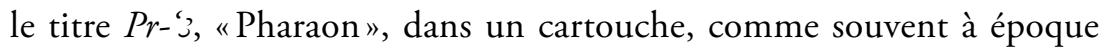
tardive. Loccupation romaine avait officiellement cessé en 298 avec le retrait complet du Dodécaschène. Les deux graffiti, si discrètement situés soient-ils, entérinent le passage de relais entre la domination romaine et la pleine suzeraineté méroïtique.

Aux deux inscriptions de Philae est venue s'ajouter récemment la table d'offrandes de ce roi par un heureux hasard, comme en réserve parfois la muséologie. Découverte en 1834 dans une chapelle de Begrawwiya Nord par Giuseppe Ferlini, l'aventurier de sinistre mémoire qui détruisit la pyramide de la reine Amanishakhéto pour y retrouver son fameux trésor de bijoux, elle fut rapportée à Bologne où elle passa longtemps pour anépigraphe, de mauvaises conditions de transport ou de conservation ayant depuis sa découverte effacé le texte cursif original. Mais une copie du décor dessinée par Ferlini a été retrouvée en 2002 par l'égyptologue italienne Paola Davoli et publiée avec la collaboration de Michael Zach. Ce fac-similé avait été réalisé soixante-dix ans avant le déchiffrement de l'écriture par Griffith, ce qui paradoxalement est à la fois une source d'erreur (certaines griffures dans la pierre ont été considérées comme partie des signes) et un gage 
de fidélité (il n'y a pas eu d'interprétation à partir de signes connus). Or, la paléographie du texte montre des formes extrêmement évoluées, que l'on doit dater $\mathrm{du}_{\mathrm{IV}}^{\mathrm{e}}$ siècle de notre ère. On ignore en revanche dans quelle pyramide exactement Ferlini a retrouvé la table d'offrandes, mais, d'après ses vagues indications, ce serait l'une de celles que nous avons décrites ci-dessus, là où se situent les inhumations les plus tardives de la nécropole. Ce texte nous livre également des fragments des noms de sa mère, terminé par-Amani, "Amon", et de son père, Sebera[...]teli. Ce dernier, une fois de plus, n'est pas connu par ailleurs et il est donc possible que YesbokhéAmani ait appartenu à une lignée collatérale.

Ces éléments récents permettent de mieux cerner le règne de Yesbokhé-Amani. Il n'est pas impossible qu'il se soit déplacé en personne en Basse-Nubie. Le lion de Qasr Ibrim, bien que retrouvé hors contexte, dans une strate médiévale, devait orner à l'origine l'entrée d'un bâtiment palatial. Il présente en effet des similitudes frappantes avec ceux que les fouilles italiennes ont exhumés devant les portes du palais de Natakamani à Napata, et il est assez probable que l'inscription ait été gravée à la hâte sur une statue ancienne, peut-être pour honorer le passage du souverain. Son inhumation à Méroé indique que Yesbokhé-Amani tenait encore l'ensemble du royaume. La date du retrait des troupes romaines du Dodécaschène, ainsi que la paléographie tardive que présente sa table d'offrandes et la position de sa sépulture parmi les dernières de la nécropole royale permettent de placer son règne avec assurance dans les premières décennies du Iv e siècle. Il fut sans doute le dernier souverain important de Méroé et précéda de peu la désintégration du royaume.

C'est toutefois un peu plus tard que nous situerions le règne d'Aryesbokhé. Nous avons vu précédemment que Reisner avait retrouvé dans la chambre funéraire de la pyramide Beg. N.16 deux tables d'offrandes comportant des bénédictions de type royal. L'une était au nom d'Amanitaraqidé, l'autre commémorait un certain Aryesbokhé. L'hypogée de Beg. N.16, pillé et ouvert, se situe juste sous la chapelle effondrée de la pyramide Beg. N. 36 , si bien qu'il est plausible que l'une des deux tables en provienne. D'autre part, la substructure de Beg. N.36 est d'un type plus récent que celle de Beg.N.16. De même, les inscriptions des deux tables d'offrandes montrent d'importantes différences paléographiques, celle d'Amanitaraqidé étant la plus ancienne. Les spécialistes allemands Fritz Hintze et Inge Hofmann ont donc attribué Beg. N.16 à Amanitaraqidé et Beg. N. 36 à Aryesbokhé. Une autre difficulté se présentait toutefois: la pyramide Beg. N.16 a été reconstruite et une chapelle funéraire ménagée à l'intérieur même du monument, ce qui est sans précédent. Les pyramides méroïtiques étaient en effet pleines et les chapelles construites à l'extérieur, 
adossées contre le mur est du monument. Pour contourner cette difficulté, on supposa que, lors de la construction de la pyramide Beg. N.36, très proche de Beg. N.16, au point que leurs deux descenderies sont situées sous Beg. N.36, la chapelle de la plus ancienne des deux pyramides avait été rasée et replacée à l'intérieur même du monument. Toutefois, on sait désormais que l'on ne restaurait pas les sépultures ruinées. Même aux temps glorieux d'Amanishakhéto, cette reine fit construire son imposante pyramide (Beg. N.6) sur les arases de celle d'Arnékhamani (Beg. N. 53), antérieure de deux siècles et sans doute effondrée alors.

Il faut donc supposer que l'ensemble constitué par Beg. N.16 et 36 recouvre trois règnes, à savoir, dans l'ordre chronologique: le possesseur du monument originel de Beg. N.16, celui de Beg. N.36 et celui pour qui fut modifié Beg. N.16. Le premier nous paraît être, en raison de sa position initiale dans le second rang, le roi Amanakharéqérem, à la fin du I ${ }^{\text {er }}$ siècle de notre ère. Le deuxième est probablement le possesseur de la première table d'offrandes, Amanitaraqidé, à la charnière des $\mathrm{II}^{\mathrm{e}}$ et $\mathrm{III}^{\mathrm{e}}$ siècles. Le troisième est sans doute un défunt très tardif. La réutilisation inédite d'une ancienne pyramide comme chapelle funéraire est caractéristique d'une époque de troubles et d'une économie diminuée. Or, il se trouve que la deuxième table d'offrandes, celle d'Aryesbokhé, présente une paléographie très tardive, à dater vraisemblablement de la première moitié du Iv siècle, offrant des similitudes avec ce que l'on peut lire sur la table d'offrandes de Yesbokhé-Amani. Le texte est non seulement de type tardif mais sa gravure et même sa rédaction sont extrêmement négligées pour une inscription royale. Il n'y a par exemple aucun séparateur de mots (un signe constitué de deux points superposés) avant les bénédictions finales.

Les noms de la mère et du père du défunt sont peu lisibles:

des origines

à la chute

du sultanat

Fung Amani[...]patidé pour la première, Téritédakhateye (?) pour le second. Ici encore, aucun des deux n'est connu par ailleurs et ne peut être identifié de manière certaine comme roi ou reine. Le redoublement de la formule de filiation maternelle semble indiquer, comme nous l'avons évoqué plus haut pour Tamélorade-Amani, un remariage de la mère. Contrairement à Tamélorade-Amani, il n'y a ici pas de raison de douter du statut royal du défunt. Son nom, qui signifie "Horus l'a fait chef» ou "Horus règne en chef ", l'inclut bien dans une lignée royale, comme peu avant lui YesbokhéAmani (ou, mieux, Amani-Yesbokhé), où le dieu Amon est cette fois cité. Toutefois, un dernier écueil demeure concernant le défunt, à savoir le lieu où reposait sa dépouille. Le déplacement de sa table d'offrandes, de l'entrée de Beg. N. 16 à la chambre funéraire de cette même tombe, ne fait pas de difficulté: il est dû aux effondrements et aux pillages. En revanche, le riche matériel de la première inhumation en Beg. N.16, ou du moins ce qu'il en restait, 
a été retrouvé dispersé dans les appartements funéraires, ce qui laisse supposer que l'on n'ait pas procédé à une nouvelle inhumation, qui aurait normalement été précédée d'un nettoyage de la structure. Les rares ossements en Beg. N. 16 (deux mains ornées d'anneaux d'or et des fragments dispersés) ne sont d'aucun secours pour savoir si cet hypogée a reçu un enterrement secondaire, mais le désordre introduit par les pillages répétés ne permet pas d'écarter cette hypothèse.

\section{La chute du royaume de Méroé}

La fin du royaume koushite n'est mentionnée dans aucun texte antique. Aucune source grecque, latine ou guèze ne nous a rapporté la date précise ou les circonstances exactes de la disparition du dernier État de type pharaonique. Il est toutefois possible de la placer de façon assurée entre 330 et 350 apr. J.-C. Le témoignage principal est une série de stèles rédigées en grec et en guèze (l'ancienne langue éthiopienne) et relatant les hauts faits du roi Ézana, le plus illustre des souverains axoumites et le premier à avoir embrassé la foi chrétienne. Dans toutes ces inscriptions, Ézana se présente comme «roi des Axoumites et des Himyarites, [...], des Bedjas et des Koushites (Kasu)». Un premier récit, dont il existe trois versions, une en grec (DAE 4) et deux en guèze, l'une transcrite en écriture éthiopienne (DAE 7) et l'autre en écriture sudarabique (DAE 6), relate une campagne contre les Bedjas. Le roi y est décrit comme «fils d'Arès», version hellénisée du dieu axoumite de la guerre, Mahrem.

Un second récit, en guèze (DAE 11, voir encadré), semble dater du début de la conversion d'Ézana, puisqu'il évoque plusieurs fois le "Seigneur du Ciel» et une fois «le Seigneur de la Terre», un des titres les plus courants du dieu des chrétiens utilisé par la suite en Éthiopie. Le texte décrit une région où le pouvoir central méroïtique n'existe déjà plus et qui est désormais aux mains des Noubas, à l'exception de quelques enclaves encore tenues par les Kasu, c'est-à-dire les Koushites, contre qui Ézana engage également un combat victorieux. Un troisième texte, en grec, publié en 1970, évoque cette fois le Christ et la Trinité et atteste donc la conversion complète d'Ézana. Il y rapporte une campagne contre les Noubas qui, sur les marches occidentales de l'Empire, ont attaqué les tribus vassales du pouvoir axoumite. Il pourrait toutefois s'agir de la même que la précédente, qui évoque un casus belli similaire.

Ces stèles témoignent de la mainmise progressive des Noubas sur un territoire de Koush pourtant présenté dans la titulature initiale d'Ézana comme un des nombreux vassaux d'Axoum. Cette suzeraineté n'est pas une conséquence des combats contre les Kasu relatés 


\section{Inscription d'Ézana, roi d'Axoum, sur sa guerre contre les Noubas et les Koushites}

stèle DAE 11 formant le dos d'un trône, retrouvée à Axoum, traduction du texte guèze par Munro-Hay, 1991

Par la puissance du Seigneur du Ciel qui, dans le firmament et sur la terre, détient le pouvoir sur toute chose, Ézana, fils d'Ella Amida, Bisi Halen, roi d'Axoum, de Himyar, Raidan, des Sabéens, de Salhin, de Tsiyamo, des Bedjas et des Koushites, roi des rois, fils d'Ella Amida, invaincu par l'ennemi. Que la puissance du Seigneur du Ciel, qui m'a fait roi et règne invincible pour l'éternité, fasse qu'aucun ennemi ne me résiste, qu'aucun ennemi ne me poursuive. Par la puissance du Seigneur de l'Univers, j'ai combattu contre les Noubas, alors que les peuples noubas s'étaient révoltés et que les Noubas se vantaient en disant: «Il n’osera pas franchir le Tekezé!» Quand ils eurent opprimé les Mangourtos, les Hasas et les Baryas et quand les Noirs [les Noubas] combattirent les Rouges [Éthiopiens] et qu'ils eurent manqués à leur parole pour la seconde et la troisième fois et mis à mort leurs voisins sans pitié, qu'ils eurent rançonné nos messagers et les ambassadeurs que je leur avais envoyés pour les admonester et eurent pillé leurs biens jusqu'à leurs lances et enfin, quand aux nouveaux messagers que j'ai envoyés, ils répondirent sans les écouter par des refus, des mépris et des agressions, alors je me mis en marche.

des origines

à la chute

du sultanat

Fung

Je partis par la puissance du Seigneur de la Terre et je combattis sur le Tekezé et le gué de Kémalké. Là, je les mis en fuite et les poursuivis sans repos pendant vingt-trois jours, pendant lesquels j'en massacrais partout où ils s'arrêtaient. Je fis les autres prisonniers et en tirai du butin. En même temps, ceux de mes gens qui étaient au combat ramenèrent des captifs et du butin. En même temps, j’incendiai leurs villages, aussi bien ceux de pierre que ceux de paille. Mes gens prirent leurs céréales, leur bronze, leur fer et leur cuivre, renversant les idoles dans leurs établissements, ainsi que leur grain et leur coton, et les jetèrent eux-mêmes dans la Seda [le Nil]. Beaucoup perdirent leur vie dans le fleuve, personne n'en sait le nombre. En même temps, mes gens percèrent et coulèrent leurs bateaux qui transportaient une foule d'hommes et de femmes. Je capturai deux officiels qui étaient venus comme espions, montés sur des chameaux, nommés Yesaka et Boutala, et le chef Angabene. Les nobles suivants furent mis à mort, à savoir Danako, Dagale, Anako, Haware. Les soldats avaient blessé leur prêtre Karkara et lui prirent un collier d'argent et une boîte en or. Ainsi tombèrent cinq nobles et un prêtre. 
J'arrivai chez les Koushites (Kasu), les combattis et les fis prisonniers au confluent de la Seda [le Nil] et du Tekezé [en fait l'Atbara]. Le jour après mon arrivée, j'envoyai au combat les bataillons de Mahaza, Hara, Damawa (?), Falha (?) et Sera (?) le long de la Seda en remontant vers les cités aux murs de pierre et celles aux murs de paille. Leurs cités aux murs de pierre étaient Alwa et Daro.

Mes troupes les tuèrent et les capturèrent, jetèrent (d'autres) dans l'eau, puis revinrent saines et sauves après avoir terrifié leurs ennemis et les avoir vaincus grâce au pouvoir du Seigneur du Ciel. Ensuite, j'envoyai les bataillons de Halen, Laken (?), Sabarat, Falha et Sera le long de la Seda en descendant vers les quatre villes de paille des Noubas et la ville de Negwes. Les villes des Koushites (Kasu) avec des murs de pierre que les Noubas avaient prises étaient Tabito (?), Fertoti. Et les troupes pénétrèrent sur le territoire des Noubas rouges et mes gens revinrent sains et saufs après avoir fait des prisonniers et du butin et tué par la puissance du Seigneur du Ciel.

Puis j'érigeai un trône au confluent de la Seda et du Tekezé [le Nil et l'Atbara] en face de la ville aux murs de pierre qui s'élève sur la presqu'île [actuellement la ville d'Atbara]. Voyez ce que le Seigneur du Ciel m’a donné. Prisonniers: 214 hommes, 415 femmes, au total 629; tués: 602 hommes, 156 femmes et enfants, au total 758; en additionnant les prisonniers et les tués: 1387. Le butin s'éleva à 10560 têtes de bétail et 51050 moutons.

J'érigeai un trône à Shado par la puissance du Seigneur du Ciel qui m’a aidé et m'a donné le pouvoir. Puisse le Seigneur du Ciel affermir mon règne et, de la même façon qu'il a vaincu mes ennemis pour moi, puisse-t-il continuer à le faire où que j'aille. Comme il a désormais conquis pour moi et a soumis à moi mes ennemis, je veux régner avec justice et équité, sans causer d'injustices à mes peuples.

Je mets ce trône que j'ai érigé sous la protection du Seigneur du Ciel qui m’a fait roi et de celui de la Terre qui le porte. Si quelqu'un se trouve l'arracher, le dégrader ou le déplacer, que lui et sa lignée soient déracinés et anéantis. Ils devront être bannis. Car j’ai érigé ce trône par la puissance du Seigneur du Ciel. 
le Soudan

\section{8}

des origines

à la chute

du sultanat

Fung dans l'inscription DAE 11, puisqu'elle est déjà présente dans les récits de la guerre contre les Bedjas, antérieurs à la conversion du roi. En fait, Méroé avait déjà été prise par les Axoumites plusieurs années auparavant. En témoignent deux fragments de stèles en grec retrouvés dans les fouilles de la ville par Garstang puis par Shinnie. Seules quelques lignes incomplètes peuvent être lues, mais elles contiennent des détails éclairants. La première a préservé des bribes de titulature d'un «roi des Axoumites et des Himyarites", "[fils d']Arès", et des allusions à des pillages, à des rapts de jeunes femmes de haut rang, à un tribut et à une statue de bronze. La seconde devait appartenir à un trône votif inscrit, comme avaient l'habitude d'en ériger les rois d'Axoum dans les territoires vaincus, puisqu' elle comporte la mention de "ce trône». Le dieu Arès y est également cité. Malgré le piètre état de conservation de ces inscriptions, elles permettent d'établir qu'avant la conversion d'Ézana une armée axoumite avait investi et pillé la capitale de Koush. Deux graffiti en guèze ont d'ailleurs été retrouvés sur une pyramide de Méroé (Beg. N.2) et dans le temple de Kawa. En revanche, on ne sait s'il faut attribuer cette première campagne à Ézana avant sa conversion ou à un de ses prédécesseurs païens, Ouazebas ou Ousanas. L'absence de stèle au nom d'Ézana racontant cet épisode parmi celles, pourtant nombreuses, qu'ont mis au jour les fouilles du site d'Axoum incite à privilégier un roi précédent.

Le règne d'Ézana est imparfaitement daté. Ses stèles, à l'instar des textes royaux méroïtiques auxquelles elles ressemblent fortement, ne comprennent aucune indication calendaire. On ne possède à cet égard que la copie d'une lettre que lui a adressée l'empereur romain Constance II (337361), s'inquiétant de l'orthodoxie doctrinale de Frumence de Tyr, précepteur d'Ézana, qui avait converti son élève au christianisme et était devenu par la suite le premier évêque d'Axoum. Mais la copie ne comportant pas de date, elle ne permet pas de préciser davantage la chronologie du règne d'Ézana et notamment de sa conversion. L'occupation axoumite de Méroé, si elle est bien le fait d'un de ses prédécesseurs, peut déjà avoir eu lieu aux environs de 330 et donc avoir précédé et favorisé l'invasion des Noubas.

Une autre date, malheureusement imprécise parce qu'issue d'analyses au carbone 14, situe l'établissement d'un premier royaume nouba dans la région de Méroé vers $350 \pm 50$ (date calibrée). Sur le site d'el-Hobagi, situé au sud de Méroé sur la rive gauche du Nil, l'archéologue français Patrice Lenoble avait repéré une nécropole d'élite post-méroïtique composée de grands tumuli. Deux d'entre eux (HвG III et vI) ont pu être fouillés entre 1985 et 1990, avant que les travaux s'arrêtent faute de moyens financiers. Ils ont révélé des inhumations princières accompagnées de sacrifices de bovins et d'un cheval et dotées d'un riche matériel: lances, 
flèches et bols de bronze de très belle exécution. Tous ces artefacts sont clairement méroïtiques, mais l'abandon de la forme pyramidale, l'absence des monuments caractéristiques des sépultures koushites (chapelle et table d'offrandes) montrent que sur une culture matérielle méroïtique s'était greffée une nouvelle élite qui ne partageait pas entièrement les mêmes coutumes funéraires.

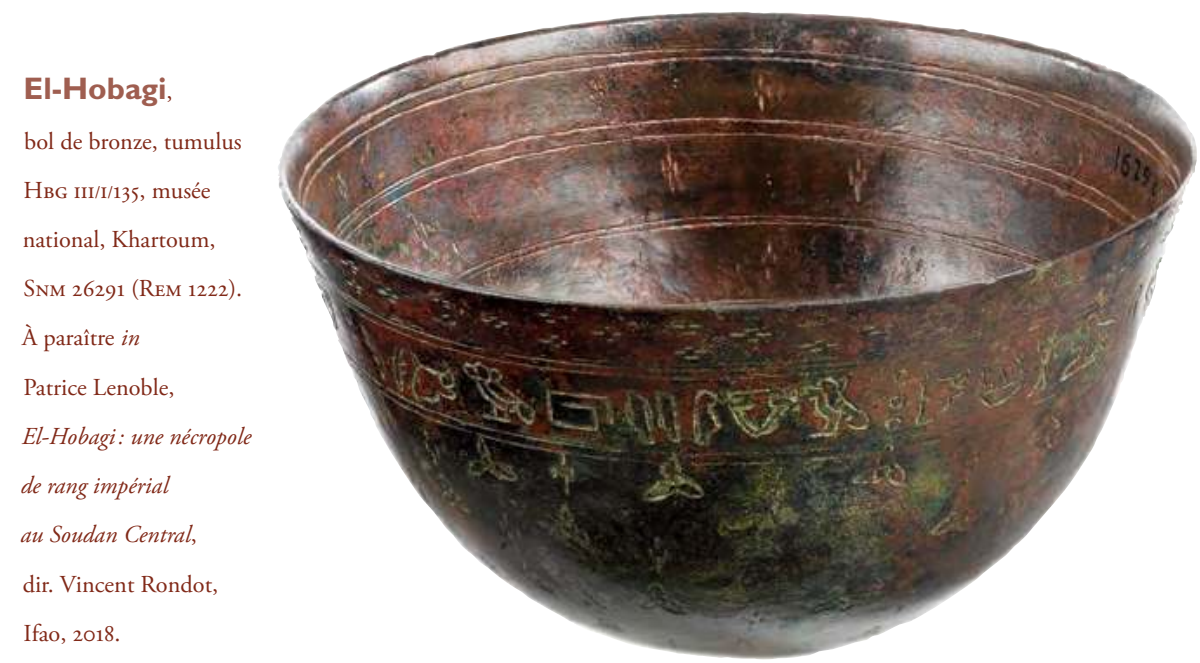

Parmi les objets les plus significatifs se trouvait un bol de bronze sur lequel avait été gravée, dès sa fabrication, une inscription en hiéroglyphes méroïtiques, la plus tardive actuellement connue. Son étude par le présent auteur montre qu'il est vraisemblablement contemporain du prince enterré sous le tumulus HBG III où il fut trouvé en compagnie d'éléments qui ont permis la datation autour de 350 apr. J.-C. Les signes sont en effet proches de l'inscription de Yesbokhé-Amani sur la statue de lion de Qasr Ibrim (voir section précédente, p. 322 sq.), tout en étant à certains égards plus évolués. Surtout, le texte, qui décrit le dédicateur du bol comme "fidèle (?) du roi et du dieu», comprend deux séquences qui ne semblent pas méroïtiques. Elles livrent le titre et le nom du dédicateur en question, qui a offert au défunt le bol orné et y a fait inscrire son nom et ses titres, suivant en cela un usage méroïtique bien attesté. La comparaison avec les langues nubiennes et les noms des chefs noubas tués par Ézana dans la stèle DAE 11 suggère d'identifier ce dédicateur comme «le chef de Yaram, Galaya le Léopard», bien que cette traduction reste éminemment fragile. Le bol de bronze d'el-Hobagi témoigne d'un remplacement d'élite au sein d'une culture prestigieuse partiellement préservée, comme en a connu l'Égypte sous les Hyksôs puis sous les dynasties libyennes et koushite, ou la Chine sous les Mongols puis les Mandchous — 